\title{
Type 2 diabetes mellitus and gastrointestinal cancer
}

Citation for published version (APA):

de Jong, RGPJ. (2019). Type 2 diabetes mellitus and gastrointestinal cancer: Disease, drugs, or distortion? [Doctoral Thesis, Maastricht University]. Maastricht University. https://doi.org/10.26481/dis.20190605rj

Document status and date:

Published: 01/01/2019

DOI:

10.26481/dis.20190605rj

Document Version:

Publisher's PDF, also known as Version of record

\section{Please check the document version of this publication:}

- A submitted manuscript is the version of the article upon submission and before peer-review. There can be important differences between the submitted version and the official published version of record.

People interested in the research are advised to contact the author for the final version of the publication, or visit the DOI to the publisher's website.

- The final author version and the galley proof are versions of the publication after peer review.

- The final published version features the final layout of the paper including the volume, issue and page numbers.

Link to publication

\footnotetext{
General rights rights.

- You may freely distribute the URL identifying the publication in the public portal. please follow below link for the End User Agreement:

www.umlib.nl/taverne-license

Take down policy

If you believe that this document breaches copyright please contact us at:

repository@maastrichtuniversity.nl

providing details and we will investigate your claim.
}

Copyright and moral rights for the publications made accessible in the public portal are retained by the authors and/or other copyright owners and it is a condition of accessing publications that users recognise and abide by the legal requirements associated with these

- Users may download and print one copy of any publication from the public portal for the purpose of private study or research.

- You may not further distribute the material or use it for any profit-making activity or commercial gain

If the publication is distributed under the terms of Article $25 \mathrm{fa}$ of the Dutch Copyright Act, indicated by the "Taverne" license above, 

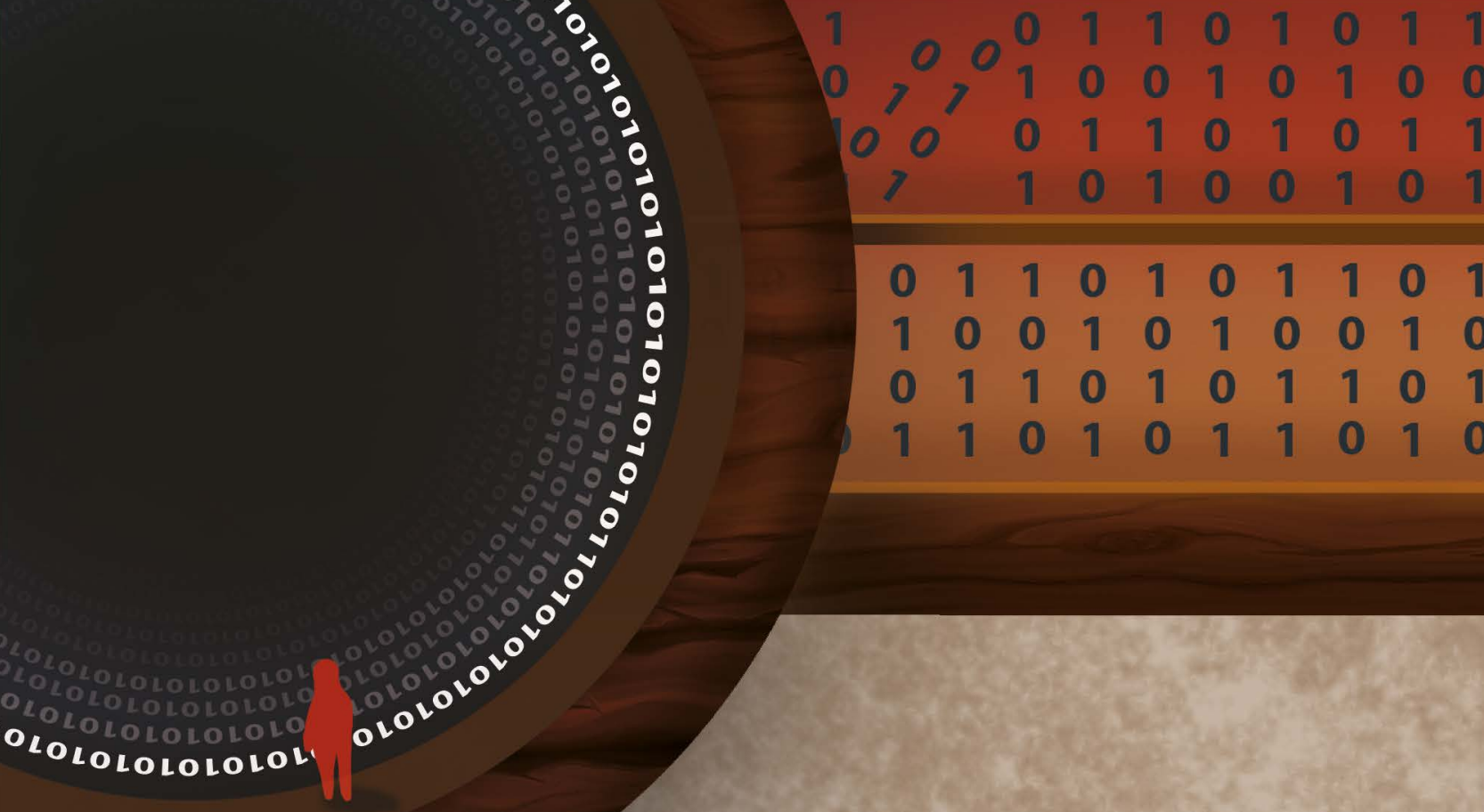

$\begin{array}{llllllllll}0 & 1 & 1 & 0 & 1 & 0 & 1 & 1 & 0 & 1\end{array}$ $\begin{array}{llllllllll}1 & 0 & 0 & 1 & 0 & 1 & 0 & 0 & 1 & 0\end{array}$ $\begin{array}{llllllllll}0 & 1 & 1 & 0 & 1 & 0 & 1 & 1 & 0 & 1\end{array}$ $\begin{array}{llllllllll}1 & 1 & 0 & 1 & 0 & 1 & 1 & 0 & 1 & 0\end{array}$ 0.020 .0

Type 2 diabetes mellitus and gastrointestinal cancer :

Disease, drugs, or distortion?

Roy de Jong 


\section{Colofon}

The work presented in this dissertation was performed within VieCuri Medical Centre and GROW - School for Oncology \& Developmental Biology, Maastricht University

Copyright (C), R.G.P.J. de Jong, Maastricht 2019

No part of this book may be reproduced or transmitted in any form or by any means, without prior permission in writing by the author, or when appropriate, by the publishers of the publications.

ISBN: 978-94-6380-347-2

Cover design: Evelien Jagtman

Layout: Tiny Wouters

Production: ProefschriftMaken

The printing of this thesis was financially supported by Maastricht University and Netherlands Comprehensive Cancer Organisation (Integraal Kankercentrum Nederland). 


\title{
Type 2 diabetes mellitus and gastrointestinal cancer:
}

\author{
Disease, drugs, or distortion?
}

\begin{abstract}
PROEFSCHRIFT
ter verkrijging van de graad van doctor aan de Universiteit Maastricht, op gezag van de Rector Magnificus, Prof. dr. Rianne M. Letschert, volgens het besluit van het College van Decanen,

in het openbaar te verdedigen

op woensdag 5 juni 2019 om 14.00 uur
\end{abstract}

door

Ronaldus Gerardus Petrus Jacobus de Jong 


\section{Promotores}

Prof. dr. A.A.M. Masclee

Prof. dr. M.L.G. Janssen-Heijnen

\section{Copromotor}

Dr. F. de Vries

\section{Beoordelingscommissie}

Prof. dr. A.P. de Bruïne (voorzitter)

Prof. dr. J.P.W. van den Bergh

Prof. dr. J.C.H. Hardwick, Universiteit Leiden

Prof. dr. M.C.J.M. Sturkenboom, Erasmus Universiteit Rotterdam

Prof. dr. Ir. M.P. Weijenberg 


\section{Contents}

$\begin{array}{lll}\text { Chapter } 1 & \text { General introduction } & 7\end{array}$

Chapter $2 \quad$ Gastrointestinal cancer incidence in type 2 diabetes mellitus; $\quad 23$ results from a large population-based cohort study in the UK

Chapter 3 Impact of detection bias on the risk of gastrointestinal cancer and its subsites in type 2 diabetes mellitus

Chapter 4 Brief report: Comparability of the age and sex distribution of the UK Clinical Practice Research Datalink and the total Dutch population

Chapter $5 \quad$ No decreased risk of gastrointestinal cancers in users of metformin in the Netherlands; a time-varying analysis of metformin exposure

Chapter 6 Use of incretin agents and risk of acute and chronic pancreatitis: A population-based cohort study

Chapter 7 Letter to the Editor: Comments on "Use of metformin and risk of kidney cancer in patients with type 2 diabetes", Chin-Hsiao Tseng, Eur J Cancer 2016;52:19-25

Chapter 8 High glycaemic burden increases risk of gastrointestinal cancer in patients with type 2 diabetes mellitus; a population-based cohort study in the Netherlands

Chapter 9 General discussion

Summary

Nederlandse samenvatting

Valorisation

List of publications

Dankwoord 193

Curriculum vitae 

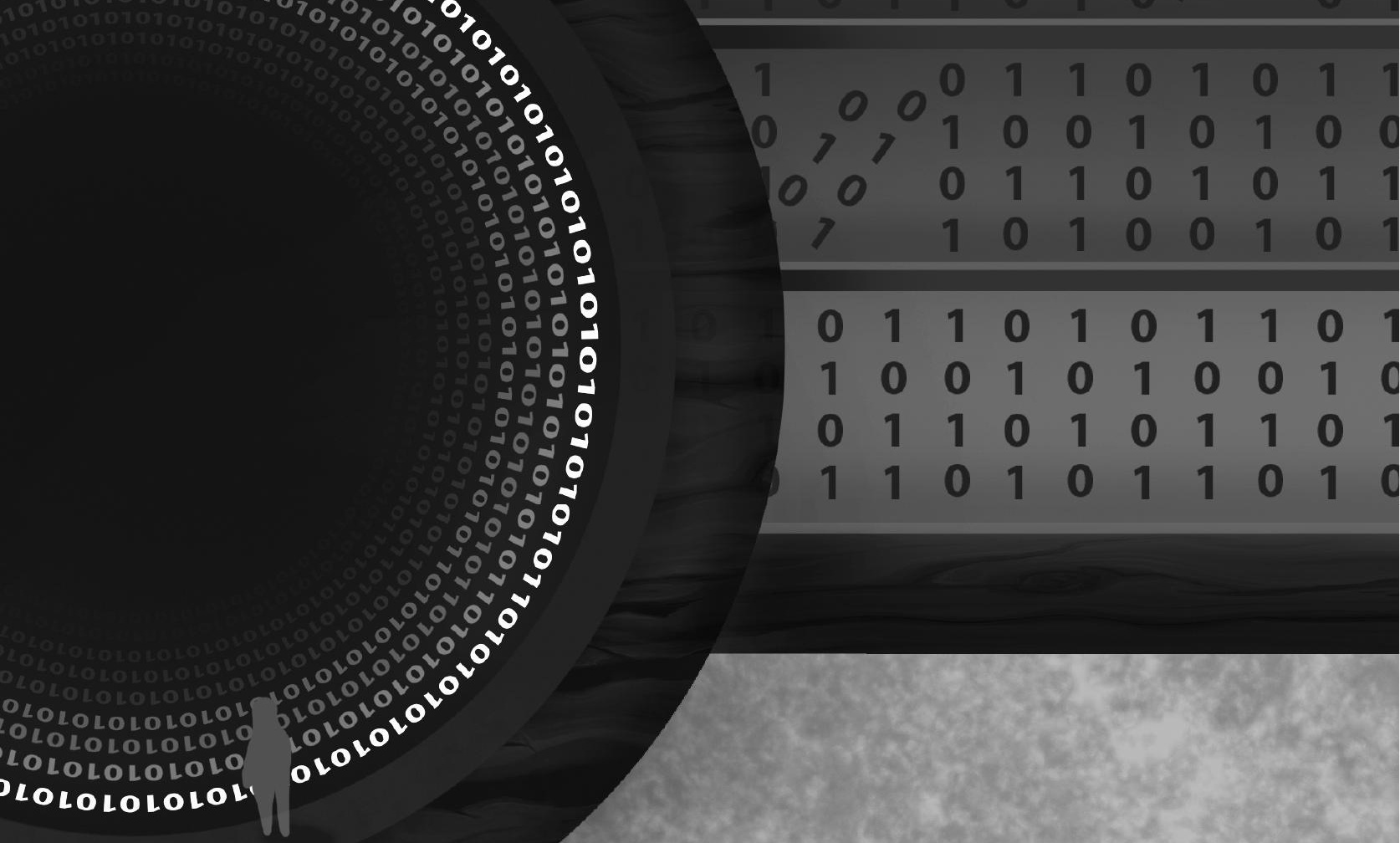

$\begin{array}{llllllllll}0 & 1 & 1 & 0 & 1 & 0 & 1 & 1 & 0 & 1\end{array}$

$\begin{array}{lllllllll}1 & 0 & 0 & 1 & 0 & 1 & 0 & 0 & 1\end{array}$

$\begin{array}{llllllllll}0 & 1 & 1 & 0 & 1 & 0 & 1 & 1 & 0 & 1\end{array}$

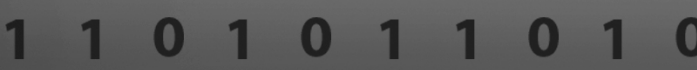

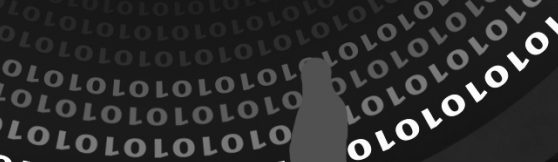
$010^{2}$ 


\section{1}

General introduction 



\section{General introduction}

Type 2 diabetes mellitus (T2DM) and gastrointestinal (GI) cancer are increasing global health problems. For both entities, the incidence and prevalence are still rising. ${ }^{1}$ Cancer and diabetes are diagnosed within the same individual more frequently than would be expected to occur by chance, even after adjusting for confounding factors. ${ }^{1}$ After several decades of research, it is still under debate whether T2DM truly is a risk factor for the development of $\mathrm{Gl}$ cancer or whether T2DM is more of a 'risk indicator' of pathophysiological mechanisms that increase the chance of developing cancer. Furthermore, for clinicians the prevention of disease complications is an important goal of disease management. If stringent management of T2DM would convey a clinically relevant reduction of $\mathrm{Gl}$ cancer risk, this may have important implications for clinical practice. In this thesis multiple aspects of the complex association between T2DM and GI cancer are analysed, with a special focus on the impact of anti-diabetic drugs (ADDs), glycaemic control, and methodological issues.

\subsection{Gastrointestinal cancer}

GI cancer comprises all malignancies of the digestive tract and its related digestive organs, including the oesophagus, stomach, liver, biliary tract, gallbladder, pancreas, small intestine, large intestine, rectum and anus. Symptoms for each cancer type relate to the affected organ and may include bowel or ductal (mechanical) obstruction (e.g. dysphagia, ileus, or jaundice), abnormal bleeding and blood loss, metabolic derangements with weight loss and malnutrition and other associated problems.

In the Netherlands, the most commonly diagnosed GI cancer is colorectal cancer, followed by pancreatic cancer and oesophageal cancer. In 2015 the highest ever observed incidence of GI cancer so far was reported (Crude Rate (CR): 142 per 100,000 persons per year). ${ }^{2}$ Almost two-thirds of the diagnosed $\mathrm{Gl}$ cancers concerned colorectal cancer (CR 92 per 100,000 persons per year). ${ }^{2}$ Up to 2015, the incidence of GI cancer has increased in particular for colorectal cancer, oesophageal cancer, and pancreatic cancer. This contrasts with a decline by almost one third of the incidence of gastric cancer.

GI cancers are complex, multifactorial diseases for which various risk factors have been identified. Non-modifiable risk factors include high age and male sex, which are also the most important risk factors for $\mathrm{Gl}$ cancer in general. Other risk factors include race (e.g. liver cancer occurs more frequently in Asians, and colorectal cancer is seen more frequently in blacks) ${ }^{3}$, and personal and family medical history of specific cancers. ${ }^{4}$ Apart from certain occupational exposures ${ }^{5}$, environmental factors, and certain infections (e.g. liver fluke for cholangiocarcinoma), there are also some modifiable risk factors. These 
are largely related to obesity, dietary habits and lifestyle choices (e.g. physical inactivity, smoking, alcohol use). ${ }^{6-8}$ These modifiable factors influence the risk of Gl cancer in varying degrees.

\subsection{Type 2 diabetes mellitus}

Diabetes mellitus is an umbrella term for a heterogeneous group of chronic, metabolic diseases characterized by increased blood glucose levels (hyperglycaemia), resulting from a deficient endogenous insulin production by the pancreas, insulin resistance, or both. ${ }^{9,10}$ The number of cases and the prevalence of diabetes have been rising over the past decades, coinciding with the global obesity epidemic. As a result, diabetes has become a leading threat to global public health. ${ }^{9}$

In 2014, worldwide, an estimated 422 million adults were suffering from diabetes, compared to 108 million in $1980 .^{9}$ Between 1980 and 2014, the global prevalence has nearly doubled from $4.7 \%$ to $8.5 \%{ }^{9}$ Separate estimates of diabetes prevalence for type 1 diabetes mellitus and T2DM do not exist, as laboratory tests to distinguish between these subtypes are not always available. However, approximately $90-95 \%$ of diabetes mellitus cases are comprised of individuals with T2DM. ${ }^{10}$

The diagnosis of T2DM is based on one of four abnormalities: a glycated haemoglobin (HbA1c) level $\geq 6.5 \%$ (48 mmol/mol), a fasting plasma glucose level $\geq 7.0 \mathrm{mmol} / \mathrm{L}$, a random elevated blood glucose level with symptoms (polyuria, polydipsia, nocturia, blurred vision, or weight loss), or an abnormal oral glucose tolerance test (OGTT). ${ }^{10,11}$ Although specific aetiologies for T2DM are unknown, it is thought to result from the presence of insulin resistance (the body's inability to effectively use insulin). The risk of T2DM is determined by a combination of genetic and metabolic factors such as ethnicity, family history of diabetes, history of gestational diabetes, older age, overweight and obesity, unhealthy diet, physical inactivity and smoking. ${ }^{9}$ T2DM may go undiagnosed for multiple years until complications (such as retinopathy, nephropathy, or neuropathy) occur. ${ }^{9}$ As there is yet no cure for T2DM, treatment is mainly focused on effective management of blood glucose levels through lifestyle modifications and the use of ADDs, and on the prevention of long-term complications. Multiple pharmacologic agents are available for lowering the blood glucose level in patients with T2DM. These drugs either focus on lowering peripheral insulin resistance and gluconeogenesis (metformin, thiazolidinediones) or on increasing the endogenous insulin output by the pancreas (sulfonylureas, glinides). To date, the Dutch and international guidelines advise the use of metformin as a first-line drug treatment when lifestyle advice such as dietary modification, physical exercise, and weight reduction fail to maintain glucose levels within normal range. ${ }^{10,11}$ Subsequently, when T2DM progresses and glycaemic control is 
inadequate, other ADDs or exogenous insulin may be added to the therapeutic drug regimen.

\subsection{Diabetes and gastrointestinal cancer}

T2DM has currently been associated with some, but not all, GI cancers. Substantial heterogeneity exists between results of observational studies, and at present high quality evidence is only available for associations between T2DM and colorectal cancer (15-30\% increased risk) and intrahepatic cholangiocarcinoma (doubled risk). ${ }^{12}$ In addition, T2DM has also been associated with an increased risk of liver and pancreatic cancer, but methodological aspects have so far precluded to draw firm conclusions. ${ }^{12,13}$ The biological relationship between T2DM and GI cancer is yet poorly understood. ${ }^{1,14}$ It is currently thought that the relationship may not be entirely attributable to the direct effects of T2DM, such as hyperglycaemia, which effects will be further discussed in section 1.5. ${ }^{1,15}$ Instead, T2DM may be a marker of an altered cancer risk due to changes in underlying metabolic conditions, such as insulin resistance, hyperinsulinaemia or inflammation. ${ }^{1}$ Insulin resistance, hyperinsulinaemia (either endogenous due to insulin resistance, or exogenous due to administered insulin or insulin secretagogues) and elevated levels of Insulin-like Growth Factor-1 (IGF-1) reduce apoptosis and increase cell proliferation in target cells, leading to tumour development. ${ }^{16-19}$ Insulin itself is also known to have mitogenic properties ${ }^{20}$, and, in particular, both the liver and the pancreas are exposed to high levels of endogenously produced insulin through the portal venous system. ${ }^{21}$ Alternatively, the relationship may be due to the sharing of common predisposing conditions, such as obesity, lack of physical activity, or a high-caloric diet. ${ }^{1}$ In addition, there is an added level of complexity in the association between T2DM and pancreatic cancer, as both diseases involve the same organ. While some studies suggest that diabetes can be an early manifestation of pancreatic cancer, other studies point in the direction of diabetes as an aetiological factor. ${ }^{22-26}$ Lastly, associations have been found between drugs used in the treatment of T2DM and GI cancer risk, complicating the evaluation of the association between T2DM and Gl cancer. This will be further discussed in section 1.4 .

\subsection{Anti-diabetic drugs and gastrointestinal cancer}

Several drugs used in the treatment of T2DM have been associated with either a decreased or increased (GI) cancer risk. Below, the evidence regarding the associations between ADDs and GI cancer risk are summarised.

Substantial in-vitro and in-vivo evidence has suggested that metformin has anti-cancer properties. $^{27}$ Metformin has been shown to interact with several metabolic pathways, 
such as the LKB1/AMPK pathway, that are often disrupted in sporadic cancers. ${ }^{28,29}$ AMPK activation by metformin leads to inhibition of mammalian target of rapamycin (mTOR) signaling, which regulates protein synthesis, cell growth and cell proliferation. ${ }^{30}$ Besides, metformin exerts systemic effects that could be responsible for its chemoprotective effects, such as a reduction in signaling molecules (glucose, insulin, and IGF-1), modification of inflammatory processes, or enhancement of the immune response. ${ }^{20,31,32}$ The use of metformin has been predominantly associated with a decreased risk of $\mathrm{Gl}$ cancers in observational studies. Although an increased risk of colorectal cancer has also been reported. ${ }^{33,34}$ In 2005, Evans et al. first highlighted an association between the use of metformin and reduced cancer risk in T2DM patients. ${ }^{35}$ Since then, numerous observational studies have reported varying degrees of a protective effect of metformin for a variety of $\mathrm{Gl}$ cancer types including liver, colorectal, pancreatic, gastric and oesophageal cancer. ${ }^{36}$ In contrast, data from meta-analyses of randomized controlled trials (11 RCTs with 398 cancers during 51,681 person-years, comparing metformin with active glucose-lowering therapy or placebo/usual care) have not supported metformin's protective role on cancer development. ${ }^{37,38}$ Furthermore, it has been shown that timerelated biases have greatly impacted the results regarding the use of metformin and risk of multiple Gl cancer types. ${ }^{39}$ This methodological aspect will be further discussed in section 1.6. Based on the evidence mentioned above, the debate on metformin's anticancer effect is still ongoing.

Sulfonylureas (SUs) and exogenous administered insulin may increase the risk of $\mathrm{Gl}$ cancer by increasing the levels of circulating insulin, which has direct and indirect mitogenic properties. ${ }^{40}$ Insulin may directly stimulate proliferation of tumour cells by binding to the insulin receptor $A$. Indirect effects of insulin include promoting the synthesis of insulin-like growth factor (IGF)-1 in hepatocytes and a decrease of hepatic synthesis of IGF binding protein 1 and 2, resulting in a relative increase in free circulating IGF-1.

A meta-analysis of 33 RCTs, involving 26,022 T2DM patients and comparing the risk of cancer between users of SUs and users of other ADDs, did not show a significant difference in cancer risk (Odds Ratio (OR) 0.93, 95\% Cl 0.77-1.12). However, significant heterogeneity was observed $\left(I^{2}=30 \%, p=0.05\right)$ and incomplete follow-up in each RCT was high. ${ }^{41}$ Furthermore, adjusted analyses of pooled data from observational studies (15 cohort studies and 11 case-control studies involving over 1.8 million T2DM patients and 48,201 cancer events) comparing the use of SUs with the use of other ADDs did not show a significant difference in cancer risk (adjusted Hazard Ratio (HR) 1.05, 95\% $\mathrm{Cl}$ 0.96-1.15 and adjusted OR $1.13,95 \% \mathrm{Cl}$ 0.93-1.17 respectively for cohort and case-control studies). ${ }^{41}$ However, observational studies included in the analyses generally had a moderate to high risk of bias and also showed marked heterogeneity. 
Regarding exogenous insulins, no significant differences in $\mathrm{Gl}$ cancer risk have been observed in RCTs comparing the use of insulin glargine with other types of insulin or non-insulin ADDs. ${ }^{42,43}$ In subsequent meta-analyses of observational studies, an increased risk of pancreatic and colorectal cancer has been found when comparing the use of insulin to the use of non-insulin antidiabetic drugs. ${ }^{44}$ In contrast, lower risks of various $\mathrm{Gl}$ cancers have been observed when comparing the use of insulin glargine to the use of non-glargine insulin. ${ }^{44,45}$ Yet, important limitations have been noted for observational studies on the risk of cancer with the use of insulin, such as marked heterogeneity between studies, limited confounder adjustment, and short follow-up periods.

In vitro and in vivo studies have shown that thiazolidinediones (TZDs) possess anticancer properties in gastrointestinal cancer cells through various intracellular signalling pathways, resulting in cell growth arrest, induction of apoptosis, and inhibition of cell invasion. ${ }^{46} \mathrm{~A}$ meta-analysis of RCTs has also shown a reduced risk of bowel cancer in users of rosiglitazone versus either placebo or other types of ADDs (OR 0.63, 95\% $\mathrm{Cl}$ 0.41-0.96, $\mathrm{p}=0.03$ ), but not for pioglitazone or TZDs overall. ${ }^{47}$ In addition, a decreased risk of both colorectal cancer (RR 0.93, 95\% Cl 0.90-0.97, 6 cohort studies) and liver cancer (RR $0.65,95 \% \mathrm{Cl} 0.48-0.89,4$ cohort studies) has been observed in a meta-analysis of observational studies wherein use of TZDs was compared to no use of TZDs. $^{48}$

Lastly, incretin-based drugs (glucagon-like peptide-1 receptor agonists (GLP-1RAs), such as exanatide en liraglutide, and dipeptidyl peptidase-4 (DPP-4) inhibitors, such as saxagliptin or sitagliptin) have been associated with an increased risk pancreatic cancer. $^{44,49,50}$ This concern has arisen from the association between incretins and pancreatitis that was found in adverse-event database studies. ${ }^{51,52}$ Subsequent observational studies have so far produced conflicting results, with most recent and methodologically most accurate studies showing no evidence of an increased risk of pancreatic cancer in users of incretins compared to either sulfonylureas or other noninsulin ADDs. ${ }^{53-56}$

\subsection{Hyperglycaemia and gastrointestinal cancer}

In patients with T2DM, the risk of long-term complications is partially related to the degree of glycaemic control over time. ${ }^{57}$ It is therefore interesting to explore whether the level of glycaemic control also influences the risk of Gl cancer, especially as cancer cells are highly dependent on glycolysis for energy, resulting in a high requirement for glucose to generate adenosine triphosphate (ATP; also known as the Warburg effect). ${ }^{58}$ Based on observational studies, high blood glucose levels or inadequate glycaemic 
control are thought to impact cancer risk. ${ }^{59,60}$ However, the evidence for an association between various measures of hyperglycaemia in patients with T2DM and cancer risk has been inconsistent. In a meta-analysis of clinical trials, cancer risk did not seem to be affected by the level of glycaemic control (i.e. randomisation to either standard or intensive glycaemic control). ${ }^{61}$ In contrast, in a meta-analysis of observational studies, $\mathrm{HbA1c}$ levels in the diabetic range were associated with an increased risk of GI cancers. ${ }^{62}$ Additionally, another meta-analysis of epidemiological studies has shown an increased risk of colorectal and pancreatic cancer in groups with the highest compared to those with the lowest ranges of markers of glycaemia (e.g. insulin, glycated haemoglobin [HbA1c], fasting blood glucose). ${ }^{63}$ However, the studies used in meta-analyses all utilized individual or mean markers of glycaemia at the start of follow-up. Therefore, these measurements do not capture the cumulative effects of long-term hyperglycaemia over time which could cause considerable confounding.

\subsection{Methodological considerations}

\section{Confounding}

Evaluating the independent effects of shared risk factors, drug treatments for comorbid conditions, the use of various ADDs, and the possible effects of T2DM on the risk of GI cancer is challenging. ${ }^{13}$ Results of observational studies may have been confounded due to incomplete or incorrect adjustment for shared risk factors for T2DM and GI cancer. Also, residual confounding may be present due to unmeasured confounding variables. For example, many patients with T2DM are overweight or obese, which is partially related to an unhealthy diet or physical inactivity. ${ }^{64}$ These are also established risk factors for most Gl-cancers. ${ }^{65}$ On top of that, most T2DM patients receive drug treatments for comorbid conditions and will receive various ADDs in order to lower the blood glucose concentration.

\section{Bias}

The influence of bias on the association between T2DM and GI cancer is an important issue that must be taken into consideration. First, detection bias may arise as patients who are diagnosed with T2DM often experience an increased level of medical surveillance as compared to patients without a diagnosis of T2DM. ${ }^{66}$ This results in an increased likelihood of a cancer being detected in the T2DM population. Second, protopathic bias is a type of bias that is exemplified by pancreatic cancer, in which symptoms of T2DM are the initial presentation of the growing malignancy. ${ }^{67}$ 
Many observational studies on the use of metformin and risk of incident cancer have been criticized for confounding and several types of bias. ${ }^{39,68}$ These biases mainly revolve around two axes. The first being the classification of observed person time to different exposure categories, and the second being the implicit effect of the natural history of T2DM, both of which can be described as time-related biases. ${ }^{13}$ As recently described by Klil-Drori et al. ${ }^{13}$ these biases come down to this:

"...by incorrectly classifying various observational periods as periods of metformin use, one can easily change the likelihood of a cancer event, and thus create a spurious protective association (immortal time bias). Furthermore, when metformin use is compared with the use of antidiabetic drugs that are typically introduced at a later stage of T2DM (without accounting for the duration of disease), the progression of diabetes can confound any association between drug use and cancer (time-lag bias or confounding by indication)."

Moreover, observational studies in which these biases were accounted for revealed no associations between metformin use and specific cancer types. ${ }^{69-71}$

\subsection{Aims and outline}

Based on the existing data and literature, the association between T2DM and GI cancer is complex, not consistently reported, and subject to various methodological issues and biases, such as confounding and detection bias. Therefore, additional research is necessary to fill this knowledge gap. Studies on the association between T2DM and cancer often focus on cancer in general, or on highly prevalent cancers, such as colorectal cancer, or cancers for which strong associations have previously been described in the literature, such as liver and pancreatic cancer. Evidence for an association between other types of GI cancer (oesophageal cancer, gastric cancer) is less pronounced.

The studies in this thesis focus on the general association between T2DM and all GI cancer types, and diabetes-related factors that may influence this association while taking methodological challenges into account.

The main objectives of the studies described in this thesis are:

I. To evaluate the association between T2DM and different GI cancer types, and to what extent this association is explained by bias;

II. To evaluate the association between the use of anti-diabetic drugs and the risk of GI cancers, specifically the use of metformin and incretins;

III. To evaluate the association between the level of hyperglycaemia over time and the risk of Gl cancers. 
First, in Part I of this thesis (Chapter 2, 3 and 4), we aim to evaluate the incidence and risk of all GI cancers and its sub-sites in patients with T2DM compared to non-diabetic individuals. Two observational studies are presented using different prospective data sources. In Chapter 2 the incidence rates of $\mathrm{Gl}$ cancers are determined in a British cohort of anti-diabetic drug users and matched controls obtained from the Clinical Practice Research Datalink (CPRD) in the United Kingdom. In Chapter 3 the incidence and risk of GI cancer is assessed in a Dutch cohort of anti-diabetic drug users and matched controls, using the linked database of the Eindhoven region of the Netherlands Cancer Registry and PHARMO Database Network (E-NCR-PHARMO database). We hypothesize that patients with T2DM may have higher incidence rates and risks of most, but possibly not all, GI cancers. Furthermore, the effects of detection bias/reverse causality on GI cancer risk are explored in these studies. Since our aim is to come to more definite conclusions on the association between T2DM and GI cancer for clinicians in The Netherlands, it is important to evaluate whether the results from UK-data can be extrapolated to the Dutch situation. Therefore, Chapter 4 is dedicated to the representativeness of the CPRD database for the Dutch population by comparing both the age- and the sex distribution of the CPRD database with the total Dutch population.

Part II focuses on the impact of two anti-diabetic drugs on the risk of GI cancer and pancreatitis in patients with T2DM, using the linked E-NCR-PHARMO database and CPRD as data sources. Previous studies on the use of metformin and GI cancer have shown decreased risks of GI cancers in metformin users, but these studies are often affected by various (time-related) biases. In contrast, high quality studies applying time-varying exposure definitions of metformin did not confirm the suggested protective effects of metformin use on GI cancer risk. In Chapter 5 our aim is to assess whether T2DM patients using metformin are at a decreased risk of developing $\mathrm{Gl}$ cancer compared to T2DM patients not using metformin, using a time-varying exposure definition of antidiabetic drug use. On the one hand, we hypothesize on a decreased risk of GI cancers in users of metformin based on the biological evidence. On the other hand, based on the latest observational evidence, we expect to find no differences in the risk of Gl cancers between users of metformin and other non-insulin anti-diabetic drugs. In Chapter 6 the risk of pancreatitis with the use of incretin-based anti-diabetic drugs is investigated by using the CPRD database. Pancreatitis is a debilitating disease that may convey an increased risk of pancreatic cancer over time. Post-marketing reports of incretin-based drugs have shown that incretins may cause pancreatitis. In addition, in Chapter 7 the possible effect of selection bias in a study that focused on the risk of kidney cancer with use of metformin is discussed. 
In Part III (Chapter 8) the aim is to investigate whether hyperglycaemia over time is associated with an increased risk of Gl cancer in T2DM patients, using a previously described HbA1c-based measure of glycaemia: glycaemic burden (amount of time spend above a predefined HbA1c threshold during follow-up). Previous evidence points towards a higher risk of cancer with higher levels of glycaemia, but this is based on research using limited definitions of hyperglycaemia, such as high versus low $\mathrm{HbA} 1 \mathrm{c}$ at the start of follow-up or mean $\mathrm{HbA1c}$ during the year before diagnosis of cancer. We hypothesized that patients with higher levels of glycaemic burden are at increased risk of developing Gl cancer compared to T2DM who did not accumulate any glycaemic burden over time.

Finally, in the general discussion (Chapter 9) the main findings, methodological considerations, study limitations, and practical and clinical implications of the results presented in this thesis are discussed. 


\section{References}

1. Giovannucci E, Harlan DM, Archer MC, Bergenstal RM, Gapstur SM, Habel LA, et al. Diabetes and cancer: a consensus report. CA: a cancer journal for clinicians. 2010;60(4):207-21.

2. Netherlands Cancer Registry. Cijfers over kanker: Netherlands Comprehensive Cancer Organization; 2016 [cited 2016 01-09-2016]. Available from: www.cijfersoverkanker.nl.

3. Ashktorab H, Kupfer SS, Brim H, Carethers JM. Racial Disparity in Gastrointestinal Cancer Risk. Gastroenterology. 2017;153(4):910-23.

4. Henrikson NB, Webber EM, Goddard KA, Scrol A, Piper M, Williams MS, et al. Family history and the natural history of colorectal cancer: systematic review. Genet Med 2015;17(9):702-12.

5. Charbotel B, Fervers B, Droz JP. Occupational exposures in rare cancers: A critical review of the literature. Crit Rev Oncol Hematol 2014;90(2):99-134.

6. Kyrgiou M, Kalliala I, Markozannes G, Gunter MJ, Paraskevaidis E, Gabra H, et al. Adiposity and cancer at major anatomical sites: umbrella review of the literature. BMJ 2017;356:j477.

7. Thomson CA, LeWinn K, Newton TR, Alberts DS, Martinez ME. Nutrition and diet in the development of gastrointestinal cancer. Curr Oncol Rep 2003;5(3):192-202.

8. Katzke VA, Kaaks R, Kuhn T. Lifestyle and cancer risk. Cancer J 2015;21(2):104-10.

9. World Health O. Global Report on Diabetes. 2014.

10. American Diabetes A. Diagnosis and classification of diabetes mellitus. Diabetes Care. 2010;33 Suppl 1:S62-9.

11. Bouma M, Rutten GE, de Grauw WJ, Wiersma T, Goudswaard AN, Nederlands Huisartsen G. [Summary of the practice guideline 'Diabetes mellitus type 2' (second revision) from the Dutch College of General Practitioners]. Ned Tijdschr Geneeskd. 2006;150(41):2251-6.

12. Tsilidis KK, Kasimis JC, Lopez DS, Ntzani EE, loannidis JP. Type 2 diabetes and cancer: umbrella review of meta-analyses of observational studies. BMJ 2015;350:g7607.

13. Klil-Drori AJ, Azoulay L, Pollak MN. Cancer, obesity, diabetes, and antidiabetic drugs: is the fog clearing? Nat Rev Clin Oncol 2017;14(2):85-99.

14. Jalving M, Gietema JA, Lefrandt JD, de Jong S, Reyners AK, Gans RO, et al. Metformin: taking away the candy for cancer? Eur J Cancer 2010;46(13):2369-80.

15. Johnson JA, Pollak M. Insulin, glucose and the increased risk of cancer in patients with type 2 diabetes. Diabetologia 2010;53(10):2086-8.

16. Johnson JA, Carstensen B, Witte D, Bowker SL, Lipscombe L, Renehan AG, et al. Diabetes and cancer (1): evaluating the temporal relationship between type 2 diabetes and cancer incidence. Diabetologia 2012; 55(6):1607-18.

17. Perks CM, Vernon EG, Rosendahl AH, Tonge D, Holly JM. IGF-II and IGFBP-2 differentially regulate PTEN in human breast cancer cells. Oncogene 2007;26(40):5966-72.

18. Pollak M. Do cancer cells care if their host is hungry? Cell Metab 2009;9(5):401-3.

19. Gallagher EJ, Fierz Y, Ferguson RD, LeRoith D. The pathway from diabetes and obesity to cancer, on the route to targeted therapy. Endocr Pract 2010;16(5):864-73.

20. Pollak M. Insulin and insulin-like growth factor signalling in neoplasia. Nat Rev Cancer 2008;8(12): 915-28.

21. Garg SK, Maurer H, Reed K, Selagamsetty R. Diabetes and cancer: two diseases with obesity as a common risk factor. Diabetes Obes Metab 2014;16(2):97-110.

22. Pannala R, Basu A, Petersen GM, Chari ST. New-onset diabetes: a potential clue to the early diagnosis of pancreatic cancer. Lancet Oncol 2009;10(1):88-95.

23. Ben $\mathrm{Q}, \mathrm{Xu}$ M, Ning X, Liu J, Hong S, Huang W, et al. Diabetes mellitus and risk of pancreatic cancer: A meta-analysis of cohort studies. Eur J Cancer 2011;47(13):1928-37.

24. Pannala R, Leirness JB, Bamlet WR, Basu A, Petersen GM, Chari ST. Prevalence and clinical profile of pancreatic cancer-associated diabetes mellitus. Gastroenterology 2008;134(4):981-7.

25. Chari ST, Leibson CL, Rabe KG, Timmons LJ, Ransom J, de Andrade M, et al. Pancreatic cancer-associated diabetes mellitus: prevalence and temporal association with diagnosis of cancer. Gastroenterology 2008;134(1):95-101. 
26. Ben $Q$, Cai $Q$, Li Z, Yuan $Y$, Ning $X$, Deng $S$, et al. The relationship between new-onset diabetes mellitus and pancreatic cancer risk: a case-control study. EurJ Cancer 2011;47(2):248-54.

27. Chae YK, Arya A, Malecek MK, Shin DS, Carneiro B, Chandra S, et al. Repurposing metformin for cancer treatment: current clinical studies. Oncotarget 2016;7(26):40767-80.

28. Sanchez-Cespedes M. A role for LKB1 gene in human cancer beyond the Peutz-Jeghers syndrome. Oncogene 2007;26(57):7825-32.

29. Pryor R, Cabreiro F. Repurposing metformin: an old drug with new tricks in its binding pockets. Biochem J 2015;471(3):307-22.

30. Shi WY, Xiao D, Wang L, Dong LH, Yan ZX, Shen ZX, et al. Therapeutic metformin/AMPK activation blocked lymphoma cell growth via inhibition of mTOR pathway and induction of autophagy. Cell Death Dis 2012;3:e275.

31. Moiseeva O, Deschenes-Simard X, St-Germain E, Igelmann S, Huot G, Cadar AE, et al. Metformin inhibits the senescence-associated secretory phenotype by interfering with IKK/NF-kappaB activation. Aging Cell 2013;12(3):489-98.

32. Eikawa S, Nishida M, Mizukami S, Yamazaki C, Nakayama E, Udono H. Immune-mediated antitumor effect by type 2 diabetes drug, metformin. Proc Natl Acad Sci U S A 2015;112(6):1809-14.

33. Gandini S, Puntoni M, Heckman-Stoddard BM, Dunn BK, Ford L, DeCensi A, et al. Metformin and cancer risk and mortality: a systematic review and meta-analysis taking into account biases and confounders. Cancer Prev Res 2014;7(9):867-85.

34. Knapen LM, Dittrich ST, de Vries F, Starup-Linde J, Vestergaard P, Henry RM, et al. Use of biguanides and the risk of colorectal cancer: a register-based cohort study. Curr Drug Saf 2013;8(5):349-56.

35. Evans JM, Donnelly LA, Emslie-Smith AM, Alessi DR, Morris AD. Metformin and reduced risk of cancer in diabetic patients. BMJ 2005;330(7503):1304-5

36. Franciosi M, Lucisano G, Lapice E, Strippoli GF, Pellegrini F, Nicolucci A. Metformin therapy and risk of cancer in patients with type 2 diabetes: systematic review. PloS One 2013;8(8):e71583.

37. Stevens RJ, Ali R, Bankhead CR, Bethel MA, Cairns BJ, Camisasca RP, et al. Cancer outcomes and all-cause mortality in adults allocated to metformin: systematic review and collaborative meta-analysis of randomised clinical trials. Diabetologia 2012;55(10):2593-603.

38. Thakkar B, Aronis KN, Vamvini MT, Shields K, Mantzoros CS. Metformin and sulfonylureas in relation to cancer risk in type II diabetes patients: a meta-analysis using primary data of published studies. Metabolism 2013;62(7):922-34.

39. Suissa S, Azoulay L. Metformin and the risk of cancer: time-related biases in observational studies. Diab Care 2012;35(12):2665-73.

40. Gallagher EJ, LeRoith D. Diabetes, antihyperglycemic medications and cancer risk: smoke or fire? Curr Opin Endocrinol Diab Obes 2013;20(5):485-94.

41. Chen Y, Du L, Li L, Ma J, Geng X, Yao X, et al. Cancer risk of sulfonylureas in patients with type 2 diabetes mellitus: A systematic review. J Diabetes 2017;9(5):482-94.

42. Rosenstock J, Fonseca V, McGill JB, Riddle M, Halle JP, Hramiak I, et al. Similar risk of malignancy with insulin glargine and neutral protamine Hagedorn (NPH) insulin in patients with type 2 diabetes: findings from a 5 year randomised, open-label study. Diabetologia 2009;52(9):1971-3.

43. Home PD, Lagarenne P. Combined randomised controlled trial experience of malignancies in studies using insulin glargine. Diabetologia 2009;52(12):2499-506.

44. Karlstad O, Starup-Linde J, Vestergaard P, Hjellvik V, Bazelier MT, Schmidt MK, et al. Use of insulin and insulin analogs and risk of cancer - systematic review and meta-analysis of observational studies. Curr Drug Saf 2013;8(5):333-48

45. Tang $X$, Yang L, He Z, Liu J. Insulin glargine and cancer risk in patients with diabetes: a meta-analysis. PloS One 2012;7(12):e51814.

46. Okumura T. Mechanisms by which thiazolidinediones induce anti-cancer effects in cancers in digestive organs. J Gastroenterol 2010;45(11):1097-102.

47. Monami M, Dicembrini I, Mannucci E. Thiazolidinediones and cancer: results of a meta-analysis of randomized clinical trials. Acta Diabetol 2014;51(1):91-101.

48. Bosetti C, Rosato V, Buniato D, Zambon A, La Vecchia C, Corrao G. Cancer risk for patients using thiazolidinediones for type 2 diabetes: a meta-analysis. Oncologist 2013;18(2):148-56. 
49. Kowall B, Rathmann W, Kostev K. Are sulfonylurea and insulin therapies associated with a larger risk of cancer than metformin therapy? A retrospective database analysis. Diab Care 2015;38(1):59-65.

50. Egan AG, Blind E, Dunder K, de Graeff PA, Hummer BT, Bourcier T, et al. Pancreatic safety of incretinbased drugs--FDA and EMA assessment. N Engl J Med 2014;370(9):794-7.

51. Elashoff M, Matveyenko AV, Gier B, Elashoff R, Butler PC. Pancreatitis, pancreatic, and thyroid cancer with glucagon-like peptide-1-based therapies. Gastroenterology 2011;141(1):150-6.

52. Raschi E, Piccinni C, Poluzzi E, Marchesini G, De Ponti F. The association of pancreatitis with antidiabetic drug use: gaining insight through the FDA pharmacovigilance database. Acta Diabetol 2013;50(4): 569-77.

53. Tseng $\mathrm{CH}$. Sitagliptin and pancreatic cancer risk in patients with type 2 diabetes. Eur J Clin Invest 2016;46(1):70-9.

54. Knapen LM, van Dalem J, Keulemans YC, van Erp NP, Bazelier MT, De Bruin ML, et al. Use of incretin agents and risk of pancreatic cancer: a population-based cohort study. Diabetes Obes Metab 2016;18(3):258-65.

55. Gokhale M, Buse JB, Gray CL, Pate V, Marquis MA, Sturmer T. Dipeptidyl-peptidase-4 inhibitors and pancreatic cancer: a cohort study. Diabetes Obes Metab 2014;16(12):1247-56.

56. Azoulay L, Filion KB, Platt RW, Dahl M, Dormuth CR, Clemens KK, et al. Incretin based drugs and the risk of pancreatic cancer: international multicentre cohort study. BMJ 2016;352:i581.

57. Aronson D. Hyperglycemia and the pathobiology of diabetic complications. Adv Cardiol 2008;45:1-16.

58. Vander Heiden MG, Cantley LC, Thompson CB. Understanding the Warburg effect: the metabolic requirements of cell proliferation. Science 2009;324(5930):1029-33.

59. Jee SH, Ohrr H, Sull JW, Yun JE, Ji M, Samet JM. Fasting serum glucose level and cancer risk in Korean men and women. JAMA 2005;293(2):194-202.

60. Stocks T, Rapp K, Bjorge T, Manjer J, Ulmer H, Selmer R, et al. Blood glucose and risk of incident and fatal cancer in the metabolic syndrome and cancer project (me-can): analysis of six prospective cohorts. PLoS Med 2009;6(12):e1000201.

61. Johnson JA, Bowker SL. Intensive glycaemic control and cancer risk in type 2 diabetes: a meta-analysis of major trials. Diabetologia 2011;54(1):25-31.

62. de Beer JC, Liebenberg L. Does cancer risk increase with HbA1C, independent of diabetes? Br J Cancer 2014;110(9):2361-8.

63. Pisani P. Hyper-insulinaemia and cancer, meta-analyses of epidemiological studies. Arch Physiol Biochem 2008;114(1):63-70.

64. Hemmingsen B, Gimenez-Perez G, Mauricio D, Roque IFM, Metzendorf MI, Richter B. Diet, physical activity or both for prevention or delay of type 2 diabetes mellitus and its associated complications in people at increased risk of developing type 2 diabetes mellitus. The Cochrane database of systematic reviews. 2017;12:CD003054.

65. Mysuru Shivanna L, Urooj A. A Review on Dietary and Non-Dietary Risk Factors Associated with Gastrointestinal Cancer. J Gastrointest Cancer 2016;47(3):247-54.

66. Carstensen B, Witte DR, Friis S. Canner occurrence in Danish diabetic patients: duration and insulin effects. Diabetologia 2012;55(4):948-58.

67. De Bruijn KM, Ruiter R, de Keyser CE, Hofman A, Stricker BH, van Eijck CH. Detection bias may be the main cause of increased cancer incidence among diabetics: results from the Rotterdam Study. Eur J Cancer 2014;50(14):2449-55.

68. Golozar A, Liu S, Lin JA, Peairs K, Yeh HC. Does Metformin Reduce Cancer Risks? Methodologic Considerations. Curr Diab Rep 2016;16(1):4.

69. Kowall B, Stang A, Rathmann W, Kostev K. No reduced risk of overall, colorectal, lung, breast, and prostate cancer with metformin therapy in diabetic patients: database analyses from Germany and the UK. Pharmacoepidemiol Drug Saf 2015;24(8):865-74.

70. Tsilidis KK, Capothanassi D, Allen NE, Rizos EC, Lopez DS, van Veldhoven K, et al. Metformin does not affect cancer risk: a cohort study in the U.K. Clinical Practice Research Datalink analyzed like an intentionto-treat trial. Diab Care 2014;37(9):2522-32.

71. Smiechowski B, Azoulay L, Yin H, Pollak MN, Suissa S. The use of metformin and colorectal cancer incidence in patients with type II diabetes mellitus. Cancer Epidemiol Biomarkers Prev 2013;22(10): 1877-83. 


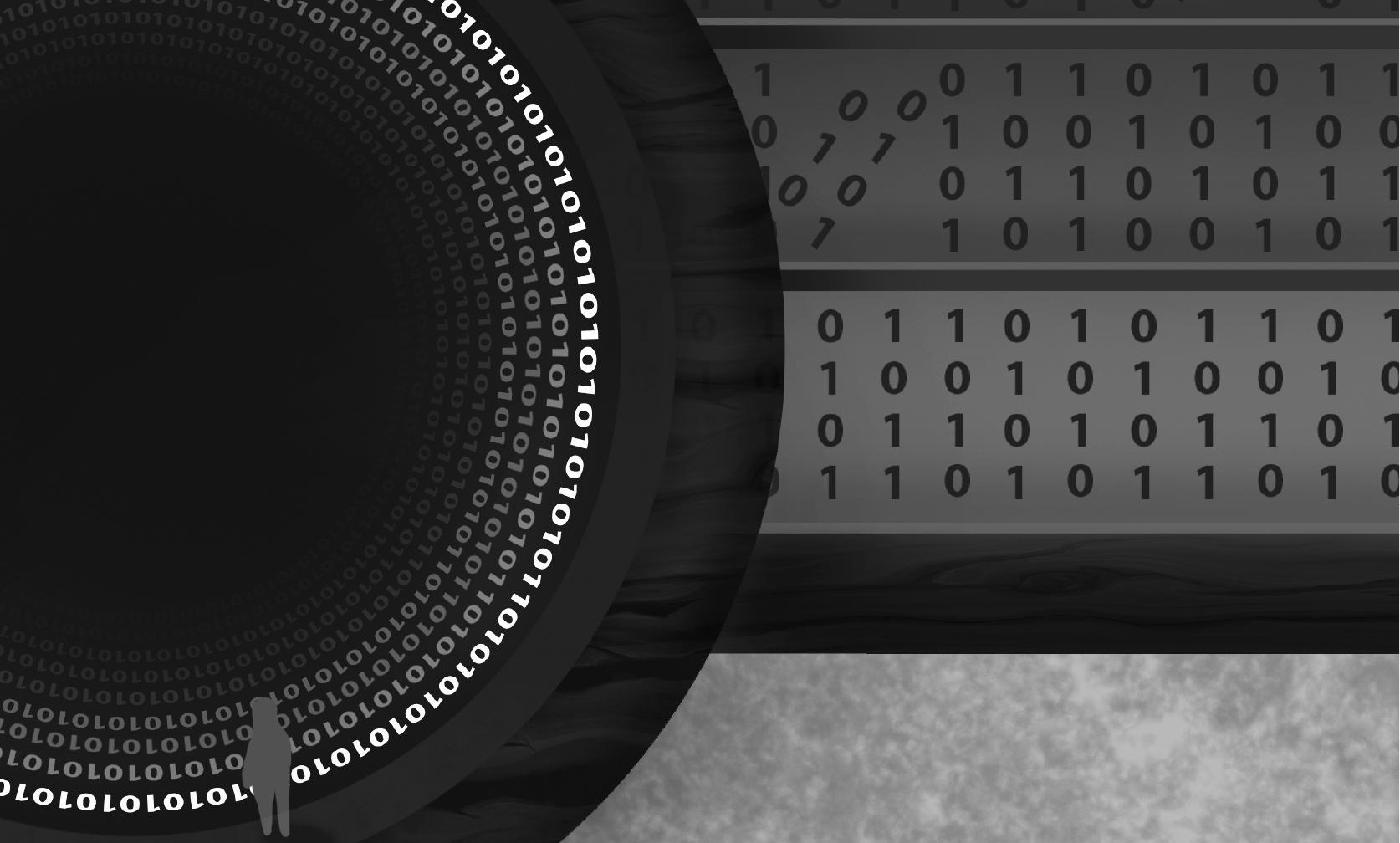

$\begin{array}{llllllllll}0 & 1 & 1 & 0 & 1 & 0 & 1 & 1 & 0 & 1\end{array}$

$\begin{array}{lllllllll}1 & 0 & 0 & 1 & 0 & 1 & 0 & 0 & 1\end{array}$

$\begin{array}{llllllllll}0 & 1 & 1 & 0 & 1 & 0 & 1 & 1 & 0 & 1\end{array}$

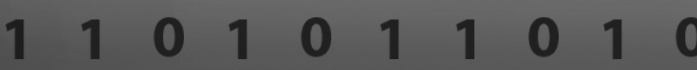

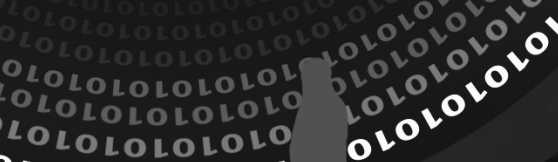
$010^{2}$ 


\title{
Chapter
}

\section{Gastrointestinal cancer incidence in type 2 diabetes}

mellitus; results from a large population-based cohort

\author{
study in the UK
}

Roy G.P.J. de Jong, Paul J.H.L. Peeters, Andrea M. Burden, Marie L. de Bruin, Harm R. Haak, Ad A.M. Masclee, Frank de Vries, Maryska L.G. Janssen-Heijnen 


\section{Abstract}

\section{Background}

Patients with type 2 diabetes mellitus (T2DM) have been shown to have higher incidences of liver, pancreatic, and colorectal cancer compared to non-diabetic individuals. Current evidence is conflicting for other gastrointestinal (GI) cancers. Therefore, we aimed to determine incidence rates (IRs) of all GI cancers in patients with and without T2DM.

\section{Methods}

A cohort study was performed using the UK Clinical Practice Research Datalink (1988-2012). A cohort of antidiabetic drug users was matched at baseline to a nondiabetic cohort, by age, sex, and practice. Crude IRs and 95\% confidence intervals $(95 \% \mathrm{Cl})$ of $\mathrm{Gl}$ cancers per 100,000 person-years were calculated stratified by age, sex, and calendar year.

\section{Results}

333,438 T2DM and 333,438 non-diabetic individuals were analyzed. IRs of liver (IR 26, $95 \% \mathrm{Cl} 24-28$ versus $8.9,95 \% \mathrm{Cl} 7.7-10$ ), pancreatic (IR 65, 95\% Cl 62-69 versus 31, $95 \% \mathrm{Cl} 28-34$ ), and colon cancer (IR 119, 95\% Cl 114-124 versus 109, 95\% Cl 104-114) were significantly higher in the diabetic compared to the non-diabetic cohort, whereas the IR of oesophageal cancer was significantly lower (IR 41, 95\% Cl 39-44 versus 47, 95\% $\mathrm{Cl}$ 44-51). Sex-specific IRs of colon cancer remained significantly higher in men with T2DM, and IRs of esophageal cancer remained significantly lower in women with T2DM.

\section{Conclusion}

In this study, T2DM patients were shown to have higher crude IRs of liver, pancreatic and colon cancer, but not of gastric, biliary, and rectal cancer. Moreover, the lower observed IRs of oesophageal cancer in diabetic patients warrants further investigation. 


\section{Introduction}

There is a growing body of evidence on an increased risk of cancer in type 2 diabetic patients, including gastrointestinal (GI) malignancies. ${ }^{1-7}$ However, the data are conflicting for specific Gl cancer sites, such as the upper gastrointestinal tract and biliary system. The strongest associations have been found for liver and pancreatic cancer, although ascertainment bias and reverse causality may have played an important role. ${ }^{8-10}$ Furthermore, age-sex stratified analyses have not always been reported, despite the demonstration of age- and sex-specific differences in cancer risk, with Gl cancer occurring more frequently at a higher age and more frequently in men. ${ }^{1}$

Type 2 diabetic patients may have an increased risk of Gl cancers through several common risk factors, such an older age, exposure to alcohol, smoking, a high caloric diet, lack of physical activity, and increased body mass index (BMI). ${ }^{1}$ In addition, site-specific risk factors that are more prevalent among diabetic patients may play an important role. These include gastro-oesophageal reflux disease in oesophageal cancer, Helicobacter pylori infections in gastric cancer, gallstone formation in biliary tract cancer, and nonalcoholic fatty liver disease or cirrhosis in hepatocellular carcinoma. ${ }^{11-14}$

The underlying biological mechanisms that may explain the association between type 2 diabetes mellitus and cancer have yet to be further unraveled. In general, three pathophysiological mechanisms have been proposed which act through metabolic, hormonal and inflammatory pathways, namely: hyperglycaemia/hyperinsulinaemia, insulin/insulin-like growth factor (IGF) axis and chronic inflammation. Hyperinsulinaemia stimulates IGF-1 production, which may subsequently promote tumor growth by induction of cell proliferation and inhibition of apoptosis. Hyperinsulinaemia is also the hallmark of insulin resistance, which in turn stimulates the release of pro-inflammatory cytokines causing a pro-inflammatory state. ${ }^{1}$

Most studies have reported relative measures of risk of cancer with diabetes, without a focus on the absolute numbers regarding the incidence of $\mathrm{Gl}$ cancer in the diabetic population. To our knowledge population-based incidence rates of all subtypes of GI cancers in diabetic patients versus matched controls are unknown. Therefore, our aim was to determine incidence rates of GI malignancies for each site of the digestive tract in type 2 diabetic and non-diabetic individuals in the United Kingdom (UK). 


\section{Materials and methods}

\section{Data source}

Data were obtained from the UK Clinical Practice Research Datalink (CPRD). The CPRD is an ongoing primary care database that comprises anonymized electronic medical records from British general practitioners since 1987, with coverage of over 11.3 million patients from 674 practices. ${ }^{15,16}$ Currently, the population of active patients represents $6.9 \%$ of the total UK population. CPRD records include demographic information, medication prescription details, clinical events, preventive care provided, diagnostic tests, specialist referrals, hospital admissions, and major outcomes. ${ }^{16}$ The accuracy and completeness of CPRD data have been well-validated. ${ }^{17,18}$ The protocol of this study was approved by CPRD's Independent Scientific Advisory Committee (Protocol 15_143).

\section{Study population}

To examine $\mathrm{Gl}$ cancer incidence rates (IRs) across anatomic subsite, age, sex, and calendar year among type 2 diabetic patients and non-diabetic individuals, we included a cohort of antidiabetic drug (ADD) users (diabetic cohort) and a (1:1) matched reference cohort using incidence sampling technique (Supplementary Figure S2.1). The diabetic cohort consisted of all registered adult patients (aged 18+ years) with at least one prescription for an ADD recorded in CPRD during valid data collection (January 1988December 2012). The date of first ADD prescription defined start of follow-up (index date). Each diabetic patient was matched to a reference patient without any past recorded prescriptions for ADDs by sex, year of birth, and practice. Reference patients were assigned the same index date as their matched diabetic patient. Patients in the reference cohort could become diabetic patients if an ADD prescription was recorded. At the prescription date the patient was censored as a reference and matched, as a diabetic patient, to a new reference. Non-diabetic reference subjects could have suffered from any other disease than diabetes mellitus or those mentioned as exclusion criteria below. Patients with a prescription for insulin at the index date, without a concomitant prescription for a non-insulin ADD, were excluded if (a) they had a recorded diagnosis for type 1 diabetes mellitus or (b) they were under 30 years of age at cohort entry. These patients were considered having type 1 diabetes mellitus. Secondly, all subjects with a history of the cancer of interest prior to cohort entry (i.e. all subjects with a history of gastric cancer when investigating gastric cancer) were excluded. Furthermore, all metformin only users who had a history of polycystic ovary syndrome (PCOS) prior to cohort entry were excluded, as they are more likely to receive metformin as a treatment for PCOS, instead of type 2 diabetes mellitus. In addition, we excluded diabetic patients 
without any subsequent prescriptions for an ADD (after the initial prescription recorded at baseline). All matched individuals of excluded subjects were excluded as well.

\section{Outcome}

All study participants were followed up from the index date to a diagnosis of a $\mathrm{Gl}$ malignancy, the end of data collection, the date of transfer out of the practice area, or death, whichever came first. The first medical record for a GI cancer in CPRD after cohort entry was taken as the diagnosis date of a new case. Subsites of cancer were classified according to their anatomical location; i.e. cancer of the esophagus, stomach, liver, gallbladder and extra-hepatic bile ducts (biliary), pancreas, small intestines, colon and rectum. A high level of validity for the recording of cancer in the CPRD has been previously reported. ${ }^{19}$

\section{Statistical analyses}

To describe and compare both cohorts at baseline, we analyzed various lifestyle factors (smoking status, alcohol use, body mass index), a diagnosis of various comorbidities ever before (gallstone disease, gastro-esophageal reflux disease (GERD), Helicobacter pylori infection, hypertension, inflammatory bowel disease (IBD), chronic liver disease, and chronic pancreatitis), use of drugs during the past 6 months before start of follow-up (antihypertensives, aspirin, non-steroidal anti-inflammatory drugs (NSAIDs), protonpump inhibitors, and statins), and if a subject had a colonoscopy for colorectal cancer screening purposes during the year before start of follow-up. Overall, age-, sex-, and site-specific incidence rates (IR) per 100,000 person years (py) and incidence rate ratios (IRR) with 95\% confidence intervals (Cl) were calculated for $\mathrm{Gl}$ cancers in the diabetic and reference cohort. IRRs were calculated by dividing the IR of the non-diabetic cohort by the IR of the type 2 diabetic cohort. Differences between IRs were tested for statistical significance using the normal theory test $(\alpha<0.05) .{ }^{20}$ To assess secular trends, data were presented by age group and time period of cancer diagnosis. Age groups consisted of 5-year intervals, with the exception of those aged '18 through 29 years' (as cancer is rare in these patients) and ending with ' $85+$ years'. Calendar time was broken down into six periods: 2001-2002, 2003-2004, 2005-2006, 2007-2008, 2009-2010, and 2011-2012. Time periods for 1988-2000 were not shown due to lower accuracy of CPRD database during that period. Due to a small number of small intestinal cancer cases, graphs for this cancer site are not shown as no reliable conclusions could be drawn. Furthermore, when the number of cases in a specific subgroup was less than six, data were not shown (suppressed) for reasons of patient privacy. 


\section{Sensitivity analyses}

To prevent possible detection bias after the diagnosis of type 2 diabetes mellitus and account for possible reverse causality, a sensitivity analysis was performed by excluding the first year of follow-up after the index date from the analysis for all patients and subsequently calculating subsite- and sex-specific IRs during the remaining follow-up period. All data management and statistical analyses were conducted using SAS 9.2 (SAS Institute Inc., Cary, NC, USA).

\section{Results}

During more than 3.6 million person-years of follow-up, 10,977 Gl cancer cases were observed in 333,438 type 2 diabetic patients and 333,438 non-diabetic individuals. Baseline characteristics are presented in Table 2.1. Type 2 diabetic patients had on average a higher BMI, and a higher proportion was former smokers. Non-diabetic individuals were more often current smokers, and a higher proportion had used alcohol. In addition, statistical significant differences were seen between the type 2 diabetic and non-diabetic cohort in the histories of various comorbidities (e.g. gallstone disease, gastro-esophageal reflux disease, hypertension) at baseline, use of drugs (e.g. antihypertensives, aspirin, statins) during the 6 months before baseline, and colorectal cancer screening colonoscopy during the year before cohort entry.

\section{Cancer incidence by cancer site}

The IRs of any GI cancer (IR 330, 95\% Cl 322-339 vs. 276, 95\% Cl 268-284 per 100.000 py; IRR 1.20, 95\% Cl 1.15-1.24), liver (IR 26, 95\% Cl 24-28 vs. 8.9, 95\% Cl 7.7-10; IRR 2.87, 95\% Cl 2.40-3.44), pancreatic (IR 65, 95\% Cl 62-69 vs. 31, 95\% Cl 28-34; IRR 2.12, 95\% Cl 1.92-2.34), and colon cancer (IR 119, 95\% Cl 114-124 vs. 109, 95\% Cl 104-114; IRR 1.09, 95\% Cl 1.03-1.16) were significantly higher $(p<0.05)$ in the diabetic cohort compared to the reference cohort (Table 2.2). In contrast, the IR of esophageal cancer was significantly lower in the diabetic cohort compared to reference cohort (IR $41,95 \% \mathrm{Cl} 39-44$ vs. $47,95 \% \mathrm{Cl} 44-51$; IRR 0.87, 95\% Cl 0.79-0.96, $\mathrm{p}<0.05)$. Among the other subsites of GI cancer no significant differences in IRs between the diabetic and reference cohorts were seen. Similar results were found in a sensitivity analysis excluding 1 year of follow-up after the index date, except for pancreatic cancer in the diabetic cohort which declined to an IR of $48,95 \% \mathrm{Cl} 45-52$ (data not shown). However, the difference in IRs for pancreatic cancer between the diabetic and reference cohort remained statistically significant. 
Table 2.1 Baseline characteristics of the type 2 diabetic and non-diabetic cohorts.

\begin{tabular}{|c|c|c|c|}
\hline Characteristic & $\begin{array}{c}\text { Type } 2 \text { diabetic cohort } \\
\left(n=333,438^{\mathrm{a}}\right)\end{array}$ & $\begin{array}{c}\text { Non-diabetic cohort } \\
\left(n=333,438^{\mathrm{a}}\right)\end{array}$ & p-value \\
\hline Median age at start follow-up (years, IQR) & $61.8(52-73)$ & $61.8(52-73)$ & \\
\hline Male (n, \%) & $183,297(55)$ & $183,297(55)$ & \\
\hline \multicolumn{4}{|l|}{ Type of antidiabetic drug ${ }^{b}(n, \%)$} \\
\hline Metformin & $205,288(61.6)$ & & \\
\hline Sulfonylureas & $105,273(31.6)$ & & \\
\hline Thiazolidinediones & $7,632(2.3)$ & & \\
\hline Meglitinides & $1,017(0.3)$ & & \\
\hline DPP4-inhibitors & $1,584(0.5)$ & & \\
\hline GLP-1 analogues & $481(0.1)$ & & \\
\hline Insulin & $49,340(14.8)$ & & \\
\hline \multicolumn{4}{|l|}{ Body mass index (BMI) category (n, \%) } \\
\hline$<20$ & $4,929(1.5)$ & $13,357(4.0)$ & \\
\hline $20-24$ & $45,379(13.6)$ & $87,337(26.2)$ & \\
\hline $25-29$ & $96,021(28.8)$ & $95,728(28.7)$ & \\
\hline $30-34$ & $73,749(22.1)$ & $36,223(10.9)$ & \\
\hline$\geq 35$ & $58,551(17.6)$ & $14,601 \quad(4.4)$ & \\
\hline Unknown & $54,809(16.4)$ & $86,192(25.8)$ & $<0.05$ \\
\hline \multicolumn{4}{|l|}{ Smoking status (n, \%) } \\
\hline Current & $69,225(20.8)$ & $70,518(21.1)$ & \\
\hline Former & $68,672(20.6)$ & $52,520(15.8)$ & \\
\hline Never & $147,391(44.2)$ & $150,281(45.1)$ & \\
\hline Unknown & $48,150(14.4)$ & 60,119 (18.0) & $<0.05$ \\
\hline \multicolumn{4}{|l|}{ Alcohol use (n, \%) } \\
\hline Yes & $184,431(55.3)$ & $198,074(59.4)$ & \\
\hline No & $72,026(21.6)$ & $47,918(14.4)$ & \\
\hline Unknown & $76,981(23.1)$ & $87,446(26.2)$ & $<0.05$ \\
\hline \multicolumn{4}{|l|}{ Comorbidities (n, \%) } \\
\hline Gallstone disease & $9,173(2.8)$ & $5,737(1.7)$ & $<0.05$ \\
\hline Gastro-esophageal reflux disease & $29,463(8.8)$ & $26,638(8.0)$ & $<0.05$ \\
\hline Helicobacter pylori infection & $3,756(1.1)$ & $3,543(1.1)$ & $<0.05$ \\
\hline Hypertension & 146,486 (43.9) & $83,326(25.0)$ & $<0.05$ \\
\hline Inflammatory bowel disease & $3,090(0.9)$ & $2,516(0.7)$ & $<0.05$ \\
\hline Chronic liver disease & $3,613(1.1)$ & $1,190(0.4)$ & $<0.05$ \\
\hline Chronic pancreatitis & $1,419(0.4)$ & $270(0.1)$ & $<0.05$ \\
\hline \multicolumn{4}{|l|}{ Other drug-use ${ }^{b}(n, \%)$} \\
\hline Antihypertensives & $192,086(57.6)$ & 102,911 (30.9) & $<0.05$ \\
\hline Aspirin & $92,558(27.8)$ & $41,511(12.4)$ & $<0.05$ \\
\hline $\mathrm{NSAIDs}^{\mathrm{C}}$ & $44,265(13.3)$ & $38,245(11.5)$ & $<0.05$ \\
\hline Proton-pump inhibitors & $53,164(15.9)$ & $35,558(10.7)$ & $<0.05$ \\
\hline Statins & $130,666(39.2)$ & $43,526(13.0)$ & $<0.05$ \\
\hline Colorectal cancer screening ( $n, \%)$ & $2,903(0.9)$ & $3,577(1.1)$ & $<0.05$ \\
\hline
\end{tabular}

${ }^{a}$ Based on analysis of any gastrointestinal cancer; ${ }^{b}$ Multiple prescriptions on the index date occurred; ${ }^{c}$ Nonsteroidal anti-inflammatory drugs (excluding apirin). 


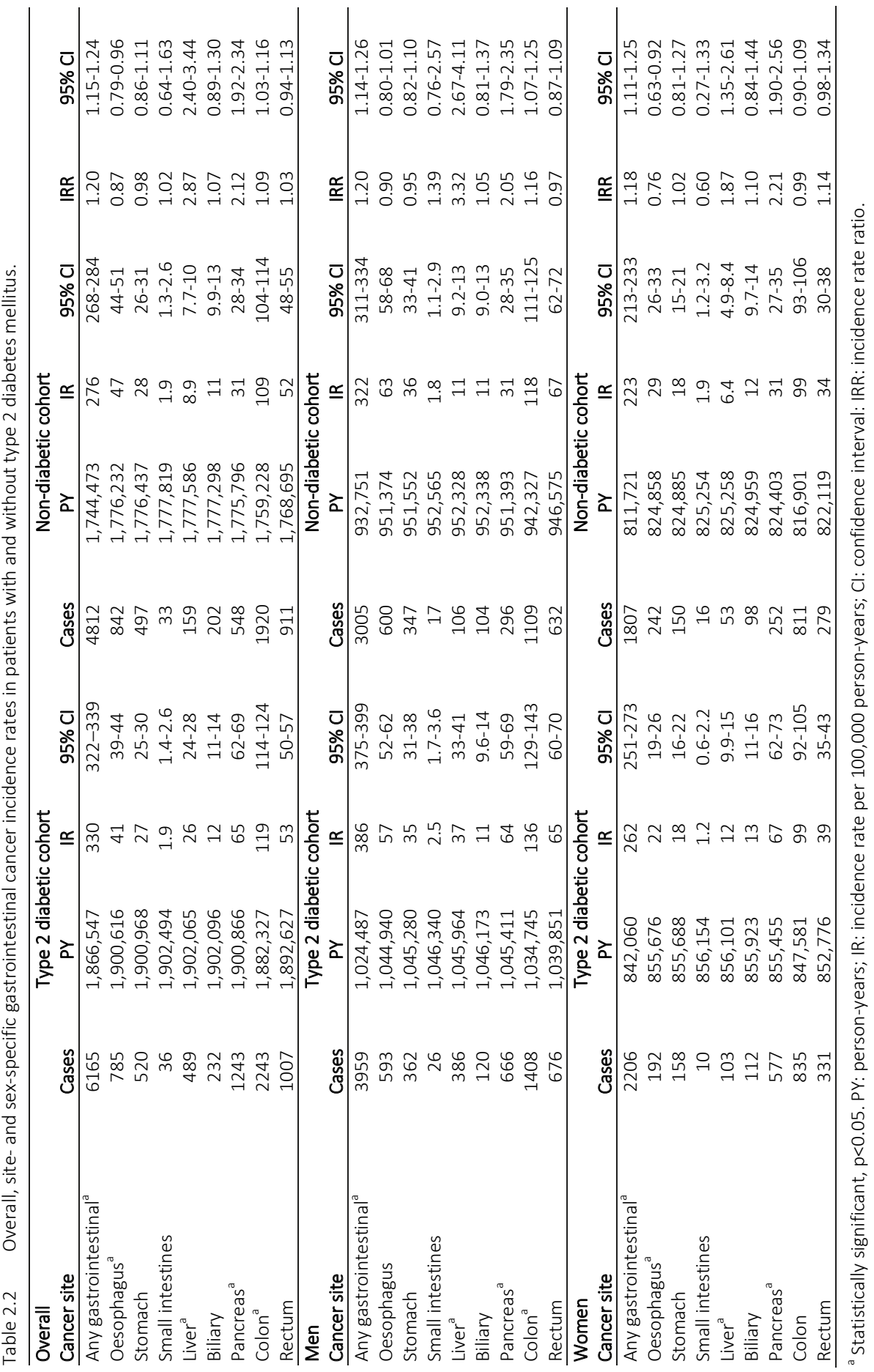




\section{Cancer incidence by sex}

Men with type 2 diabetes mellitus had significantly higher IRs of any $\mathrm{GI}$, liver, pancreatic and colon cancer compared to male reference patients (Table 2.2). In women with type 2 diabetes mellitus, significantly higher IRs were observed for any GI, liver, and pancreatic cancer compared to female reference patients. The lower IRs for esophageal cancer in the diabetic cohort only remained statistically significant in women, although in general, males had higher IRs of esophageal cancer than females. Among the other $\mathrm{GI}$ cancer sites no significant differences in IRs between the diabetic and reference cohorts were found after stratifying by sex.

\section{Cancer incidence by age}

Figure 2.1 shows the site-specific IRs of GI cancers stratified by 5-year age groups for the diabetic and reference cohorts. Amongst all cancer sites, IRs increased with increasing age for both populations. Differences between the diabetic and reference cohort for IR at increasing age were most pronounced in liver, pancreatic and colon cancer. For other GI cancer sites, IRs by age overlapped between the two cohorts. Age-specific IRs of gastrointestinal cancers did not differ evidently when stratified by sex (data not shown).

\section{Cancer incidence over time}

IRs of any $\mathrm{Gl}$, liver, and pancreatic cancer in the diabetic cohort remained clearly elevated over time compared to the reference cohort (Figure 2.2). Moreover, IRs of liver cancer more than doubled in time in the diabetic cohort, while remaining stable in the reference cohort. Also, trends of increasing IRs for colon cancer were observed in both the diabetic and reference cohort. In contrast, IRs of pancreatic cancer declined slightly over time in both cohorts, while IRs of any GI, esophageal, gastric, and biliary cancer remained more or less stable. In addition, IRs of esophageal cancer differed only in the time periods 2003-2004 and 2005-2006 between the two cohorts, being higher in the reference cohort. For other GI cancer subsites no noteworthy differences in IRs were seen between the diabetic and reference cohorts over time. 

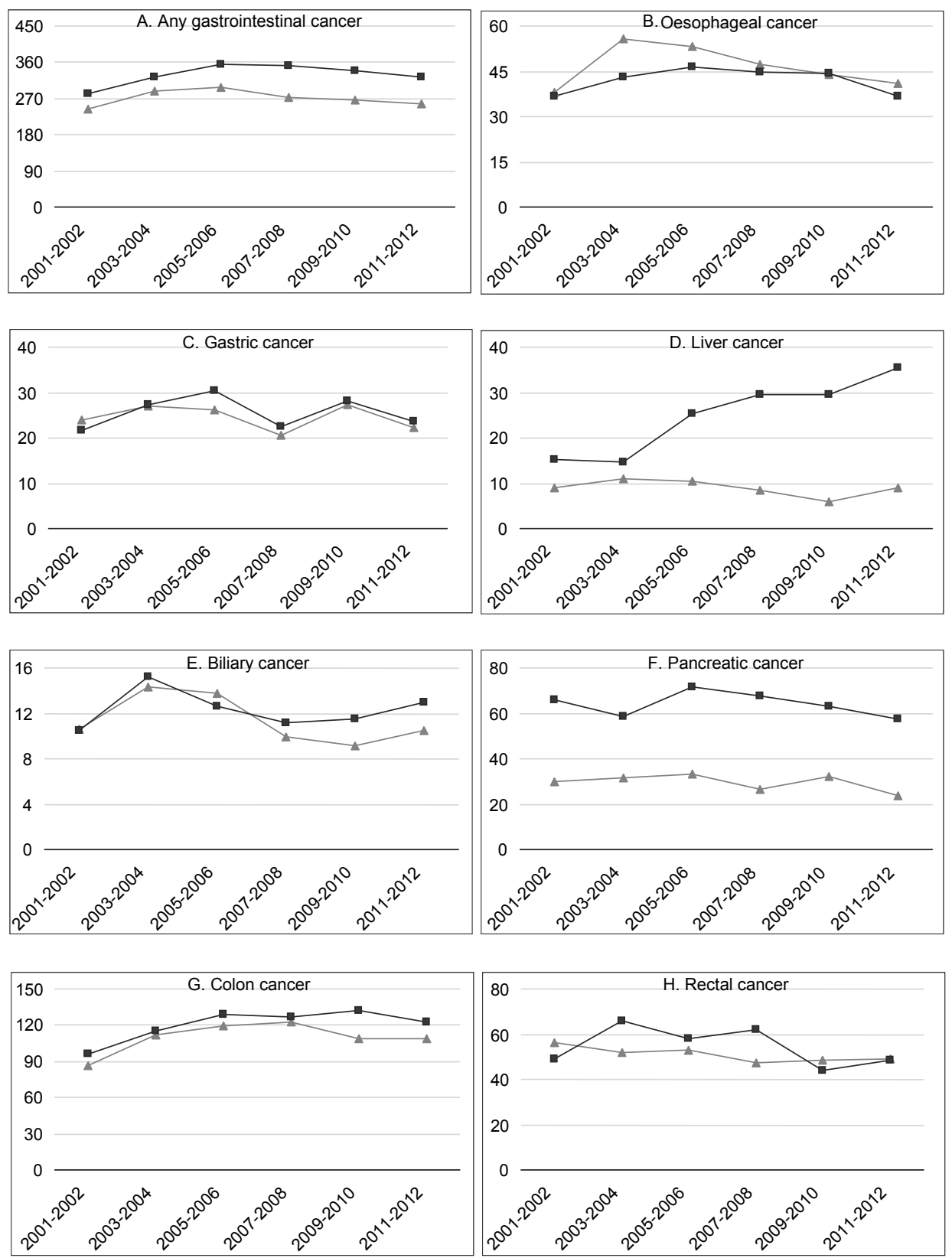

Figure 2.1 Overall and site-specific Gl cancer incidence rates stratified by 5-year age categories ( $\mathrm{x}$-axis). The $y$-axis indicates the incidence rate in number of events per 100,000 person-years. Gl: gastrointestinal, T2DM: Type 2 diabetes mellitus, IR: incidence rate. Black line: type 2 diabetic cohort, Grey line: reference cohort. 

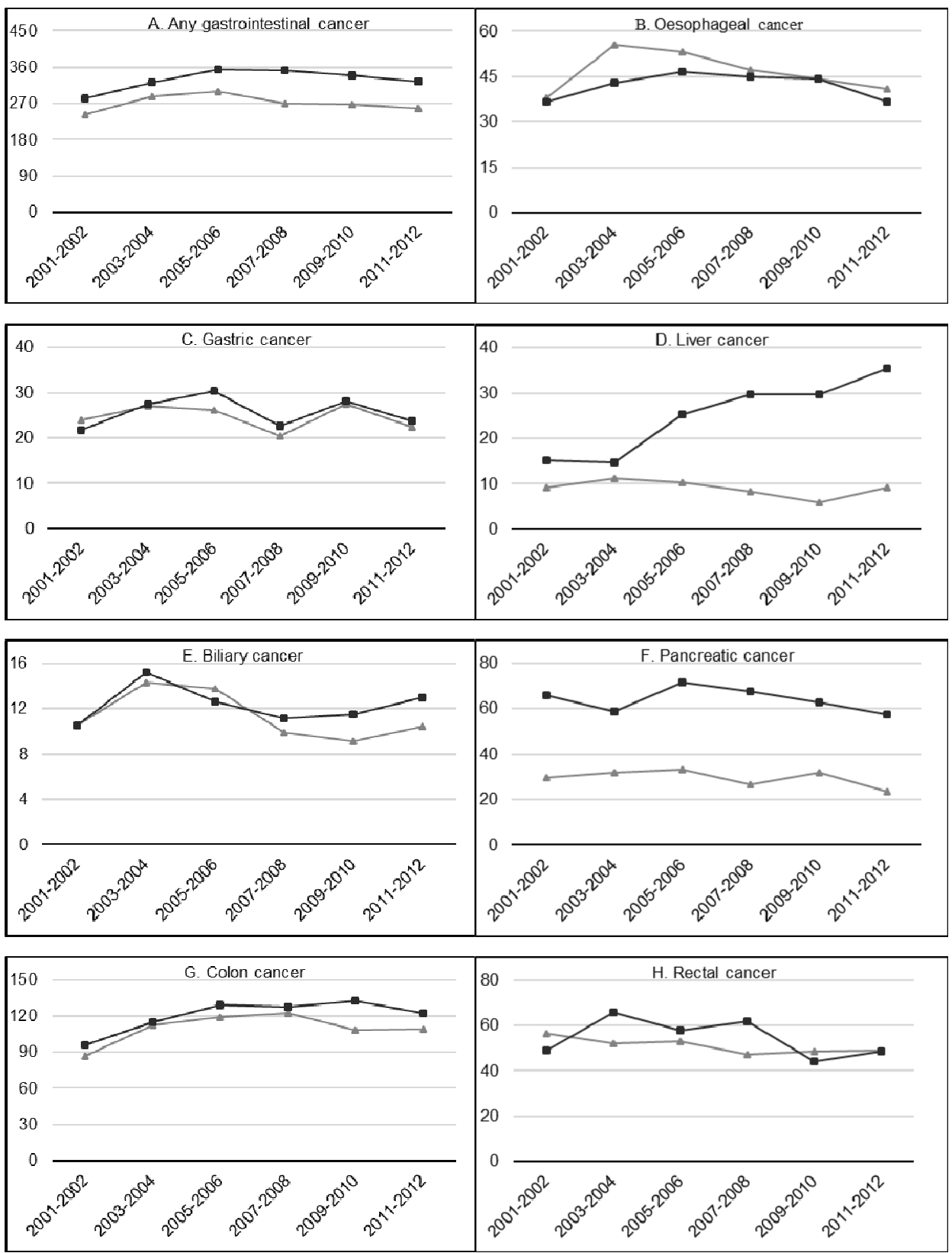

Figure 2.2 Time trends in any and site-specific IRs of GI cancer in the diabetic and non-diabetic cohort, by calendar period (2001-2012; $x$-axis). The y-axis indicates the IR in number of events per 100,000 person-years. GI: gastrointestinal, IR: incidence rate. Black line: type 2 diabetic cohort, Grey line: reference cohort. 


\section{Discussion}

This study provides a comprehensive overview of IRs of GI cancers in people with and without diabetes mellitus using the CPRD database. Yearly, approximately one in every 300 type 2 diabetic patients in the UK developed a GI cancer. In general, IRs of any GI, liver, pancreatic, and colon cancer were higher in diabetic patients compared to nondiabetic individuals, with an IR of 26 per 100,000 person-years for liver cancer, an IR of 65 per 100,000 person-years for pancreatic cancer, and an IR of 119 for colon cancer in the diabetic population. In contrast, patients with type 2 diabetes mellitus had lower IRs of esophageal cancer compared to individuals without diabetes, however this difference was small, namely 6 esophageal cancers per 100,000 person-years. In the diabetic cohort, IRs for any GI, liver, pancreatic, and colon cancer were clearly elevated in almost all age groups and time periods compared to the non-diabetic cohort. In addition, an increasing time trend was observed for liver cancer in the diabetic cohort, for colon cancer in both cohorts, whereas for pancreatic cancer a decreasing trend was observed in both cohorts.

A substantial number of studies have reported increased risks of liver, pancreatic, and colon cancer in patients with type 2 diabetes mellitus independent of other risk factors. ${ }^{21-29}$ As a result, type 2 diabetes mellitus is considered as a risk factor for these cancer types. ${ }^{1}$ Our results support this claim, especially for liver and pancreatic cancer where the differences in IRs were most pronounced. Furthermore, these differences became more apparent when stratified by age and time period. However, more recent studies have shown that part of the association might be affected by detection bias or reverse causation. ${ }^{8,30}$ To minimize these biases, a sensitivity analysis was performed, excluding the first year of follow-up after the index date, which did not change the results, except for a substantial, but non-significant decrease in the IR of pancreatic cancer in the diabetic cohort. This might suggest that reverse causality plays a role in pancreatic cancer.

Insulin is thought to be one of the major hormonal contributors to the diabetes-cancer link. ${ }^{1}$ On the one hand, both the liver and the pancreas are exposed to higher levels of endogenous insulin compared to other organs via the portal venous system, possibly leading to an increased risk of cancer. ${ }^{1}$ On the other hand, both liver and pancreatic cancers are known to impair glucose regulation and induce diabetes as well. ${ }^{8,31}$ Therefore, the association between type 2 diabetes mellitus and these cancers may very well be bidirectional.

As for colorectal cancer (CRC), a recent umbrella review of meta-analyses showed that meta-analyses reporting an increased risk of CRC in diabetics are robust, showing an absolute risk increase of around 30 percent. $^{32}$ More importantly, because of the sheer 
number of incident CRC cases worldwide, the growing number of type 2 diabetics, and the increasing time trend observed in this study, this might have an enormous impact on the world population and global health care systems. Furthermore, since CRC screening programs have been implemented or are at present being implemented in an increasing number of countries, more targeted and tailored screening of diabetics should be considered in the near future.

In contrast to the other gastrointestinal cancer sites, we observed a significantly lower IR of esophageal cancer in patients with type 2 diabetes mellitus compared to non-diabetic individuals, although the observed difference was small (IR 41 vs. 47 per 100,000 py) and did not differ much after stratification by sex. Lifestyle factors such as smoking and alcohol use are important risk factors for esophageal cancer, especially for squamous cell carcinoma. ${ }^{33}$ At baseline these factors differed significantly between the diabetic and reference cohorts, the latter being more often current smokers and users of alcohol, which could explain the observed difference in IRs. On the other hand, type 2 diabetic patients had a higher BMI compared to non-diabetic individuals, predisposing them to a higher risk of gastro-esophageal reflux disease, reflux esophagitis, and subsequently Barrett's esophagus and adenocarcinoma of the esophagus. ${ }^{34-36}$ Unfortunately, histologic subtypes of esophageal cancer could not be analyzed in this study. Indeed, it is known that the two main histologic subtypes of esophageal cancer (squamous cell carcinoma and adenocarcinoma) show marked epidemiological, pathogenic, and biological differences. ${ }^{34}$ For instance, the incidence of esophageal adenocarcinoma has increased in recent years, whereas the incidence of esophageal squamous cell carcinoma has markedly decreased. ${ }^{37}$ In general, a modestly increased risk of esophageal cancer in type 2 diabetic patients (summary relative risk 1.30, 95\% Cl: 1.12-1.50) compared to non-diabetic individuals has been observed, although not remaining significant after stratification for sex. ${ }^{34}$

The major strength of this study is the use of the CPRD, one of the world's largest population-based databases. The CPRD contains approximately $7 \%$ of the UK population, and is representative of the UK general population in terms of age, sex, and ethnicity. ${ }^{15,16}$ In addition, a high level of validity for the recording of cancer in the CPRD has been previously reported, with cancer diagnosis being valid and accurate more than $90 \%$ of the time. ${ }^{19}$ However, potential ascertainment or misclassification bias could not be ruled out. Furthermore, we reported the absolute number of cases and IRs of GI cancers instead of relative risks, to adequately show the difference in IRs between both populations.

The main limitation of this study is that causal interpretation of the findings is restricted. Secondly, diabetic status was defined by the recorded prescription of ADDs. Therefore, misclassification of exposure, and thereby diabetic status, might have occurred since the 
derived prescription from the GP system may not have been dispensed by the pharmacy, or actually used by the subject. However, most diabetic patients require chronic medication for adequate glycaemic control, making misclassification less likely for those being prescribed drugs on a regular basis. Also, it is possible that type 2 diabetic patients not treated with ADDs or undetected diabetes mellitus were included in the reference population. This could have biased the results by diminishing the difference in IRS between cohorts. Additionally, controls could have suffered from any other disease than diabetes mellitus or those mentioned as exclusion criteria. This could have impacted their survival and therewith their chance of developing cancer. This might explain the somewhat lower total person-years of follow-up in controls. Furthermore, it is possible that the results are confounded, as we could not take into account any risk factors (e.g. smoking, consumption of alcohol, obesity, drug use, and comorbidities) that might contribute to a higher cancer rate in diabetic patients. Also, type 2 diabetic patients and controls were matched on general practice, but residual confounding by socio-economic status could still be present. In addition, the observed IRs in the reference cohort were generally higher compared to age-standardized incidence rates (ASRs) of GI cancers in the general population of the UK (38). We calculated ASRs using the direct method according to the Segi-Doll world standard population to verify whether IRs were comparable to previously reported ASRs in the UK. ${ }^{39,40}$ After age-standardization, ASRs of the reference cohort were in line with ASRs in the UK as reported in the tenth volume of the Cancer Incidence in Five Continents series, published by the International Agency for Research on Cancer and the International Association of Cancer Registries (data not shown). ${ }^{38}$

This large retrospective population-based cohort study shows that patients with type 2 diabetes mellitus have higher incidence rates for liver, pancreatic, and colon cancer compared to non-diabetic individuals. In general, one in every 300 type 2 diabetic patients developed a GI cancer every year. Furthermore, we found no differences in IRs between type 2 diabetic and non-diabetic individuals for gastric, biliary, and rectal cancer. Conversely, slightly lower IRs were observed in type 2 diabetic patients for esophageal cancer. The results of this study underline the importance of clinical awareness for liver, pancreatic, and colon cancer in the type 2 diabetic population. In addition, the lower observed IRs of esophageal cancer in diabetic patients warrants further investigation. 


\section{References}

1. Giovannucci E, Harlan DM, Archer MC, Bergenstal RM, Gapstur SM, Habel LA, et al. Diabetes and cancer: a consensus report. CA Cancer J Clin 2010;60:207-21.

2. Habib SL, Rojna M. Diabetes and risk of cancer, ISRN Oncol 2013;2013:583786.

3. Jamal MM, Yoon EJ, Vega KJ, Hashemzadeh M, Chang KJ. Diabetes mellitus as a risk factor for gastrointestinal cancer among American veterans. World J Gastroenterol 2009;15:5274-8.

4. Chiu CC, Huang CC, Chen YC, Chen TJ, Liang Y, Lin SJ, et al. Increased risk of gastrointestinal malignancy in patients with diabetes mellitus and correlations with anti-diabetes drugs: a nationwide population-based study in Taiwan. Intern Med 2013;52:939-46.

5. P.J. Peeters, M.T. Bazelier, H.G. Leufkens, F. de Vries, M.L. De Bruin, The risk of colorectal cancer in patients with type 2 diabetes: associations with treatment stage and obesity, Diabetes Care 38 (2015) 495-502.

6. L.M. Knapen, J. van Dalem, Y.C. Keulemans, N.P. van Erp, M.T. Bazelier, M.L. De Bruin, et al., Use of incretin agents and risk of pancreatic cancer: a population-based cohort study, Diabetes Obes. Metab. 18 (3) (2015) 258-265.

7. J. Starup-Linde, O. Karlstad, S.A. Eriksen, P. Vestergaard, H.K. Bronsveld, F. de Vries, et al., CARING (CAncer Risk and INsulin analoGues): the association of diabetes mellitus and cancer risk with focus on possible determinants - a systematic review and a meta-analysis, Curr. Drug Saf. 8 (2013) 296-332.

8. J.A. Johnson, S.L. Bowker, K. Richardson, C.A. Marra, Time-varying incidence of cancer after the onset of type 2 diabetes: evidence of potential detection bias, Diabetologia 54 (2011) 2263-2271.

9. A. Nicolucci, Epidemiological aspects of neoplasms in diabetes, Acta Diabetol. 47 (2010) 87-95.

10. P. Vigneri, F. Frasca, L. Sciacca, G. Pandini, R. Vigneri, Diabetes and cancer, Endocr. Relat. Cancer 16 (2009) 1103-1123.

11. J. Lagergren, R. Bergstrom, A. Lindgren, O. Nyren, Symptomatic gastroesophageal reflux as a risk factor for esophageal adenocarcinoma, N. Engl. J. Med. 340 (1999) 825-831.

12. C. Bosetti, V. Rosato, J. Polesel, F. Levi, R. Talamini, M. Montella, et al., Diabetes mellitus and cancer risk in a network of case-control studies, Nutr. Cancer 64 (2012) 643-651.

13. S.W. Lin, N.D. Freedman, A.R. Hollenbeck, A. Schatzkin, C.C. Abnet, Prospective study of self-reported diabetes and risk of upper gastrointestinal cancers, Cancer Epidemiol. Biomark. Prev. 20 (2011) 954-961.

14. K. Hemminki, X. Li, J. Sundquist, K. Sundquist, Risk of cancer following hospitalization for type 2 diabetes, Oncol. 15 (2010) 548-555.

15. J. Parkinson, S. Davis, T.P. van Staa, The general practice research (GPRD) database: now and the future [online text], in: R.D. Mann, E.B. Andrews (Eds.), Pharmacovigilance, 2nd ed., John Wiley \& Sons, Hoboken, 2007, pp. 341-348.

16. E. Herrett, A.M. Gallagher, K. Bhaskaran, H. Forbes, R. Mathur, T. van Staa, et al., Data Resource profile: Clinical Practice Research Datalink (CPRD), Int. J. Epidemiol. 44 (3) (2015) 827-836.

17. N.F. Khan, S.E. Harrison, P.W. Rose, Validity of diagnostic coding within the general practice research database: a systematic review, Br. J. Gen. Pract. J. R. Coll. Gen. Practition. 60 (2010) e128-e136.

18. E. Herrett, S.L. Thomas, W.M. Schoonen, L. Smeeth, A.J. Hall, Validation and validity of diagnoses in the General practice research database: a systematic review, Br. J. Clin. Pharmacol. 69 (2010) 4-14.

19. A. Dregan, H. Moller, T. Murray-Thomas, M.C. Gulliford, Validity of cancer diagnosis in a primary care database compared with linked cancer registrations in England. Population-based cohort study, Cancer Epidemiol. 36 (2012) 425-429.

20. B. Rosner, Fundamentals of Biostatisticsm, sixth edition, Duxbury Press, 2006, pp. 751-752.

21. J. Luo, R. Chlebowski, S. Liu, K.A. McGlynn, N. Parekh, D.L. White, et al., Diabetes mellitus as a risk factor for gastrointestinal cancers among postmenopausal women, Cancer Causes Control CCC 24 (2013) 577585.

22. A.A. Ogunleye, S.A. Ogston, A.D. Morris, J.M. Evans, A cohort study of the risk of cancer associated with type 2 diabetes, Br. J. Cancer 101 (2009) 1199-1201.

23. S.C. Larsson, N. Orsini, A. Wolk, Diabetes mellitus and risk of colorectal cancer: a meta-analysis, J. Natl. Cancer Inst. 97 (2005) 1679-1687. 
24. E.A. Atchison, G. Gridley, J.D. Carreon, M.F. Leitzmann, K.A. McGlynn, Risk of cancer in a large cohort of U.S. veterans with diabetes, Int. J. Cancer J. Int. Du Cancer. 128 (2011) 635-643.

25. L. Deng, Z. Gui, L. Zhao, J. Wang, L. Shen, Diabetes mellitus and the incidence of colorectal cancer: an updated systematic review and meta-analysis, Digest. Dis. Sci. 57 (2012) 1576-1585.

26. J.W. Elena, E. Steplowski, K. Yu, P. Hartge, G.S. Tobias, M.J. Brotzman, et al., Diabetes and risk of pancreatic cancer: a pooled analysis from the pancreatic cancer cohort consortium, Cancer Causes Control CCC 24 (2013) 13-25.

27. D. Li, H. Tang, M.M. Hassan, E.A. Holly, P.M. Bracci, D.T. Silverman, Diabetes and risk of pancreatic cancer: a pooled analysis of three large case-control studies, Cancer Causes Control CCC 22 (2011) 189197.

28. J. Chen, Y. Han, C. Xu, T. Xiao, B. Wang, Effect of type 2 diabetes mellitus on the risk for hepatocellular carcinoma in chronic liver diseases: a meta-analysis of cohort studies, Eur. J. Cancer Prev. 24 (2015) 8999.

29. S. Schlesinger, K. Aleksandrova, T. Pischon, M. Jenab, V. Fedirko, E. Trepo, et al., Diabetes mellitus, insulin treatment, diabetes duration, and risk of biliary tract cancer and hepatocellular carcinoma in a European cohort, Ann. Oncol. 24 (2013) 2449-2455.

30. K.M. De Bruijn, R. Ruiter, C.E. de Keyser, A. Hofman, B.H. Stricker, C.H. van Eijck, Detection bias may be the main cause of increased cancer incidence among diabetics: results from the Rotterdam study, Eur. J. Cancer 50 (2014) 2449-2455.

31. D. Li, Diabetes and pancreatic cancer, Mol. Carcinog. 51 (2012) 64-74.

32. K.K. Tsilidis, J.C. Kasimis, D.S. Lopez, E.E. Ntzani, J.P. Ioannidis, Type 2 diabetes and cancer: umbrella review of meta-analyses of observational studies, BMJ 350 (2015) g7607.

33. J. Steevens, L.J. Schouten, R.A. Goldbohm, P.A. van den Brandt, Alcohol consumption, cigarette smoking and risk of subtypes of oesophageal and gastric cancer: a prospective cohort study, Gut 59 (2010) 39-48.

34. W. Huang, H. Ren, Q. Ben, Q. Cai, W. Zhu, Z. Li, Risk of esophageal cancer in diabetes mellitus: a metaanalysis of observational studies, Cancer Causes Control CCC 23 (2012) 263-272.

35. F. Mearin, J.R. Malagelada, Gastroparesis and dyspepsia in patients with diabetes mellitus, Eur. J. Gastroenterol. Hepatol. 7 (1995) 717-723.

36. T. Kamiya, H. Adachi, M. Hirako, M. Shikano, E. Matsuhisa, T. Wada, et al., Impaired gastric motility and its relationship to reflux symptoms in patients with nonerosive gastroesophageal reflux disease, J. Gastroenterol. 44 (2009) 183-189.

37. A.A. Botterweck, L.J. Schouten, A. Volovics, E. Dorant, P.A. van Den Brandt, Trends in incidence of adenocarcinoma of the oesophagus and gastric cardia in ten European countries, Int. J. Epidemiol. 29 (2000) 645-654.

38. D. Forman, F. Bray, D.H. Brewster, C. Gombe Mbalawa, B. Kohler, M. Piñeros, et al., Cancer Incidence in Five Continents, Vol. X. IARC Scientific Publication No 164, International Agency for Research on Cancer, Lyon, 2014.

39. M. Segi, I. Fukushima, M. Kurihara, A proposal on a calculation method to be applied by geographical comparison of cancer mortality, Tohoku. J. Exp. Med. 60 (1954) 307-310.

40. R. Doll, P. Payne, J. Waterhouse, Cancer Incidence in Five Continents: A Technica Report, Springer-Verlag (for UICC, Berlin, 1966. 


\section{Supplementary figure}

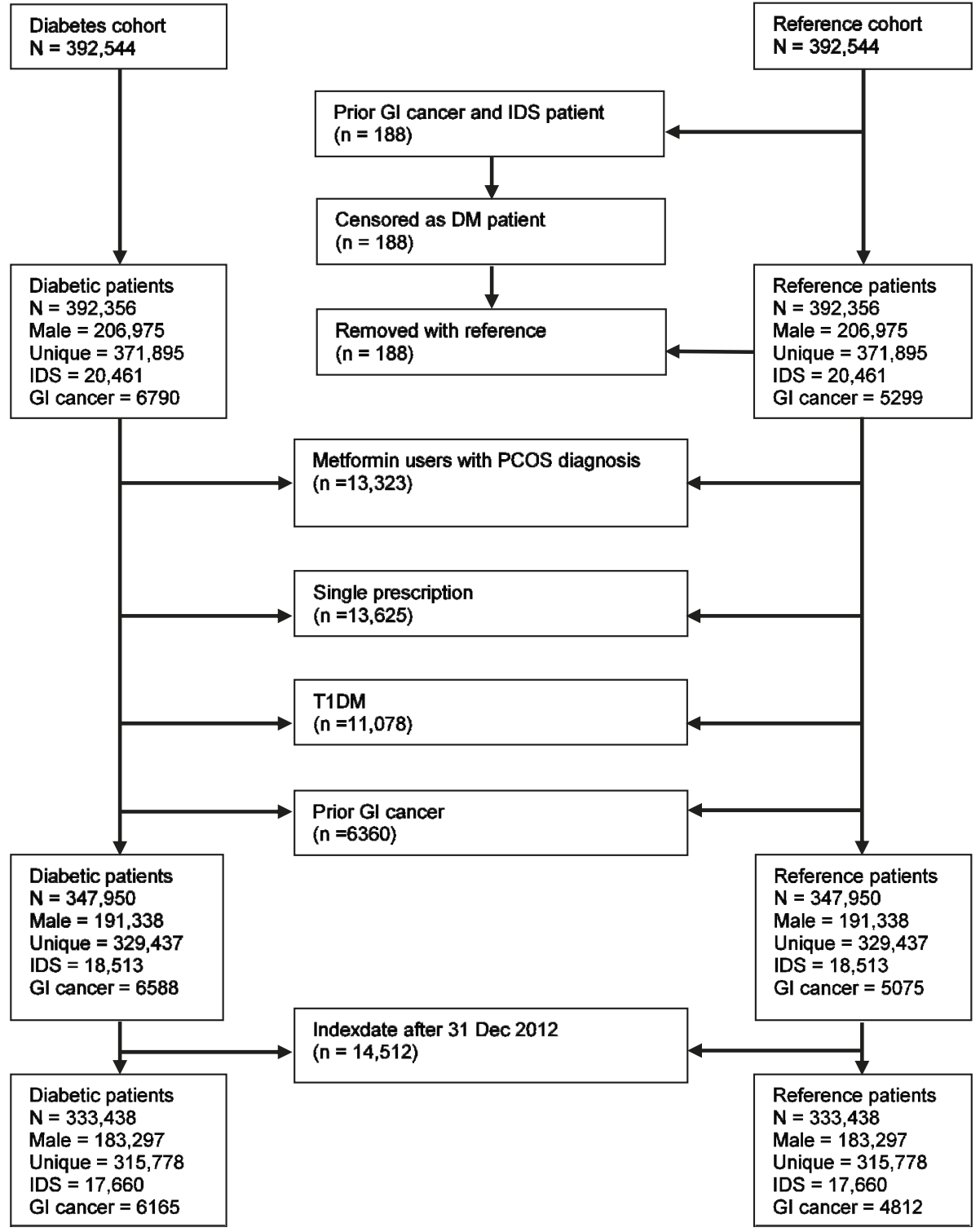

Figure S2.1 Study flow chart of eligible patients in the diabetic and non-diabetic reference cohort. GI: gastrointestinal cancer; IDS: incidence density sampling, i.e. patients that become diabetic after attributing time to the reference cohort. 

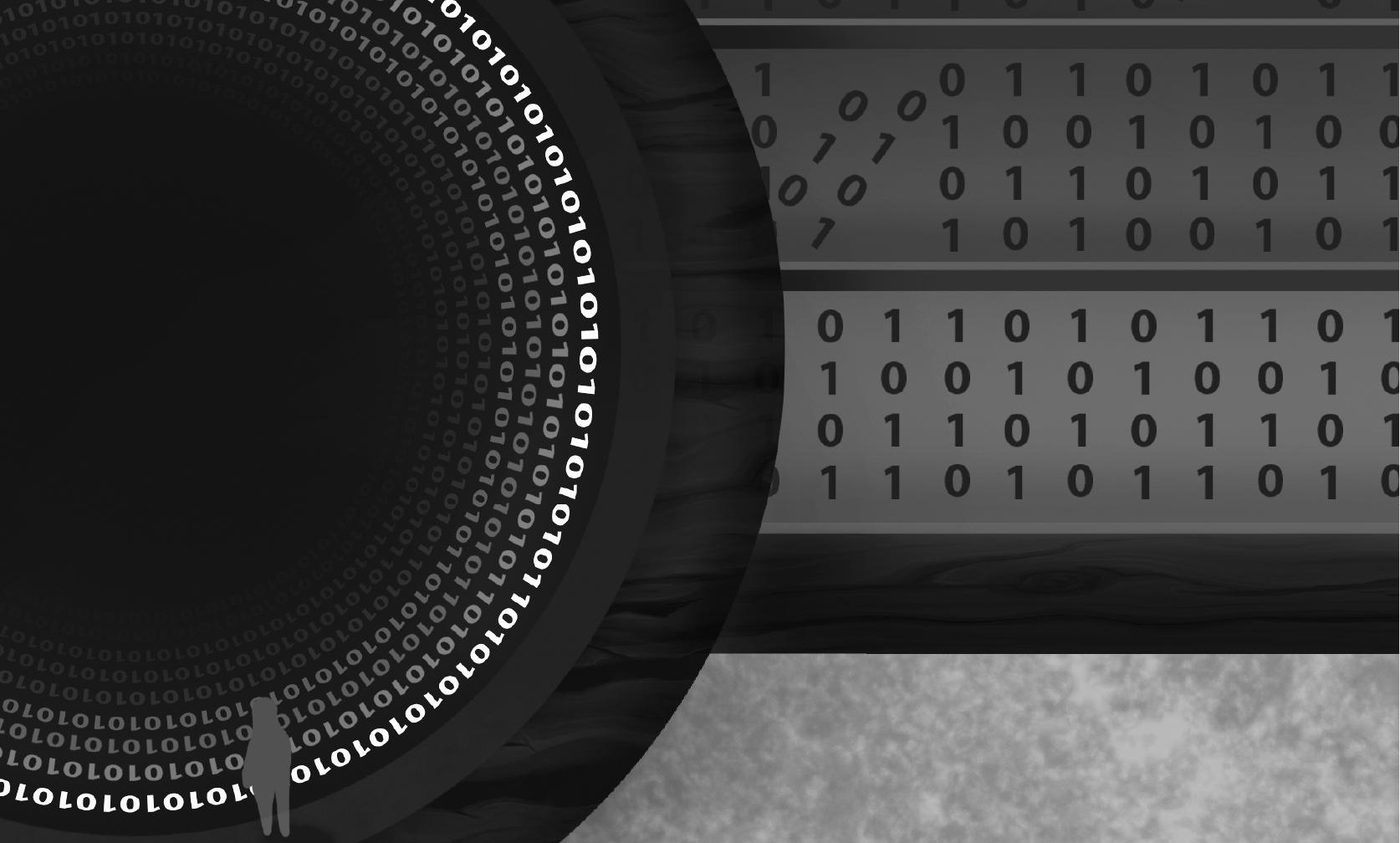

$\begin{array}{llllllllll}0 & 1 & 1 & 0 & 1 & 0 & 1 & 1 & 0 & 1\end{array}$

$\begin{array}{lllllllll}1 & 0 & 0 & 1 & 0 & 1 & 0 & 0 & 1\end{array}$

$\begin{array}{llllllllll}0 & 1 & 1 & 0 & 1 & 0 & 1 & 1 & 0 & 1\end{array}$

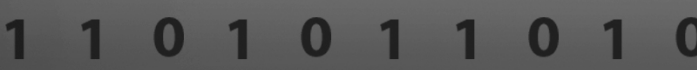

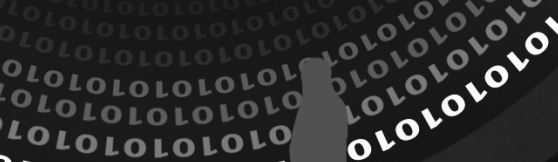
$010^{2}$ 


\section{Chapter 3}

\section{Impact of detection bias on the risk of gastrointestinal cancer and its subsites in type 2 diabetes mellitus}

Roy G.P.J. de Jong, Andrea M. Burden, Sander de Kort, Myrthe P.P. van Herk-Sukel, Pauline A.J. Vissers, Paddy K.C. Janssen, Harm R. Haak Ad A.M. Masclee, Frank de Vries, Maryska L.G. Janssen-Heijnen European Journal of Cancer 2017;79:61-71 


\section{Abstract}

\section{Background}

Type 2 diabetes mellitus (T2DM) may be a risk factor for gastrointestinal (GI) cancers, but variations in study designs of observational studies may have yielded biased results due to detection bias. Furthermore, differences in risk for $\mathrm{Gl}$ cancer subsites have not been extensively evaluated. We aimed to determine the risk of $\mathrm{Gl}$ cancer and its subsites in patients with T2DM and how it is affected by detection bias.

\section{Methods}

A matched cohort study was performed using the NCR-PHARMO database. New users of $\geq 1$ non-insulin anti-diabetic drug during 1998-2011 were matched with non-diabetic controls by year of birth, sex, and time between database entry and index. Cox regression analyses were performed with and without lag-period to estimate hazard ratios (HRs) for GI cancer and its subsites. Covariables included age, sex, use of other drugs and history of hospitalisation.

\section{Results}

An increased risk of GI cancer was observed in T2DM patients (HR 1.5, 95\% confidence interval [Cl] 1.3-1.7) compared with controls, which was attenuated in the 1-year lagged analysis (HR 1.4, 95\% Cl 1.2-1.7). Stratified by subsite, statistically significant increased risks of pancreatic ( $\mathrm{HR} 4.7,95 \% \mathrm{Cl} 3.1-7.2)$, extrahepatic bile duct (HR 4.2, 95\% Cl 1.511.8) and distal colon cancer ( $\mathrm{HR} 1.5,95 \% \mathrm{Cl} 1.1-2.1)$ were found, which remained statistically significantly increased in the lagged analysis.

\section{Conclusions}

T2DM patients had a $40 \%$ increased risk of GI cancer. Increased GI cancer risks tended to be weaker when reducing detection bias by applying a 1-year lag-period. Future observational studies should therefore include sensitivity analyses in which this bias is minimised. 


\section{Background}

Gastrointestinal (GI) cancers, encompassing malignancies of the gut, from the oesophagus till the anus; including the liver, gallbladder, extrahepatic bile ducts and the pancreas, are among the most common and lethal malignant neoplasms. In 2015, almost $25 \%$ of the total cancer incidence, and a third of the total cancer mortality in the Netherlands was due to a GI cancer. ${ }^{1}$ Furthermore, data from the Netherlands Cancer Registry (NCR) indicate incidences of these cancers are rising. ${ }^{1}$

Previous studies using NCR data have shown a higher prevalence of type 2 diabetes mellitus (T2DM) in patients with various Gl cancers. ${ }^{2,3}$ Indeed, a growing body of evidence suggests that T2DM may be a risk factor for the development of Gl cancers (Table 3.1). ${ }^{4-13}$ The strongest associations have been described for liver and pancreatic cancer, with both a two-fold increased risk. ${ }^{14,15}$ In addition, a $15 \%-30 \%$ increased risk has been reported for colorectal cancer. ${ }^{16-18}$ With 830,000 individuals living in the Netherlands with diabetes mellitus in 2011 (of which $\pm 90 \%$ with T2DM), diabetes mellitus poses a highly prevalent and potentially modifiable risk factor for GI cancer development. ${ }^{19}$ There has been much discussion about whether previously reported associations in observational studies present an underlying biological mechanism between T2DM and cancer or represent detection bias or even reverse causality. These biases could have been the result of a diagnostic (protopathic) bias, i.e. an increased odds of detecting cancer shortly after the onset of diabetes, or by specific Gl cancers inducing disturbances in glucose homoeostasis. ${ }^{20,21}$ To address this form of methodological bias, a lag time between disease onset and the start of follow-up for cancer outcomes can be considered. ${ }^{22}$

Furthermore, epidemiologic studies have shown that risk factors of GI cancer may vary within specific $\mathrm{Gl}$ cancer anatomic subsites or histologic subtypes. ${ }^{23,24}$ For instance, different risk factors have been identified for oesophageal squamous cell carcinoma and adenocarcinoma, and also for proximal and distal gastric cancer. ${ }^{23}$ Up to now, data on subsite-specific risks of GI cancer in patients with T2DM are limited. ${ }^{25}$

Therefore, our primary aim was to determine the overall risk of GI cancer in patients with T2DM, and explore the effects of detection bias/reverse causality on the association between T2DM and risk of GI cancer. Second, we stratified these analyses for specific GI cancer subsites/subtypes. 
Table 3.1 Overview of GI cancer risk in patients with type 2 diabetes mellitus in meta-analyses of cohort studies.

\begin{tabular}{|c|c|c|c|c|c|c|}
\hline Author (Ref.) & $\begin{array}{c}\text { Oesophageal } \\
\text { cancer }\end{array}$ & $\begin{array}{l}\text { Gastric } \\
\text { cancer }\end{array}$ & $\begin{array}{c}\text { Colorectal } \\
\text { cancer }\end{array}$ & $\begin{array}{l}\text { Liver } \\
\text { cancer }\end{array}$ & $\begin{array}{c}\text { Bile duct } \\
\text { cancer }\end{array}$ & $\begin{array}{c}\text { Pancreatic } \\
\text { cancer }\end{array}$ \\
\hline Larsson et al. $2005^{14}$ & & & $\begin{array}{c}\text { RR 1.30 } \\
(1.20-1.40)\end{array}$ & & & \\
\hline Huang et al. $2011^{7}$ & $\begin{array}{l}\text { SRR } 1.30 \\
(1.12-1.50)\end{array}$ & & & & & \\
\hline Ge et al. $2011^{8}$ & & $\begin{array}{c}\text { SRR } 1.09 \\
(0.98-1.22)\end{array}$ & & & & \\
\hline Ren et al. $2011^{11}$ & & & & & $\begin{array}{c}\text { GB: SRR } 1.52 \\
(1.26-1.84)\end{array}$ & \\
\hline Ben et al. $2011^{12}$ & & & & & & $\begin{array}{c}\text { SRR } 1.95 \\
(1.66-2.28)\end{array}$ \\
\hline Jiang et al. $2012^{10}$ & & & $\begin{array}{c}\text { SRR } 1.27 \\
(1.21-1.34)\end{array}$ & & & \\
\hline Jing et al. $2012^{9}$ & & & & $\begin{array}{c}\text { ICC: SRR } 1.97 \\
(1.57-2.46)\end{array}$ & $\begin{array}{c}\text { ECC: SRR } 1.63 \\
(1.29-2.05)\end{array}$ & \\
\hline Wang et al. $2012^{13}$ & & & & $\begin{array}{c}\text { HCC: SRR } 2.31 \\
(1.87-2.84)\end{array}$ & & \\
\hline Deng et al. $2012^{15}$ & & & $\begin{array}{c}\text { RR } 1.26 \\
(1.20-1.31)\end{array}$ & & & \\
\hline Wu et al. $2013^{6}$ & & & $\begin{array}{c}\text { RR } 1.22 \\
(1.19-1.26)\end{array}$ & & & \\
\hline
\end{tabular}

ECC: extrahepatic cholangiocarcioma; HCC: hepatocellular carcionoma; HR: hazard ratio; GB: gallbladder; ICC: intrahepatic cholangiocarcinoma; Ref: reference number; RR: relative risk; SRR: summary relative risk.

\section{Methods}

\section{Data source}

Data for this population-based cohort study were obtained from the PHARMO Database Network and linked at the individual patient level to the Eindhoven area of the NCR (ENCR-PHARMO database). The construct and validity of the linked database have been described elsewhere. ${ }^{26}$ Data from the Eindhoven area of the NCR, maintained by the Netherlands Comprehensive Cancer Organisation, cover a demographic region with approximately 2.4 million inhabitants ( $\pm 15 \%$ of the Dutch population) and no academic hospitals. Trained registration clerks actively collect data on diagnosis, patient characteristics, staging and initial treatment from hospital medical records. Vital status is obtained by linkage to Dutch municipal records.

The PHARMO Database Network is a large, patient-centric data network including linked observational databases designed for drug safety and outcomes research. For this study the Out-patient (community) Pharmacy Database was used, which contains longitudinal drug dispensing records, and included information on dispensing date, dose descriptions 
and amount dispensed. All drugs are coded according to their Anatomical Therapeutic Chemical/Defined Daily Dose Classification code. ${ }^{27}$ Both the NCR and the PHARMO Database Network are recognized as high-quality data sources for (pharmaco) epidemiological research that have collected information in overlapping regions in the Netherlands for a period of over 10 years. ${ }^{26}$

\section{Population and study design}

We selected all individuals aged 30 years and older who received at least one antidiabetic drug (ADD) prescription (ATC code 'A10A' or 'A10B') in the E-NCR-PHARMO database between 1 January 1998 and 31 December 2011. These subjects were classified as potential T2DM patients and the first prescription for an ADD defined their start of follow-up (index date). A random sample of subjects who never received ADDs during the study period was extracted from the database and classified as non-diabetic controls (Figure 3.1).

Next, non-diabetic controls were matched to a T2DM patient by year of birth, sex and the time between database entry and the index date ( \pm 90 days). Non-diabetic controls were assigned the same index date as their matched T2DM patients. For T2DM patients with more than one matched control the most optimal control was selected based on highest similarity of matching parameters, yielding a 1:1 matched cohort.

Potential T2DM patients who initiated ADD treatment with insulin or an insulin analogue (ATC code 'A10A') were excluded to minimize the amount of people with type 1 diabetes mellitus being misclassified as T2DM. All study subjects with a history of GI cancer before the index date were excluded. Furthermore, we excluded all prevalent ADD-users, i.e. T2DM patients without a minimum of 1 year of ADD-free follow-up in the NCR-PHARMO database before the index date. In addition, all individuals matched to excluded subjects were excluded as well. Individuals were followed from the index date until the first occurrence of a Gl cancer, death from any cause, migration out of the PHARMO catchment area or end of data collection, whichever came first.

\section{Outcomes}

GI cancers were classified according to the International Classification of Diseases of oncology. ${ }^{28}$ These included 'any GI cancer' (C15-26, excluding anal cancer), oesophageal cancer (C15), gastric cancer (C16), small intestinal cancer (C17), colon cancer (C18), rectal cancer (C19-20), hepatic cancer (C22), biliary tract cancer (C23: gallbladder, and C24: extrahepatic bile duct cancer) and pancreatic cancer (C25). In addition, stratified analyses were performed by sublocalisation of Gl cancer sites (see Supplementary Table S3.1 for sublocalisations). For the site-specific analyses, subjects were followed until the 
first-occurrence of the site-specific GI cancer event, despite other types of GI cancers occurring during follow-up.

\section{Covariables}

Both time-fixed and time-dependent covariables were considered as confounders based on the existing literature. As time-fixed covariables sex and the number of hospitalisations before the index date (hospitalisation categories 0 or 1 ) were considered. Time-dependent covariables were determined at the start of every 90-day time-period and included: age, the duration of diabetes in years (time since first recorded NIAD prescription), the use of other drugs known to impact GI cancer risk in the 90 days before the start of each interval (statins, aspirin, non-aspirin non-steroidal anti-inflammatory drugs, proton pump inhibitors (PPIs), bisphosphonates, tamoxifen and oral contraceptives). In addition, the use of Helicobacter pylori eradication therapy was used as a proxy-indicator for Helicobacter pylori infection (see Supplementary Table S3.2 for ATC codes).

\section{Statistical analyses}

Differences in demographic and clinical characteristics at baseline between T2DM patients and matched controls were compared using chi-squared test for categorical variables and Student's t-test for continuous variables. Incidence rates (IR) of GI cancer for every (sub)group were calculated by dividing the number of GI cancer events by the total amount of person-years of follow-up (for the IR of GI cancers by tumour stage see Supplementary Table S3.3).

Cox proportional hazards analysis was used to estimate the hazard ratio (HR) and 95\% confidence intervals (Cls) of $\mathrm{Gl}$ cancer in T2DM patients versus matched controls. Stratified analyses were performed by sex, for specific GI cancer sites and for subsites of specific Gl cancer sites. Covariables were entered into the final model if they changed the beta coefficient of the primary exposure variable by more than $5 \%$. Detection bias after the onset of T2DM was reduced by repeating the overall analyses with a lag-period of 1 year. The lag-period implied censoring a subject on the date of cancer diagnosis if the cancer occurred during the first year of follow-up.

\section{Sensitivity analysis}

To further explore the effects of reducing detection bias, we preformed sensitivity analyses in which we repeated the 1-year lagged analyses as described previously with a lag-period of three years instead. All data management and analyses were performed with SAS software version 9.4 (SAS Institute, Cary, NC). 
Patients (aged $\geq 30$ years) with $\geq 1$ recorded ADD prescription (ATC 'A10A or A10B') between 1 January 1998 and 31 December 2011 within the Eindhoven region of the NCR-PHARMO catchment area $(\mathrm{N}=67,459)$
Matching (1:1) on sex, year of birth, and most equivalent time between cohort entry and (given) index date ( \pm 90 days)

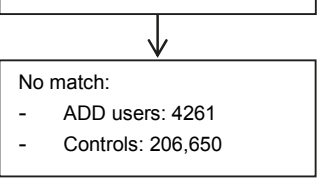

ADD-users with at least one matched control $(\mathrm{N}=63,198)$

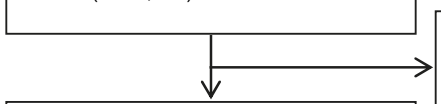

Patients with a NIAD as first recorded ADD $(\mathrm{N}=54,288)$

Patients with insulin as the first recorded $A D D(N=8,910)$

Subjects with a history of gastrointestinal cancer

- ADD users: 484

- Controls: 460

\section{Prevalent NIAD users without} history of gastrointestinal cancer $(\mathrm{N}=53,804)$

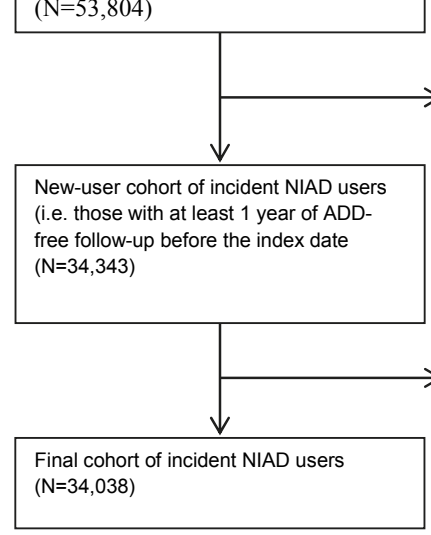

Random sample (1:4) from patients living in Eindhoven region of NCR-PHARMO catchment area (aged $\geq 30$ years) without recorded ADD prescriptions between 1 January 1998 and 31 December 2011 $(\mathrm{N}=269,848)$

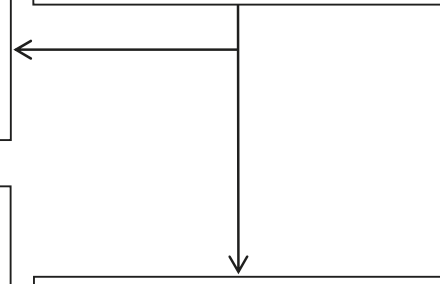

Selected controls with best fit to matched ADD-user $(\mathrm{N}=63,198)$

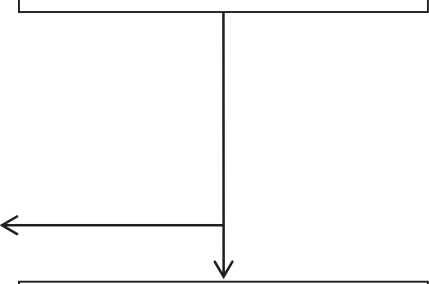

Controls without history of gastrointestinal cancer $(\mathrm{N}=62,738)$

Prevalent NIAD users (i.e. those with less than 1 year of ADD-free follow-up before the index date $(\mathrm{N}=19,461)$

Deleted with matched subject:

- ADD-users: 305

- Controls: 28,700

Figure 3.1 Flow-chart of study population. ADD: anti-diabetic drug; ATC: Anatomical Therapeutic Classification; NCR: Netherlands Cancer Registration; NIAD: Non-Insulin Anti-diabetic Drug. 


\section{Results}

\section{Baseline characteristics}

In both T2DM patients and non-diabetic controls, the mean age at baseline was 63.9 years, and $51 \%$ of subjects were males (Table 3.2). There were no differences seen between the age and sex distribution at baseline. After at least 1 year of ADD-free follow-up, most incident ADD users initiated treatment with metformin (73.8\%) and/or sulfonylureas (28.0\%). Statistically significant differences were observed for the use of various other drugs during the 90 days before the start of follow-up, with the largest differences seen for prior use of statins, antihypertensives and PPIs. In addition, T2DM patients were more often hospitalised before the index date (51.7\% versus $38.5 \%)$.

Table 3.2 Baseline characteristics of type 2 diabetic patients and matched non-diabetic controls.

\begin{tabular}{|c|c|c|c|c|c|}
\hline \multirow{2}{*}{$\frac{\text { Characteristic }}{\text { Age (years; Mean, SD) }}$} & \multicolumn{2}{|c|}{$\begin{array}{l}\text { Type } 2 \text { diabetic } \\
(n=34,038)\end{array}$} & \multicolumn{2}{|c|}{$\begin{array}{l}\text { Non-diabetic } \\
(n=34,038)\end{array}$} & \multirow{2}{*}{$\begin{array}{c}\text { p-value }{ }^{a} \\
1.00\end{array}$} \\
\hline & 63.9 & 12.6 & 63.9 & 12.6 & \\
\hline Sex (n, \% male) & 17,343 & 51 & 17,343 & 51 & 1.00 \\
\hline \multicolumn{6}{|l|}{ Use of anti-diabetic drugs ${ }^{b}(n, \%)$} \\
\hline Metformin & 25,115 & 73.8 & & & \\
\hline Sulfonylureas & 9,536 & 28.0 & & & \\
\hline Thiazolidinediones & 388 & 1.1 & & & \\
\hline Meglitinides & 38 & 0.1 & & & \\
\hline Incretins & 66 & 0.2 & & & \\
\hline \multicolumn{6}{|l|}{ Use of other drugs ( $n, \%$ ) } \\
\hline Anti-hypertensives & 20,667 & 60.7 & 9,495 & 27.9 & $<0.01$ \\
\hline Aspirin & 6,156 & 18.1 & 3,080 & 9.1 & $<0.01$ \\
\hline Bisphosphonates & 1,112 & 3.3 & 812 & 2.4 & $<0.01$ \\
\hline H. pylori eradication therapy & 40 & 0.1 & 24 & 0.1 & 0.05 \\
\hline Non-aspirin NSAIDs & 5,171 & 15.2 & 3,324 & 9.8 & $<0.01$ \\
\hline Proton pump inhibitors & 6,795 & 20.0 & 3,268 & 9.6 & $<0.01$ \\
\hline Statins & 13,396 & 39.4 & 4,529 & 13.3 & $<0.01$ \\
\hline \multicolumn{6}{|l|}{ History of hospitalisations ( $n, \%$ ) } \\
\hline 0 hospitalisations & 16,450 & 48.3 & 20,932 & 61.5 & $<0.01$ \\
\hline$\geq 1$ hospitalisations & 17,588 & 51.7 & 13,106 & 38.5 & \\
\hline
\end{tabular}

${ }^{a}$ p-value based on student's T-test for continuous variables and Chi-squared test for categorical variables. ${ }^{b}$ During 90-days before the index date. H. pylori: helicobacter pylori; NSAIDs: non-steroidal anti-inflammatory drugs.

\section{Risk of GI cancer overall}

Generally, an increased risk of GI cancer was observed in patients with T2DM compared with non-diabetic controls (Adj. HR 1.5, 95\% Cl 1.3-1.7; Table 3.3), which remained statistically significant increased when applying a 1-year lag-period (Adj. HR 1.4, 
$95 \% \mathrm{Cl} 1.2-1.7)$. After stratification by $\mathrm{Gl}$ cancer subsite, we observed a 4 -fold increased risk of hepato-pancreatico-biliary (HPB) cancer (Adj. HR 4.4, 95\% 3.0-6.4), but not for upper and lower GI cancer (Adj. HR 1.1, 95\% Cl 0.77-1.5 and Adj. HR 1.2, 95\% Cl 0.99-1.4, respectively). In the analysis that reduced detection bias (i.e. with the addition of a 1year lag-period), a slightly attenuated risk of HPB cancer was seen (Adj. HR 4.0, 95\% Cl 2.4-6.7). When stratifying the analyses by sex, statistically significant increased risks of overall GI cancer and of lower GI cancer were seen in the 1-year lagged analyses in men (Adj. HR 1.6, 95\% Cl 1.2-1.9, and Adj. HR 1.3, 95\% Cl 1.0-1.8 respectively), but not in women (Table 3.4). Also, the increased risk of HBP cancer was more pronounced in men than in women.

\section{Risk of specific Gl cancer sites}

After we had broken down our analyses by Gl cancer site, we observed a statistically significant increased risk of colon cancer (Adj. HR 1.4, 95\% Cl 1.1-1.7), pancreatic cancer (Adj. HR 4.7, 95\% Cl 3.1-7.2) and biliary tract cancer (Adj. HR 3.5, 95\% Cl 1.4-8.4) in patients with T2DM compared with non-diabetic controls (Table 3.3). The latter two remained significantly increased in the 1-year lagged analysis (Adj. HR 3.6, 95\% Cl 2.0-6.5 and Adj. HR 4.2, 95\% Cl 1.3-13.1, respectively). However, no statistically significantly increased risk of pancreatic or biliary tract cancer was seen in the sensitivity analyses (Adj. HR 2.0, 95\% Cl 0.96-4.2 and Adj HR 8.1, 95\% Cl 0.95-68.8 respectively). In the sexspecific analyses, the increased risk of colon cancer confined to men, and the risk of pancreatic cancer was more pronounced in men (Table 3.4).

\section{Risk of GI cancer subsites/subtypes}

After stratifying the specific GI cancer sites by sublocalisation and subtype (Table 3.5), an increased risk in patients with T2DM was found for extra-hepatic bile duct cancer (Adj. HR 4.2, 95\% Cl 1.5-11.8), and for distal colon cancer (HR 1.5, 95\% 1.1-2.1), both of which remained statistically significantly raised after removal of detection bias. No significant differences were observed for other subsites of GI cancer. Also, we did not observe any significant differences for histologic subtypes of oesophageal cancer. 


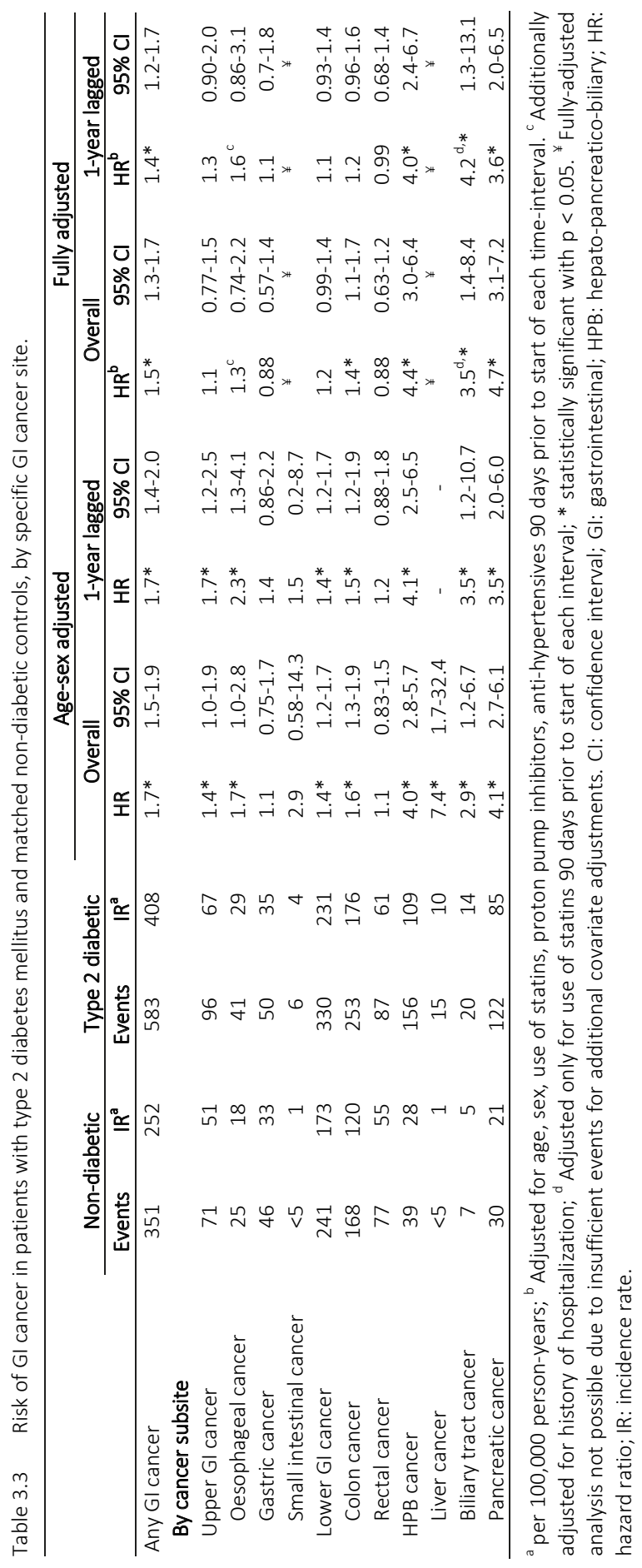




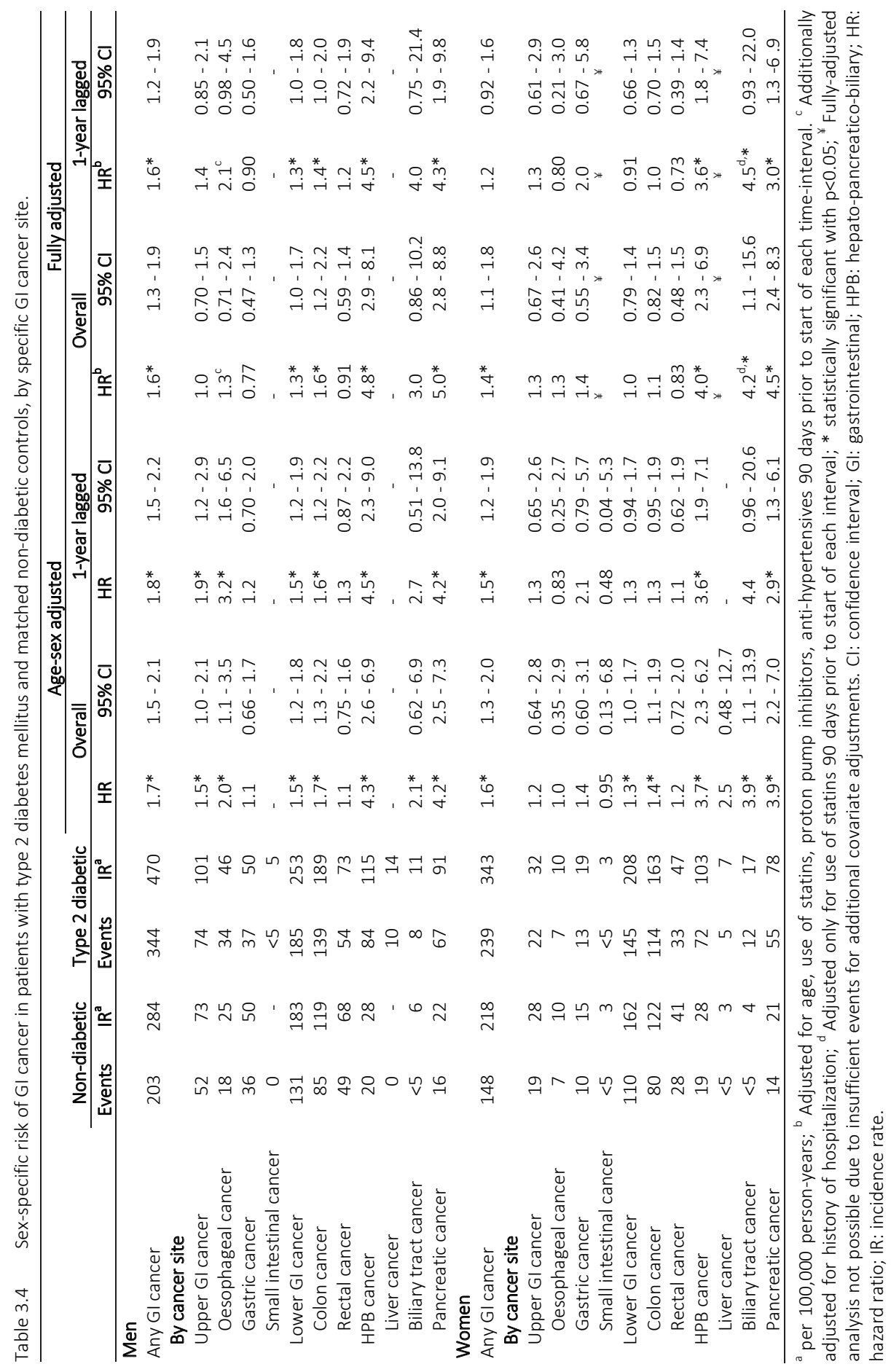




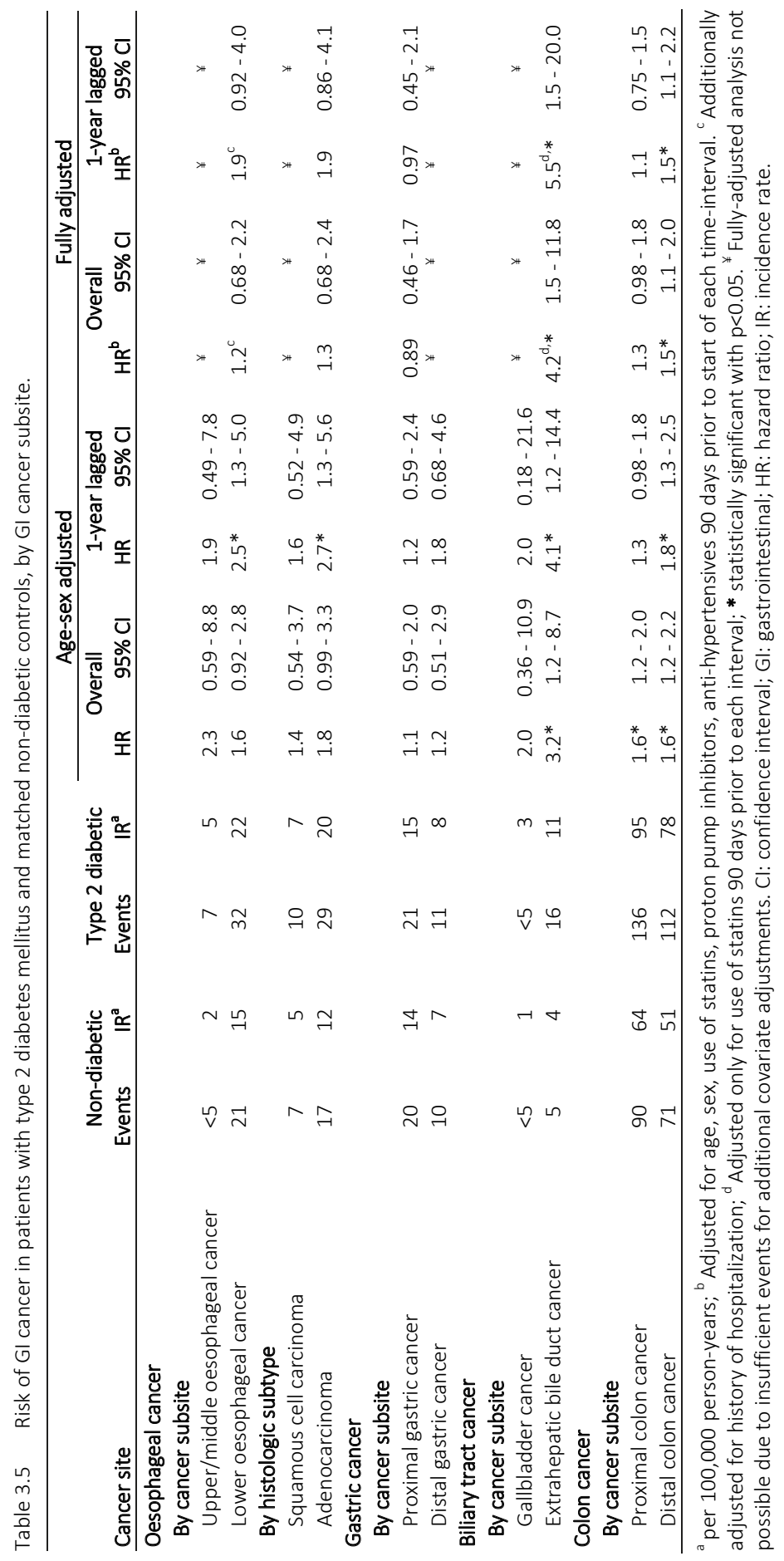




\section{Discussion}

We observed a $50 \%$ increased risk of $\mathrm{Gl}$ cancer in patients with T2DM compared with non-diabetic controls. However, after accounting for potential detection bias this dropped to a $40 \%$ increased risk. The overall increased risk in T2DM patients was explained by a four-fold increased risk of HPB cancers, which was driven by pancreatic cancer (five-fold increase) and biliary tract cancer (four-fold increase). The risk of HPB and pancreatic cancer, but not biliary tract cancer, was attenuated following adjustment to minimize detection bias.

While several pathways have been proposed, including insulin resistance and fatinduced chronic inflammation ${ }^{5,29}$, the precise biological mechanisms by which T2DM increases the risk of $\mathrm{Gl}$ cancer remains unclear. Insulin may promote carcinogenesis through the insulin receptor and insulin-like growth factor receptor (IGF-R), which are overexpressed on various types of tumour cells. ${ }^{30}$ Binding of these receptors by insulin activates the mTOR signalling pathway (mammalian target of rapamycin signalling pathway), resulting in abnormal cell proliferation, inhibition of apoptosis, angiogenesis and carcinogenesis. ${ }^{31}$ Hyperinsulinaemia may also predispose to carcinogenesis by indirectly increasing the production of IGF-1 via the liver, and by increasing the amount of bioavailable IGF-1 by decreasing the level of IGF-binding proteins. ${ }^{29}$

The results of this study add to the current evidence from observational studies. In their meta-analyses of cohort studies, Ben et al. ${ }^{14}$ found a two-fold increased risk of pancreatic cancer in newly diagnosed T2DM patients, and Ren et al. ${ }^{13}$ observed a 1.4-fold increased risk of extrahepatic biliary tract cancer. However, the potential for reverse causality is a primary concern for these cancers, as both can induce hyperglycaemia or frank diabetes. ${ }^{32}$ Our results may still be affected by an unknown degree of protopathic bias (reverse causality), as a 1-year lag-period may not be enough to exclude the effects of these cancers on the development of T2DM symptoms. Indeed, when increasing the lag-period to 3 years, no statistically significantly increased risks of pancreatic cancer and biliary tract cancer between T2DM patients and controls were observed (Adj. HR 2.0, 95\% Cl 0.96-4.8 and Adj. HR 8.1, 95\% Cl 0.95-68.8, respectively). However, this could also be explained by a lack of statistical power. Nonetheless, an increased risk of pancreatic cancer with longstanding T2DM (10 years) has been reported in the literature, suggesting that diabetes might still be a risk factor for pancreatic cancer development. ${ }^{14}$

An interesting finding in this study was the difference in risk between genders and distal and proximal colon cancer. We identified that men, but not women, with T2DM were at an increased risk of colon cancer. Varying differences in the risk of colorectal cancer have been reported in men and women with $\mathrm{T}_{2} \mathrm{DM}^{25,33-35}$, and large meta-analyses of 
observational studies have reported moderate (20-30\%) increased risks of colorectal cancer in both men and women. . $16,17,36-38$ With regards to colon cancer, three metaanalyses have reported increased risks of both proximal and distal colon cancer in patients with T2DM, with stronger risk estimates for proximal colon cancer. ${ }^{16,37,38}$ However, differences in observed risks could result from variations in the definitions of proximal and distal colon cancer in the literature as it cannot always be defined from which part of the colon a tumour has originated.

In contrast to meta-analyses of cohort studies, we did not find a statistically significant increased risk of liver cancer in patients with T2DM. Wang et al. ${ }^{15}$ reported a relative risk of 2.4 (95\% $\mathrm{Cl}$ 1.7-3.6) for hepatocellular carcinoma in T2DM patients, combining results from seven cohort studies. The most likely reason we could not replicate these findings is because of a lack of statistical power for this cancer site. Similarly, we did not find an increased risk of specific upper Gl cancer sites like oesophageal, gastric, and small intestinal cancer in our cohort. Moreover, when all sites were combined we also did not identify an increased risk of upper GI cancer. This adds to the current literature for the risk of upper Gl cancers, such as oesophageal and gastric cancer, in patients with T2DM. ${ }^{6,39-42}$

Our study has a number of limitations worth mentioning. First, we were not able to correct for several important general and cancer-specific risk factors, including obesity, smoking status, alcohol use, physical inactivity and high-caloric diet, which could have confounded the results. The majority of T2DM patients are obese, and obesity has been shown to be associated with and increased risk of Gl cancers. ${ }^{43}$ Moreover, visceral or abdominal fat is more metabolically active and therefore potentially more harmful than fat distributed at the hips. ${ }^{31}$ Second, due to the relatively small size of the population and the matched design, a lack of statistical power existed for cancer sites, such as liver cancer and small intestinal cancer. This also resulted in a limited ability to statistically adjust for confounders in a multivariate analysis for subsites of GI cancer. Although we acknowledge that propensity score adjustment would be an effective strategy to further reduce residual confounding and limit the number of covariates in the multivariate model $^{22}$, it cannot overcome the unmeasured confounding in the data source and therefore this strategy was not applied. Third, the subsite-specific analyses were of an exploratory nature rather than a hypothesis-testing one. Fourth, T2DM patients were identified based on the use of anti-diabetic drugs, leading to potential misclassification of diet-controlled T2DM patients as controls. Also, included patients were required to have at least one drug prescription via their community pharmacy. Patients not registered at a pharmacy were therefore not included. Consequently, the control group may be sicker than the general population, which may have resulted in an elevated risk of Gl cancer in this group. Ultimately, this would bias the risk ratio towards the null, yet 
we observed a statistically significant association between T2DM and GI cancer sites. Finally, a causal relationship between T2DM and Gl cancer cannot be proven in the present study. T2DM may function as a proxy indicator of several pathophysiologic mechanisms that, in turn, may promote cancer growth, such as insulin resistance, hyperglycaemia, hyperinsulinaemia, chronic inflammation and increase hormone levels. The strengths of this study are provided by the use of the population-based linked ENCR-PHARMO database, which guarantees a high level of cancer ascertainment and longitudinal information on drug exposure during follow-up. This prevents an overestimation of the number of (false positive) cancers, which may occur in studies using an insurance claims database or data from general practitioners without linking to some form of cancer registry or pathology database. In addition, the longitudinal nature of the PHARMO database provides reliable information on confounding drug exposures during follow-up; such as statins, non-steroidal anti-inflammatory drugs and PPIs. In conclusion, following an adjustment for potential detection bias, T2DM was associated with a $40 \%$ increased risk of $\mathrm{Gl}$ cancer, and a four-fold increased risk of pancreatic and biliary tract cancer. In particular, the strong associations found for HPB cancers and pancreatic cancer may be partly caused by an increased detection of these cancers in the first years after the onset of T2DM. Future studies investigating associations between T2DM and GI cancer should therefore always include a sensitivity analysis in which detection bias or reverse causality are kept to a minimum by including one or multiple years of lag-time. 


\section{References}

1. Netherlands Cancer Registry. Cijfers over kanker: Netherlands Comprehensive Cancer Organization; 2016 [cited 2016 01-09-2016]. Available from: www.cijfersoverkanker.nl.

2. De Marco MF, Janssen-Heijnen ML, van der Heijden LH, Coebergh JW. Comorbidity and colorectal cancer according to subsite and stage: a population-based study. Eur J Cancer 2000;36(1):95-9.

3. van de Poll-Franse LV, Houterman S, Janssen-Heijnen ML, Dercksen MW, Coebergh JW, Haak HR. Less aggressive treatment and worse overall survival in cancer patients with diabetes: a large population based analysis. Int J Cancer J Int du Cancer 2007;120(9):1986-92.

4. Peeters PJ, Bazelier MT, Leufkens HG, de Vries F, De Bruin ML. The risk of colorectal cancer in patients with type 2 diabetes: associations with treatment stage and obesity. Diabetes Care 2015;38(3):495-502.

5. Giovannucci E, Harlan DM, Archer MC, Bergenstal RM, Gapstur SM, Habel LA, et al. Diabetes and cancer: a consensus report. CA Cancer J Clin 2010;60(4):207-21.

6. Tsilidis KK, Kasimis JC, Lopez DS, Ntzani EE, loannidis JP. Type 2 diabetes and cancer: umbrella review of meta-analyses of observational studies. BMJ 2015;350:g7607. -

7. Habib SL, Rojna M. Diabetes and risk of cancer. ISRN Oncol 2013;2013:583786.

8. Wu L, Yu C, Jiang H, Tang J, Huang HL, Gao J, et al. Diabetes mellitus and the occurrence of colorectal cancer: an updated metaanalysis of cohort studies. Diabetes Technol Ther 2013;15(5):419-e27.

9. Huang W, Ren H, Ben Q, Cai Q, Zhu W, Li Z. Risk of esophageal cancer in diabetes mellitus: a metaanalysis of observational studies. Cancer Causes Control CCC 2012;23(2):263-72.

10. Ge Z, Ben Q, Qian J, Wang Y, Li Y. Diabetes mellitus and risk of gastric cancer: a systematic review and meta-analysis of observational studies. Eur J Gastroenterol Hepatol 2011;23(12): 1127-35.

11. Jing $W$, Jin $G$, Zhou $X$, Zhou $Y$, Zhang $Y$, Shao $C$, et al. Diabetes mellitus and increased risk of cholangiocarcinoma: a meta-analysis. Eur J Cancer Prev the Official Journal of the European Cancer Prevention Organisation 2012;21(1):24-31.

12. Jiang $Y$, Ben $Q$, Shen $H$, Lu W, Zhang $Y$, Zhu J. Diabetes mellitus and incidence and mortality of colorectal cancer: a systematic review and meta-analysis of cohort studies. Eur J Epidemiol 2011;26(11):863-76.

13. Ren HB, Yu T, Liu C, Li YQ. Diabetes mellitus and increased risk of biliary tract cancer: systematic review and meta-analysis. Cancer Causes Control CCC 2011;22(6):837-47.

14. Ben $Q$, Xu M, Ning X, Liu J, Hong S, Huang W, et al. Diabetes mellitus and risk of pancreatic cancer: a meta-analysis of cohort studies. Eur J Cancer 2011;47(13):1928-37.

15. Wang C, Wang X, Gong G, Ben Q, Qiu W, Chen Y, et al. Increased risk of hepatocellular carcinoma in patients with diabetes mellitus: a systematic review and meta-analysis of cohort studies. Int J Cancer J Int du Cancer 2012;130(7):1639-48.

16. Larsson SC, Orsini N, Wolk A. Diabetes mellitus and risk of colorectal cancer: a meta-analysis. J Natl Cancer Inst 2005;97(22):1679-87.

17. Deng L, Gui Z, Zhao L, Wang J, Shen L. Diabetes mellitus and the incidence of colorectal cancer: an updated systematic review and meta-analysis. Dig Dis Sci 2012;57(6):1576-85.

18. He J, Stram DO, Kolonel LN, Henderson BE, Le Marchand L, Haiman CA. The association of diabetes with colorectal cancer risk: the Multiethnic Cohort. Br J Cancer 2010;103(1):120-6.

19. Baan CA, Poos MJJC, Uiters E, Savelkoul M. Hoe vaak komt diabetes mellitus voor en hoeveel mensen sterven eraan? Volksgezondheid Toekomst Verkenning. Nationaal Kompas Volksgezondheid Bilthoven; 2014.

20. Harding JL, Shaw JE, Peeters A, Cartensen B, Magliano DJ. Cancer risk among people with type 1 and type 2 diabetes: disentangling true associations, detection bias, and reverse causation. Diabetes Care 2015;38(2):264-70.

21. De Bruijn KM, Ruiter R, de Keyser CE, Hofman A, Stricker BH, van Eijck CH. Detection bias may be the main cause of increased cancer incidence among diabetics: results from the Rotterdam Study. Eur J Cancer 2014;50(14):2449-55.

22. Patorno E, Garry EM, Patrick AR, Schneeweiss S, Gillet VG, Zorina O, et al. Addressing limitations in observational studies of the association between glucose-lowering medications and allcause mortality: a review. Drug Saf 2015;38(3):295-310. 
23. Steevens J, Schouten LJ, Goldbohm RA, van den Brandt PA. Alcohol consumption, cigarette smoking and risk of subtypes of oesophageal and gastric cancer: a prospective cohort study. Gut 2010;59(1):39-48.

24. van Blankenstein M, Looman CW, Hop WC, Bytzer P. The incidence of adenocarcinoma and squamous cell carcinoma of the esophagus: Barrett's esophagus makes a difference. Am J Gastroenterol 2005;100(4):766-74.

25. de Kort S, Simons CC, van den Brandt PA, Goldbohm RA, Arts IC, de Bruine AP, et al. Diabetes mellitus type 2 and subsitespecific colorectal cancer risk in men and women: results from the Netherlands Cohort Study on diet and cancer. Eur J Gastroenterol Hepatol 2016;28(8):896-903.

26. van Herk-Sukel MP, van de Poll-Franse LV, Lemmens VE, Vreugdenhil G, Pruijt JF, Coebergh JW, et al. New opportunities for drug outcomes research in cancer patients: the linkage of the Eindhoven Cancer Registry and the PHARMO Record Linkage System. Eur J Cancer 2010;46(2):395-404.

27. World Health Organization. Collaborating centre for drug stastistics methodology e ATC/DDD index. 2016.

28. International classification of diseases of Oncology. Version 2013. 1st ed. Geneva: WHO; 1976.

29. Wojciechowska J, Krajewski W, Bolanowski M, Krecicki T, Zatonski T. Diabetes and cancer: a review of current knowledge. Exp Clin Endocrinol Diabetes Official Journal, German Society of Endocrinology [and] German Diabetes Association 2016;124(5):263-75.

30. Belfiore A. The role of insulin receptor isoforms and hybrid insulin/IGF-I receptors in human cancer. Curr Pharm Des 2007;13(7):671-86.

31. Vigneri P, Frasca F, Sciacca L, Pandini G, Vigneri R. Diabetes and cancer. Endocrine-related cancer 2009;16(4):1103-23.

32. Li J, Cao G, Ma Q, Liu H, Li W, Han L. The bidirectional interaction between pancreatic cancer and diabetes. World J Surg Oncol 2012;10:171.

33. Woo H, Lee J, Lee J, Park JW, Park S, Kim J, et al. Diabetes mellitus and site-specific colorectal cancer risk in Korea: a casecontrol study. J Prev Med Public Health 2016;49(1):45-52.

34. Tavani A, Bravi F, Bosetti C, Franceschi S, Levi F, Talamini R, et al. Diabetes mellitus and subsite-specific colorectal cancer risks in the lowa Women's Health Study. Cancer Epidemiol Biomarkers Prev a publication of the American Association for Cancer Research, cosponsored by the American Society of Preventive Oncology 2005;14(9):2277.

35. Jarvandi S, Davidson NO, Schootman M. Increased risk of colorectal cancer in type 2 diabetes is independent of diet quality. PLoS One 2013;8(9):e74616

36. Kramer HU, Schottker B, Raum E, Brenner H. Type 2 diabetes mellitus and colorectal cancer: metaanalysis on sex-specific differences. Eur J Cancer 2012;48(9):1269-82.

37. Luo W, Cao Y, Liao C, Gao F. Diabetes mellitus and the incidence and mortality of colorectal cancer: a meta-analysis of 24 cohort studies. Colorectal Dis 2012;14(11):1307-12.

38. Sun L, Yu S. Diabetes mellitus is an independent risk factor for colorectal cancer. Dig Dis Sci 2012; 57(6):1586e97.

39. Dixon JL, Copeland LA, Zeber JE, MacCarthy AA, Reznik SI, Smythe WR, et al. Association between diabetes and esophageal cancer, independent of obesity, in the United States Veterans Affairs population. Dis Esophagus 2016;29(7):747-51.

40. Cheng KC, Chen YL, Lai SW, Tsai PY, Sung FC. Risk of esophagus cancer in diabetes mellitus: a populationbased casecontrol study in Taiwan. BMC Gastroenterol 2012;12:177.

41. Jiang X, Bernstein L, Tseng CC, Wu AH. Diabetes and risk of esophageal and gastric adenocarcinomas. Int J Cancer J Int du Cancer 2012;131(6):1417-22.

42. Tseng $\mathrm{CH}$, Tseng FH. Diabetes and gastric cancer: the potential links. World J Gastroenterol WJG 2014;20(7):1701-11.

43. Bhaskaran K, Douglas I, Forbes H, dos-Santos-Silva I, Leon DA, Smeeth L. Body-mass index and risk of 22 specific cancers: a population-based cohort study of 5.24 million UK adults. Lancet 2014;384(9945): 755-65. 


\section{Supplementary tables}

Table S3.1 Sublocalisations of specific gastrointestinal cancer sites included in the analysis.

\begin{tabular}{ll}
\hline Cancer site & Sublocalisation \\
\hline Any GI cancer (C15-C26) & Upper GI cancer (C15-17) \\
& Lower GI cancer (C18-20) \\
& Hepato-Pancreatico-biliary (HPB) GI cancer (C22-25) \\
Oesophageal cancer (C15) & Upper and middle third oesophageal cancer (C15.0, C15.3, C15.4) \\
& Lower third oesophageal cancer (C15.5) \\
& Oesophageal squamous cell carcinoma (ICD-O code 8070/2) \\
& Oesophageal adenocarcinoma (ICD-O code 8140, 8144, 8260, 8480/1,8490) \\
Gastric cancer (C16) & Proximal gastric cancer (C16.0/2) \\
& Distal gastric cancer (C16.3/4) \\
Liver cancer (C22) & Intrahepatic bile duct cancer (C22.1) \\
Biliary tract cancer (C23-24) & Gallbladder cancer (C23) \\
Pancreatic cancer (C25) & Extrahepatic bile duct cancer (C24) \\
Proximal pancreatic cancer (C25.0) & Distal pancreatic cancer (C25.1/2) \\
Colorectal cancer (C18-20) & Colon cancer (C18) \\
& Rectal cancer (C19-20) \\
Colon cancer & Proximal colon cancer (C18.1/5) \\
& Distal colon cancer (C18.6/7) \\
\hline
\end{tabular}

NOTE: cancers for which a specific sublocalisation could not be determined were categorized as unspecified/NOS. 
Table S3.2 ATC codes for confounder drugs.

\begin{tabular}{|c|c|c|}
\hline Drug & ATC & Description \\
\hline \multirow[t]{5}{*}{ Anti-hypertensives } & $\mathrm{CO} 2^{*}$ & Antihypertensives \\
\hline & $\mathrm{CO}^{*}$ & Diuretics \\
\hline & COT* & Beta blocking agents \\
\hline & CO8* & Calcium channel blockers \\
\hline & co9* & Agents acting on the renin-angiotensin system \\
\hline \multirow[t]{15}{*}{ Aspirin } & A01AD05 & acetylsalicylic acid \\
\hline & B01AC06 & acetylsalicylic acid \\
\hline & N02BA01 & acetylsalicylic acid \\
\hline & N02BA01 & acetylsalicylic acid \\
\hline & N02BA01 & acetylsalicylic acid \\
\hline & M01BA03 & acetylsalicylic acid and corticosteroids \\
\hline & N02BA51 & acetylsalicylic acid, combinations excl. psycholeptics \\
\hline & B01AC56 & acetylsalicylic acid, combinations with proton pump inhibitors \\
\hline & N02BA71 & acetylsalicylic acid, combinations with psycholeptics \\
\hline & C10BX08 & atorvastatin and acetylsalicylic acid \\
\hline & С10BX06 & atorvastatin, acetylsalicylic acid and ramipril \\
\hline & C10BX02 & pravastatin and acetylsalicylic acid \\
\hline & C10BX05 & rosuvastatin and acetylsalicylic acid \\
\hline & C10BX01 & simvastatin and acetylsalicylic acid \\
\hline & C10BX04 & simvastatin, acetylsalicylic acid and ramipril \\
\hline \multirow[t]{2}{*}{ Bisphosphonates } & M05BA* & Bisphosphonates \\
\hline & M05BB* & Bisphosphonates, combinations \\
\hline $\begin{array}{l}\text { Helicobacter pylori } \\
\text { eradication therapy }\end{array}$ & A02BD* & Combinations for eradication of Helicobacter pylori \\
\hline \multirow{9}{*}{$\begin{array}{l}\text { Non-steroidal anti- } \\
\text { inflammatory drugs } \\
\text { (excluding aspirin) }\end{array}$} & A01AD02 & Benzydamine \\
\hline & C01EB03 & Indometacin \\
\hline & C01EB16 & Ibuprofen \\
\hline & G02CC* & Antiinflammatory products for vaginal administration \\
\hline & L01XX33 & Celecoxib \\
\hline & M01A* & Anti-inflammatory and antirheumatic products, non-steroids \\
\hline & $\mathrm{R} 02 \mathrm{AX} *$ & Flurbiprofen, Ibuprofen \\
\hline & S01BC* & Anti-inflammatory agents, non-steroids \\
\hline & S01CC* & $\begin{array}{l}\text { Anti-inflammatory agents, non-steroids and anti-infectives in } \\
\text { combination }\end{array}$ \\
\hline Oral contraceptives & G03A* & Hormonal contraceptives for systemic use \\
\hline \multirow[t]{3}{*}{ Proton pump inhibitors } & $\mathrm{A} 02 \mathrm{BC}^{*}$ & Proton pump inhibitors \\
\hline & A02BD* & Combinations for eradication of Helicobacter pylori \\
\hline & M01AE52 & Naproxen and esomeprazole \\
\hline Tamoxifen & L02BA01 & Tamoxifen \\
\hline
\end{tabular}




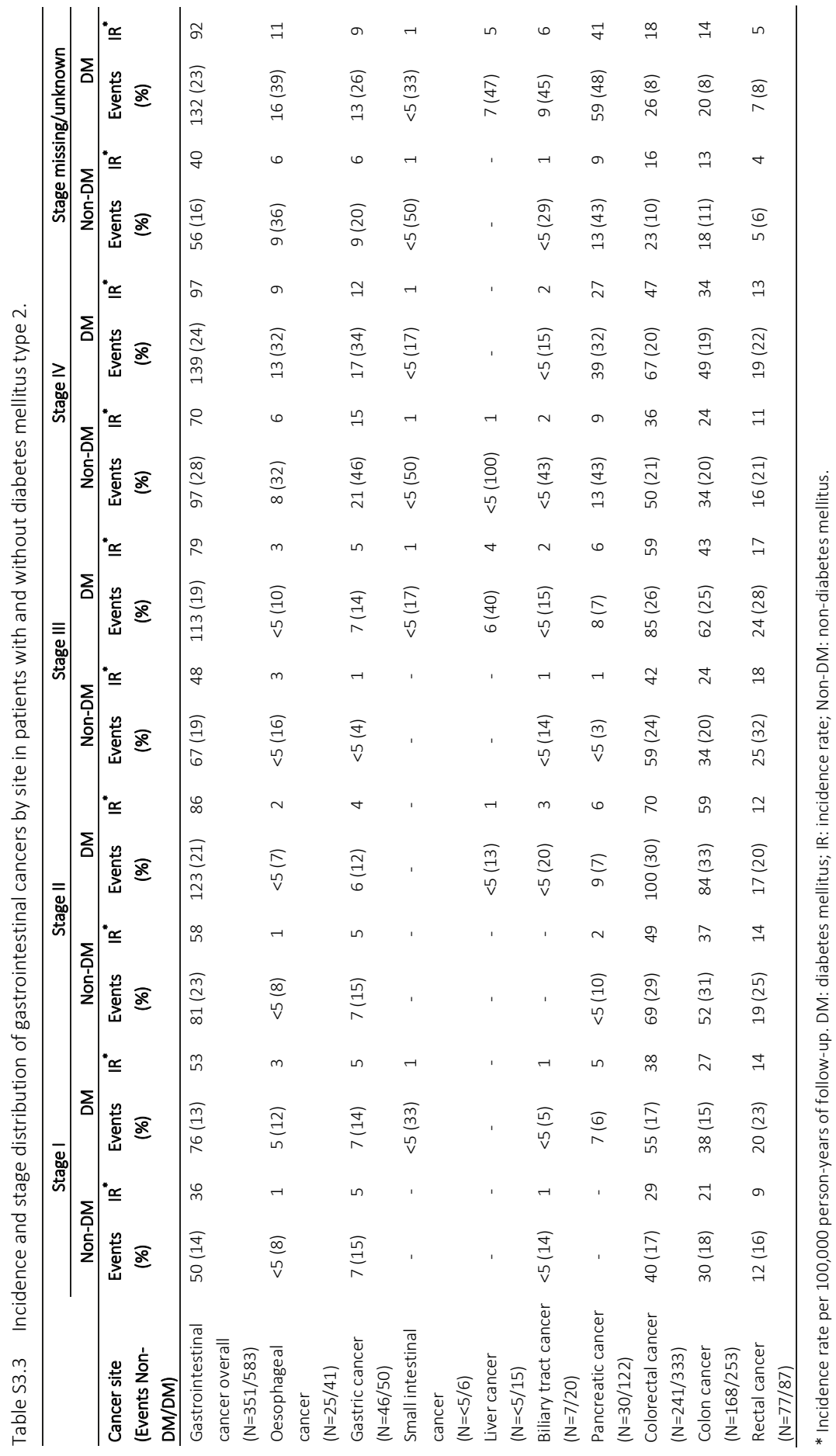




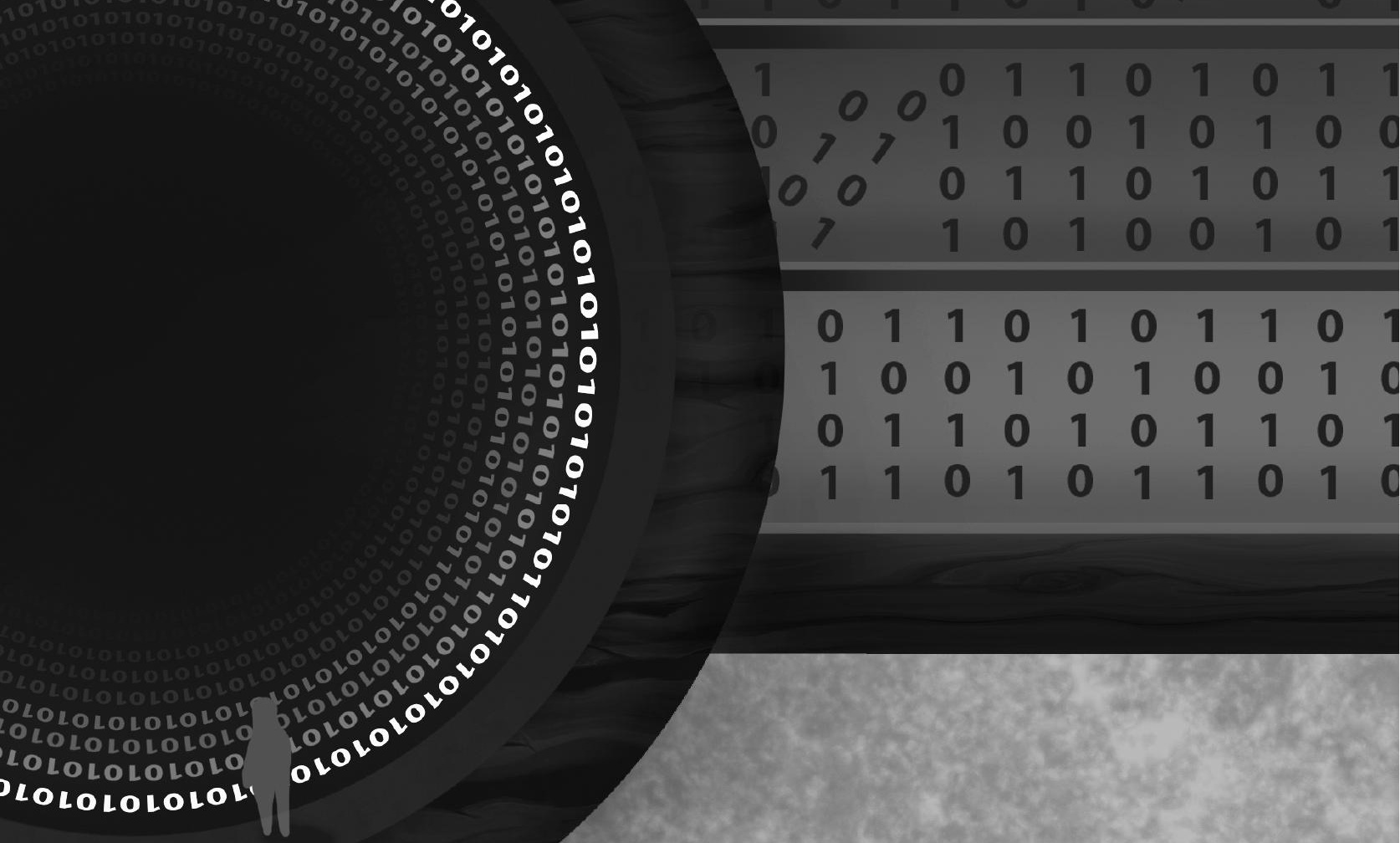

$\begin{array}{llllllllll}0 & 1 & 1 & 0 & 1 & 0 & 1 & 1 & 0 & 1\end{array}$

$\begin{array}{lllllllll}1 & 0 & 0 & 1 & 0 & 1 & 0 & 0 & 1\end{array}$

$\begin{array}{llllllllll}0 & 1 & 1 & 0 & 1 & 0 & 1 & 1 & 0 & 1\end{array}$

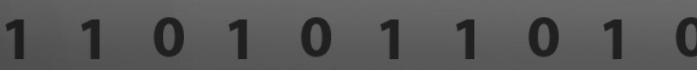

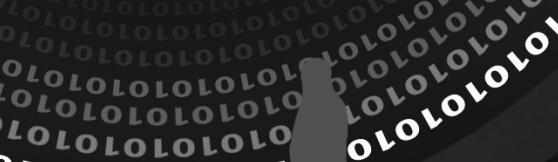
$010^{2}$ 


\section{Chapter 4}

Brief report: Comparability of the age and sex distribution of the UK Clinical Practice Research Datalink and the total Dutch population

Roy G.P.J. de Jong, Arlene M. Gallagher, Emily Herrett, Ad A.M. Masclee, Maryska L.G. Janssen-Heijnen, and Frank de Vries Pharmacoepidemiology and drug safety 2016;25:1460-1464 


\section{Abstract}

\section{Purpose}

The UK Clinical Practice Research Datalink (CPRD) is increasingly being used by Dutch researchers in epidemiology and pharmacoepidemiology. It is however unclear if the UK CPRD is representative of the Dutch population and whether study results would apply to the Dutch population. Therefore, as first step, our objective was to compare the age and sex distribution of the CPRD with the total Dutch population.

\section{Methods}

As a measure of representativeness, the age and sex distribution of the UK CPRD were visually and numerically compared with Dutch census data from the StatLine database of the Dutch National Bureau of Statistics in 2011.

\section{Results}

The age distribution of men and women in the CPRD population was comparable to the Dutch male and female population. Differences of more than $10 \%$ only occurred in older age categories (75+ in men and $80+$ in women).

\section{Conclusions}

Results from observational studies that have used CPRD data are applicable to the Dutch population, and a useful resource for decision making in the Netherlands. Nevertheless, differences in drug exposure likelihood between countries should be kept in mind, as these could still cause variations in the actual population studied, thereby decreasing its generalizability. 


\section{Introduction}

The United Kingdom (UK) Clinical Practice Research Datalink (CPRD) is one of the world's largest primary care databases and is frequently used for post-authorisation safety studies, pharmaco-epidemiology, and disease epidemiology. ${ }^{1-5}$ Examples include the evaluation of side effects of dopamine agonists 2 or diabetes drugs ${ }^{3,4}$, and the epidemiology of fractures. ${ }^{5}$

From a global perspective, the healthcare system in the Netherlands, a small country not far from the UK, is largely comparable to that of the UK's National Health Service (NHS); i.e. everyone has equal access to medical care regardless of income or socioeconomic status. In both countries, the general practitioner (GP) is the gatekeeper of the public healthcare system, meaning patients cannot refer themselves to secondary or tertiary care without the GP's approval. These conditions are key for conducting populationbased pharmaco-epidemiological studies.

Although the Dutch public healthcare system has excellent conditions for establishing a large primary care database for pharmaco-epidemiological research that is comparable to the CPRD in terms of sample size, this has not yet occurred. Smaller primary care databases do exist (e.g. Netherlands Information Network of General Practice (LINH), Integrated Primary Care Information (IPCI), PHARMO Database Network); however these are generally restricted by a limited set of medical codes (approximately 1000 different "International Classification of Primary Care" codes versus over 100000 READ codes in the CPRD), few validation studies, considerable smaller sample size (e.g. 350000 in LINH and 1.5 million in IPCI versus over 11 million in CPRD in 2011), and limited access to routinely collected lifestyle data, such as tobacco use, alcohol consumption, and socioeconomic status. ${ }^{6}$ Furthermore, claims that these data are representative for the total Dutch population are seldom supported by published figures. ${ }^{7,8}$ For these reasons, an increasing number of CPRD studies are being conducted by researchers from the Netherlands and are financially supported by Dutch universities and funding agencies such as ZonMw and NWO. A recent study showed that the CPRD is representative of the total UK population with respect to age and sex and covers $6.9 \%$ of the UK population. ${ }^{1,9}$ A wide range of diagnoses in the CPRD have been validated in a number of studies, and data quality are further enhanced by NHS annual reward and incentive programme that details GP practice achievement results, the Quality and Outcomes Framework (QOF). The QOF awards GPs for regular recording of detailed data on a wide range of diseases. As a result, the CPRD contains millions of recordings for measurements such as blood pressure, cholesterol values, and lung function. In addition, the strength of CPRD's data partially explains why officials of the Food and Drug Administration in the United States 
perform studies using the CPRD database for drug safety monitoring and regulatory decision making. ${ }^{10-12}$

Although there are many similarities between healthcare systems of the UK and the Netherlands, it is unclear whether results from CPRD studies would apply to the Dutch population. Therefore, our objective was to compare the age and sex distribution of the CPRD to the total Dutch population.

\section{Methods}

Using the same sample of data from the previously published CPRD data resource profile, the age and sex distribution of the CPRD primary care data on 27 March 2011 were visually and numerically compared with UK and Dutch census data in 2011. ${ }^{1}$ The CPRD (formerly known as Value Added Medical Products, and later General Practice Research Database ${ }^{13,14}$ ) harnesses data from UK's general practices and produces a primary care dataset since 1987 . Through the years, it has become one of the largest databases of longitudinal medical records from primary care in the world, with coverage of over 11.3 million patients from 674 practices. To date, 4.4 million active (alive, currently registered) patients meet quality criteria (approximately $6.9 \%$ of the UK population), who are broadly representative of the UK general population in terms of age, sex, and ethnicity. For this study, visual comparison was performed by inspecting the overlap between the respective lines in a graph (Figure 4.1). An additional comparison calculated the differences between proportional distributions of 5-year age groups of CPRD data versus Dutch census data in 2011. We are not aware of any objective methods to define representativeness of patients in a research database compared to a country's total population. We therefore described the absolute and proportional differences between the age and sex distributions of CPRD and Dutch Census data in order to leave this to the reader, and made a subjective decision to consider an age-sex specific difference of $<10 \%$ representative (Table 4.1 ). Numbers for computing sex-stratified age categories of the total Dutch population in March 2011 were obtained from the StatLine database of the Dutch National Bureau of Statistics (www.cbs.nl).

\section{Results}

In general, the age distribution of men and women in the CPRD population was comparable to the Dutch male and female population (Figure 4.1). 

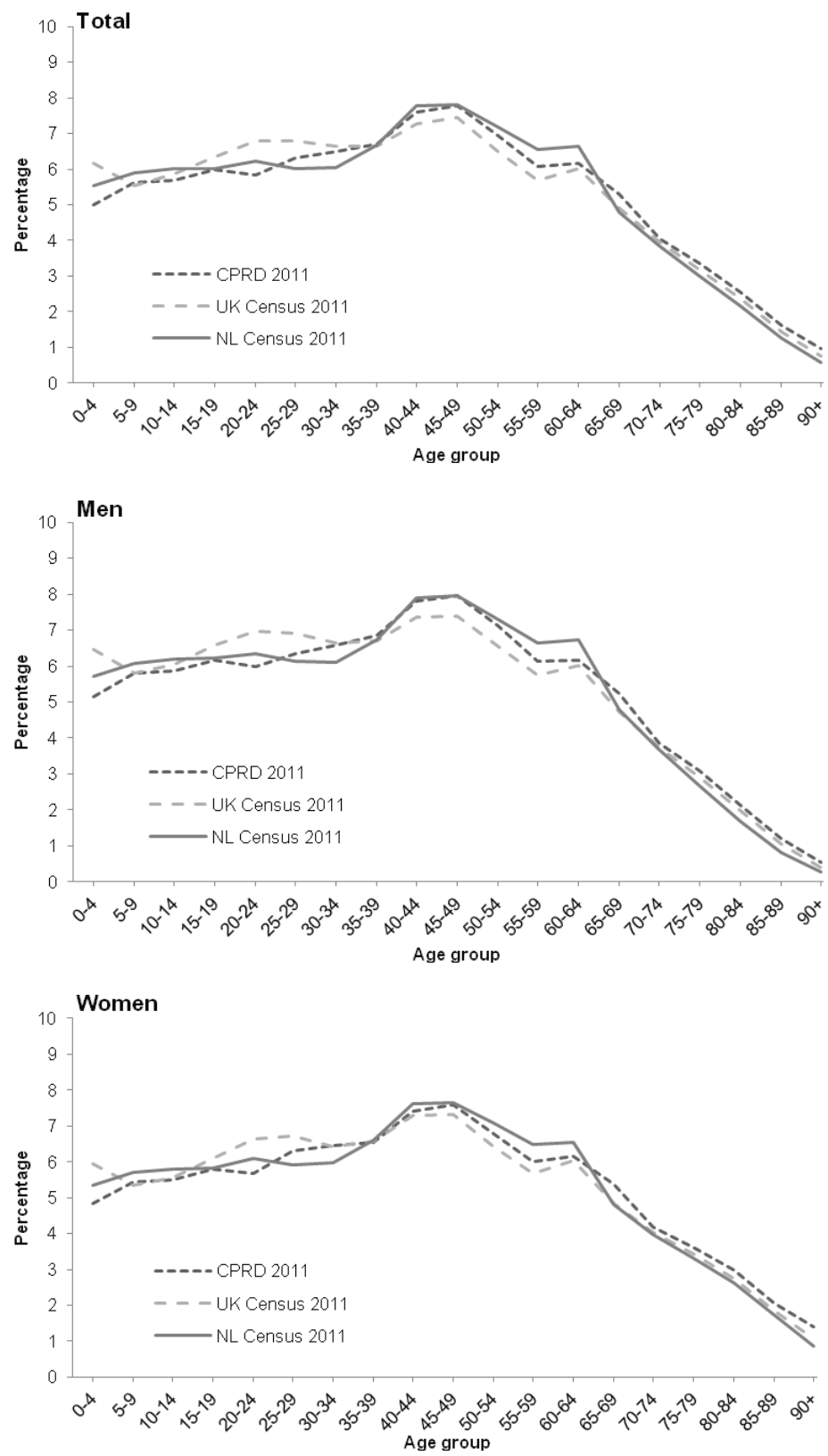

Figure 4.1 Age distribution of the CPRD primary care data on 27 March 2011 compared with UK and NL Census data from 2011, in both men and women (top panel), men only (middle panel) and women only (bottom panel). These data are based on a one-million patient sample of CPRD. Adapted from Herrett et al. Int. J Epidemiol 2015. 
Overall, the percentage men and women in the CPRD in 2011 was the same as in the Dutch population ( $49.5 \%$ men, 50.5\% women). The additional comparison based on calculating the differences between proportional distributions of 5-year age groups showed that differences of more than $10 \%$ occurred only in older age categories, starting from $75+$ in men, and $80+$ in women (Table 4.1).

\section{Discussion}

In this study, we showed that the age and sex distribution of the CPRD was visually and numerically comparable to that of the total Dutch population in 2011.

To our knowledge, this is the first study to directly compare the age and sex distribution of the CPRD to the total Dutch population. Apart from LINH, a national data network compiling electronic medical records (EMR) of 92 primary care practices with 211 GPs and over 350000 patients, we are not aware of any Dutch EMR database with data from GPs, which has published data on its representativeness according to the total Dutch population. The IPCI database is a longitudinal primary care database maintained by the department of Medical Informatics of the Erasmus Medical Centre in Rotterdam. In published papers of studies using the IPCl database it is frequently stated that the database is comparable to the total Dutch population in terms of age and sex. ${ }^{15,16}$ However, we could not verify this claim in a (peer-reviewed) publication. In a report of the Netherlands Institute for Health Services Research (NIVEL), which maintains the LINH database, it is shown that LINH is generally comparable to the total Dutch population, with a slight underrepresentation of women of 75 years and older. ${ }^{8}$ However, age- and sex-stratified proportions were calculated as compared to the total LINH population and not as compared to the total LINH population stratified by sex, making direct comparison with our results difficult.

Our calculations of the differences between proportional distributions of 5-year age groups show that the CPRD is comparable to the Dutch population in terms of age and sex up to age 75 in men and age 80 in women. However, in Figure 4.1 it can be clearly seen that the age distribution of CPRD and Dutch census data almost overlap in these higher age groups. The large differences for higher age groups seen in Table 4.1 may be a spurious finding, because the calculations were based on very small proportions of the total population. Of note, some difference is also seen between CPRD and the UK population in Figure 4.1. Men and to a lesser extent women aged between 20 and 35 years of age are underrepresented in CPRD, which has been attributed to the fact that these individuals probably do not register with a GP. ${ }^{9}$ 


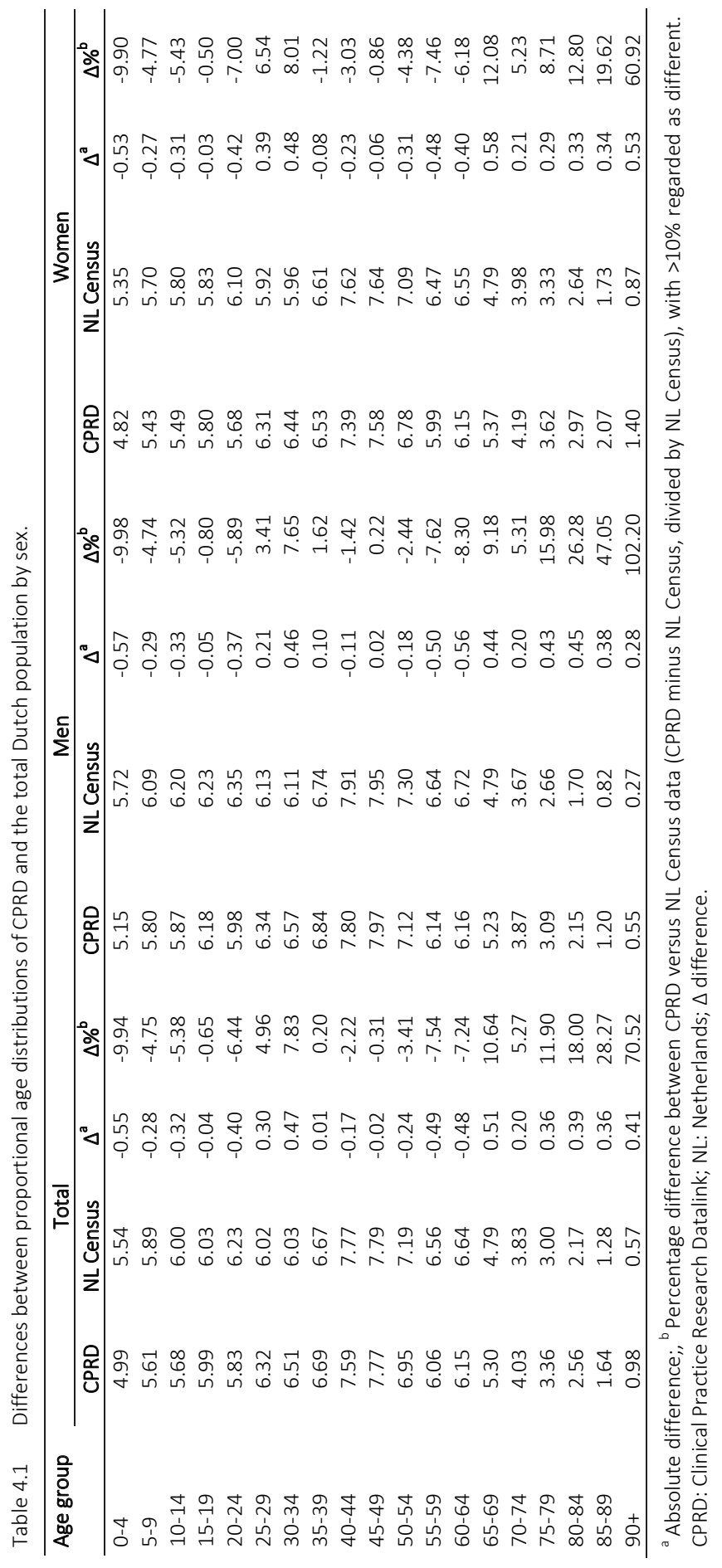


Several strengths have to be noted for this study. First, UK CPRD data were compared to data from the StatLine database of the Dutch National Bureau of Statistics, a reliable source of population-based information, regulated by national and European codes and laws. ${ }^{17}$ Second, by calculating the differences between proportional distributions in all age groups, we demonstrated that the distributions were not only visually, but also numerically comparable. Last, by showing the overall representativeness of the CPRD database of another population besides the UK population, CPRD may be used as rich data source for healthcare policymakers outside the UK.

There are also several limitations to this comparison. First, there are no objective methods to define representativeness of patients in a research database compared to a country's total population. To overcome this, we gave the reader insight into the various ways of comparing these data. Furthermore, the CPRD population was compared to the total Dutch population in terms of age and sex only. Therefore, we cannot rule out differences in for instance ethnicity, socioeconomic class, or lifestyle, which may in turn impact disease prevalence, exposure to important risk factors, or the degree of health care seeking behaviour. Based on the report of the OECD health indicators, the UK population has higher rates of tobacco and alcohol consumption, and especially obesity among adults, compared to the Dutch population. ${ }^{18}$ Although the results of our study imply that the UK CPRD may also be representative of the total Dutch population, information on a specific population of drug users is ultimately necessary to know whether results from pharmaco-epidemiological studies are transferrable to one's own region. As of yet, we have not looked into the comparability of various subpopulations in CPRD and The Netherlands. In addition, relative risks of disease outcomes found in CPRD could be extrapolated to the Dutch population, incidence rates or absolute risks cannot. In conclusion, this study showed that the age and sex distribution of CPRD were generally comparable to that of the total Dutch population. Results from observational studies that have used CPRD data are applicable to the total Dutch population (similar to how relative risks from randomized clinical trials apply to their demarcated population), and a useful resource for decision making in the Netherlands. Nevertheless, differences in drug exposure likelihood between countries should be kept in mind, as these could still cause variations in the actual population studied, thereby decreasing its generalizability. In addition, the results of this study may encourage scientists from other countries with similar healthcare systems to perform comparable studies of CPRD representativeness. 


\section{References}

1. Herrett E, Gallagher AM, Bhaskaran K, et al. Data resource profile: Clinical Practice Research Datalink (CPRD). Int J Epidemiol 2015;44(3):827-36.

2. Schade R, Andersohn F, Suissa S, Haverkamp W, Garbe E. Dopamine agonistsand the risk of cardiac-valve regurgitation. N Engl J Med 2007;356(1):29-38.

3. Knapen LM, van Dalem J, Keulemans YC, et al. Use of incretin agents and riskof pancreatic cancer: a population-based cohort study. Diabetes Obes Metab 2015;18(3):258-65.

4. Lo RV, III, Haynes K, Ming EE, et al. Safety of saxagliptin: rationale for and design of a series of postmarketing observational studies. Pharmacoepidemiol Drug Saf 2012;21(11):1202-15.

5. van Staa TP, Dennison EM, Leufkens HG, Cooper C. Epidemiology of fractures in England and Wales. Bone 2001;29(6):517-22.

6. Requena G, Huerta C, Gardarsdottir H, et al. Hip/femur fractures associated with the use of benzodiazepines (anxiolytics, hypnotics and related drugs): a methodological approach to assess consistencies across databases from the PROTECTEU project. Pharmacoepidemiol Drug Saf 2015;25(S1): 66-78.

7. Abbing-Karahagopian $V$, Kurz $X$, de Vries $F$, et al. Bridging differences in outcomes of pharmacoepidemiological studies: design and first results of the PROTECT project. Curr Clin Pharmacol 2014;9(2): $130-8$.

8. NIVEL. Representativiteit van LINH. 2010.

9. Campbell J, Dedman DJ, Eaton SC, Gallagher AM, Williams TJ. Is the GPRD GOLD population comparable to the UK population? Pharmacoepidemiol Drug Saf 2013;22(Suppl 1):280

10. Zhou EH, Gelperin K, Levenson MS, Rose M, Hsueh YH, Graham DJ. Risk of acute myocardial infarction, stroke, or death in patients initiating olmesartan or other angiotensin receptor blockers-a cohort study using the Clinical Practice Research Datalink. Pharmacoepidemiol Drug Saf 2014;23(4):340-7.

11. Hammad TA, Graham DJ, Staffa JA, Kornegay CJ, Dal Pan GJ. Onset of acute myocardial infarction after use of non-steroidal anti-inflammatory drugs. Pharmacoepidemiol Drug Saf 2008;17(4):315-21.

12. US Food and Drug Administration (FDA). FDA Drug Safety Communication: possible fracture risk with high dose, long-term use of proton pump inhibitors. 2010.

13. Kousoulis AA, Rafi I, de Lusignan S. The CPRD and the RCGP: building on research success by enhancing benefits for patients and practices. Br J Gen Pract 2015;65(631):54-5.

14. Williams T, van Staa T, Puri S, Eaton S. Recent advances in the utility and use of the General Practice Research Database as an example of a UK Primary Care Data resource. Ther Adv Drug Saf 2012;3(2): 89-99.

15. Noordam R, Aarts N, Verhamme KM, Sturkenboom MC, Stricker BH, Visser LE. Prescription and indication trends of antidepressant drugs in the Netherlands between 1996 and 2012: a dynamic population-based study. Eur J Clin Pharmacol 2015;71(3):369-75.

16. Masclee GM, Coloma PM, Spaander MC, Kuipers EJ, Sturkenboom MC.NSAIDs, statins, low-dose aspirin and PPIs, and the risk of oesophageal adenocarcinoma among patients with Barrett's oesophagus: a population-based case-control study. BMJ Open 2015;5(1e006640).

17. Centraal Bureau voor de Statistiek. CBS Kwaliteitsverklaring. 2014.

18. OECD. Health at a Glance 2015: OECD Indicators. OECD Publishing: Paris, 2015. 

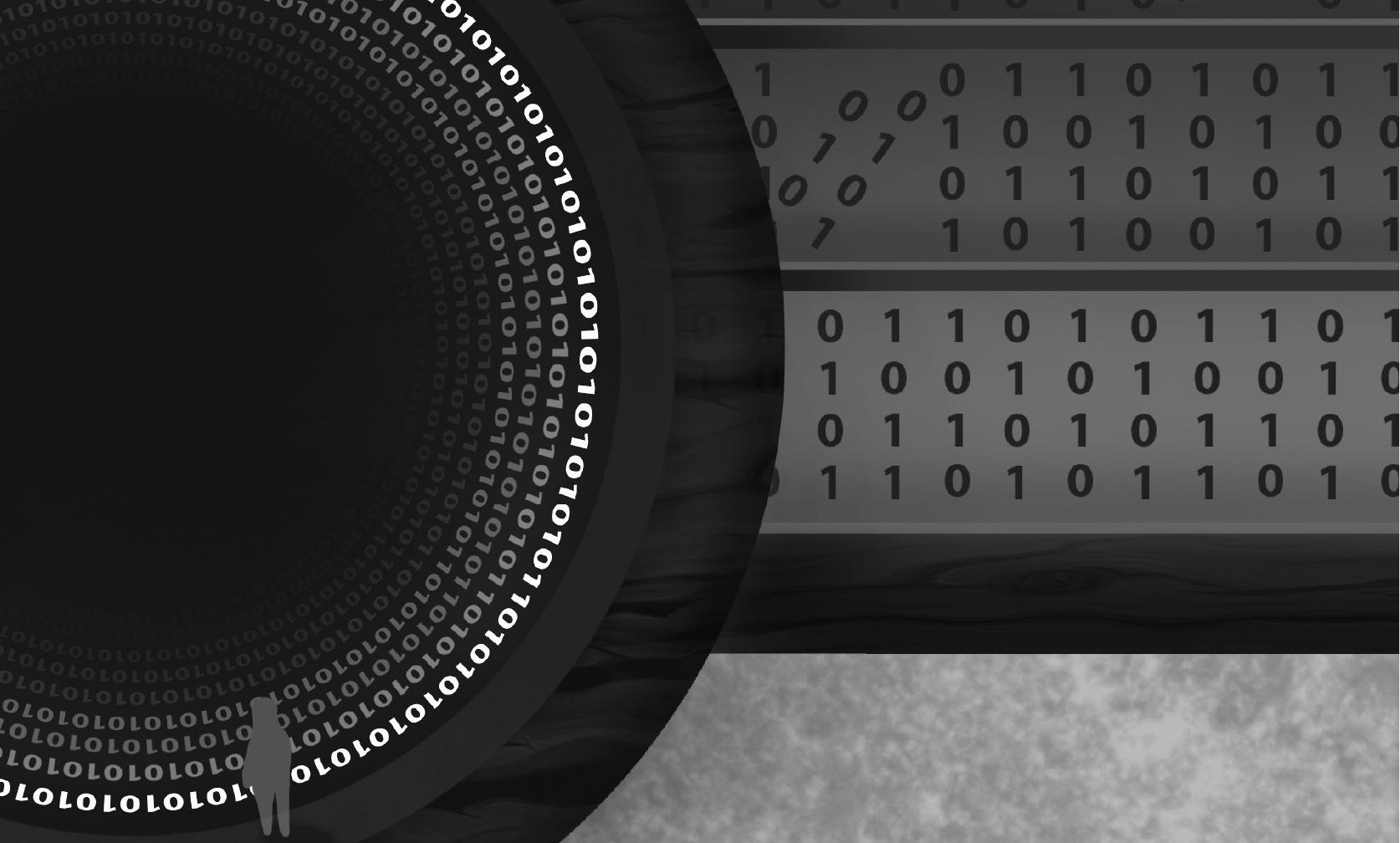

$\begin{array}{llllllllll}0 & 1 & 1 & 0 & 1 & 0 & 1 & 1 & 0 & 1\end{array}$

$\begin{array}{lllllllll}1 & 0 & 0 & 1 & 0 & 1 & 0 & 0 & 1\end{array}$

$\begin{array}{llllllllll}0 & 1 & 1 & 0 & 1 & 0 & 1 & 1 & 0 & 1\end{array}$

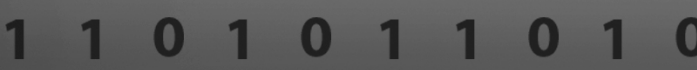

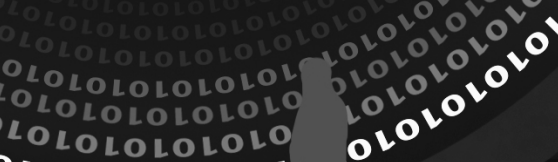
$010^{2}$ 


\section{Chapter 5}

\section{No decreased risk of gastrointestinal cancers in users of metformin in the Netherlands; a time-varying analysis of}

metformin exposure

Roy G.P.J. de Jong, Andrea M. Burden, Sander de Kort, Myrthe P.P. van Herk-Sukel, Pauline A.J. Vissers, Paddy K.C. Janssen, Harm R. Haak, Ad A. Masclee, Frank de Vries, Maryska L.G. Janssen-Heijnen Cancer Prevention Research 2017;10:290-297 


\section{Abstract}

\section{Background}

Previous studies on metformin use and gastrointestinal (GI) cancer risk have yielded inconclusive results on metformin's chemoprotective effects. We aimed to evaluate GI cancer risk in users of metformin in The Netherlands using a time-varying approach in a large population-based database.

\section{Methods}

A cohort study was performed using the E-NCR-PHARMO database. Patients using $\geq 1$ non-insulin antidiabetic drug (NIAD) during 1998 to 2011 were included $(N=57,621)$. Exposure to NIADs was modelled time-varyingly. Cox regression analysis estimated HRs of $\mathrm{Gl}$ cancers in current metformin users versus current users of other NIADs. Covariables included age, sex, drugs known to impact cancer risk, history of hospitalization, and starting year of follow-up. A sensitivity analysis was performed, applying a new-user design.

\section{Results}

Current use of metformin was not associated with a decreased risk of $\mathrm{Gl}$ cancer [HR, 0.97; 95\% confidence interval (Cl), 0.82-1.15] or specific $\mathrm{Gl}$ cancer sites. The sensitivity analysis yielded comparable results. No decreasing trends were observed with increasing cumulative dose of metformin [HR 1.05, 95\% Cl, 0.85-1.28; $\mathrm{HR} \mathrm{0.89,95 \%} \mathrm{Cl,}$ 0.73-1.10; HR 0.96, 95\% Cl, 0.77-1.19 for dose tertiles low (<405 g), medium (405-998 g), and high $(\geq 999 \mathrm{~g})$ ]. In contrast, an increased risk of pancreatic cancer was found in current users of metformin plus insulin ( $H R$, 4.90; 95\% Cl, 2.64-9.10).

\section{Conclusions}

In conclusion, no decreased risk of $\mathrm{Gl}$ cancer was found in current metformin users compared with current users of other NIADs. Variations in the exposure definition of metformin use may be one of the explanations of previously found reduced cancer risks in metformin users. 


\section{Introduction}

Metformin is an antidiabetic drug (ADD) that is widely used as the preferred first-line treatment for hyperglycaemia in type 2 diabetes mellitus (T2DM). The Dutch guideline for the treatment of T2DM advises metformin as first-line treatment as well, beside lifestyle advice such as dietary modification, physical exercise, and weight reduction. ${ }^{1}$ Metformin not only effectively lowers the blood glucose concentration through inhibition of gluconeogenesis and glycogenolysis in the liver, but is also known to decrease insulin resistance and hyperinsulinaemia through the insulin/IGF-1 signalling pathway. $^{2,3}$ Because insulin resistance is known to be a risk factor for cancer development, metformin may have a role in chemoprevention of cancer. ${ }^{4-6}$ Other ways through which metformin may reduce cancer risk are: (1) direct activation of AMPactivated protein kinase (AMPK) signalling, which leads to inhibition of the mTOR signalling pathway, and subsequently to reduced cell proliferation, protein synthesis, and tumour angiogenesis ${ }^{4}$; (2) metformin may have anti-inflammatory effects on malignant cells and may inhibit malignant stem cells, which are important in cancer initiation, recurrence, and resistance to chemotherapies. ${ }^{7}$

Observational studies have shown reduced risks of up to $64 \%$ for colorectal cancer, $94 \%$ for liver cancer, and 85\% for pancreatic cancer in patients with T2DM using metformin. ${ }^{8}$ ${ }^{15}$ However, the validity of the reported risk reductions in observational studies may be limited due to methodological issues, such as confounding by indication, prevalent user bias, and time-related biases. ${ }^{16-18}$ Moreover, recent studies that have used a timevarying approach of metformin exposure could not confirm the lower risk of several cancers with use of metformin. ${ }^{19,20}$ Although metformin may contain antineoplastic properties based on the aforementioned in vitro evidence, this effect may not be clinically relevant and therefore not visible when applying an optimal exposure definition of metformin use in an observational design.

The aim of our study was to evaluate the risk of gastrointestinal (GI) cancers in patients with T2DM using metformin applying a time-varying approach to ADD exposure, and to show differences between a prevalent user design and a new-user design.

\section{Materials and methods}

\section{Data source}

Data for this population-based cohort study were obtained from the PHARMO Database Network and linked at the individual patient level to the Eindhoven area of the 
Netherlands Cancer Registry (E-NCR-PHARMO database). The construct and validity of the linked database have been described elsewhere. ${ }^{21}$ The Eindhoven area of the NCR, maintained by the Netherlands Comprehensive Cancer Organisation (NCCO), covers a demographic region with approximately 2.4 million inhabitants $( \pm 15 \%$ of the Dutch population). Trained registration clerks actively collect data on newly diagnosed cancers, patient characteristics, staging, and initial treatment from hospital medical records. Vital status is obtained by linkage to Dutch municipal records.

The PHARMO Database Network is a large, patient-centric data network including linked observational databases designed for drug safety and outcomes research. For this study, the Out-patient (community) Pharmacy Database was used, which contains longitudinal drug dispensing records, and included information on dispensing date, dose descriptions, and amount dispensed. All drugs are coded according to their Anatomical Therapeutic Chemical/Defined Daily Dose Classification (ATC/DDD) code. ${ }^{22}$ Both the NCR and the PHARMO Database Network are recognized as high-quality data sources for (pharmaco-)epidemiological research that have collected information in overlapping regions in the Netherlands for a period of over 10 years. ${ }^{21}$

\section{Study design and population}

We conducted a cohort study of all adult patients aged $\geq 30$ years with at least one drug dispensing for an ADD [ATC codes "A10A" insulins, or "A10B" non-insulin antidiabetic drugs (NIAD)] in the E-NCR-PHARMO region between January 1, 1998, and December 31, 2011 (Figure 5.1). The date of first recorded ADD defined the index date. We restricted the cohort to patients aged $\geq 30$ years at the time of their first recorded prescription, as GI cancer rarely occurs before that age and to reduce misclassification by including type 1 diabetic patients. Patients for whom the first recorded ADD was insulin (ATC code "A10A") were excluded as they were more likely to have type 1 diabetes mellitus. Since coverage of the PHARMO database has gradually increased over time, there is a small chance that some prevalent T2DM patients were excluded, as patients could have entered the database at a later stage of their disease. Patients diagnosed with any type of $\mathrm{Gl}$ cancer before the index date were excluded.

\section{Exposure classification}

Follow-up time for all subjects was divided into fixed 90-day time intervals in order to model drug exposure over time in a time-varying way. Exposure to metformin and nonmetformin NIADs (other NIADs) was defined at the beginning of every 90-day interval. If a patient received a metformin or other NIAD prescription in the 90-days prior to the start of an interval, they were classified as a "current user" of that drug, otherwise they 
were classified as a "past user." All patients were classified as "current user" of either metformin or a non-metformin other NIAD at each time interval, but they could move between current and past use throughout follow-up. The cumulative dose of metformin was calculated at each current metformin use interval by summation of the total dose of each metformin prescription during the previous current use intervals. The whole sample median value was used to impute missing values of the recorded dose per tablet and for missing and/or extreme values of the amount of tablets dispensed. Cumulative dose at the end of follow-up was stratified by tertiles of cumulative metformin dose and classified as low (<405 g), medium (405-998 g), and high ( $\geq 999 \mathrm{~g}$ ) cumulative dose.

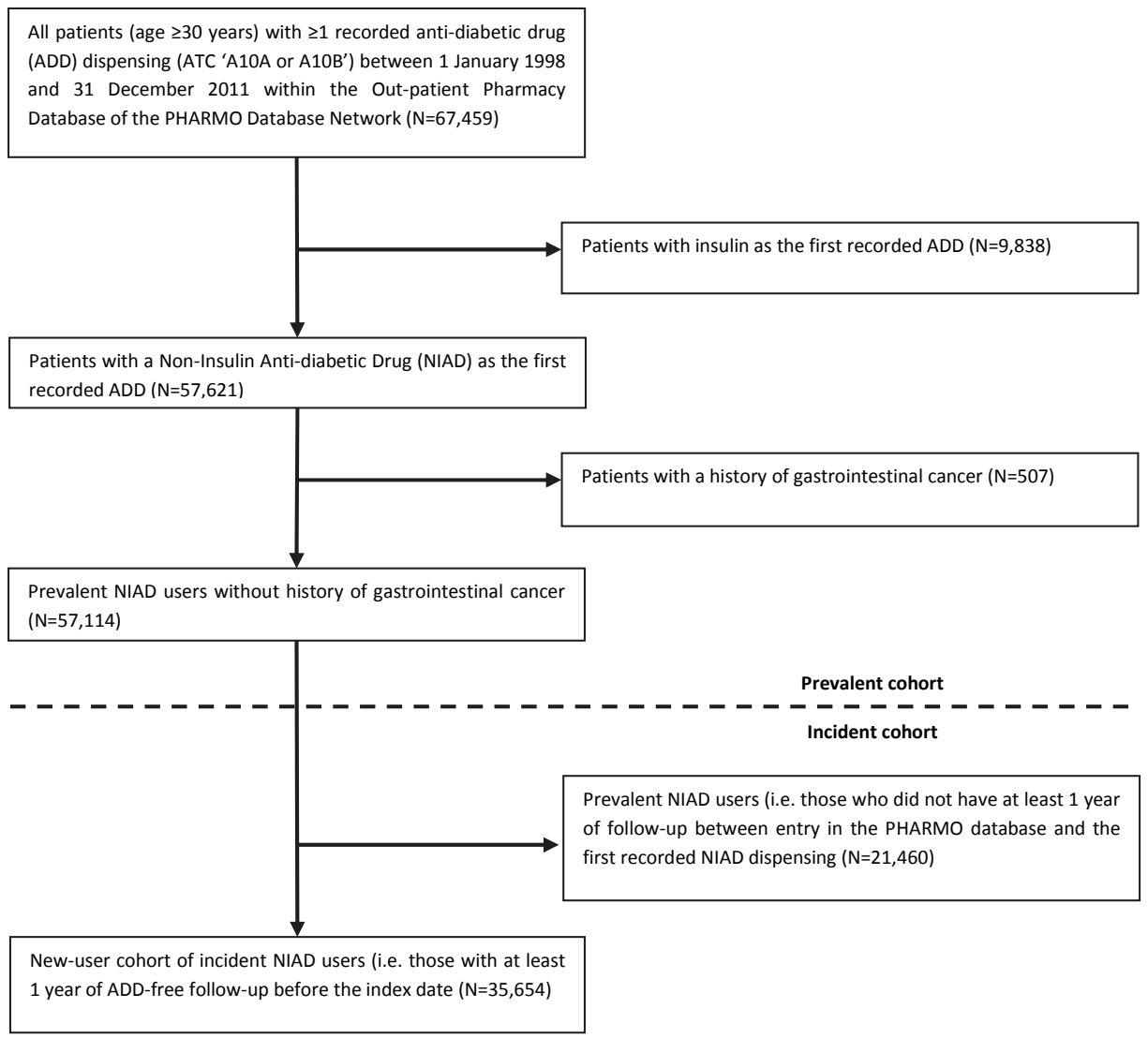

Figure 5.1 Flowchart of study population.

\section{Outcomes}

All patients were followed from the index date until a first ever diagnosis of a GI cancer, death from any cause, end of registration within the PHARMO catchment area, or end of 
data collection (December 31, 2011), whichever came first. Gl cancers were classified according to the International Classification of Diseases of oncology. ${ }^{23}$ These included "any GI cancer" (C15-26), oesophageal cancer (C15), gastric cancer (C16), small intestinal cancer (C17), colorectal cancer (CRC, C18-C20), hepatic cancer (C22), biliary tract cancer (C23: gallbladder, and C24: extrahepatic bile duct cancer), and pancreatic cancer (C25).

\section{Covariables}

A number of covariables were considered as confounders based on the current literature. As time-fixed covariables sex and history of hospitalization prior to the index date (hospitalization categories 0 or $\geq 1$ ) were considered. Time-dependent covariables were determined at the start of every 90-day time period and included age, the duration of diabetes in years (time since first recorded NIAD dispensing), and the use of other drugs known to impact $\mathrm{Gl}$ cancer risk in the 90 days prior to the start of each interval [statins, aspirin, non-aspirin non-steroidal anti-inflammatory drugs (NSAID), proton pump inhibitors, bisphosphonates, tamoxifen, oral contraceptives, and insulin). In addition, the use of helicobacter pylori ( $\mathrm{H}$. pylori) eradication therapy was used as proxyindicator for $\mathrm{H}$. pylori infection. Also, the year of start of follow-up was included as covariable as the index date of current metformin users and current users of other NIADs differed significantly at baseline (Table 5.1).

\section{Statistical analysis}

Differences in demographic characteristics between current users of metformin and current users of other NIADs at baseline were compared using the Mann-Whitney U test for continuous variables and the $\chi^{2}$ test for categorical variables.

Incidence rates per 100,000 person-years of follow-up were calculated by dividing the number of events by the total amount of person-years of follow-up. Overall and sitespecific $\mathrm{HRs}$ and $95 \%$ confidence intervals $(\mathrm{Cl})$ of $\mathrm{Gl}$ cancer in current users of metformin versus current users of other NIADs were calculated using time-varying Cox proportional hazards models. Stratified analyses were performed by sex, and by stratifying current metformin use by treatment stage and tertiles of cumulative dose. Subgroups of current metformin use by treatment stage included metformin monotherapy, metformin plus a sulfonylurea (SU) derivative, metformin plus another (non-SU) NIAD, and metformin plus insulin (regardless of other NIAD use). Potential confounders were entered into the regression models if they independently changed the $\beta$-coefficient for current metformin use by at least $5 \%$ in a univariate analysis. 
Table $5.1 \quad$ Baseline characteristics of current users of metformin or other NIADs.

\begin{tabular}{|c|c|c|c|c|c|}
\hline \multirow{2}{*}{$\frac{\text { Characteristic }}{\text { Age (mean, SD) }}$} & \multicolumn{2}{|c|}{$\begin{array}{l}\text { Current metformin users } \\
\qquad n=37,215\end{array}$} & \multicolumn{2}{|c|}{$\begin{array}{l}\text { Current other NIADs users } \\
n=19,899\end{array}$} & \multirow{2}{*}{$\frac{p \text {-value }}{<0.01}$} \\
\hline & 63.5 & 12.7 & 67.0 & 12.9 & \\
\hline Sex ( $n, \%$ male) & 18,151 & 48.8 & 9,353 & 47.0 & $<0.01$ \\
\hline Year of index date (mean, SD) & 2006 & 3.4 & 2002 & 3.4 & $<0.01$ \\
\hline \multicolumn{6}{|l|}{ Anti-diabetic drug use $(n, \%)^{b}$} \\
\hline Metformin & 37,215 & 100.0 & 0 & 0.0 & $<0.01$ \\
\hline Sulfonylureas & 4,621 & 12.4 & 19,166 & 96.3 & $<0.01$ \\
\hline Thiazolidinediones & 357 & 1.0 & 632 & 3.2 & $<0.01$ \\
\hline Meglitinides & 9 & 0.0 & 54 & 0.3 & $<0.01$ \\
\hline Incretins & 71 & 0.2 & 53 & 0.3 & 0.06 \\
\hline \multicolumn{6}{|l|}{ Use of other drugs $(n, \%)^{c}$} \\
\hline Anti-hypertensives & 21,653 & 58.2 & 10,246 & 51.5 & $<0.01$ \\
\hline Aspirin & 6,326 & 17.0 & 3,102 & 15.6 & $<0.01$ \\
\hline Bisphosphonates & 922 & 2.5 & 549 & 2.8 & 0.04 \\
\hline H. pylori eradication therapy & 41 & 0.1 & 9 & 0.1 & 0.01 \\
\hline Non-aspirin NSAIDs & 4,832 & 13.0 & 2,630 & 13.2 & 0.43 \\
\hline Proton pump inhibitors & 6,478 & 17.4 & 2,702 & 13.6 & $<0.01$ \\
\hline Statins & 14,898 & 40.0 & 4,408 & 22.2 & $<0.01$ \\
\hline \multicolumn{6}{|l|}{ History of hospitalization ( $n, \%$ ) } \\
\hline 0 hospitalisations & 22,621 & 60.8 & 14,310 & 71.9 & \\
\hline$\geq 1$ hospitalisations & 14,594 & 39.2 & 5,589 & 28.1 & $<0.01$ \\
\hline
\end{tabular}

a $p$-value based on Mann-Whitney $U$ test for continuous variables and Chi-squared test for categorical variables.

${ }^{b}$ At the start of follow-up (t0), ${ }^{c}$ During 90 days before the index date. Abbreviations: H. pylori, helicobacter pylori; NIADs, non-insulin anti-antidiabetic drugs; NSAIDs, non-steroidal anti-inflammatory drugs.

\section{Sensitivity analyses}

Sensitivity analyses with a new-user design were performed to account for prevalent user bias. The main analyses were repeated with an inception cohort of incident NIAD users only (Figure 5.1). To create an inception cohort of incident NIAD users, we excluded all prevalent NIAD users, i.e., those who did not have at least 1 year of followup between entry in the PHARMO database and the first recorded NIAD dispensing. Data management and statistical analyses were conducted using SAS 9.4 software.

\section{Results}

\section{Baseline characteristics}

At the start of follow-up, 37,215 T2DM patients were current metformin users and 19,899 were current users of other NIADs (Table 5.1). Current metformin users were on average younger (mean age, 63.5 vs. 67.0 years, $p<0.01)$ and more often males $(48.8 \%$ vs. $47.0 \%, p<0.01$ ) compared with current other NIAD users. The year of start of follow- 
up was more recent for current metformin users than current other NIAD users (mean, 2006 vs. 2002, $\mathrm{p}<0.01$ ). Most diabetic patients started follow-up either on metformin monotherapy or on SU (96.3\% of current other NIAD users). Furthermore, current metformin users used more other drugs besides ADDs as compared with other NIAD users, such as statins (40.0\% vs. $22.2 \%, p<0.01)$, aspirin (17.0\% vs. $15.6 \%, p<0.01)$, antihypertensives ( $58.2 \%$ vs. $51.5 \%, p<0.01)$, and proton pump inhibitors ( $17.4 \%$ vs. $13.6 \%$, $\mathrm{p}<0.01)$. Current metformin users were being hospitalized prior to the index date more often (39.2\% vs. $28.1 \%, p<0.01)$.

\section{Gl cancer overall}

During more than 280,000 person-years of follow-up (mean, 4.9 years per person), 1,076 GI cancers were observed (IR, 381 per 100,000 person-years). No statistically significant decreased risk of $\mathrm{Gl}$ cancer was observed in current metformin users compared with current other NIAD users (fully adjusted HR 0.97; 95\% Cl, 0.82-1.15; Table 5.2). Stratified analyses of subgroups of current metformin use by treatment stage and tertiles of cumulative dose did not reveal a decreased risk of $\mathrm{Gl}$ cancer. Furthermore, the sensitivity analysis and stratified analysis by sex yielded similar results (Table 5.2 and Supplementary Table S5.1, respectively).

\section{Gl cancer sites}

In the site-specific analyses, no significant differences in HRs of GI cancers were observed in current metformin users versus current other NIAD users (Table 5.3). However, a statistically significant increased HR of pancreatic cancer was observed in the subgroup of current users of metformin plus insulin (fully adjusted HR 4.90; $95 \% \mathrm{Cl}$, 2.64-9.10) and in female current metformin users (fully adjusted $\mathrm{HR} 1.95 ; 95 \% \mathrm{Cl}$, 1.01-3.76; Supplementary Table S5.2). Furthermore, there were no trends with increasing cumulative dose of metformin. In addition, the new-user design did not show statistically significant decreased HRs of $\mathrm{Gl}$ cancer sites in current metformin users compared with current other NIAD users (Table 5.4), whereas increased HRs of pancreatic cancer with current use of metformin plus a SU derivative and metformin plus insulin remained (fully adjustedHR1.98; 95\% Cl, 1.10-3.59 and fully adjusted HR 10.26; 95\% Cl, 4.96-21.22, respectively). 


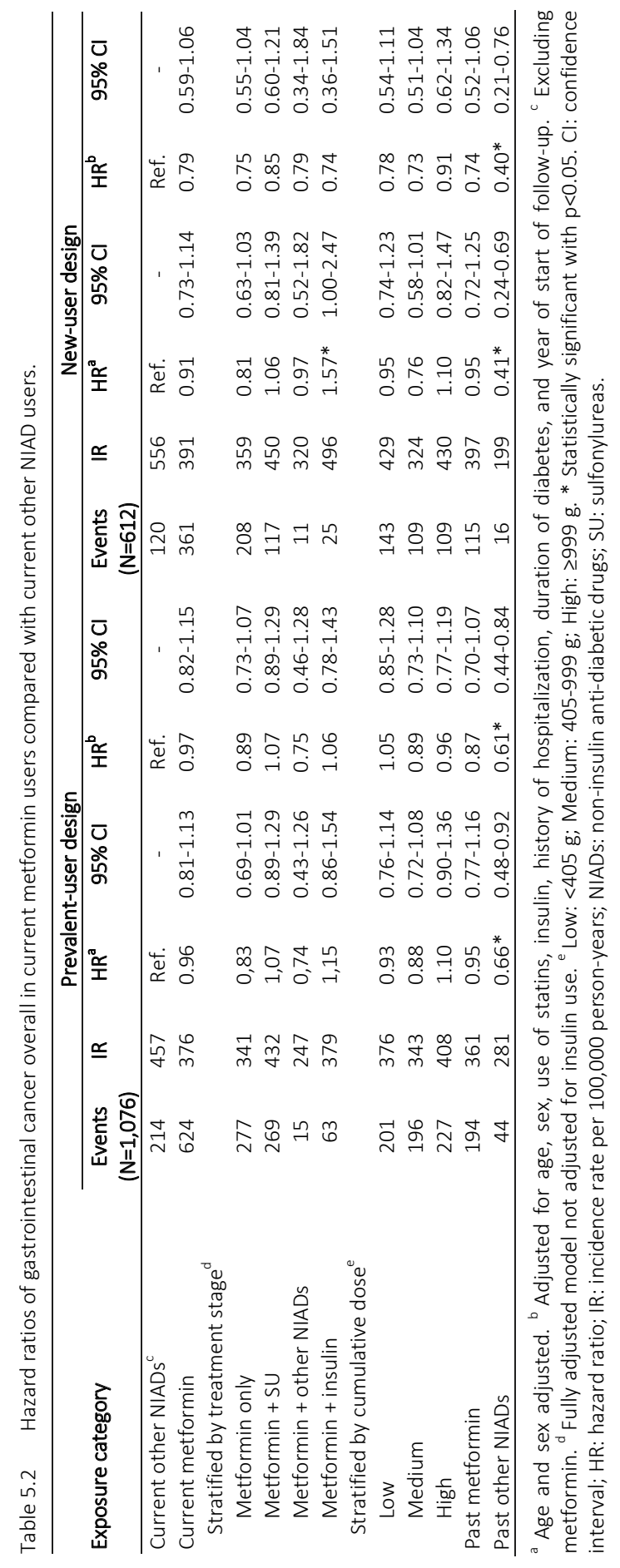




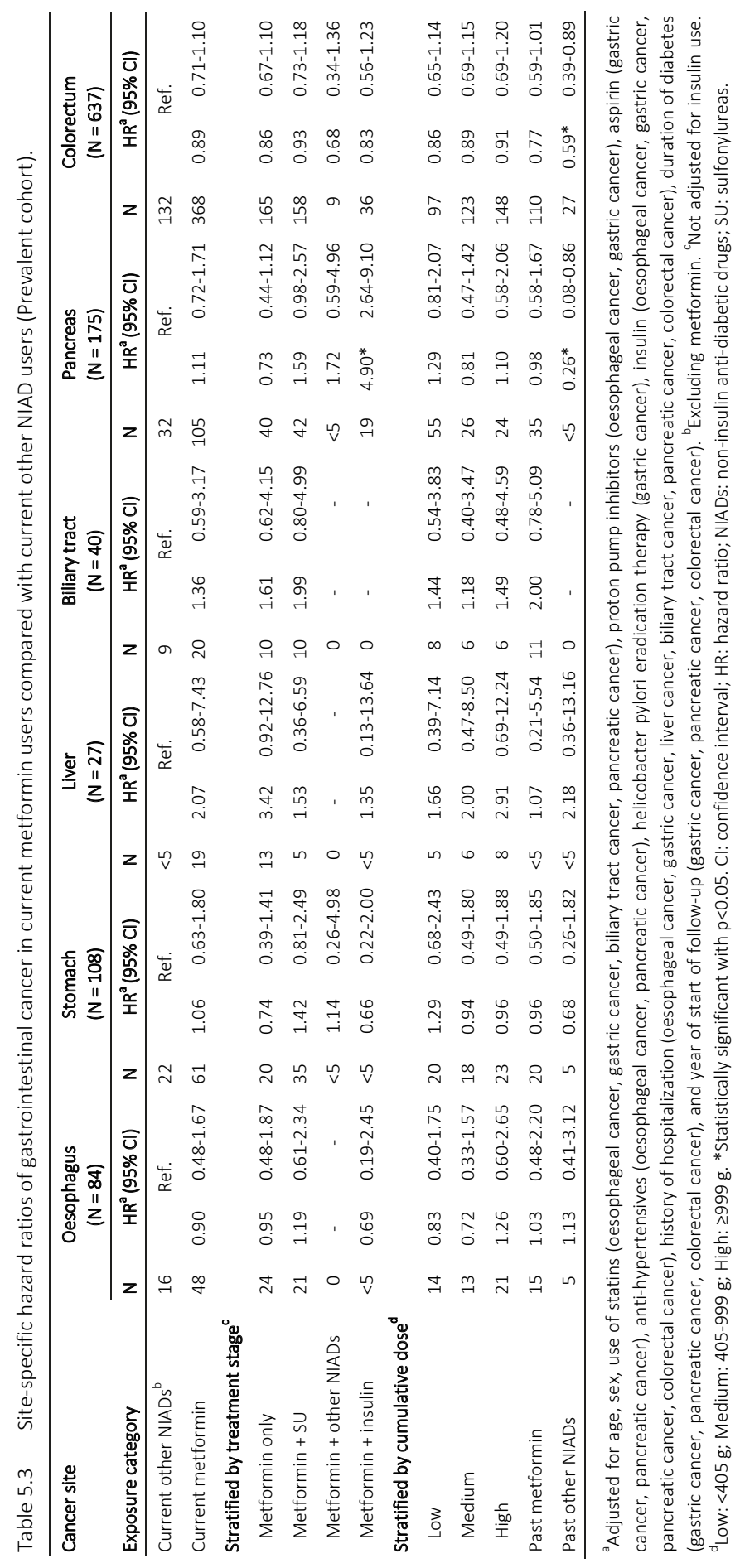




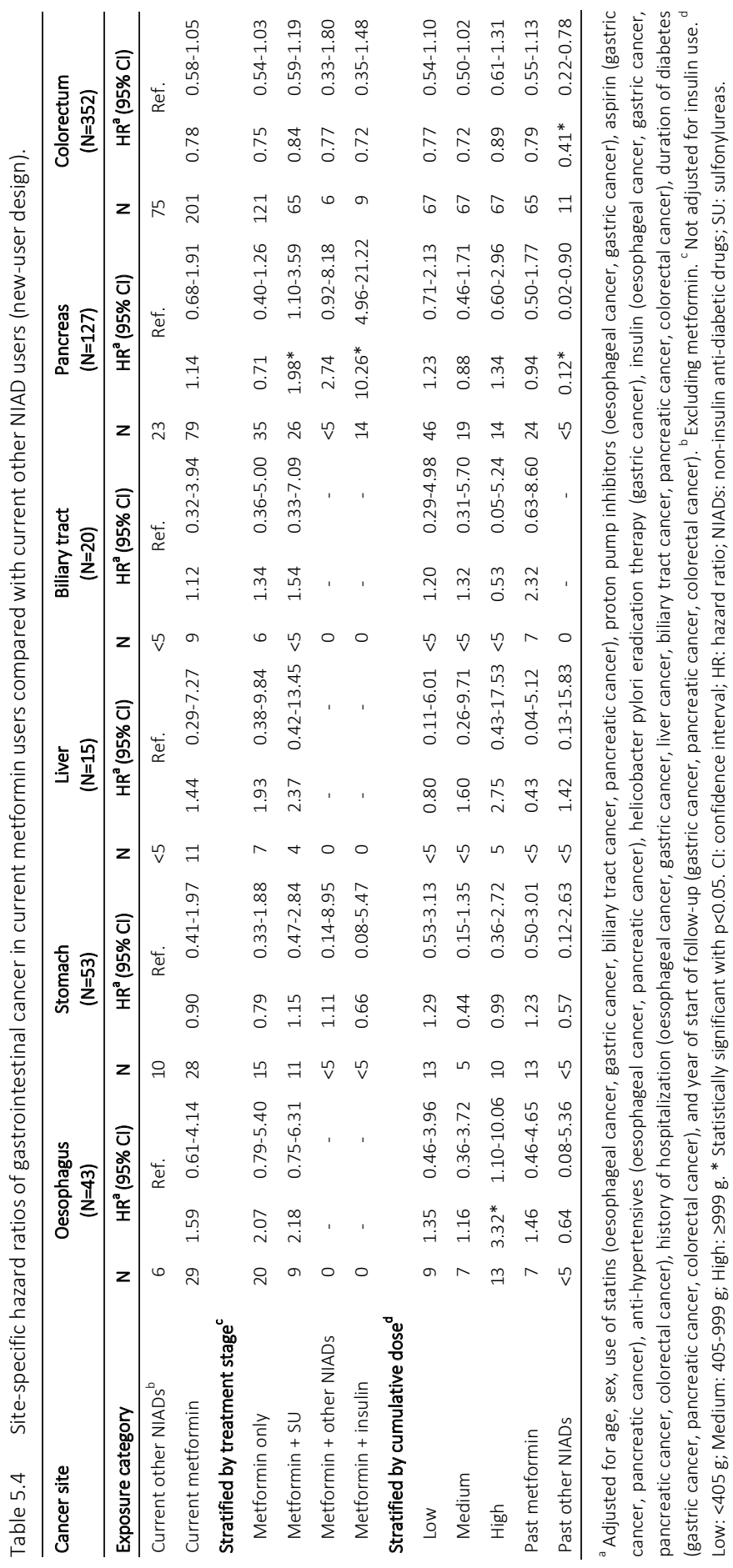




\section{Discussion}

In this population-based cohort study, in which we used a time-varying approach to determine metformin exposure in diabetic patients, no reduced risk of Gl cancer was found when comparing current use of metformin with current use of other NIADs. In addition, results from the sensitivity analysis, in which a new-user design was applied, did not significantly differ from the main analyses with a prevalent cohort of NIAD users. The risk of pancreatic cancer was increased in female current users of metformin, and in current users of metformin combined with insulin compared with current other NIAD users in both the main and sensitivity analysis.

The results of this study add to the evidence of recently published observational studies on the effect of metformin and (GI) cancer risk. ${ }^{20,24-31}$ These studies showed no statistically significant reductions in Gl cancer risk in users of metformin compared with users of other NIADs. Furthermore, these studies meet methodological standards due to a time-varying definition of exposure to metformin and because metformin exposure in this study minimizes exposure misclassification and time-related bias. In addition, the results of our study will support future meta-analyses on the risk of GI cancer with use of metformin, and will help draw a firmer conclusion on metformin's chemoprotective effects.

The observed increased risk of pancreatic cancer in current users of metformin plus insulin and plus a SU derivative might be explained by the potential mitogenic effects of insulin and SU, as insulin secretagogues. A recent meta-analysis of observational studies reported an increased risk of pancreatic cancer with use of insulin versus NIADs. ${ }^{32}$ However, the authors advised cautious interpretation of their results as they had identified various methodological issues such as confounding by indication and timerelated bias in multiple included studies. ${ }^{32}$ Bodmer and colleagues have reported an almost doubled risk of pancreatic cancer in users of SU (Adjusted OR 1.90; 95\% Cl, 1.322.74). ${ }^{10}$. However, also with respect to $\mathrm{SU}$, studies on cancer risk have reported contrasting results. ${ }^{33}$ In addition, the increased risk of pancreatic cancer in these subgroups of current metformin use may be explained by protopathic bias. It is possible that SU or insulins were added to metformin treatment as a result of disturbances in glucose homeostasis by an emerging pancreatic cancer.

Meta-analyses of observational studies on metformin and cancer risk have presented mixed results for various GI cancers, possibly due to the high heterogeneity among included studies (e. g., in definition of T2DM, type of database, geographic region). ${ }^{33-40}$ Meta-analyses on metformin and cancer risk often combine results of observational studies with different types of exposure definitions to metformin, which potentially cause varying amounts of exposure misclassification and time-related bias. Future meta- 
analyses on the risk of cancer with use of metformin would benefit from an in-depth description of possible biases and confounding in all included studies, and by performing stratified analyses including only studies with a low level of confounding and bias. In fact, Gandini and colleagues performed a systematic review and meta-analysis of observational studies on metformin and cancer risk with emphasis on studies controlling for confounding by body mass index (BMI) and for time-related biases. ${ }^{41}$ of the 47 included studies, only 18 were deemed to not have time-related biases. Regarding GI cancer risk, only the risk of colorectal cancer remained slightly decreased when analysing studies without time-related bias [ $\mathrm{N}=3$; summary relative risk (SRR), 0.92; 95\% Cl, 0.850.98]. Albeit, this decreased risk was not observed when analysing studies that adjusted for BMI ( $\mathrm{N}=6)$. For liver and pancreatic cancer, no statistically significant decreased risks were found (SRR 0.77, 95\% Cl, 0.38-1.55 and 0.65, 95\% Cl, 0.39-1.08, respectively).

Certain limitations of our study merit discussion. First, it is possible that the results are not without any residual confounding due to our inability to correct for lifestyle factors (e.g., obesity, alcohol use, smoking status, and physical activity), diabetes severity $(\mathrm{HbA} 1 \mathrm{c})$, dietary habits, and the presence of unmeasured comorbidities (e.g., gastrooesophageal reflux disease, chronic liver disease, or chronic pancreatitis). Second, a lack of statistical power existed for some cancer sites, such as liver cancer, and biliary tract cancer, especially in the sensitivity analyses wherein a new-user cohort was used. This resulted in a limited ability to statistically adjust for confounders in the multivariate analyses. Third, confounding by indication could have influenced the results, which we tried to minimize by including a cohort of ADD users only. Metformin is prescribed more readily to obese diabetic patients, as it may contribute to weight loss. In turn, obesity and its proxy indicator, high BMI, are closely linked to Gl cancer risk. ${ }^{42}$ Furthermore, although we compared metformin use with the use of other NIADs, the majority of other NIAD users was comprised of SU users with or without other NIADs (excluding metformin). Fourth, most GI cancers take decades to form, and the average follow-up time per person was 4.9 years. It is possible that the null results found in our study may be explained by the fact that most cancers were already present when patients started using metformin. Yet, we also do not know if metformin use may be able to slow down tumour progression, thereby delaying its diagnosis. Lastly, statistically significant inverse associations were found for GI cancer risk in past other NIAD users. The reasons, however, for becoming a past other NIAD user may vary greatly (e.g., start of insulin monotherapy or missing data due to a patient switching to a pharmacy outside the PHARMO catchment area). Therefore, the group of "past other NIAD use" is a very heterogeneous group, and no valid conclusions can be drawn from the point estimates in this group. 
One of the major strengths of this study was the availability of complete and longitudinal drug dispensing data from PHARMO Database Network, which allowed us to model drug exposure during follow-up in a time-varying way. Furthermore, these drug dispensing data are derived directly from community pharmacies in the overlapping E-NCRPHARMO region, with each dispensing being either picked up by the patient or directly delivered to the patient's address. Therefore, these data come very close to actual drug intake by the patient. In addition, cancer data from the NCR are known to contain highquality data over a wide range of cancers and cancer characteristics, which guarantees a high level of cancer ascertainment. Furthermore, to account for prevalent user bias, we repeated the analyses in incident NIAD users. Inclusion of prevalent users in the main analyses could potentially introduce two biases. First, prevalent users probably have a survival benefit over incident users, as they are survivors of the early phase of therapy and make up a "survivor cohort" that generally consists of healthier patients. Secondly, prevalent drug use might alter the levels of risk factors (e.g., obesity, insulin resistance) over time, causing these risk factors to lose their confounding effect. ${ }^{17}$

In summary, we found that in current metformin users, the risks of GI cancer were not significantly different from current other NIAD users. Our data add to the evidence of recent publications and highlight that methodological standards for drug exposure definitions should be met in observational studies. Future meta-analyses will benefit from an in-depth description of possible (time-related) biases and confounding factors in all included studies, and by performing stratified analyses by studies with a low level of confounding and bias. 


\section{References}

1. Bouma M, Rutten GE, de Grauw WJ, Wiersma T, Goudswaard AN, Nederlands Huisartsen G. Summary of the practice guideline 'Diabetes mellitus type 2' (second revision) from the Dutch College of General Practitioners. Ned Tijdschr Geneeskd 2006;150:2251-6.

2. Wulffele MG, Kooy A, de Zeeuw D, Stehouwer CD, Gansevoort RT. The effect of metformin on blood pressure, plasma cholesterol and triglycerides in type 2 diabetes mellitus: A systematic review. J Intern Med 2004;256: 1-14.

3. Giovannucci E, Harlan DM, Archer MC, Bergenstal RM, Gapstur SM, Habel LA, et al. Diabetes and cancer: A consensus report. CA Cancer J Clin 2010;60:207-21.

4. Pollak MN. Investigating metformin for cancer prevention and treatment: The end of the beginning. Cancer Discov 2012;2:778-90.

5. Dowling RJ, Goodwin PJ, Stambolic V. Understanding the benefit of metformin use in cancer treatment. BMC Med 2011;9:33.

6. Shaw RJ, Lamia KA, Vasquez D, Koo SH, Bardeesy N, Depinho RA, et al. The kinase LKB1 mediates glucose homeostasis in liver and therapeutic effects of metformin. Science 2005;310:1642-6.

7. Hirsch HA, Iliopoulos D, Struhl K. Metformin inhibits the inflammatory response associated with cellular transformation and cancer stem cell growth. Proc Natl Acad Sci U S A 2013;110:972-7.

8. Libby G, Donnelly LA, Donnan PT, Alessi DR, Morris AD, Evans JM. New users of metformin are at low risk of incident cancer: A cohort study among people with type 2 diabetes. Diabetes Care 2009;32: 1620-5.

9. Currie CJ, Poole CD, Gale EA. The influence of glucose-lowering therapies on cancer risk in type 2 diabetes. Diabetologia 2009;52:1766-77.

10. Bodmer M, Becker C, Meier C, Jick SS, Meier CR. Use of antidiabetic agents and the risk of pancreatic cancer: A case-control analysis. Am J Gastroenterol 2012;107:620-6.

11. Bodmer M, Becker C, Meier C, Jick SS, Meier CR. Use of metformin is not associated with a decreased risk of colorectal cancer: A case-control analysis. Cancer Epidemiol Biomarkers Prev 2012;21:280-6.

12. Chiu CC, Huang CC, Chen YC, Chen TJ, Liang Y, Lin SJ, et al. Increased risk of gastrointestinal malignancy in patients with diabetes mellitus and correlations with anti-diabetes drugs: A nationwide populationbased study in Taiwan. Intern Med 2013;52:939-46.

13. Lee MS, Hsu CC, Wahlqvist ML, Tsai HN, Chang YH, Huang YC. Type 2 diabetes increases and metformin reduces total, colorectal, liver and pancreatic cancer incidences in Taiwanese: A representative population prospective cohort study of 800,000 individuals. BMC Cancer 2011; 11:20.

14. Donadon V, Balbi M, Mas MD, Casarin P, Zanette G. Metformin and reduced risk of hepatocellular carcinoma in diabetic patients with chronic liver disease. Liver Int 2010;30:750-8.

15. Sehdev A, Shih YC, Vekhter B, Bissonnette MB, Olopade OI, Polite BN. Metformin for primary colorectal cancer prevention in patients with diabetes: A case-control study in a US population. Cancer 2015;121: 1071-8.

16. Suissa S, Azoulay L. Metformin and the risk of cancer: Time-related biases in observational studies. Diabetes care 2012;35:2665-73.

17. Golozar A, Liu S, Lin JA, Peairs K, Yeh HC. Does metformin reduce cancer risks? Methodologic considerations. Curr Diab Rep 2016;16:4.

18. Yang $X L, M a R C$, So $W Y$, Kong $A P, X u$ G, Chan JC. Addressing different biases in analysing drug use on cancer risk in diabetes in non-clinical trial settings-what, why and how? Diabetes Obes Metab 2012;14:579-85.

19. Knapen LM, Dittrich ST, de Vries F, Starup-Linde J, Vestergaard P, Henry RM, et al. Use of biguanides and the risk of colorectal cancer: A register-based cohort study. Curr Drug Saf 2013;8:349-56.

20. Smiechowski B, Azoulay L, Yin H, Pollak MN, Suissa S. The use of metformin and colorectal cancer incidence in patients with type II diabetes mellitus. Cancer Epidemiol Biomarkers Prev 2013;22: 1877-83.

21. van Herk-Sukel MP, van de Poll-Franse LV, Lemmens VE, Vreugdenhil G, Pruijt JF, Coebergh JW, et al. New opportunities for drug outcomes research in cancer patients: The linkage of the Eindhoven Cancer Registry and the PHARMO Record Linkage System. Eur J Cancer 2010;46:395-404.

22. WHO Collaborating Centre for Drug Statistics methodology. ATC Index with DDD's. Oslo: WHO. 2016. 
23. International Classification of Diseases of Oncology. Version 2013; first edition. Geneva: World Health Organization; 1976.

24. Gong Z, Aragaki AK, Chlebowski RT, Manson JE, Rohan TE, Chen C, et al. Diabetes, metformin and incidence of and death from invasive cancer in postmenopausal women: Results from the women's health initiative. Int J Cancer 2016;138:1915-27.

25. Wang SY, Chuang CS, Muo CH, Tu ST, Lin MC, Sung FC, et al. Metformin and the incidence of cancer in patients with diabetes: A nested case-control study. Diabetes Care 2013;36:e155-6.

26. But A, Wang H, Mannisto S, Pukkala E, Haukka J. Assessing the effect of treatment duration on the association between anti-diabetic medication and cancer risk. PLoS One 2014;9:e113162.

27. Tsilidis KK, Capothanassi D, Allen NE, Rizos EC, Lopez DS, van Veldhoven K, et al. Metformin does not affect cancer risk: a cohort study in the U.K. Clinical Practice Research Datalink analyzed like an intention-to-treat trial. Diabetes Care 2014;37:2522-32.

28. Walker EJ, Ko AH, Holly EA, Bracci PM. Metformin use among type 2 diabetics and risk of pancreatic cancer in a clinic-based case-control study. Int J Cancer 2015;136:E646-53.

29. Agrawal S, Patel P, Agrawal A, Makhijani N, Markert R, Deidrich W. Metformin use and the risk of esophageal cancer in Barrett esophagus. South Med J 2014;107:774-9.

30. Miele L, Bosetti C, Turati F, Rapaccini G, Gasbarrini A, La Vecchia C, et al. Diabetes and insulin therapy, but not metformin, are related to hepatocellular cancer risk. Gastroenterol Res Pract 2015;2015:570356.

31. Kowall B, Stang A, Rathmann W, Kostev K. No reduced risk of overall, colorectal, lung, breast, and prostate cancer with metformin therapy in diabetic patients: Database analyses from Germany and the UK. Pharmacoepidemiol Drug Saf 2015;24:865-74.

32. Karlstad O, Starup-Linde J, Vestergaard P, Hjellvik V, Bazelier MT, Schmidt MK, et al. Use of insulin and insulin analogs and risk of cancer - systematic review and meta-analysis of observational studies. Curr Drug Saf 2013; 8:333-48.

33. Soranna D, Scotti L, Zambon A, Bosetti C, Grassi G, Catapano A, et al. Cancer risk associated with use of metformin and sulfonylurea in type 2 diabetes: A meta-analysis. Oncologist 2012;17:813-22.

34. Zhang P, Li H, Tan X, Chen L, Wang S. Association of metformin use with cancer incidence and mortality: A meta-analysis. Cancer Epidemiol 2013; 37:207-18.

35. Wang Z, Lai ST, Xie L, Zhao JD, Ma NY, Zhu J, et al. Metformin is associated with reduced risk of pancreatic cancer in patients with type 2 diabetes mellitus: A systematic review and meta-analysis. Diabetes Res Clin Pract 2014;106:19-26.

36. Decensi A, Puntoni M, Goodwin P, Cazzaniga M, Gennari A, Bonanni B, et al. Metformin and cancer risk in diabetic patients: A systematic review and meta-analysis. Cancer Prev Res (Phila) 2010;3:1451-61.

37. Noto H, Goto A, Tsujimoto T, Noda M. Cancer risk in diabetic patients treated with metformin: A systematic review and meta-analysis. PLoS One 2012;7:e33411.

38. Singh $\mathrm{S}$, Singh $\mathrm{H}$, Singh PP, Murad MH, Limburg PJ. Antidiabetic medications and the risk of colorectal cancer in patients with diabetes mellitus: A systematic review and meta-analysis. Cancer Epidemiol Biomarkers Prev 2013;22:2258-68.

39. Singh S, Singh PP, Singh AG, Murad MH, McWilliams RR, Chari ST. Antidiabetic medications and risk of pancreatic cancer in patients with diabetes mellitus: A systematic review and meta-analysis. Am J Gastroenterol 2013;108:510-9; quiz 20.

40. Singh S, Singh PP, Singh AG, Murad MH, Sanchez W. Anti-diabetic medications and the risk of hepatocellular cancer: A systematic review and meta-analysis. Am J Gastroenterol 2013;108:881-91; quiz 92.

41. Gandini S, Puntoni M, Heckman-Stoddard BM, Dunn BK, Ford L, DeCensi A, et al. Metformin and cancer risk and mortality: A systematic review and meta-analysis taking into account biases and confounders. Cancer Prev Res (Phila) 2014;7:867-85.

42. Donohoe CL, O'Farrell NJ, Doyle SL, Reynolds JV. The role of obesity in gastrointestinal cancer: Evidence and opinion. Therap Adv Gastroenterol 2014;7:38-50. 


\section{Supplementary tables}

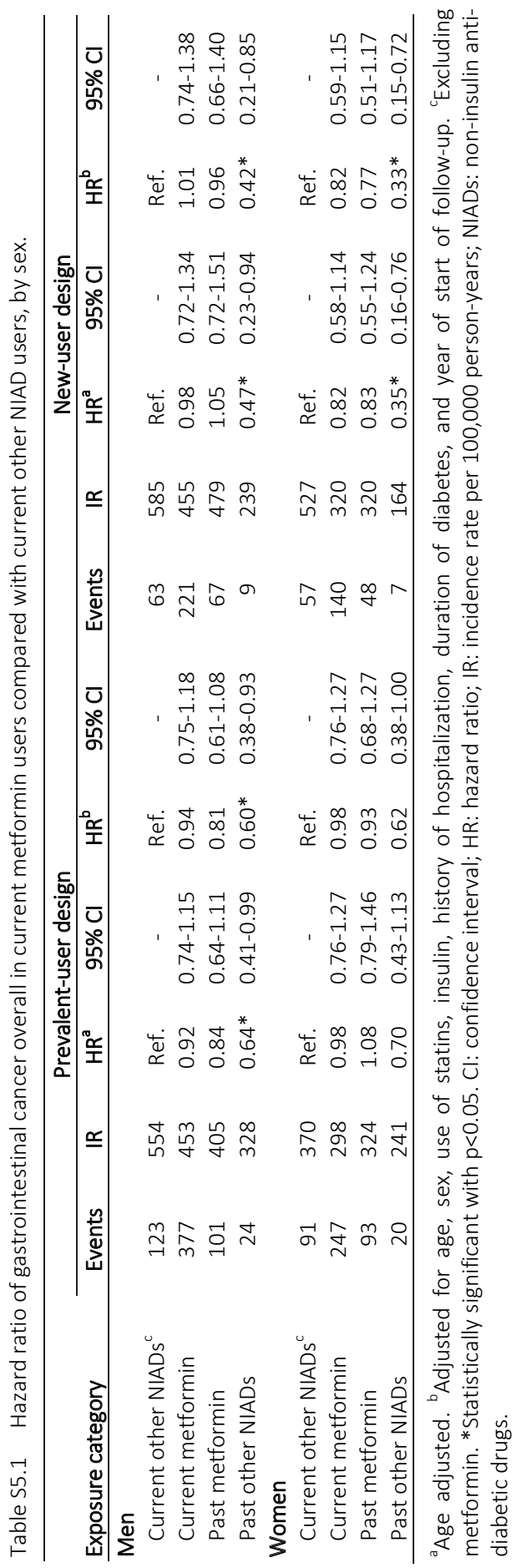




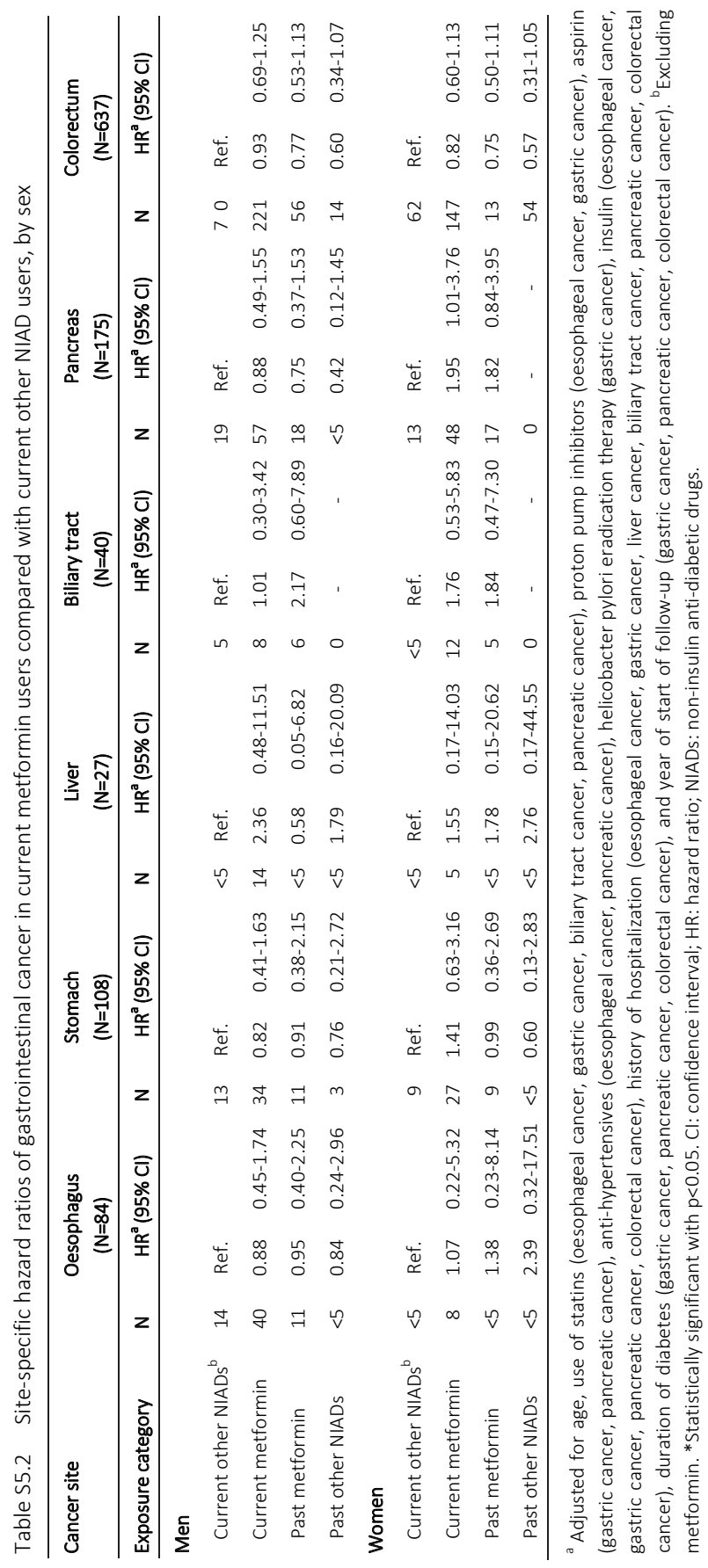




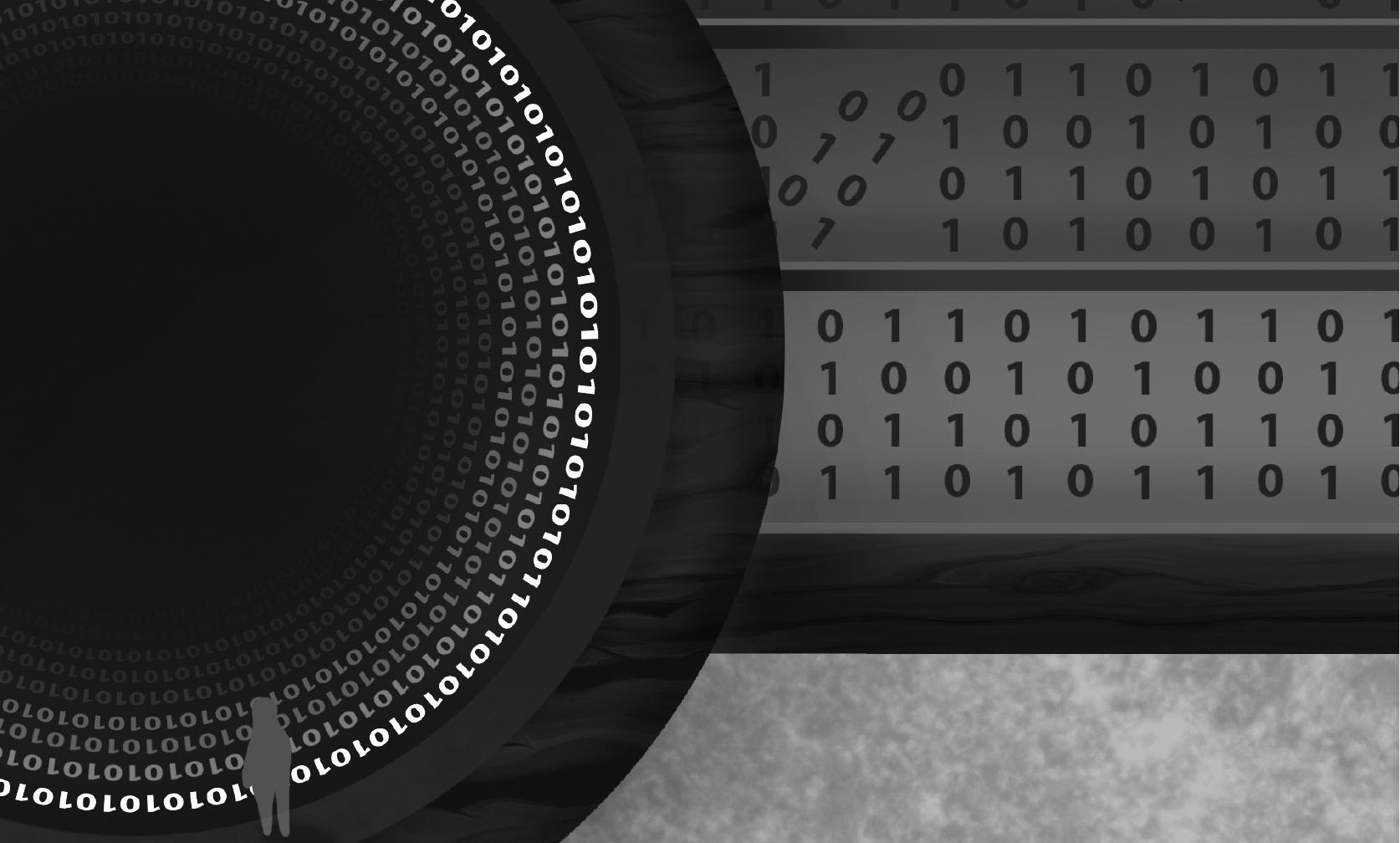

$\begin{array}{llllllllll}0 & 1 & 1 & 0 & 1 & 0 & 1 & 1 & 0 & 1\end{array}$

$\begin{array}{lllllllll}1 & 0 & 0 & 1 & 0 & 1 & 0 & 0 & 1\end{array}$

$\begin{array}{llllllllll}0 & 1 & 1 & 0 & 1 & 0 & 1 & 1 & 0 & 1\end{array}$

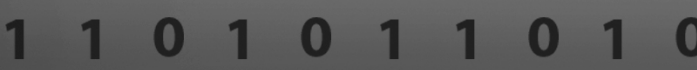

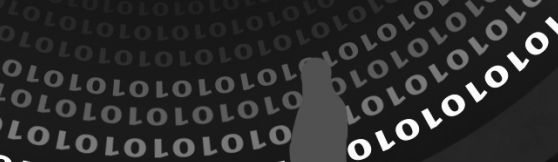
$010^{2}$ 


\section{Chapter 6}

Use of incretin agents and risk of acute and chronic pancreatitis: A population-based cohort study

Lotte M. Knapen, Roy G. P.J. de Jong, Johanna H.M. Driessen, Yolande C. Keulemans, Nielka P. van Erp, Marie L. De Bruin, Hubert G.M. Leufkens, Sander Croes, Frank de Vries

Diabetes Obesity and Metabolism 2017;19:401-411 


\section{Abstract}

Aim

To determine the association between the use of incretin agents (dipeptidyl peptidase-4 inhibitors and glucagon-like peptide-1 receptor agonists) for the treatment of type 2 diabetes mellitus (T2DM) and the risk of any, acute and chronic pancreatitis.

\section{Research design and methods}

A population-based cohort study was conducted using data from the UK Clinical Practice Research Datalink (CPRD 2007-2012). A total of 182,428 adult patients with $\geq 1$ noninsulin antidiabetic drug (NIAD) prescription were matched to control subjects without diabetes. Cox regression was used to estimate adjusted hazard ratios (HRs) and 95\% confidence intervals $(\mathrm{Cls})$ of pancreatitis in incretin-users $(\mathrm{N}=28,370)$ compared with controls and with other NIAD users. Adjustments were made for lifestyle, disease and drug history. In a sensitivity analysis, a new-user design was used.

\section{Results}

Current incretin users had a 1.5-fold increased risk of any pancreatitis compared with NIAD users (adjusted HR 1.47, 95\% Cl 1.06-2.04). In incident current incretin users the risk of any and acute pancreatitis was increased 2.1- and 2.0-fold compared with NIAD users (adjusted HR 2.12, 95\% Cl 1.31-3.43 and adjusted HR 1.96, 95\% Cl 1.13-3.41), whereas there was no increased risk found for chronic pancreatitis.

\section{Conclusions}

Incretin use was associated with an increased risk of any pancreatitis. Moreover, risk of any and acute pancreatitis was higher when applying a new-user design. We were not able to detect an association with chronic pancreatitis, but the number in this subgroup was small. 


\section{Introduction}

Type 2 diabetes mellitus (T2DM) has become a major threat to human health. Almost 90\% of patients with T2DM fail to achieve target values for glucose, lipids and blood pressure while treated with non-insulin antidiabetic drugs (NIADs) or insulin. ${ }^{1}$ Incretin agents or incretin-based therapies (glucagon-like peptide-1 receptor agonists [GLP-1RAs], such as exenatide or liraglutide, and dipeptidyl peptidase-4 [DPP-4] inhibitors, such as saxagliptin, linagliptin, vildagliptin or sitagliptin) are new therapeutic agents for the treatment of T2DM. Incretin-based therapies have an antihyperglycaemic effect, while promoting weight loss with a minimal risk of hypoglycaemia. ${ }^{2}$ Yet, in recent years, evidence has become available that pancreatitis might be an important side effect. $^{3}$

The glucagon-like peptide 1 (GLP-1) receptors are expressed in pancreatic islet $\beta$-cells as well as other cell types. They are directly stimulated by GLP-1RAs and indirectly stimulated by DPP-4 inhibitors through the increase in the body's GLP-1 concentration by inhibition of DPP-4. ${ }^{4}$ GLP-1 receptor stimulation may lead to overgrowth of the cells that cover the smaller ducts, resulting in hyperplasia, an increase in pancreatic weight, duct occlusion, back pressure and ultimately acute or chronic pancreatic inflammation. ${ }^{5-7}$ Pancreatitis is a serious condition, often leading to hospitalization, diminished quality of life and even death. ${ }^{8}$ Furthermore, there is a spectrum of pancreatitis, often starting with one attack of pancreatitis, which leads to recurrent pancreatitis in some patients $( \pm 20 \%-30 \%)$ and progresses to chronic pancreatitis in others $( \pm 10 \%)^{8,9}$

Recent literature shows limited and conflicting evidence for an association between incretin-based therapy and risk of acute pancreatitis. ${ }^{10}$ Spontaneous adverse event reporting systems have detected cases of pancreatitis in incretin users. ${ }^{11}$ One observational study found that current use of sitagliptin or exenatide was significantly associated with risk of hospitalization for acute pancreatitis ${ }^{12}$; however, a systematic review and meta-analysis, including 9 studies, with $>1.3$ million individuals and an average follow-up of 0.7 to 1.4 years, found that incretin-based therapy did not increase the risk of pancreatitis. ${ }^{13}$ Multiple observational studies have assessed the association between incretin-based therapy and pancreatitis. ${ }^{14-17}$ Given the controversy, the European Medicines Agency and the US Food and Drug Administration have called for additional studies. ${ }^{18-20}$

Furthermore, in contrast to the risk of acute pancreatitis, the risk of chronic pancreatitis with incretin use has not been investigated in an observational setting. The aim of the present study, therefore, was to evaluate the association between incretin use and the risk of any, acute and chronic pancreatitis in a population-based cohort study. 


\section{Research design and methods}

Data for this study were obtained from the UK Clinical Practice Research Datalink (CPRD; www.CPRD.com), previously known as the General Practice Research Database. The CPRD contains computerized medical records of 625 primary care practices in the UK, representing $6.9 \%$ of the population. ${ }^{21}$ The data recorded in the CPRD include demographic information, prescription details, clinical events, preventive care provided, specialist referrals, hospital admissions and major outcomes since 1987. Previous studies using CPRD data have shown a high validity concerning wide ranges of diseases, including acute and chronic pancreatitis. ${ }^{15,22,23}$

We conducted a population-based cohort study, largely according to methods that have been described previously. ${ }^{24}$ All patients aged $\geq 18$ years at start of follow-up, with $\geq 1$ NIAD prescription during the period of valid data collection, were included in the study population. The study period started on June 13, 2007 (date of first recorded prescription of an incretin in CPRD) and ended on August 31, 2012. The index date was defined as the date of first NIAD prescription after the practice had started to contribute data delivery to CPRD.

Each NIAD user was matched by sex, year of birth (within 5 years) and practice to one control patient who had never received prescriptions of NIADs or insulin during followup. The index date of each control patient was set to the index date of his/her matched NIAD user.

For NIAD users, follow-up time was divided into intervals based on their NIAD (and incretin) prescriptions; that is, for every prescription, a new interval was created. Exposure to an NIAD was defined as follows: after a washout period of 90 days, an interval was classified as "past NIAD use," until the end of follow-up or a new prescription of an antidiabetic drug, whichever came first. Otherwise an interval was classified as "current NIAD use." For control patients, the follow-up was divided into 90-day intervals. Each patient was followed from the index date up to the end of data collection, the date of transfer out of the practice area, the patient's death, or the earliest record of any, acute or chronic pancreatitis; that is, the outcome of interest, whichever came first.

NIAD users could move between current and past exposure over time. Current NIAD use was further stratified by the exposure status to incretin-based therapy and other nonincretin NIADs. Incretin use was further stratified by current GLP-1RA use and DPP-4 inhibitor use. Current, recent and past incretin use were defined as GLP-1RA/ DPP-4 inhibitor use 0 to 90, 91 to 180 and >180 days prior to start of an interval, respectively. Patients could move between current, recent and past use. To evaluate the effect of cumulative exposure to incretin-based therapy, a duration of incretin use analysis was 
performed. Current use was stratified by the number of incretin prescriptions ever before (in the UK, a single incretin prescription is generally issued every 28 days in case of chronic use). The following incretin-based therapy was recorded in the CPRD and included in this study: exenatide and liraglutide (GLP-1RAs) and sitagliptin, vildagliptin, saxagliptin and linagliptin (DPP-4 inhibitors).

Any, acute and chronic pancreatitis were classified by the use of read codes that were reviewed by a gastroenterologist (Y.K.). The group "any pancreatitis" included read codes for acute and chronic pancreatitis, as well as read codes for pancreatitis not otherwise specified. For the outcome "any pancreatitis," all patients with a history of pancreatitis, either acute or chronic, were excluded. For acute pancreatitis, all patients with a history of acute pancreatitis were excluded, and for chronic pancreatitis, all patients with a history of chronic pancreatitis were excluded (Figure 6.1). For all studied outcomes, patients with polycystic ovaries or polycystic ovarian syndrome prior to start of follow-up were excluded because metformin may be used as a treatment for these conditions (Figure 6.1).

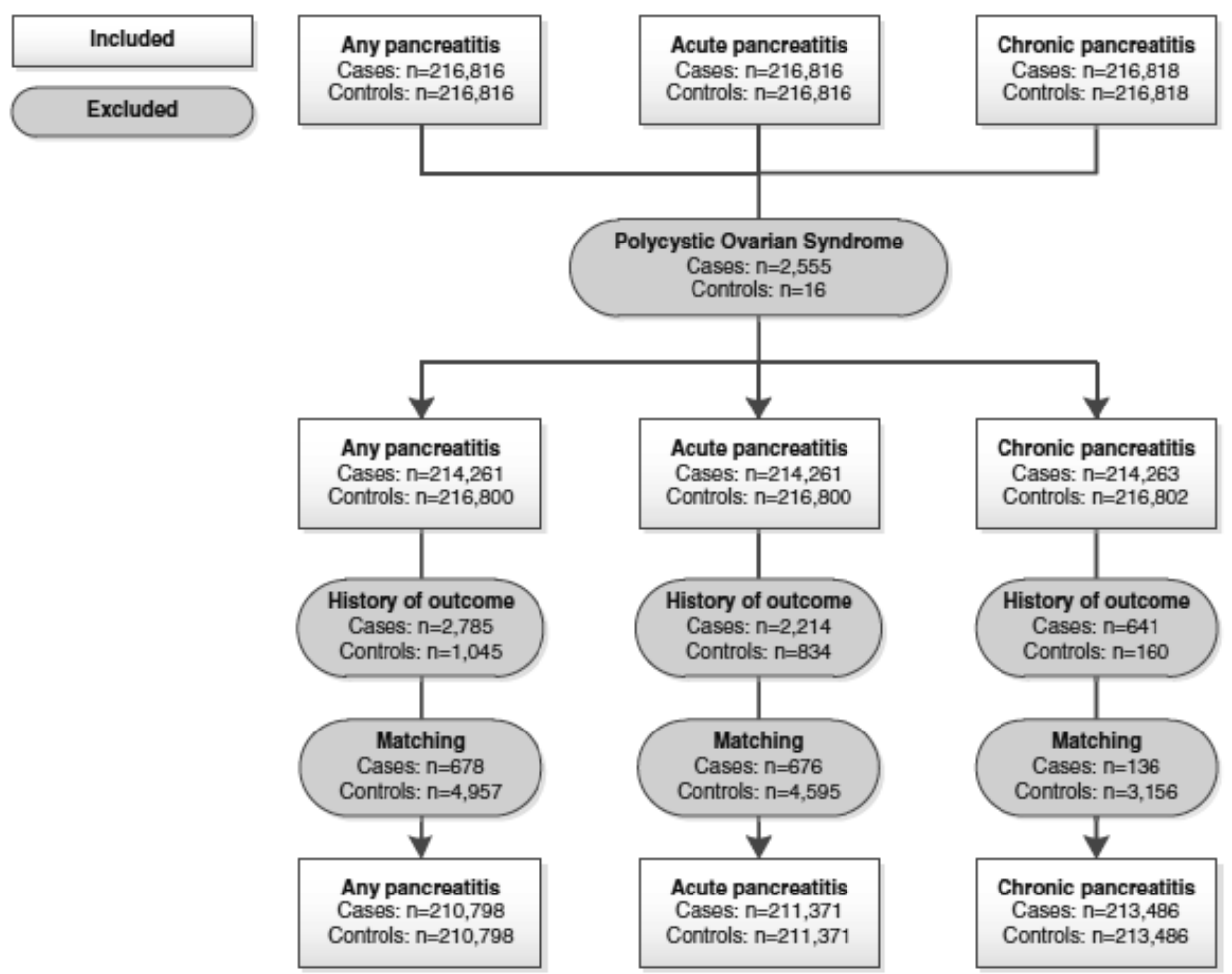

Figure 6.1 Study flow chart, stratified by study outcome. 
The presence of potential confounders was assessed by reviewing the computerized medical records for any evidence of these risk factors before the start of an interval. The following potential confounders were considered to be general risk factors and were determined at baseline: sex, body mass index (BMI), smoking status and alcohol use. Other confounders considered in the present study were determined time-dependently (i.e. at the start of each new interval): age, gallstones/endoscopic retrograde cholangiopancreatography procedure or alcoholism. ${ }^{25-28}$ Alcoholism was defined as history of specific drugs used to treat alcoholism or a diagnosis of alcoholism. In addition, the following drug prescriptions 6 months prior to the start of an interval were considered to be potential confounders: paracetamol; antibiotics (co-trimoxazole / macrolides / tetracyclines); angiotensin-converting enzyme (ACE) inhibitors; loop diuretics; statins; proton pump inhibitors; and systemic glucocorticoids. ${ }^{29-31}$ The following potential confounders for disease severity were considered time-dependently: a history of retinopathy; neuropathy; and the most recent glycated haemoglobin (HbA1c) value in the year preceding the start of an interval. ${ }^{30-32}$

We estimated the adjusted hazard ratio (HR) of any, acute and chronic pancreatitis among current NIAD users vs controls and among current incretin users vs other NIAD users using time-varying Cox proportional hazards regression (SAS 9.2, PHREG procedure). Potential confounders and indicators of disease severity were included in the final model if they independently changed the $\beta$ coefficient for the exposure of interest by at least $5 \%$, or when a consensus about inclusion existed within the team of researchers, supported by clinical evidence from the literature. A sensitivity analysis repeated the main analysis in a "new-user" design, in which only patients who had started NIADs after June 13, 2007 were included. ${ }^{33}$ To be more detailed, we excluded every patient with a NIAD prescription before June 13, 2007, therefore, patients were only included in the new user design if their record was available in the database for $\geq 1$ year and patients who were not receiving any NIADs in the period from 1987 to June 13,2007 . An additional sensitivity analysis was performed to exclude all controls with an $\mathrm{HbA} 1 \mathrm{c}$ measurement $>7 \%$ at baseline, because the $\mathrm{HbA} 1 \mathrm{c}$ level might indicate that these controls are actually T2DM patients. Furthermore, an extra sensitivity analysis was performed to compare current incretin use with current thiazolidinedione (TZD) use because TZD users might also be an appropriate comparison group. We also performed an extra sensitivity analysis to investigate the association between current incretin use and chronic pancreatitis when all patients with a history of both acute and chronic pancreatitis were excluded.

This study protocol was approved by the Independent Scientific Advisory Committee for Medicines and Healthcare Products Regulatory Agency database research by protocol number 14_036R5. 


\section{Results}

\section{Study population}

The study population for any pancreatitis consisted of 28,370 incretin users and 182,428 NIAD users, who were matched with 210,798 controls without diabetes (Figure 6.1). For acute pancreatitis we included 211,371 controls without diabetes and for chronic pancreatitis 213,486 controls (Figure 6.1). The mean duration of follow-up was 4.1 years for incretin users, 3.3 years for other NIAD users and 3.3 years for controls without diabetes. The mean duration of actual incretin use was 1.2 years. Among incretin users, $43.7 \%$ of all patients were women, and the mean age at index was 58.1 years. At baseline, the average age of incretin users was 4 years younger than users of other NIADs, and incretin users had a higher body mass index (BMI). The severity of the underlying diabetes mellitus was higher among incretin users compared with other NIAD users, as their most recently recorded mean $\mathrm{HbA} 1 \mathrm{c}$ measurement in the past 12 months was $8.7 \%$ higher. Besides exposure to ACE inhibitors, statins or various antidiabetic drug classes, there were no remarkable differences in history of comorbidities with incretin users vs other NIAD users at baseline (Table 6.1).

\section{Incretin use and risk of pancreatitis compared with controls}

Table 6.2 shows that as compared with control subjects without diabetes, current incretin users had a doubled risk of any pancreatitis (adjusted HR 2.01, 95\% Cl 1.42-2.83). The risk of developing acute pancreatitis was increased 1.6-fold (adjusted HR $1.60,95 \% \mathrm{Cl} 1.09-2.35)$, while the risk of developing chronic pancreatitis was increased almost 6-fold (adjusted HR 5.82, 95\% Cl 2.77-12.23). DPP-4 inhibitor users had a higher risk of any pancreatitis than GLP-1RA users (adjusted $\mathrm{HR} 2.21,95 \% \mathrm{Cl} 1.53-3.20$ vs adjusted HR 1.23, 95\% $\mathrm{Cl}$ 0.62-2.43). Furthermore, we observed a 4.6-fold increased risk of any pancreatitis in the youngest age group (18-59 years). The elevated risks were partly explained by the underlying disease: patients with T2DM had a 1.4-fold increased risk of any pancreatitis as compared with controls without diabetes (adjusted HR 1.41, 95\% Cl 1.18-1.68). 


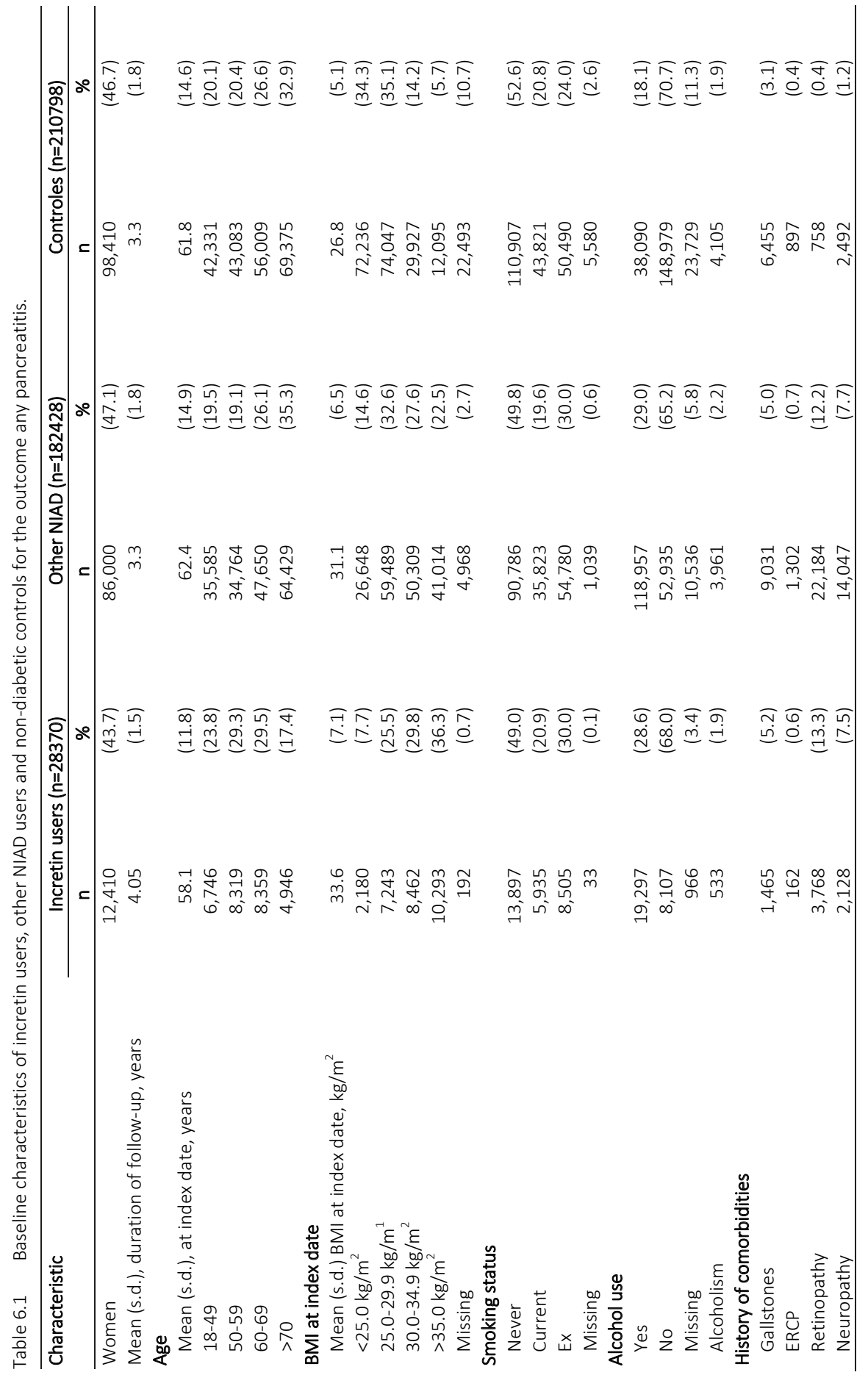




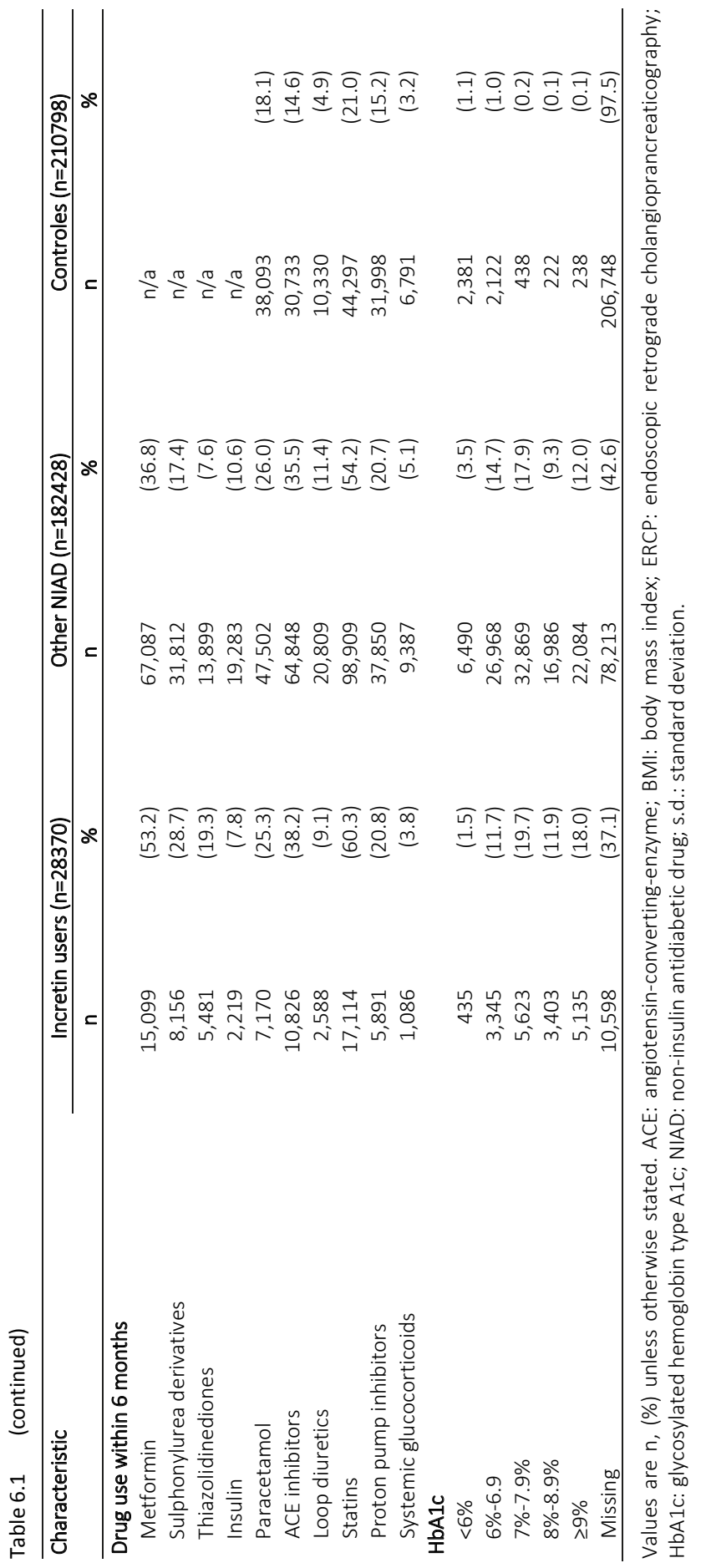




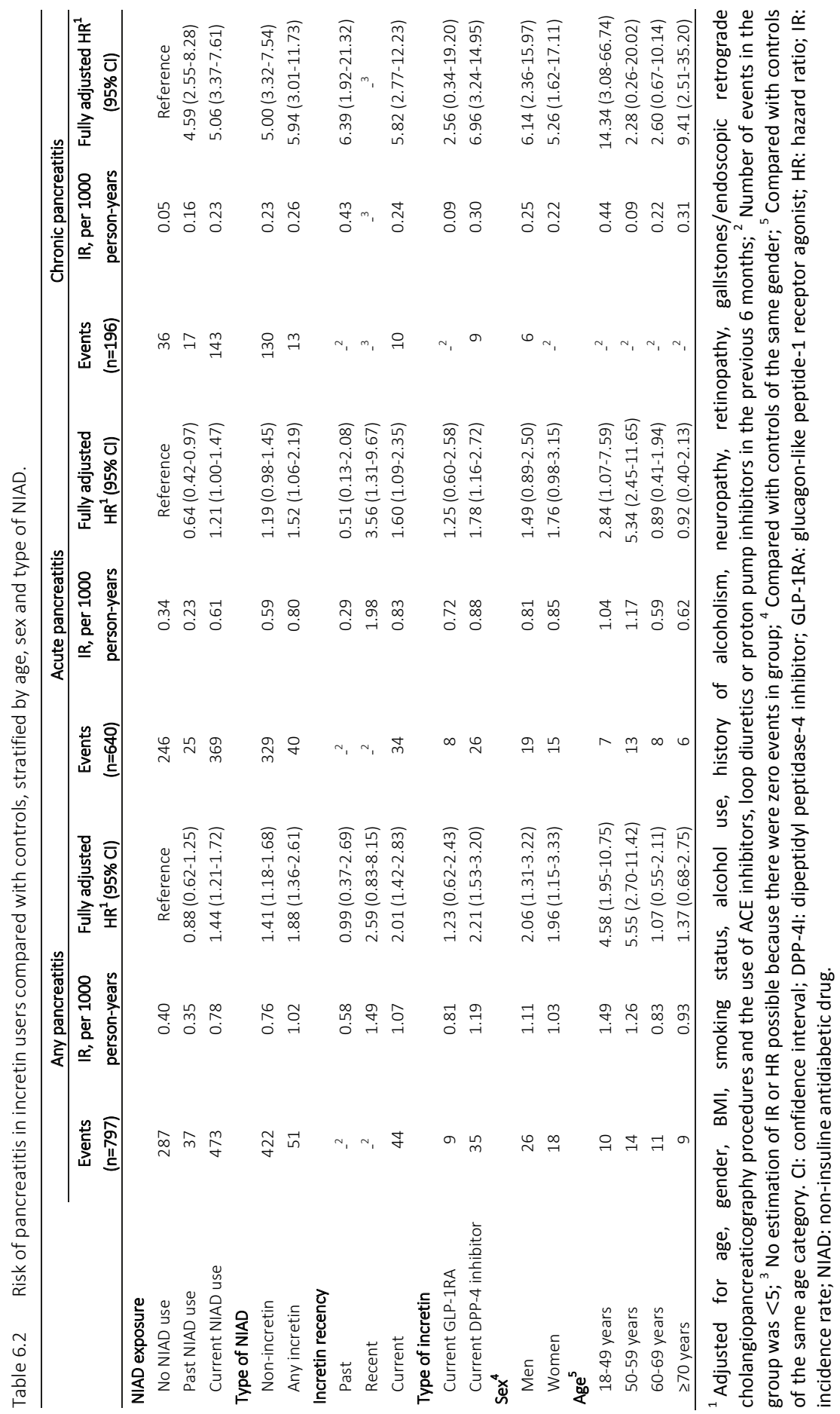




\section{Incretin use and risk of pancreatitis compared with other NIAD use}

To reduce confounding by indication, incretin users were compared with users of other NIADs (Table 6.3). Results showed a statistically significant 1.5-fold increased risk of any pancreatitis among current incretin users ( $H R$ 1.47, $95 \% \mathrm{Cl} 1.06-2.04)$, while no statistically significant association was found for the acute and chronic pancreatitis group ( $\mathrm{HR} 1.42,95 \% \mathrm{Cl} 0.98-2.06$ and $\mathrm{HR} \mathrm{0.87,95 \%} \mathrm{Cl} 0.45-1.69$, respectively). The statistical adjustment for proxy indicators of disease severity and general risk factors did not substantially change the associations (Table S6.2). Similar to the results in Table 6.2, the risk of pancreatitis was higher among younger patients (age 18-59 years), those with a $\mathrm{BMI}<25 \mathrm{~kg} / \mathrm{m} 2$, or DPP-4 inhibitor users compared with other NIAD users. No trend was observed in the duration-of-use analysis regarding the risk of pancreatitis.

\section{Sensitivity analysis}

Table 6.4 shows a sensitivity analysis with a new-user design, in which the cohort was restricted to starters of NIADs (including patients using incretin-based therapy). A statistically significant 2-fold risk of any pancreatitis was found in current incretin users vs other NIAD users (adjusted HR 2.12, 95\% Cl 1.31-3.43). This was mainly explained by the risk of acute pancreatitis (adjusted HR 1.96, 95\% Cl 1.13-3.41). The risk of acute and any pancreatitis was highest in patients who had been prescribed up to 150 to 270 days of incretin-based therapy (5-9 prescriptions), whereas there was no significant elevated risk with short ( $<5$ prescriptions) and long-term use ( $\geq 10$ prescriptions). In the extra sensitivity analysis in which controls with an $\mathrm{HbA} 1 \mathrm{c}>7 \%$ at baseline were excluded, we found that current incretin use was still associated with any pancreatitis (adjusted HR 2.01, 95\% Cl 1.42-2.83). In the extra sensitivity analysis in which TZD users were used as a comparison group for the incretin users, we found that current incretin use was still associated with any pancreatitis (adjusted HR 1.59, 95\% Cl 1.05-2.41). In the sensitivity analysis in which all patients with a history of both acute and chronic pancreatitis were excluded, we found that current incretin use was still associated with chronic pancreatitis (adjusted HR 4.73, 95\% Cl 2.97-7.54). 


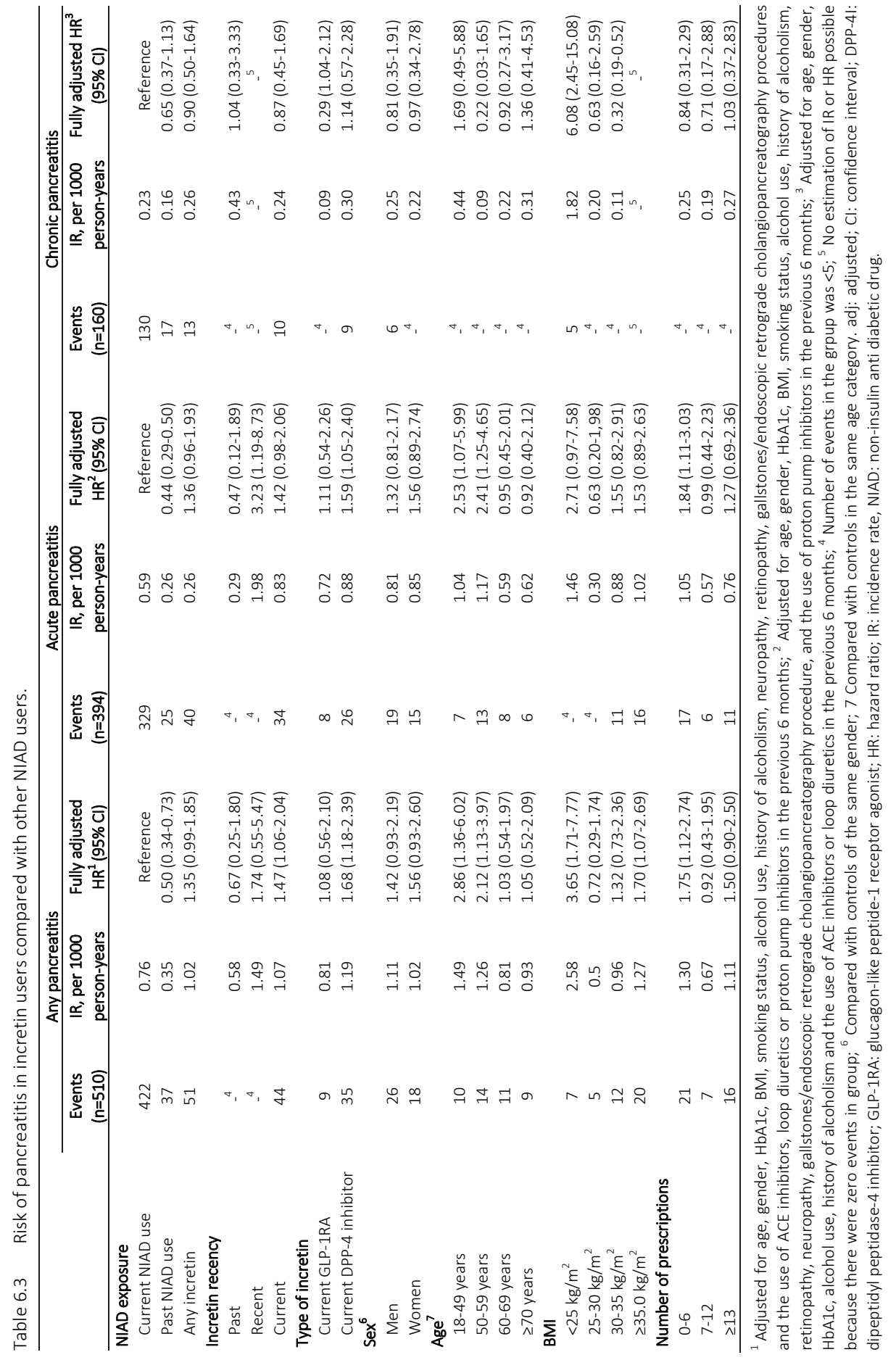




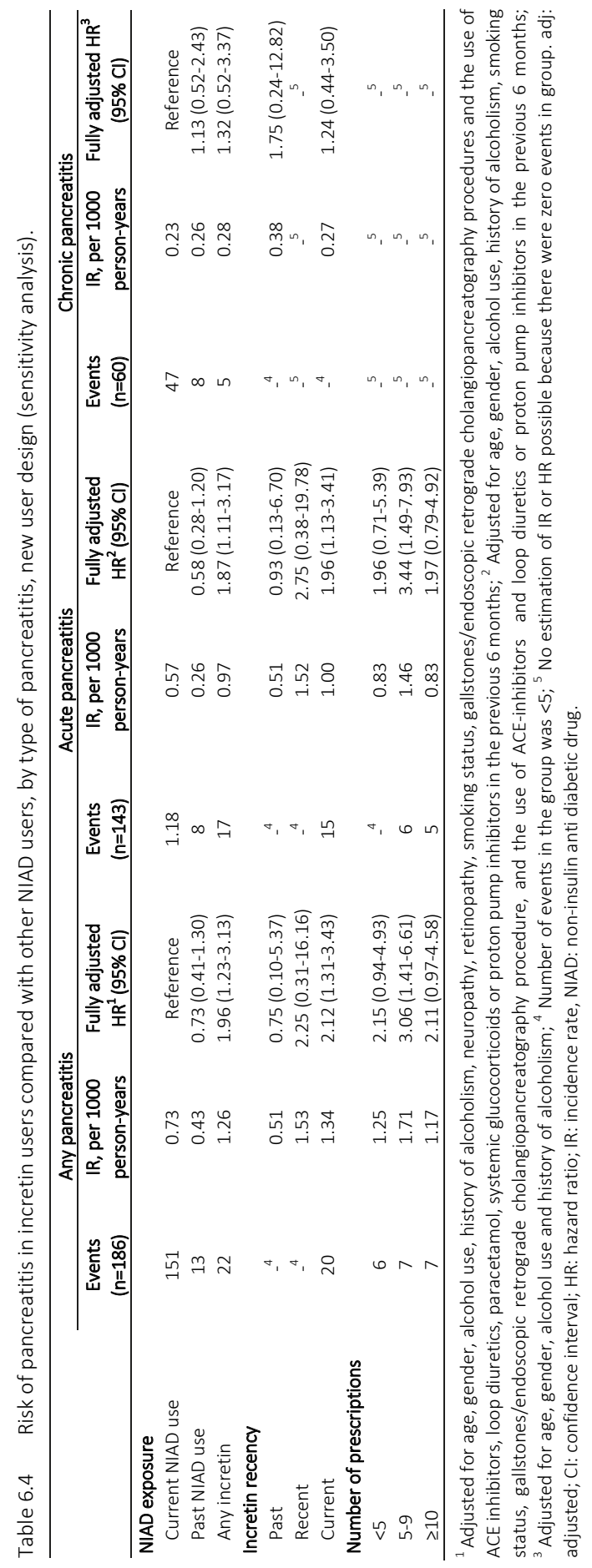




\section{Discussion}

The present study found a 1.5-fold statistically significant increased risk of any pancreatitis with current use of incretin-based therapy vs. other NIAD use. The risk of acute pancreatitis was 1.4-fold greater in current incretin users vs. other NIAD users, but this did not reach statistical significance. Furthermore, we were not able to detect an association between chronic pancreatitis and incretin use, but numbers in this subgroup were small. Interestingly, the increased risk of acute pancreatitis remained statistically significant in current users of DPP-4 inhibitors only, suggesting that differences in the pharmacodynamics properties of these agents are important for the incretinpancreatitis link.

The present results are not consistent with the results of the studies by Elashoff et al. ${ }^{3}$, Singh et al. ${ }^{12}$ and Roshanov and Dennis ${ }^{34}$ regarding the risk of acute pancreatitis with incretin use. In a case-control study, Singh et al. found that current use of sitagliptin or exenatide 30 days before the study outcome vs non-use was significantly associated with hospitalization for acute pancreatitis (odds ratio $2.24,95 \% \mathrm{Cl} 1.36-3.68$ ). ${ }^{12}$ Elashoff et al. showed that pancreatitis was significantly more often reported among patients treated with sitagliptin or exenatide as compared with users of other antidiabetic therapies; however, that study only provided hypothesis-generating evidence as it was based on data from the US Food and Drug Administration's spontaneous adverse event reporting system. ${ }^{3}$ The meta-analysis of large randomized clinical trials by Roshanov and Dennis found an $82 \%$ increase in the odds ratio of acute pancreatitis with the use of incretinbased therapy as compared with usual care $(95 \% \mathrm{Cl} 1.17-2.82){ }^{34}$

Several previous studies have shown results consistent with the present findings regarding the risk of acute pancreatitis with incretin use, identifying no statistically significant increased risk of acute pancreatitis for incretin use. ${ }^{13-15}$ A meta-analysis of 6 cohort and 2 case-control studies found no effect on the occurrence of acute pancreatitis (odds ratio $1.03,95 \% \mathrm{Cl} 0.87-1.20) .{ }^{13}$ That meta-analysis included a previous CPRD cohort study by Faillie et al., finding no effect on acute pancreatitis occurrence. ${ }^{15}$ Furthermore, a large cohort study ( $n=1,532,513$, mean follow-up 2.3 years) which included data from the CPRD did not find an association between current use of incretinbased drugs and acute pancreatitis. ${ }^{35}$ A large systematic review and meta-analysis of randomized and non-randomized studies did not suggest an increased risk of acute pancreatitis with the use of incretin-based therapy. ${ }^{14}$ In both the SAVOR ( $n=16492$, median follow-up 2.1 years) and EXAMINE ( $n=5380$, median follow-up 18 months) cardiovascular outcome trials the cases of acute and chronic pancreatitis were similar in the saxagliptin and alogliptin arms as compared with the comparator agent arm. ${ }^{36,37}$ The results of observational studies regarding the risk of pancreatitis remain conflicting. We 
therefore advise regulatory agencies to consider using observational studies to learn about the methodological factors that influence the aetiology of pancreatitis risk in people with T2DM using incretin-based therapy, rather than confirming whether an association is truly present. $^{38}$

The evidence regarding chronic pancreatitis is scarce and mainly based on in vitro and animal studies. ${ }^{39-41}$ Other studies that did find cases of chronic pancreatitis in users of incretin-based therapy were most often post-marketing reports or reports in patients with T2DM aged $\geq 40$ years with a history of a cardiovascular disease. ${ }^{42}$ We are the first to report on the risk of chronic pancreatitis in an observational setting, finding no indication that patients with T2DM using incretin-based therapy were more prone to develop chronic pancreatitis. The results should be interpreted with caution, because the number of cases was small and follow-up time might have been too short; most acute pancreatitis events in randomized controlled trials occurred between 6 and 24 months after treatment initiation. ${ }^{10}$ Furthermore, we were not able to confirm data from the literature showing a higher risk of chronic pancreatitis among men. ${ }^{9}$ It is important to note that chronic pancreatitis is a serious disease, causing significant morbidity and mortality. Two to three decades after diagnosis of chronic pancreatitis, there is a mortality rate of $50 \%$, and thus such patients have shorter survival times than the average population. ${ }^{8}$ We have only started to learn about the association between incretin use and chronic pancreatitis, and hope future studies will investigate this in more detail.

In contrast to the study by Li et al., but consistent with the study by Roshanov and Dennis, we found that DPP-4 inhibitor users had a higher risk of any pancreatitis compared with GLP-1RA users. ${ }^{14,34}$ There are key pharmacological differences between DPP-4 inhibitors and GLP-1RAs, such as the effect on $\mathrm{HbA} 1 \mathrm{c}$ reduction $(-0.6 \%$ to $-1.9 \%$ for GLP-1RAs vs. $-0.5 \%$ to $-0.8 \%$ for DPP-4 inhibitors) and body weight (reduced for GLP1RA but neutral for DPP-4 inhibitors). ${ }^{43}$ Clinical data suggest that GLP-1RAs improve $\beta$-cell function, whereas the effects of DPP-4 inhibitors are less clear. ${ }^{43}$ The different effects on $\beta$-cell function might contribute to the difference in risk of pancreatitis, but this is very speculative and more studies are needed to investigate this further.

The potential biological mechanisms of incretin agents promoting or enhancing pancreatitis are supported by limited indirect evidence. In animal models, three GLP-1induced pathways have been proposed; proliferation in b-cells, inhibition of b-cells, and enhanced differentiation of adult stem cells in the ductal pancreatic epithelium. This could lead to chronic pancreatic damage, inflammation of pancreatic acinar and ductal cells, increased formation of dysplastic pancreatic intraepithelial neoplasia (PanIN) lesions and an increase in pancreatic weight. ${ }^{3,5-7,12,15,19,20,44,45}$ Furthermore, duct cell proliferation and PanIN lesions might lead to duct occlusion, which could cause back 
pressure in the pancreas, stressing the acinar cells to release digestive enzymes with the resulting chronic pancreatitis fostering further development of PanINs and duct cell proliferation. ${ }^{7,41}$ By activating both above-mentioned pathways, incretin agents could promote acute pancreatitis and chronic pancreatitis. ${ }^{7,41}$ Additionally, it was hypothesized that an incretin-based therapy-induced pancreatitis would mostly occur soon after initiating treatment with these agents ( $<5$ prescriptions); however, based on the duration-of-use analysis it is also possible that a delayed onset of pancreatitis is induced by incretin-based therapy through underlying (cumulative) pathophysiological mechanisms, such as duct cell proliferation leading to inflammation. In the duration-ofuse analysis of the prevalent cohort, pancreatitis risk was highest in patients who had been prescribed $<7$ prescriptions, while in the incident analysis pancreatitis risk was highest in patients who had been prescribed up to 5 to 9 months of incretin-based therapy. ${ }^{46}$ The information provided from the duration-of-use analysis should be interpreted with caution because of the small number of events.

It is important to note several limitations of this observational study. True causality cannot be provided. Furthermore, it is likely that our observed associations are not without residual confounding and there might also be residual confounding as a result of adjustment for imperfect variables, such as the missing variables. Residual confounding might also be present because incretin-based therapy is less likely to be prescribed to patients with T2DM who consume alcohol, smoke or have a lower socio-economic status. This could have led to an underestimation in the results; however, it can also be proposed that incretin-based therapy is more likely to be prescribed to alcoholics with T2DM. It is known that alcoholics are more likely to experience hypoglycaemia, causing physicians to be more likely, in turn, to prescribe incretin agents rather than sulphonylurea derivatives. This could have led to overestimation in the results. Moreover, we were not able to correct for the amount of physical exercise. Hypertriglyceridemia, which is indirectly related to a lack of physical exercise, appears to increase the risk of pancreatitis, especially among overweight people. ${ }^{47}$ Incretin users might be less physically active than non-incretin users, which could lead to an overestimation of our effect. Also, incretin-based therapy may be prescribed earlier to people with a higher BMI because of the promotion of weight loss and to people with a history of a cardiovascular disease because of the cardiovascular benefits of such therapy. ${ }^{2}$ Furthermore, diagnostic bias may have influenced the results. As a result of early warnings of the possible side effects of incretin-based therapy by regulatory agencies, diabetes specialists are likely to have been vigilant for the occurrence of pancreatitis when first prescribing incretin-based therapy. This could have led to overestimation in the results. Lastly, the read codes used in this study for acute, chronic and any pancreatitis have not been validated, therefore, there might be some 
misclassification. We expect the misclassification to be non-differential, resulting in an underestimation of the relationship between incretin-based therapy and pancreatitis, which might have led to restricted statistical power.

The present study also has a number of strengths. We were able to adjust statistically for several potentially important confounders, including age, $\mathrm{HbA} 1 \mathrm{c}$, alcoholism and drug use. Also, we were able to show the effect of confounding by indication on the risk of pancreatitis. Furthermore, CPRD data are collected prospectively, eliminating the risk of recall bias. In addition, this study gives the first insights into the risk of chronic pancreatitis in users of incretin-based therapy.

In conclusion, in this first study to report on all types of pancreatitis, it was found that incretin use was associated with an increased risk of any type of pancreatitis, but not with acute or chronic pancreatitis in patients with T2DM; however, the risk of any and acute pancreatitis was higher among users of DPP-4 inhibitors and incident incretin users. Observational studies that assessed the risk of pancreatitis in incretin-based therapy had conflicting results. The complex relationship, methodological challenges and relatively small numbers of exposed patients in published research suggest that we should probably learn more about the methodological factors that influence the aetiology of incretin-induced pancreatitis, rather than to confirm whether an association is truly present. ${ }^{38}$ 


\section{References}

1. Drucker DJ, Sherman SI, Gorelick FS, Bergenstal RM, Sherwin RS, Buse JB. Incretin-based therapies for the treatment of type 2 diabetes: evaluation of the risks and benefits. Diabetes Care. 2010;33(2): 428-433.

2. Butler PC, Elashoff M, Elashoff R, Gale EA. A critical analysis of the clinical use of incretin-based therapies: are the GLP-1 therapies safe? Diabetes Care. 2013;36(7):2118-2125.

3. Elashoff M, Matveyenko AV, Gier B, Elashoff R, Butler PC. Pancreatitis, pancreatic, and thyroid cancer with glucagon-like peptide-1-based therapies. Gastroenterology. 2011;141(1):150-156.

4. Drucker DJ, Nauck MA. The incretin system: glucagon-like peptide-1 receptor agonists and dipeptidyl peptidase-4 inhibitors in type 2 diabetes. Lancet. 2006;368(9548):1696-1705.

5. Thomsen RW, Pedersen L, Moller N, Kahlert J, Beck-Nielsen H, Sorensen HT. Incretin-based therapy and risk of acute pancreatitis: a nationwide population-based case-control study. Diabetes Care. 2015;38(6):1089-1098.

6. Butler AE, Campbell-Thompson M, Gurlo T, Dawson DW, Atkinson M, Butler PC. Marked expansion of exocrine and endocrine pancreas with incretin therapy in humans with increased exocrine pancreas dysplasia and the potential for glucagon-producing neuroendocrine tumors. Diabetes. 2013;62(7): 2595-2604.

7. Ryder RE. The potential risks of pancreatitis and pancreatic cancer with GLP-1-based therapies are far outweighed by the proven and potential (cardiovascular) benefits. Diabet Med. 2013;30(10):1148-1155.

8. Yadav D, Lowenfels AB. The epidemiology of pancreatitis and pancreatic cancer. Gastroenterology. 2013;144(6):1252-1261.

9. Sankaran SJ, Xiao AY, Wu LM, Windsor JA, Forsmark CE, Petrov MS. Frequency of progression from acute to chronic pancreatitis and risk factors: a meta-analysis. Gastroenterology. 2015;149(6):1490-1500, e1491..

10. Azoulay L. Incretin-based drugs and adverse pancreatic events: almost a decade later and uncertainty remains. Diabetes Care. 2015;38(6):951-953.

11. Raschi E, Piccinni C, Poluzzi E, Marchesini G, De Ponti F. The association of pancreatitis with antidiabetic drug use: gaining insight through the FDA pharmacovigilance database. Acta Diabetol. 2013;50(4): 569-577.

12. Singh S, Chang HY, Richards TM, Weiner JP, Clark JM, Segal JB. Glucagonlike peptide 1-based therapies and risk of hospitalization for acute pancreatitis in type 2 diabetes mellitus: a populationbased matched case-control study. JAMA Intern Med. 2013;173(7):534-539.

13. Wang T, Wang F, Gou Z, et al. Using real-world data to evaluate the association of incretin-based therapies with risk of acute pancreatitis: a meta-analysis of 1,324,515 patients from observational studies. Diabetes Obes Metab. 2015;17(1):32-41.

14. Li L, Shen J, Bala MM, et al. Incretin treatment and risk of pancreatitis in patients with type 2 diabetes mellitus: systematic review and meta-analysis of randomised and non-randomised studies. BMJ. 2014;348:g2366.

15. Faillie JL, Azoulay L, Patenaude V, Hillaire-Buys D, Suissa S. Incretin based drugs and risk of acute pancreatitis in patients with type 2 diabetes: cohort study. BMJ. 2014;348:g2780.

16. Suarez EA, Koro CE, Christian JB, Spector AD, Araujo AB, Abraham S. Incretin-mimetic therapies and pancreatic disease: a review of observational data. Curr Med Res Opin. 2014;30(12):2471-2481.

17. Pappachan JM. Incretin-based therapies and pancreatitis risk: myth or reality. Endocrine. 2015;48(2):360-362.

18. Egan AG, Blind E, Dunder $K$, et al. Pancreatic safety of incretin-based drugs-FDA and EMA assessment. N Engl J Med. 2014;370(9):794-797.

19. Cohen D. European drugs agency clashes with scientists over safety of GLP-1 drugs. BMJ. 2013;347:f4838.

20. Cohen D. FDA is to assess data linking type 2 diabetes drugs with pancreatitis. BMJ. 2013;346:f1808.

21. Herrett E, Gallagher AM, Bhaskaran K, et al. Data resource profile: Clinical Practice Research Datalink (CPRD). Int J Epidemiol. 2015;44(3):827-836. 
22. Hazra N, Gulliford M. Evaluating pancreatitis in primary care: a population-based cohort study. Br J Gen Pract. 2014;64(622):e295- e301.

23. Brodovicz KG, Kou TD, Alexander CM, et al. Impact of diabetes duration and chronic pancreatitis on the association between type 2 diabetes and pancreatic cancer risk. Diabetes Obes Metab. 2012;14(12):1123-1128.

24. Knapen LM, van Dalem J, Keulemans YC, et al. Use of incretin agents and risk of pancreatic cancer: a population-based cohort study. DiabetesObes Metab. 2016;18(3):258-265.

25. Nogueira L, Freedman ND, Engels EA, Warren JL, Castro F, Koshiol J. Gallstones, cholecystectomy, and risk of digestive system cancers. Am J Epidemiol. 2014;179(6):731-739.

26. Patai A, Patai AV, Solymosi N, Tulassay Z, Herszenyi L. Prevention of acute pancreatitis following endoscopic retrograde cholangiopancreatography. Orv Hetil. 2015;156(18):715-719.

27. Zhang J, Dhakal I, Ning B, Kesteloot H. Patterns and trends of pancreatic cancer mortality rates in Arkansas, 1969-2002: a comparison with the US population. Eur J Cancer Prev. 2008;17(1):18-27.

28. Herreros-Villanueva M, Hijona E, Banales JM, Cosme A, Bujanda L. Alcohol consumption on pancreatic diseases. World J Gastroenterol. 2013;19(5):638-647.

29. Kaurich T. Drug-induced acute pancreatitis. Proc (Bayl Univ Med Cent). 2008;21(1):77-81.

30. Trivedi CD, Pitchumoni CS. Drug-induced pancreatitis: an update. J Clin Gastroenterol. 2005;39(8): 709-716.

31. Vinklerova I, Prochazka M, Prochazka V, Urbanek K. Incidence, severity, and etiology of drug-induced acute pancreatitis. Dig Dis Sci. 2010;55(10):2977-2981.

32. Urbánek K, Vinklerová I, Krystyník O, Procházka V. Acute pancreatitis induced by drugs. In: Rodrigo L, ed. Acute Pancreatitis. Rijeka, Croatia: InTech; 2011:chap 2: 17-34. ISBN 978-953-307-984-4.

33. Ray WA. Evaluating medication effects outside of clinical trials: newuser designs. Am J Epidemiol. 2003;158(9):915-920.

34. Roshanov PS, Dennis BB. Incretin-based therapies are associated with acute pancreatitis: meta-analysis of large randomized controlled trials. Diabetes Res Clin Pract. 2015;110(3):e13-e17.

35. Azoulay L, Filion KB, Platt RW, et al. Association between incretinbased drugs and the risk of acute pancreatitis. JAMA Intern Med. 2016;176(10):1464-1473.

36. Scirica BM, Bhatt DL, Braunwald E, et al. Saxagliptin and cardiovascular outcomes in patients with type 2 diabetes mellitus. N Engl J Med. 2013;369:1317-1326.

37. White WB, Cannon CP, Heller SR, et al. Alogliptin after acute coronary syndrome in patients with type 2 diabetes. N Engl J Med. 2013;369:1327-1335.

38. Sheiner LB. Learning versus confirming in clinical drug development. Clin Pharmacol Ther. 1997;61(3):275-291.

39. Franks AS, Lee PH, George CM. Pancreatitis: a potential complication of liraglutide? Ann Pharmacother. 2012;46(11):1547-1553.

40. Anderson SL, Trujillo JM. Association of pancreatitis with glucagonlike peptide-1 agonist use. Ann Pharmacother. 2010;44(5):904-909.

41. Gier B, Matveyenko AV, Kirakossian D, Dawson D, Dry SM, Butler PC. Chronic GLP-1 receptor activation by exendin-4 induces expansion of pancreatic duct glands in rats and accelerates formation of dysplastic lesions and chronic pancreatitis in the Kras(G12D) mouse model. Diabetes. 2012;61(5):1250-1262.

42. Raz I, Bhatt DL, Hirshberg B, et al. Incidence of pancreatitis and pancreatic cancer in a randomized controlled multicenter trial (SAVORTIMI 53) of the dipeptidyl peptidase-4 inhibitor saxagliptin. Diabetes Care. 2014;37(9):2435-2441.

43. Davidson JA. Incorporating incretin-based therapies into clinical practice: differences between glucagonlike Peptide 1 receptor agonists and dipeptidyl peptidase 4 inhibitors. Mayo Clin Proc. 2010;85- (12 Suppl):S27-S37.

44. Yu X, Tang H, Huang L, Yang Y, Tian B, Yu C. Exenatide-induced chronic damage of pancreatic tissue in rats. Pancreas. 2012;41(8):1235-1240.

45. Farilla L, Hui H, Bertolotto C, et al. Glucagon-like peptide-1 promotes islet cell growth and inhibits apoptosis in Zucker diabetic rats. Endocrinology. 2002;143(11):4397-4408.

46. Badalov N, Baradarian R, Iswara K, Li J, Steinberg W, Tenner S. Druginduced acute pancreatitis: an evidence-based review. Clin Gastroenterol Hepatol. 2007;5(6):648-661; quiz 644. 
Chapter 6

47. Scherer J, Singh VP, Pitchumoni CS, Yadav D. Issues in hypertriglyceridemic pancreatitis: an update. J Clin Gastroenterol. 2014;48(3):195-203. 


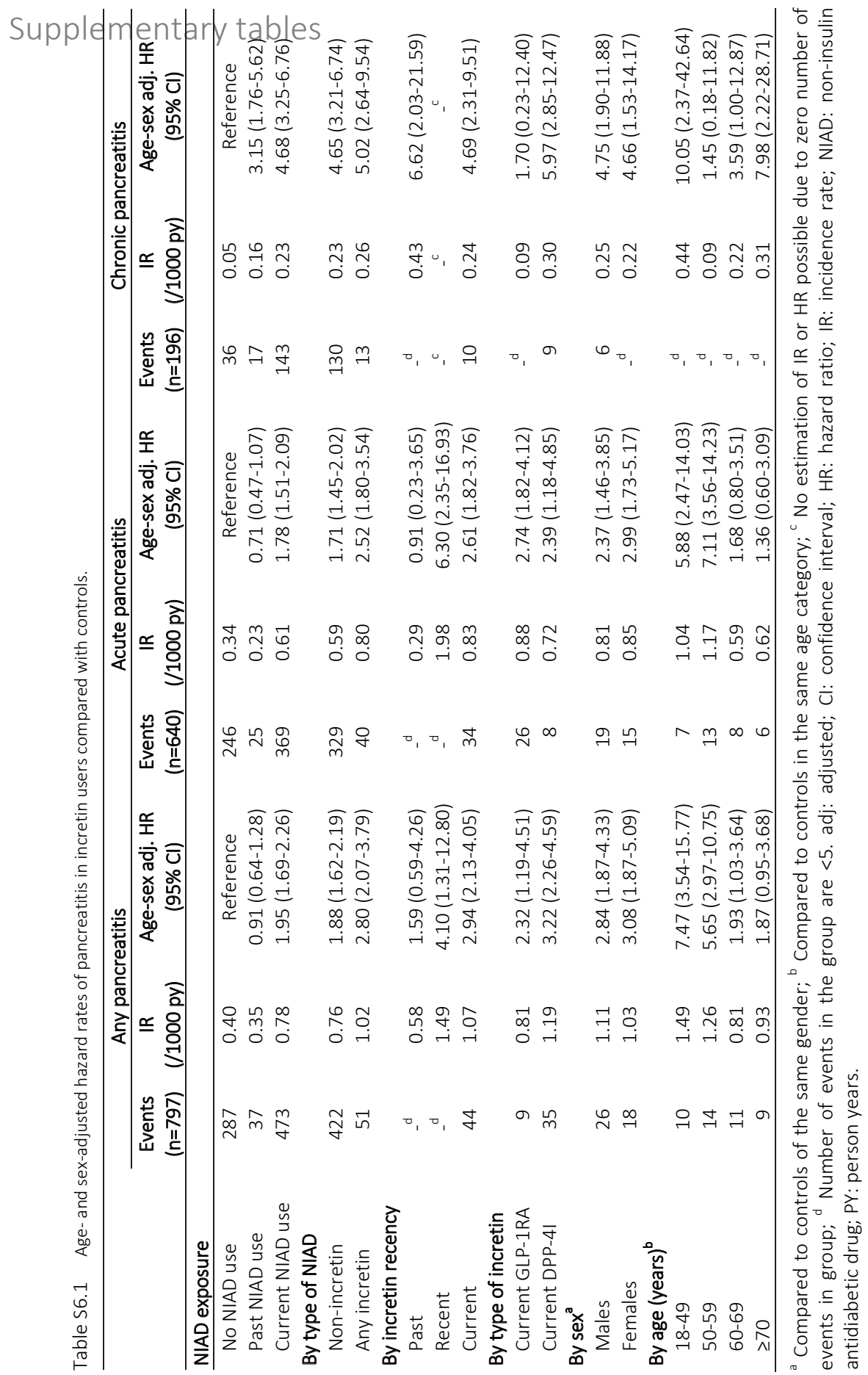




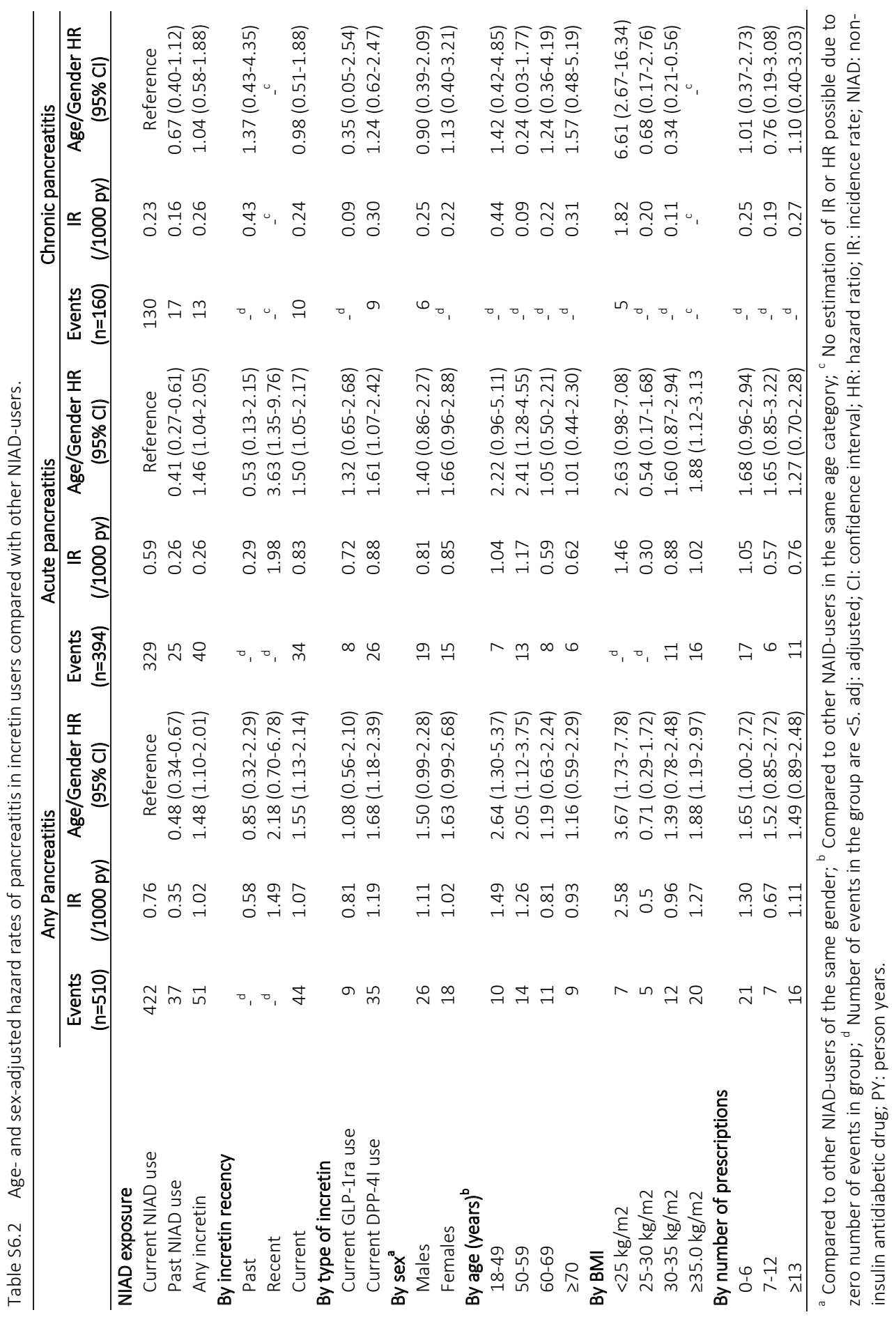




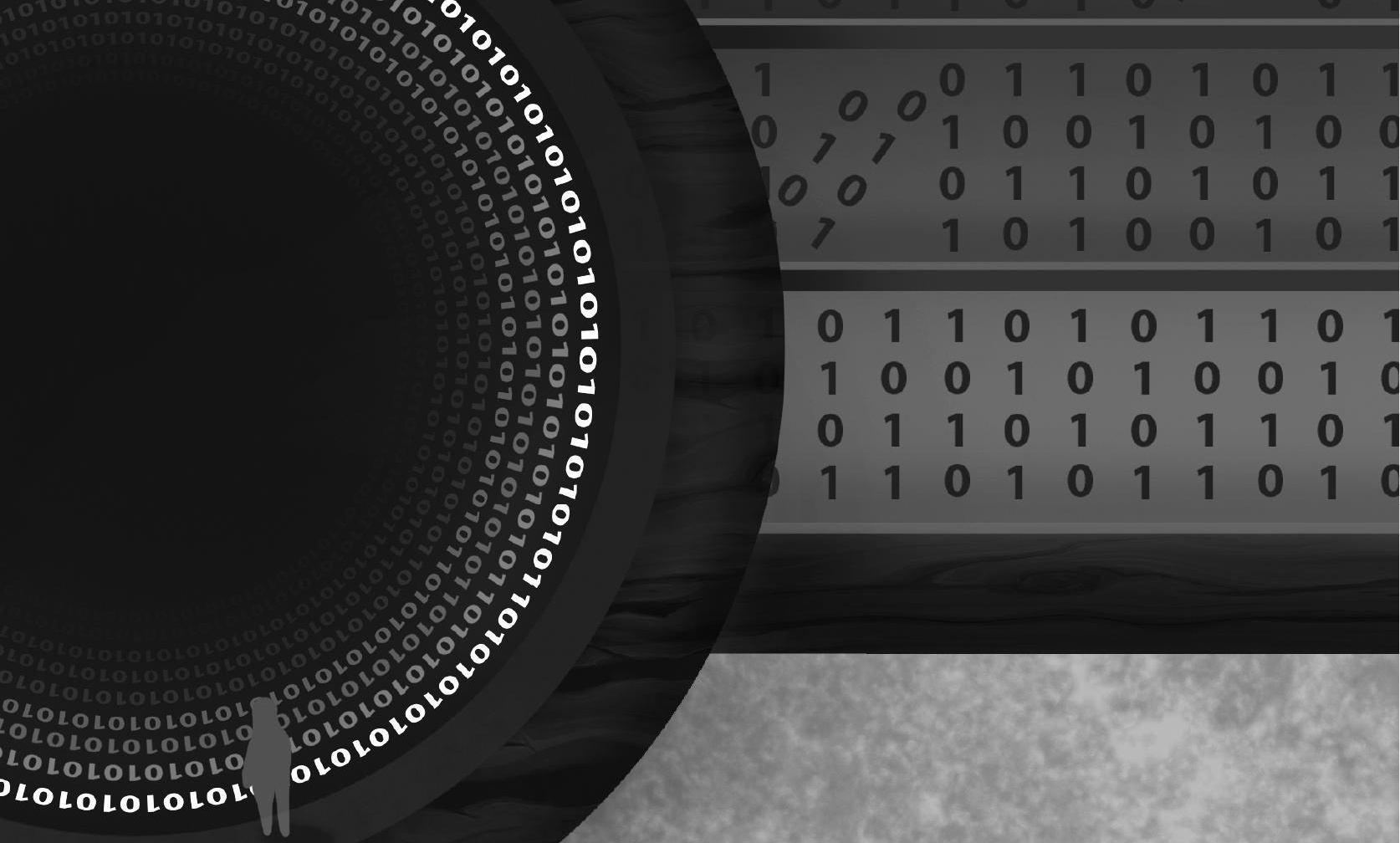

$\begin{array}{llllllllll}0 & 1 & 1 & 0 & 1 & 0 & 1 & 1 & 0 & 1\end{array}$

$\begin{array}{lllllllll}1 & 0 & 0 & 1 & 0 & 1 & 0 & 0 & 1\end{array}$

$\begin{array}{llllllllll}0 & 1 & 1 & 0 & 1 & 0 & 1 & 1 & 0 & 1\end{array}$

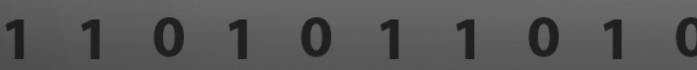

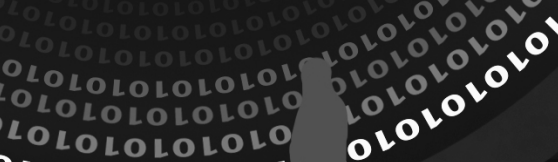
$010^{2}$ 


\section{Chapter}

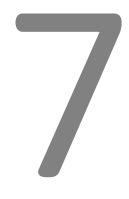

Letter to the Editor: Comments on "Use of metformin and risk of kidney cancer in patients with type 2 diabetes", Chin-Hsiao Tseng, Eur J Cancer $2016 ; 52: 19-25$

Roy G.P.J. de Jong, Johannes T.H. Nielen, Ad A.M. Masclee, Maryska L.G. Janssen-Heijnen, Frank de Vries European Journal of Cancer 2016;61:157-8 



\section{Dear Editor,}

We have read with great interest the article by Chin-Hsiao Tseng, Use of metformin and risk of kidney cancer in patients with type 2 diabetes, which appeared in the European Journal of Cancer issue of January 2016. ${ }^{1}$ We have noted, however, that the results of this study may have been affected by selection bias.

Using the Taiwanese National Health Insurance reimbursement database, Tseng performed a retrospective population-based cohort study of incident type 2 diabetic patients who either received metformin as the first antidiabetic drug (ever users of metformin) or other antidiabetic drugs as first treatment without receiving metformin during follow-up (never users of metformin). To estimate the risk of kidney cancer, the author performed a Cox regression analysis and adjusted for imbalance between baseline characteristics by applying inverse probability treatment weighting of the estimated propensity scores (PSs). Subsequently, a hazard ratio (95\% confidence interval) of 0.279 (0.254-0.307) was estimated for the risk of kidney cancer in ever users of metformin compared to never users. Unfortunately, the PS approach incorporated in the statistical model cannot completely correct for any selection bias that may have occurred during the formation of the study population. For example, the history of any cancer excluding kidney cancer was 1.4-fold higher in never users of metformin (26.88\%) versus ever users of metformin (19.32\%).

Based on the methodology section of the paper and the results in Table 2, we believe a significant selection bias may have occurred during the allocation process of individuals to the treatment group of never users of metformin. Patients using other antidiabetic drugs before they start with metformin were excluded from the study population $(n=200,785)$. Therefore, possible follow-up time designated for the group of never users of metformin is wrongfully excluded from the analysis. This can also be seen in Table 2, where the amount of follow-up time in the never users of metformin is much shorter than that in the ever users of metformin (433,005.63 vs. 1,144,982.82 person-years). In addition, this selection bias might partly explain the significant baseline differences as seen in Table 1.

Within the scientific community, there is ongoing debate concerning the protective effect of metformin on cancer development in patients with type 2 diabetes mellitus, with studies showing conflicting results for various cancers. Earlier studies concluded metformin could decrease cancer risk but were afflicted by time-related biases, such as immortal time bias. More recent studies that used methods to avoid these biases reported no effect of metformin use on cancer incidence. ${ }^{2,3}$ Based on this, we are currently not convinced that metformin has a clinically relevant protective effect on cancer development. Costly trials based on methodologically inaccurate studies should 
also not be encouraged. Therefore, we kindly ask Dr. C.-H. Tseng to reanalyze the risk of kidney cancer in users of metformin compared to non-users of metformin without the currently potential selection bias. 


\section{References}

1. Tseng $\mathrm{CH}$. Use of metformin and risk of kidney cancer in patients with type 2 diabetes. Eur J Cancer 2016;52:19-25.

2. Suissa S, Azoulay L. Metformin and the risk of cancer: time-related biases in observational studies. Diabetes Care 2012;35(12):2665-73.

3. Badrick E, Renehan AG. Diabetes and cancer: 5 years into the recent controversy. Eur J Cancer 2014;50(12):2119-25. 

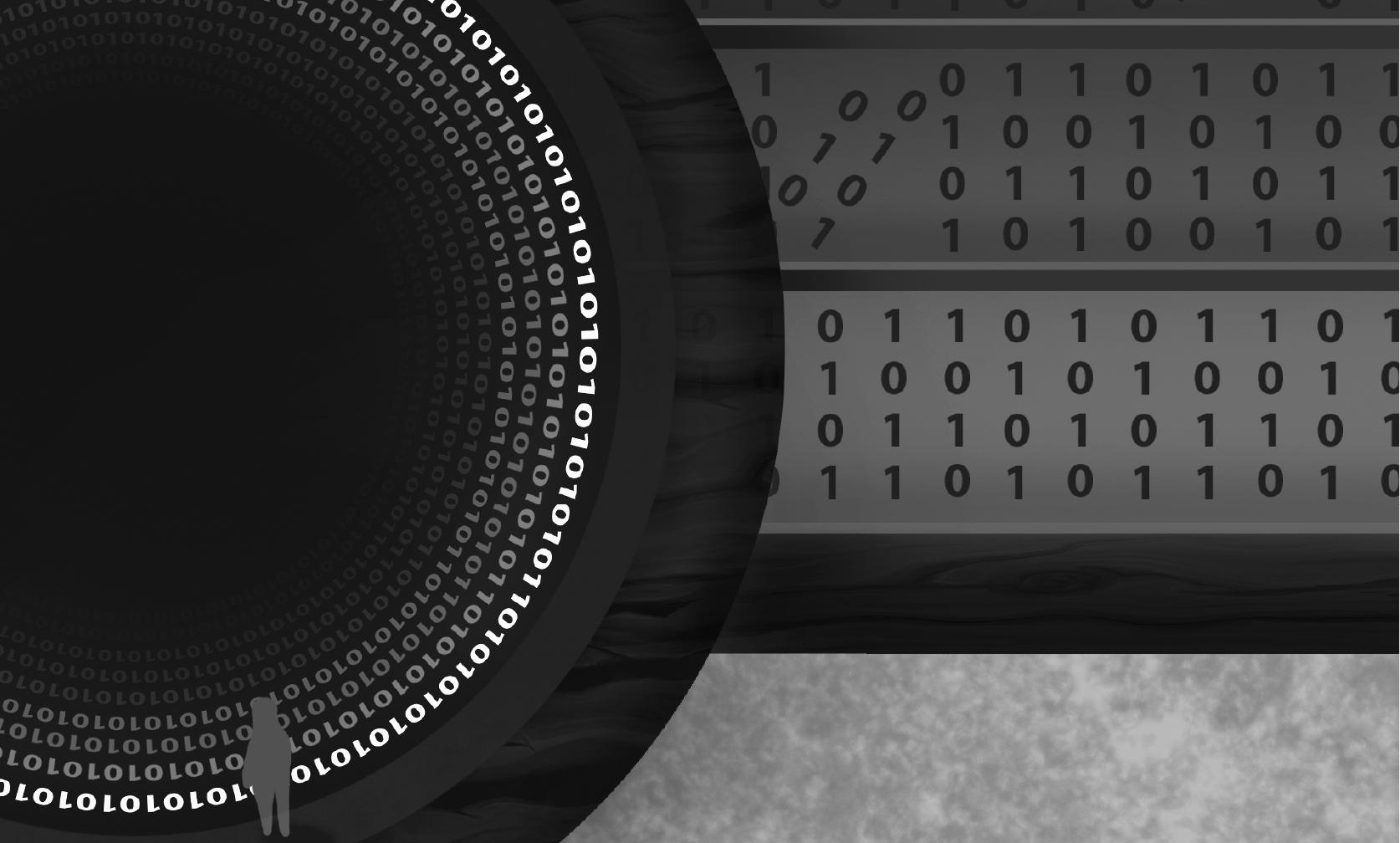

$\begin{array}{llllllllll}0 & 1 & 1 & 0 & 1 & 0 & 1 & 1 & 0 & 1\end{array}$

$\begin{array}{lllllllll}1 & 0 & 0 & 1 & 0 & 1 & 0 & 0 & 1\end{array}$

$\begin{array}{llllllllll}0 & 1 & 1 & 0 & 1 & 0 & 1 & 1 & 0 & 1\end{array}$

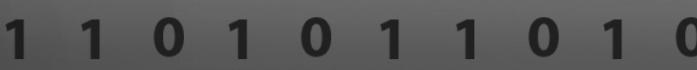

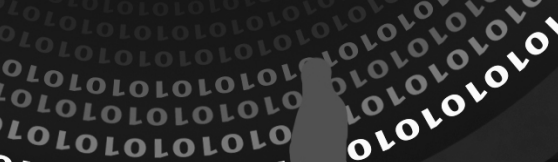
$010^{2}$ 


\section{Chapter}

High glycaemic burden increases risk of gastrointestinal cancer in patients with type 2 diabetes mellitus; a population-based cohort study in the Netherlands

Roy G.P.J. de Jong, Jetty A. Overbeek, Rients P.T. van Wijngaarden, Andrea M. Burden, Sander de Kort, Pauline A.J. Vissers, Paddy K.C. Janssen, Harm R. Haak, Ad A.M. Masclee, Frank de Vries, Maryska L.G Janssen-Heijnen In preparation for submission 

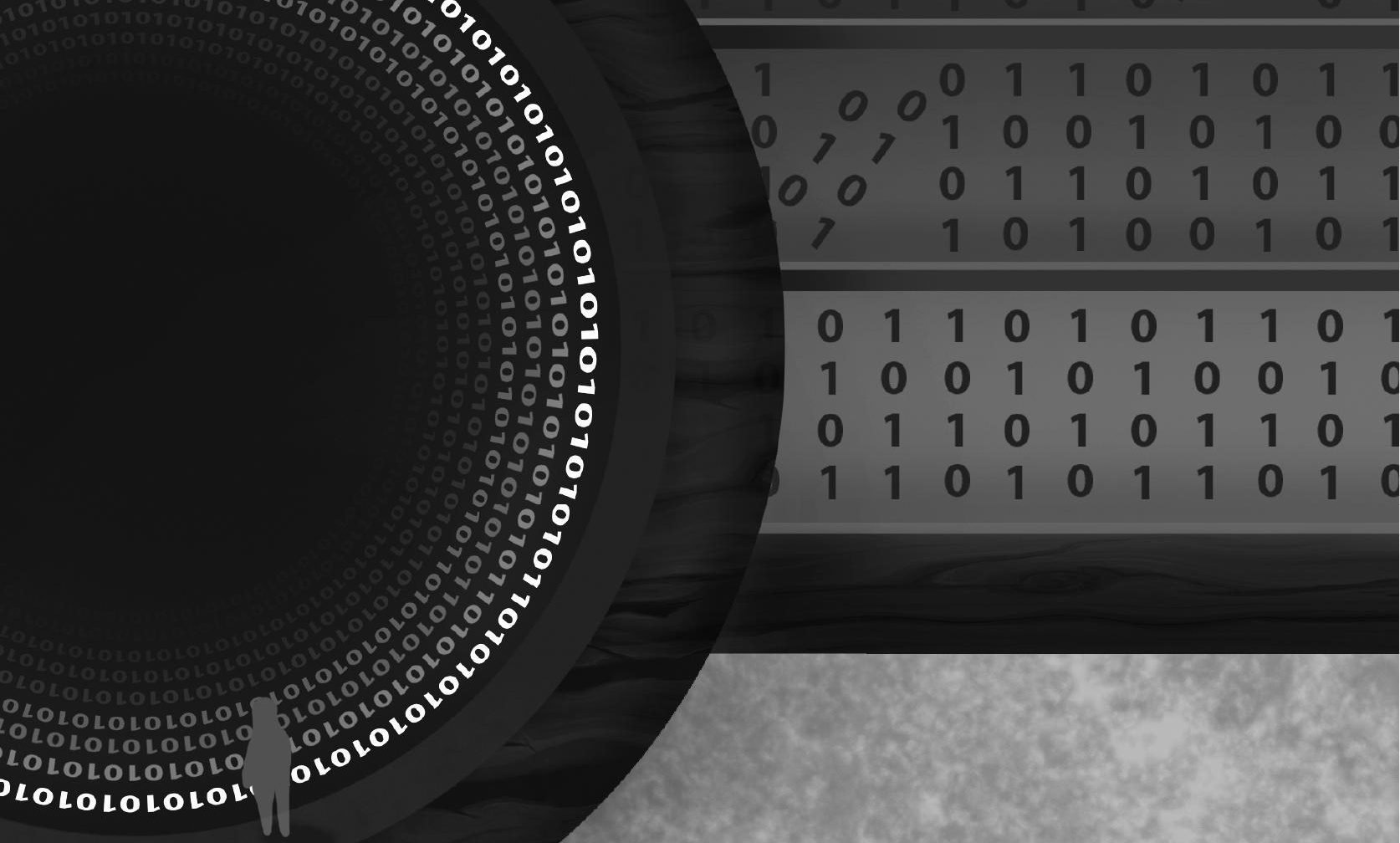

$\begin{array}{llllllllll}0 & 1 & 1 & 0 & 1 & 0 & 1 & 1 & 0 & 1\end{array}$

$\begin{array}{lllllllll}1 & 0 & 0 & 1 & 0 & 1 & 0 & 0 & 1\end{array}$

$\begin{array}{llllllllll}0 & 1 & 1 & 0 & 1 & 0 & 1 & 1 & 0 & 1\end{array}$

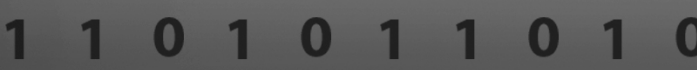

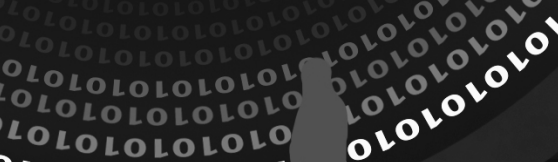
$010^{2}$ 


\section{Chapter}

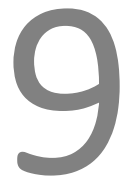

General discussion 



\section{General discussion}

In this thesis, new and original data on the risk of gastrointestinal (GI) cancer in patients with type 2 diabetes mellitus (T2DM) have been presented in order to create a better insight into the complexity of the association. We evaluated the association between T2DM and all types of Gl cancer in both the Dutch population and population of the United Kingdom (UK), and whether the association is partially explained by detection bias or protopathic bias. Furthermore, the association between the use of metformin and the risk of $\mathrm{Gl}$ cancers, and between the use of incretin-based anti-diabetic drugs (incretins) and the risk of pancreatitis, was evaluated using a time-dependent definition of drug-exposure. In addition, the association between the level of hyperglycaemia over time and Gl cancer risk was evaluated using a novel marker of hyperglycaemia called glycaemic burden. Below, the key findings of our studies in relation to the current available literature and the methodological limitations are discussed. Lastly, the general discussion ends with future directions and perspectives for researchers investigating the association between T2DM and GI cancer and the overall conclusions.

\section{The association between type 2 diabetes mellitus and gastrointestinal cancer}

The first aim of this thesis was to evaluate the association between T2DM and the risk of Gl cancer, and whether the association is partially explained by detection bias or protopathic bias. To date, T2DM has been associated with several GI cancers. ${ }^{1-3}$ The highest risk estimates have been reported for liver and pancreatic cancers. ${ }^{4,5}$ For colorectal cancer a modest $15-30 \%$ increased risk has been found in the literature. ${ }^{6,7}$ For other types of $\mathrm{Gl}$ cancers mixed results have been reported.

In Chapter 2 we created an overview of the incidence rates (IRs) of all Gl cancers in individuals with and without T2DM using the UK CPRD database. Higher IRs of any GI, liver, pancreatic, and colon cancer, a lower incidence of oesophageal cancer, and no significant differences in gastric, small intestinal, biliary, and rectal cancer were found in patients with T2DM compared to non-diabetic controls. These results are in line with recent studies performed in the Netherlands and the UK. Schrijnders et al. found increased standardized incidence ratios (SIR) of obesity-related cancers (including oesophageal adenocarcinoma, liver, pancreas, gallbladder and pancreatic cancer) in both men and women (SIR 1.80, 95\% Cl 1.59-2.01 overall, SIR 2.21, 95\% Cl 1.88-2.54 in men, and SIR 1.38, 95\% CI 1.11-1.64 in women) in the first year after the diagnosis of T2DM. $^{8}$ Also using the UK CPRD database, Peeters et. al. found comparable incidence 
rates of colorectal cancer in individuals with or without T2DM. ${ }^{9}$ In contrast, using a large cohort of individuals with insulin-treated diabetes, Swerdlow et al. reported no statistically significant differences in Gl cancer incidence rates between insulin-treated diabetes patients in the UK compared with the general population. ${ }^{10}$ However, the number of cancer events in this study was very low and misclassification of the exposure group (by inclusion of patients with type 1 diabetes mellitus) may have influenced the results.

The study in Chapter 2 was a descriptive study in which we reported unadjusted incidence rates of $\mathrm{Gl}$ cancer. The study was not designed to assess a causal relationship between T2DM and GI cancer. Differences in the incidence rates of GI cancers could have been explained by a different distribution of risk factors for GI cancer such as diet, physical inactivity, and obesity among patients with T2DM and non-diabetic controls. ${ }^{11}$ Furthermore, the main results may have been distorted by not accounting for detection bias or reverse causality. The possible influence of these biases on the results are discussed in further detail in the section on bias.

In Chapter 3, using the E-NCR-PHARMO database, we observed a 50\% increased risk of GI cancer in patients with T2DM compared with non-diabetic controls. This overall increased risk of Gl cancer in T2DM patients was explained by a four-fold increased risk of Hepato-Pancreatico-Biliary tract (HPB) cancers, which was driven by pancreatic cancer (five-fold increase) and biliary tract cancer (four-fold increase). No difference in risk of other Gl cancer types between patients with T2DM and non-diabetic controls was observed.

In a recent summary meta-analysis of other meta-analytical studies (that included observational studies), statistically significant increased risks of all GI cancers but gastric cancer were found in patients with T2DM compared to non-diabetic individuals. ${ }^{3}$ However, consistent evidence was only found for intrahepatic cholangiocarcinoma (summary random effects estimate (SRE) 1.97, 95\% Cl 1.57-2.46) and colorectal cancer (SRE 1.27, 95\% Cl 1.21-1.34), which may suggest uncertainty about the results of previous meta-analyses for other GI cancer sites. ${ }^{3}$ In particular, the differences between observational studies that were included by the original meta-analyses and presence of unaccounted bias or residual confounding could have caused false positive results. ${ }^{3}$ While meta-analyses increase statistical power and stronger evidence, a major drawback is that they can also further inflate biased results. These methodological issues, that impact observational studies, are difficult to overcome. Moreover, most studies that are included in meta-analyses did not account for possible detection bias by attributing cancer events to the T2DM population directly after the diagnosis of T2DM, which could have inflated the risk estimates. 
The association between T2DM and the risk of HPB type cancers may be more complex as compared with the association between T2DM and the risk of other GI cancer sites. A stronger association was observed in data from the United Kingdom (Chapter 2) and The Netherlands (Chapter 3). We found larger differences in the IRs of liver and pancreatic cancer between individuals with and without T2DM as compared with other GI cancer sites (Chapter 2). In Chapter 3, the highest increased risks of GI cancer were observed for liver, biliary tract and pancreatic cancer in patients with T2DM compared with nondiabetic controls. These findings are generally in line with results from previous metaanalyses of observational studies, showing an approximate two-fold increased risk of these cancer types. ${ }^{3-5}$ Both the liver and the pancreas are exposed to higher levels of endogenous insulin compared to other organs via the portal venous system. As insulin may be one of the major hormonal contributors to the diabetes-cancer link because of its mitogenic properties, this can explain why higher risk estimates are observed for HPB type cancers. ${ }^{1}$

The association between T2DM and pancreatic cancer is further complicated as pancreatic cancer may manifest itself as diabetes mellitus through various mechanisms. ${ }^{12-14}$ These mechanisms include a paraneoplastic syndrome related to diabetogenic substances excreted by pancreatic cancer cells ${ }^{15}$, parenchymal atrophy by loss of islet cell mass ${ }^{16}$, and direct beta-cell dysfunction. ${ }^{17}$ In contrast, patients with T2DM may lose the ability to produce sufficient endogenous insulin over time, requiring exogenous insulin therapy to regulate their blood glucose levels. The loss of the insulinrich pancreatic milieu may result in the loss of mitogenic stimulus to promote pancreatic hypertrophy and growth. This may explain why studies have shown higher risks of pancreatic cancer in T2DM earlier in the course of follow-up. ${ }^{12}$

Instead of finding a modestly elevated risk of colorectal cancer as was hypothesized based on the current literature, we found no difference in the risk of colorectal cancer between patients with and without T2DM. These findings are in line with previous studies performed in the Netherlands which showed no statistically significant increased risk of colorectal cancer between patients with and without T2DM, while correcting for multiple confounders (e.g. age, sex, body mass index (BMI), smoking status and alcohol use). ${ }^{18,19}$ In contrast, de Kort et al. found a statistically significant increased risk of colorectal cancer in patients with T2DM compared to non-diabetic controls also using the E-NCR-PHARMO database. ${ }^{20}$ These differences in the results may be explained by methodological variation, such as study design or statistical analyses (e.g. inclusion of specific confounders).

Pathophysiological processes that may promote the proliferation of cancer cells through hyperinsulinaemia, hyperglycaemia, insulin resistance and inflammation may form the basis for the link between T2DM and Gl cancer. However, T2DM and Gl cancers also 
share various risk factors that could (in part) explain the association. Besides nonmodifiable risk factors such as older age and race/ethnicity, a range of modifiable risk factors have been identified, including obesity, physical inactivity, smoking, alcohol abuse, and poor dietary habits. ${ }^{1}$ Most of these modifiable risk factors have increased following the industrial revolution in Europe and the United States. In observational studies, residual confounding is likely present when not all of these factors are adequately adjusted for.

Unfortunately, in the studies presented in Chapter 2 and Chapter 3, we were unable to correct for several important general confounding factors, including obesity, smoking, alcohol use, and physical inactivity. Especially not having corrected for the presence of obesity may have confounded the results. In a large umbrella review of meta-analyses $(\mathrm{N}=204)$, Kyrgiou et al. have analysed the strength and validity of the evidence of the association between adiposity and the risk of cancer. ${ }^{11}$ They found that the associations between adiposity and oesophageal adenocarcinoma, cancer of the gastric cardia, colon, rectum, biliary tract, and pancreas were supported by strong evidence. ${ }^{11}$ Moreover, previous research has shown that obesity is a known risk factor for the development of T2DM as well. ${ }^{21}$

\section{Temporal relationship between T2DM and GI cancer}

\section{Detection bias and protopathic bias}

When investigating the link between T2DM and Gl cancer it is important to take into account the temporal relationship between both entities. A diagnosis of T2DM often increases the level of medical consultation in comparison to individuals without this disease, which can result in an apparent increase in cancer risk among the T2DM population, representing a form of detection bias. ${ }^{22}$ Also, Gl cancer - specifically pancreatic cancer - may cause disturbances in glucose metabolism by interfering with endogenous insulin production by the pancreas resulting in T2DM and leading to protopathic bias in epidemiologic studies. ${ }^{23,24}$ Therefore, if an individual with T2DM is diagnosed with pancreatic cancer shortly after the diagnosis of T2DM, it is unlikely and methodically incorrect to designate T2DM as a causative factor in the development of the pancreatic cancer. Both types of biases can be minimized by applying a lag period between de diagnosis of T2DM and GI cancer. ${ }^{24,25}$

In both Chapter 2 and Chapter 3 sensitivity analyses were performed using a one-year lag period after the diagnosis of T2DM to minimize detection bias and protopathic bias. No clear differences in the incidence rates of Gl cancers were seen compared to the main analysis in Chapter 2. In Chapter 3 of this thesis, an attenuation of the risk estimates for 
GI cancer and pancreatic cancer was observed, although the risk of these cancers in patients with T2DM were still statistically significantly increased compared to nondiabetic controls. Previous studies investigating the possible effects of detection bias found significantly increased risks of colorectal and pancreatic cancers in the first three to six months following a diagnosis of T2DM. ${ }^{13,18,20}$ However, only in the study by Johnson et al. the risk of these cancers and of liver cancer remained elevated - though less prominently - after excluding the first 3 months of follow-up. ${ }^{13}$ The results of our study and the studies mentioned above indicate that detection bias and protopathic bias may have inflated the risk estimates of Gl cancer in T2DM patients when a lag period after the diagnosis of T2DM is not accounted for. However, they also suggest that the association between T2DM and GI cancer is probably not completely explained by these biases, or that a one-year lag period is insufficient to fully exclude detection bias.

\section{Latency time of cancer}

An important aspect of the temporal relationship between T2DM and GI cancer that merits discussion is the latency time of Gl cancer - i.e. the time it takes for a GI malignancy to develop from its conception up until diagnosis. When studying an exposure-disease relationship in an observational setting, assumptions need to be made about the role T2DM plays in the development of cancer, such as the time for T2DM to have a biological effect on carcinogenesis (initiation or promotion). In reality, various etiologic factors that contribute to a disease process will probably have complex interrelations. $^{26}$

In 1981, Kenneth J. Rothman proposed that induction and latent periods of disease are distinguishable time windows referring to the period between the causal action of a risk factor and disease initiation, and the period between disease initiation and detection, respectively. ${ }^{26}$ The sum of these two intervals is defined as the empirical induction period (Figure 9.1). Inappropriate assumptions about the length of the empirical induction period may result in non-differential misclassification bias of risk estimates towards the null, thereby underestimating the effect of a risk factor or even obscuring a true effect. ${ }^{26,27}$ Unfortunately, the latent time period of cancer is difficult to estimate. Rough estimates from studies on growth rates of solid cancers show that the latent time period might be approximately 5-7.5 years for colorectal cancer, assuming a linear growth rate. ${ }^{28}$ To approach an adequate assumption of the latent time period, analyses with varying latent time periods can be used, as the risk estimate should increase when the assumption becomes more adequate. ${ }^{27}$ In Chapter 3 , the mean follow-up time was 4 years. Therefore, apart from accounting for possible detection bias by applying a oneyear lag period in the analyses, sensitivity analyses involving the latent time period of GI 
cancers were not possible. To explore the possible effect of non-differential misclassification bias, future observational studies should correct for the latency time of cancer if an adequate follow-up period is available.

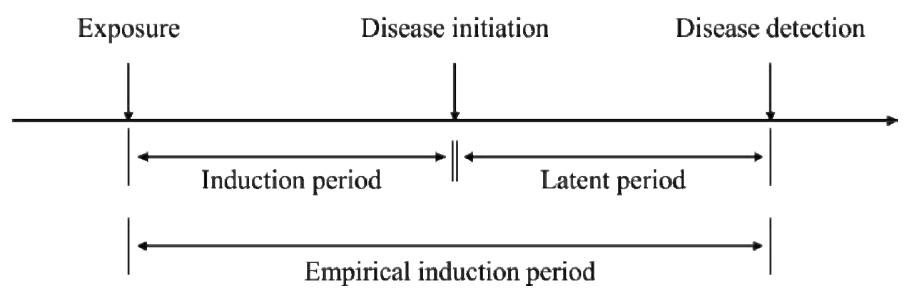

Figure 9.1 Time windows between the exposure to a (causal) risk factor, disease initiation, and disease detection as proposed by Rothman 1981.

\section{Database representativeness}

In order to assess to what extent our findings in a representative sample from the total UK population (Chapter 2 and 6) were indirectly applicable to the Netherlands, we compared the age- and sex distribution of the UK CPRD with the total Dutch population for the year 2011 in Chapter 4. The age distribution of men and women in the CPRD population was comparable to that in the Dutch male and female population in the same calendar year. Differences in the distribution of age of more than $10 \%$ only occurred in older age categories (75+ in men and $80+$ in women). This study, however, was only a first step in evaluating the applicability of CPRD's results to the Dutch population. Obviously, more variables that influence the applicability of a database's results for another population (e.g. prevalence of disease risk factors such as smoking, obesity, comorbidities and drug use) need to be compared, in order to draw firmer conclusions. Currently, pharmaco-epidemiological research, that has been conducted in CPRD, is already being used for regulatory decision making in the Netherlands. For instance through changes in drug use recommendations by the European Medicines Agency. ${ }^{29}$ We hope that with our initial study grounds have been laid for future investigators to perform more extensive comparison studies between databases and other populations in order to investigate the applicability of a database's results to a country's population. 


\section{The use of anti-diabetic drugs and risk of gastrointestinal cancer}

The second aim of this thesis was to evaluate the risk of Gl cancer in users of metformin and to evaluate the risk of pancreatitis in users of incretins. Several drugs used in the treatment of T2DM have been reported to be associated with cancer risk. ${ }^{30}$ Metformin was chosen as drug of interest in this thesis because of the ongoing debate regarding its possible effect on reducing cancer risk, while many previous studies were affected by time-related biases. ${ }^{31}$ In addition, we decided to investigate the effects of incretins on the risk of pancreatitis because of the increasing reports of this adverse event in the literature and its possible consequences for pancreatic cancer risk.

\section{Metformin}

In Chapter 5, a time-varying approach to determine metformin exposure in T2DM patients was applied in order to evaluate Gl cancer risk. During more than 280,000 person-years of follow-up with 1,076 GI cancer events, no reduced risk of GI cancer (or its specific subsites) was found when comparing current use of metformin with current use of other non-insulin anti-diabetic drugs (NIADs). Also, no reduced risks of Gl cancers were found when performing stratified analyses by treatment stage or cumulative dose. Evans et al. were the first to report an association between the use of metformin and cancer risk in $2005 .^{32}$ Since then, numerous observational studies have reported on a reduced cancer risk with use of metformin. ${ }^{33-42}$ However, not all studies have confirmed this association. ${ }^{41-44}$ In fact, an increased risk of colorectal cancer has also been reported. $^{45}$

There is a plausible biological mechanism by which metformin could reduce cancer risk. ${ }^{46}$ Metformin has been shown to interact with intracellular energy metabolism and growth pathways in cancer cells, thereby reducing cancer growth. ${ }^{46}$ Besides, metformin reduces overall insulin resistance, hyperinsulinaemia and hyperglycaemia, which have been associated with an increased risk of cancer.

Many observational studies on the risk of GI cancer and the use of metformin have been criticized for the presence of time-related biases. ${ }^{30,31,47}$ As mentioned in the introduction of this thesis, these time-related biases revolve around two axes. ${ }^{30}$ Incorrectly classifying observation time to different exposure categories (immortal time bias), and comparing the use of metformin with the use of anti-diabetic drugs (ADDs) used in a later stage of the disease without accounting for disease duration (time-lag bias or confounding by indication). ${ }^{30}$ Studies that have classified observation time correctly have so far not found a decreased risk of cancer with the use of metformin. ${ }^{48,49}$ In our study, we tried to 
minimize time-related biases by classifying exposure to ADDs time-dependently using 90-day time-intervals. As a result, exposure time could be classified appropriately to use and non-use of metformin. Furthermore, confounding by indication was minimized by comparing the use of metformin with the use of other non-insulin ADDs while adjusting for the use of other ADDs that have been associated with cancer risk and duration of T2DM in the statistical analyses. In addition, stratified analyses for each metformin-user subgroup were performed to reveal any discrepancies. Using this approach, no reduced risks of Gl cancers were found in users of metformin compared to users of other NIADs, which is in line with recent results of other well designed observational studies.

Many clinical trials on the possible cancer preventive effect of metformin are still ongoing. One notable example is a placebo-controlled phase III trial of metformin for the secondary prevention of recurrent colorectal polyps and adenomas in individuals who had undergone an index colonoscopy with polypectomy. ${ }^{50}$ A statistically significant decrease in the incidence of recurrent polyps (RR 0.67, $P=0.034$ ) and adenomas (RR 0.60, $\mathrm{P}=0.016$ ) was found at 1 year in non-diabetic individuals who were treated with low-dose oral metformin (250 mg daily). However, the absolute number of recurrent polyps and adenomas during follow-up endoscopy was clinically negligible (median number of polyps 0 [interquartile range (IQR) $0-1$ ] in the metformin group versus 1 [IQR 0-1] in the placebo group $(p=0.041)) .{ }^{50}$ Subsequently, this raises question about the clinical impact of the reported results.

Our study on the use of metformin and Gl cancer risk was not without limitations. First of all, we were not able to correct various confounding factors, such as lifestyle factors (e.g., obesity, alcohol use, smoking status, and physical activity), dietary habits, and the presence of unmeasured (disease specific) comorbidities (e.g., gastro-esophageal reflux disease, chronic liver disease, or chronic pancreatitis). Second, a lack of statistical power existed for some cancer sites, such as liver cancer and biliary tract cancer, especially in the sensitivity analyses wherein a new-user cohort was used. This resulted in a limited ability to statistically adjust for confounders in the multivariate analyses. An effective approach to control for all potential confounding factors would be to use propensity score adjustment, especially when the number of outcome events is low. ${ }^{47}$ A propensity score incorporates all of the available covariates into one score and represents the probability of receiving one drug over the other. ${ }^{47}$ Similarly to a randomized trial, this approach aims to achieve balance between the study groups with regard to measured confounders. Although we acknowledge that propensity score adjustment would be an effective strategy to further reduce residual confounding and limit the number of covariates in the multivariate model, it cannot overcome the unmeasured confounding in the data source and therefore this strategy was not applied. ${ }^{51,52}$ 
Based on the current evidence as mentioned above and the results found in our study on the risk of $\mathrm{Gl}$ cancers with the use of metformin, the use of metformin is most likely not associated with a clinically relevant reduced risk of $\mathrm{Gl}$ cancer. Expensive clinical trials should therefore be discouraged.

\section{Incretin-based anti-diabetic drugs}

In Chapter 6, a population-based cohort study was conducted using data from the UK CPRD to evaluated the risk of any, acute, and chronic pancreatitis in users of incretins compared to users of other NIADs. Adjusting for lifestyle, disease and drug history, a 1.5-fold statistically significant increased risk of any type of pancreatitis with current use of incretins versus other NIAD use was found. The risk of acute pancreatitis was 1.4-fold greater in current incretin users versus other NIAD users, but this did not reach statistical significance (HR 1.42, 95\% Cl 0.98-2.06). Furthermore, an association between chronic pancreatitis and incretin use was not detected, but the number of events in this subgroup was small ( $N=160)$. Stratified by type of incretin (DPP-4 inhibitors and GLP-1 receptor agonists), the risk of acute pancreatitis was statistically significantly increased in current users of DPP-4 inhibitors only.

Both acute and chronic pancreatitis have been associated with an increased risk of pancreatic cancer, with a 2-fold and 8-fold increased risk of pancreatic cancer more than 5 years after a diagnosis of acute and chronic pancreatitis respectively. ${ }^{53,54}$ Concerns about pancreatic cancer risk with use of incretins first arose after an increased risk of pancreatitis was reported in adverse-event databases. ${ }^{55,56}$ However, large populationbased cohort studies thereafter have shown mixed results related to pancreatic cancer risk. $^{57-62}$

Regarding the risk of pancreatitis, data from the SAFEGUARD consortium - investigating the cardio/cerebrovascular and pancreatic safety of ADDs in T2DM patients - have shown that GLP-1 receptor agonists (exenatide and liraglutide) and some DPP-4 inhibitors (alogliptin, sitagliptin, saxagliptin) show a high risk for acute pancreatitis. ${ }^{63}$ This was concluded after evaluating the existing literature at that time (up to 2015), and performing studies using adverse-event databases (e.g. Eudravigilance). However, no increased risk of acute pancreatitis was found when analysing acute pancreatitis risk with the use of incretins in T2DM patients using a combination of multiple large pharmaco-epidemiological databases (e.g. PHARMO Database Network). Furthermore, some of the more recent epidemiological studies have shown no statistically significant association between the use of incretins and the risk of pancreatitis. ${ }^{64,65}$ In a metaanalysis of 55 randomised controlled trials $(N=33,350)$, Li et al. found no evidence of an increased risk of pancreatitis with incretins versus controls $(O R 1.11,95 \% \mathrm{Cl} 0.57$ to 
2.17). Analysis by type of incretin showed similar results (OR $1.05,95 \% \mathrm{Cl} 0.37$ to 2.94 for GLP-1 agonists versus controls, and OR 1.06, 95\% Cl 0.46 to 2.45 for DPP-4 inhibitors versus controls). ${ }^{64}$ Pooled results from five observational studies (three retrospective cohort studies, and two case-control studies; $\mathrm{N}=320,289)$ also showed no statistically significant increased risk of pancreatitis in users of incretins. Also, a recent large nested case-control analysis of over 1.5 million patients, has shown no increased risk of pancreatitis in users of incretins compared to users of at least two NIADs (pooled adjusted $\mathrm{HR} 1.03,95 \% \mathrm{Cl} 0.87$ to 1.22 ). In addition, clinical trial data have not demonstrated a relationship between the use of incretins and development of pancreatic cancer. ${ }^{66}$

Based on the current evidence in the literature, incretins probably do not convey a clinically relevant increased risk of pancreatitis or pancreatic cancer in patients with T2DM. However, we were the first to separately study the risk of both acute and chronic pancreatitis with the use of incretins, and our results are yet to be replicated. Moreover, the complex interactions between both T2DM, pancreatitis, and pancreatic cancer make it difficult to analyse the potential impact of incretins on the risk of both pancreatitis and pancreatic cancer. Therefore, we think that consequent monitoring of potential side effects by means of periodic safety update reports remains warranted.

\section{Other methodological considerations}

\section{Prevalent user bias}

Prevalent user bias arises when all users of ADDs from a given calendar date, regardless of the time they had used the drug for, are included in the study population. ${ }^{30,67}$ These individuals might be at a lower risk of cancer, as the use of a certain ADD for a long period of time may reflect good glycaemic control. In a cohort of prevalent ADD users correcting for the previous duration of use is not possible, which may introduce bias. To explore any effects of this type of bias we performed sensitivity analyses using a newuser design in Chapter 5 and Chapter 6, where follow-up for included patients started at the date of the first-ever ADD prescription after a period of time wherein no ADD prescriptions were recorded. ${ }^{67}$ In the study on the risk of $\mathrm{Gl}$ cancer with use of metformin (Chapter 5) this approach did not result in an alteration of the results. In Chapter 6 the risks of any and acute pancreatitis in current users of incretins were more pronounced compared to the main analysis. 


\section{Hyperglycaemia and gastrointestinal cancer risk}

Hyperglycaemia has been associated with both micro- and macrovascular complications in individuals with T2DM. ${ }^{68,69}$ Possibly, hyperglycaemia is also associated with an increased risk of cancer. ${ }^{1}$ Previous studies investigating the association between hyperglycaemia and (GI) cancer risk have only used individual or mean measures of glycaemia (e.g. HbA1c at start of follow-up) and evidence on the cumulative effects of hyperglycaemia on Gl cancer risk are unknown. Therefore, as a means to study the possible biological relationship between T2DM and GI cancer in an observational setting, the final aim of this thesis was to evaluate the association between the level of hyperglycaemia over time and GI cancer risk in patients with T2DM, using a novel marker of hyperglycaemia called glycaemic burden (Chapter 8 ).

Glycaemic burden was defined as the sum of the differences between a subject's HbA1c value and the threshold of $7 \%(53 \mathrm{mmol} / \mathrm{mol})$. To account for differences in duration of follow-up, a yearly estimate of glycaemic burden was calculated for the analyses (glycaemic burden years; GBY), by dividing the cumulative glycaemic burden by the number of years of follow-up. Comparing to T2DM patients with up to one year of GBY, a decreased risk of GI cancer was found in patients with zero glycaemic burden (HbA1c never above $7 \%$ [53 mmol/mol] during follow-up), but no further increased risk for patients with more than one year of GBY. When stratifying the analysis by subsite of GI cancer only the risk of hepato-pancreatico-biliary tract cancers was associated with increased years of GBY.

As noted in Chapter 8, no observational studies that have used multiple $\mathrm{HbA} 1 \mathrm{c}$ records during follow-up to compare levels of glycaemic burden and risk of GI cancer have been conducted as of yet. Previous observational studies on the relationship between single $\mathrm{HbA1c}$ values and $\mathrm{Gl}$ cancer risk have pointed to an increased risk of various $\mathrm{Gl}$ cancers when comparing the highest levels of $\mathrm{HbA} 1 \mathrm{c}$ to the lowest levels of $\mathrm{HbA} 1 \mathrm{c} .^{70-73}$ Although these studies may offer valuable insight into the possible mechanism by which T2DM may increase the risk of $\mathrm{Gl}$ cancer, stratification of subjects based on the HbA1c level at cohort entry may not grasp the cumulative effects of hyperglycaemia over time.

Glucose is a major source of energy for cancer cells, as these cells mainly depend on glycolysis for energy production. ${ }^{74}$ Furthermore, function-altering mutations in receptorinitiated signalling pathways overcome growth-factor dependent uptake and metabolism of glucose. ${ }^{74}$ This high requirement for glucose and increased glucose uptake in cancer cells may be an explanation for the association between hyperglycaemia and cancer risk in previous studies. ${ }^{1}$

The study in Chapter 8 had several limitations. There was the possibility of selection bias as a considerable amount of potential study subjects had to be excluded due to a large 
number of missing $\mathrm{HbA1c}$ values. The included individuals could either represent healthier T2DM patients - those who have regular check-ups at their general practitioner or diabetes specialist due to their personal interest in their health status or less healthy T2DM patients for whom the GP or diabetes specialist orders more frequent laboratory tests. Furthermore, there is the possibility of residual confounding due to unmeasured confounding factors that may influence the level of hyperglycaemia and risk of cancer (e.g. obesity, high caloric diet, physical inactivity). ${ }^{1}$ In addition, we used the start of NIADs as proxy-indicator of the onset of T2DM. This could have caused an underestimation of the cumulative glycaemic burden, as T2DM may go undiagnosed for several years until complications have already emerged. Moreover, as the latent time period for T2DM per individual is unknown, misclassification of GBY categories could have occurred.

The study in Chapter 8 is the first observational study to evaluate the association between T2DM and glycaemic burden. Therefore, future studies are needed to replicate our findings while taking into account the limitations of our study regarding selection bias and limited ability to correct for confounding factors. Nonetheless, our results do suggest that an association is present between hyperglycaemia over time and the risk of Gl cancer in patients with T2DM.

\section{Data source limitations}

For the studies presented in this thesis data from the E-NCR-PHARMO database and data from the UK CPRD were used. Although large electronic healthcare databases contain very valuable and detailed information, data were not collected for a specific research question but for routine clinical care/evaluation and/or reimbursement purposes, and the use of such databases may have several limitations.

First, although the E-NCR-PHARMO database contains information on body mass index (BMI), this was available for a limited number of individuals only. This made statistical adjustment for BMI not possible in the studies using the this database. The importance of adjusting for BMI or obesity as confounding variable has previously been mentioned. Second, a diagnosis of T2DM was based on the use of oral ADDs, using the first-ever recorded drug prescription as the date of onset of T2DM. Hence, individuals who are managed without any medication - i.e. advising dietary and lifestyle changes - were not included within the T2DM population of the studies in this thesis. It is possible that some of these patients were included in the non-diabetic reference population. However, given the limited long-term success of lifestyle modification programs to maintain glycaemic goals in patients with type 2 diabetes, the majority of patients will require 
ADD therapy over the course of their diabetes. ${ }^{69}$ On the one hand, if the presence of T2DM really contributes to GI cancer development, this could have led to an increased risk of $\mathrm{Gl}$ cancer in the reference population and caused a bias of the risk estimates towards the null. On the other hand, the presence of this bias also strengthens the significance of the results when finding statistically significant differences between the two populations. Third, non-differential misclassification of exposure could have occurred in the studies on ADD use and GI cancer risk. The longitudinal drug dispensing database of PHARMO Database Network does not provide certainty that dispensed drugs are actually ingested by individuals. Therefore, true exposure to a certain drug an ADD or a confounder drug - may be overestimated. This misclassification of exposure could have biased the risk estimates towards the null. Ideally, one would want data confirming actual drug use in patients, but this is practically impossible to achieve.

The CRPD GOLD database uses READ codes in order to identify GI cancer events. READ codes are a coded thesaurus of clinical terms used by clinicians to record patient findings and procedures. As READ codes are dependent on the adequate administration by general practitioners in the UK, there is a chance that some GI cancer events already diagnosed yet not registered may be missed, and that patients with a registration of a specific cancer may not have that cancer at all or a different type of cancer. This could lead to a form of information bias. On the one hand, CPRD tries to minimize this registration bias by using their Quality and Outcomes Framework that incentivises general practitioners to optimize their registries. On the other hand, it is possible to link CPRD data to the UK population-based National Cancer Registry. Dregan et al. have previously investigated the validity of cancer diagnoses in CPRD compared with cancer registry data. ${ }^{75}$ In a cohort comprised of 42,556 participants, registered with English general practices in the General Practice Research Database (GPRD; currently known as CPRD), they showed the predictive value of a GPRD cancer diagnosis was $96 \%$ for gastrooesophageal cancer and $98 \%$ for colorectal cancer. ${ }^{75}$ Therefore, a high level of ascertainment is reached based on CPRD cancer records alone. For studies using the UK CPRD database in this thesis linkage to the National Cancer Registry was not performed. We assumed the information bias as mentioned above to be non-differential between exposure groups and of minimal impact on the study results.

\section{Future directions}

In this thesis the associations between overall and site-specific GI cancers on the one hand, and T2DM, the use of ADDs, and glycaemic control on the other hand were evaluated, while taking several important methodological challenges into account. The 
results presented evoke several questions for which recommendations for future studies can be made. First, because of a limited follow-up time, detection bias may not have been completely accounted for and we could not perform additional analyses to explore the effect of the latent time period of cancer on the risk estimates. Future observational studies on the association between T2DM and Gl cancer should therefore focus on minimizing distortion of the results through bias and confounding, and consider evaluating the possible influence of latent time periods of $\mathrm{Gl}$ cancer. To do so, larger databases with a longer duration of follow-up and higher number of cancer events would be necessary in order to provide enough statistical power for adequate statistical analyses and confounder adjustment. Secondly, given the current evidence, future pharmaco-epidemiological studies on the association between the use of metformin and GI cancer risk will probably not yield new results that would further impact the conclusions that can be drawn from the current literature. Therefore, new studies on this topic are not recommended, unless new methodological issues are detected that can be evaluated with novel statistical methods. Lastly, a novel marker of hyperglycaemia over time - glycaemic burden - was used to evaluate the risk of GI cancer with increasing levels of glycaemic burden for the first time. For future research it would be interesting to investigate if such a marker would have any clinical value in the management of T2DM or to compare glycaemic burden to other types of (HbA1c-based) measures of hyperglycaemia in its ability to predict the risk of complications of T2DM, also including the risk of cancer.

\section{Conclusions}

In conclusion, the main objectives of this thesis can be addressed as follows:

First, a diagnosis of T2DM has been associated with a higher risk of GI cancer, driven by an increased risk of pancreatic and liver cancer, but not other Gl cancer sites. When (partially) accounting for detection bias the risk estimates of these cancers attenuated, though remained statistically significantly elevated. This indicates that previously found risk estimates in the literature may also have been overestimated due to detection bias. Of note, residual confounding due to unmeasured risk factors may have influenced the results of our studies.

Second, the use of metformin is not associated with a decreased risk of GI cancer or its subsites. Therefore, expensive clinical trials investigating the use of metformin as chemopreventive agent are not recommended. In contrast, we found an increased risk of acute pancreatitis, but not chronic pancreatitis, in users of incretins, which was not consistent with the current evidence in the literature. In light of the mixed results and 
the fact that stratified results for acute and chronic pancreatitis have been reported for the first time in this thesis, pharmacovigilance is warranted regarding the use of incretins.

Third, the degree of hyperglycaemia over time, expressed as glycaemic burden, may be associated with a higher $\mathrm{Gl}$ cancer risk. However, future studies are needed to replicate and build forward on our initial findings. In general, Dutch clinicians should be aware of the association between T2DM and liver and pancreatic cancer, in particular in new or inadequately controlled T2DM patients. 


\section{References}

1. Giovannucci E, Harlan DM, Archer MC, Bergenstal RM, Gapstur SM, Habel LA, et al. Diabetes and cancer: a consensus report. CA Cancer J Clin 2010;60(4):207-21.

2. Johnson JA, Carstensen B, Witte D, Bowker SL, Lipscombe L, Renehan AG, et al. Diabetes and cancer (1): evaluating the temporal relationship between type 2 diabetes and cancer incidence. Diabetologia 2012;55(6):1607-18.

3. Tsilidis KK, Kasimis JC, Lopez DS, Ntzani EE, loannidis JP. Type 2 diabetes and cancer: umbrella review of meta-analyses of observational studies. BMJ 2015;350:g7607.

4. Wang $C$, Wang X, Gong G, Ben Q, Qiu W, Chen $Y$, et al. Increased risk of hepatocellular carcinoma in patients with diabetes mellitus: a systematic review and meta-analysis of cohort studies. Int J Cancer 2012;130(7):1639-48.

5. Ben $Q$, Xu M, Ning X, Liu J, Hong S, Huang W, et al. Diabetes mellitus and risk of pancreatic cancer: A meta-analysis of cohort studies. Eur J Cancer 2011;47(13):1928-37.

6. Larsson SC, Orsini N, Wolk A. Diabetes mellitus and risk of colorectal cancer: a meta-analysis. J Natl Cancer Inst 2005;97(22):1679-87.

7. Deng L, Gui Z, Zhao L, Wang J, Shen L. Diabetes mellitus and the incidence of colorectal cancer: an updated systematic review and meta-analysis. Dig Dis Sci 2012;57(6):1576-85.

8. Schrijnders D, Hendriks SH, Kleefstra N, Vissers PAJ, Johnson JA, de Bock GH, et al. Sex differences in obesity related cancer incidence in relation to type 2 diabetes diagnosis (ZODIAC-49). PloS One 2018;13(1):e0190870.

9. Peeters PJ, Bazelier MT, Leufkens HG, de Vries F, De Bruin ML. The risk of colorectal cancer in patients with type 2 diabetes: associations with treatment stage and obesity. Diab Care 2015;38(3):495-502.

10. Swerdlow AJ, Laing SP, Qiao Z, Slater SD, Burden AC, Botha JL, et al. Cancer incidence and mortality in patients with insulin-treated diabetes: a UK cohort study. Br J Cancer 2005;92(11):2070-5.

11. Kyrgiou M, Kalliala I, Markozannes G, Gunter MJ, Paraskevaidis E, Gabra H, et al. Adiposity and cancer at major anatomical sites: umbrella review of the literature. BMJ 2017;356:j477.

12. Shafqet M, Sharzehi K. Diabetes and the pancreatobiliary diseases. Curr Treat Options Gastroenterol 2017;15(4):508-19.

13. Johnson JA, Bowker SL, Richardson K, Marra CA. Time-varying incidence of cancer after the onset of type 2 diabetes: evidence of potential detection bias. Diabetologia 2011;54(9):2263-71.

14. Li J, Cao G, Ma Q, Liu H, Li W, Han L. The bidirectional interation between pancreatic cancer and diabetes. World J Surg Oncol 2012;10:171.

15. Lu Y, Garcia Rodriguez LA, Malgerud L, Gonzalez-Perez A, Martin-Perez M, Lagergren J, et al. New-onset type 2 diabetes, elevated $\mathrm{HbA1c}$, anti-diabetic medications, and risk of pancreatic cancer. Br J Cancer 2015;113(11):1607-14.

16. Makhoul I, Yacoub A, Siegel E. Type 2 diabetes mellitus is associated with increased risk of pancreatic cancer: A veteran administration registry study. SAGE Open Med 2016;4:2050312116682257.

17. Aggarwal G, Ramachandran V, Javeed N, Arumugam T, Dutta S, Klee GG, et al. Adrenomedullin is upregulated in patients with pancreatic cancer and causes insulin resistance in beta cells and mice. Gastroenterology 2012;143(6):1510-7 e1.

18. De Bruijn KM, Ruiter R, de Keyser CE, Hofman A, Stricker BH, van Eijck CH. Detection bias may be the main cause of increased cancer incidence among diabetics: results from the Rotterdam Study. Eur J Cancer 2014;50(14):2449-55.

19. de Kort S, Simons CC, van den Brandt PA, Goldbohm RA, Arts IC, de Bruine AP, et al. Diabetes mellitus type 2 and subsite-specific colorectal cancer risk in men and women: results from the Netherlands Cohort Study on diet and cancer. Eur J Gastroenterol Hepatol 2016;28(8):896-903.

20. de Kort S, Masclee AAM, Sanduleanu S, Weijenberg MP, van Herk-Sukel MPP, Oldenhof NJJ, et al. Higher risk of colorectal cancer in patients with newly diagnosed diabetes mellitus before the age of colorectal cancer screening initiation. Sci Rep 2017;7:46527.

21. Al-Goblan AS, Al-Alfi MA, Khan MZ. Mechanism linking diabetes mellitus and obesity. Diabetes Metab Syndr Obesity 2014;7:587-91. 
22. Carstensen B, Witte DR, Friis S. Cancer occurrence in Danish diabetic patients: duration and insulin effects. Diabetologia 2012;55(4):948-58.

23. Sah RP, Nagpal SJ, Mukhopadhyay D, Chari ST. New insights into pancreatic cancer-induced paraneoplastic diabetes. Nature reviews Gastroenterol Hepatol 2013;10(7):423-33.

24. Tamim H, Monfared AA, LeLorier J. Application of lag-time into exposure definitions to control for protopathic bias. Pharmacoepidemiol Drug Saf 2007;16(3):250-8.

25. Rothman KJ, Greenland S, Lash TL. Modern Epidemiology. 3, illustrated ed: Lippincott Williams \& Wilkins; 2008. 758 p.

26. Rothman KJ. Induction and latent periods. Am J Epidemiol 1981;114(2):253-9.

27. Stricker $\mathrm{BH}$, Stijnen T. Analysis of individual drug use as a time-varying determinant of exposure in prospective population-based cohort studies. Eur J Epidemiol 2010;25(4):245-51.

28. Friberg S, Mattson S. On the growth rates of human malignant tumors: implications for medical decision making. J Surg Oncol 1997;65(4):284-97.

29. EMA. Use of metformin to treat diabetes now expanded to patients with moderately reduced kidney function. London: European Medicines Agency, 201612 December 2016. Report No. Contract No.: 868987.

30. Klil-Drori AJ, Azoulay L, Pollak MN. Cancer, obesity, diabetes, and antidiabetic drugs: is the fog clearing? Nature reviews Clin Oncol 2017;14(2):85-99.

31. Suissa S, Azoulay L. Metformin and the risk of cancer: time-related biases in observational studies. Diab Care 2012;35(12):2665-73.

32. Evans JM, Donnelly LA, Emslie-Smith AM, Alessi DR, Morris AD. Metformin and reduced risk of cancer in diabetic patients. BMJ 2005;330(7503):1304-5.

33. Libby G, Donnelly LA, Donnan PT, Alessi DR, Morris AD, Evans JM. New users of metformin are at low risk of incident cancer: a cohort study among people with type 2 diabetes. Diab Care 2009;32(9):1620-5.

34. Currie CJ, Poole CD, Gale EA. The influence of glucose-lowering therapies on cancer risk in type 2 diabetes. Diabetologia 2009;52(9):1766-77.

35. Bodmer M, Becker C, Meier C, Jick SS, Meier CR. Use of antidiabetic agents and the risk of pancreatic cancer: a case-control analysis. Am J Gastroenterol 2012;107(4):620-6.

36. Bodmer M, Becker C, Meier C, Jick SS, Meier CR. Use of metformin is not associated with a decreased risk of colorectal cancer: a case-control analysis. Cancer Epidemiol Biomark Prev 2012;21(2):280-6.

37. Chiu CC, Huang CC, Chen YC, Chen TJ, Liang Y, Lin SJ, et al. Increased risk of gastrointestinal malignancy in patients with diabetes mellitus and correlations with anti-diabetes drugs: a nationwide population-based study in Taiwan. Intern Med 2013;52(9):939-46.

38. Lee MS, Hsu CC, Wahlqvist ML, Tsai HN, Chang YH, Huang YC. Type 2 diabetes increases and metformin reduces total, colorectal, liver and pancreatic cancer incidences in Taiwanese: a representative population prospective cohort study of 800,000 individuals. BMC Cancer 2011;11:20.

39. Donadon V, Balbi M, Ghersetti M, Grazioli S, Perciaccante A, Della Valentina G, et al. Antidiabetic therapy and increased risk of hepatocellular carcinoma in chronic liver disease. World J Gastroenterol 2009;15(20):2506-11.

40. Sehdev A, Shih YC, Vekhter B, Bissonnette MB, Olopade OI, Polite BN. Metformin for primary colorectal cancer prevention in patients with diabetes: a case-control study in a US population. Cancer 2015;121(7):1071-8.

41. Decensi A, Puntoni M, Goodwin P, Cazzaniga M, Gennari A, Bonanni B, et al. Metformin and cancer risk in diabetic patients: a systematic review and meta-analysis. Cancer Prev Res 2010;3(11): 1451-61.

42. Noto H, Goto A, Tsujimoto T, Noda M. Cancer risk in diabetic patients treated with metformin: a systematic review and meta-analysis. PloS One 2012;7(3):e33411.

43. Gandini S, Puntoni M, Heckman-Stoddard BM, Dunn BK, Ford L, DeCensi A, et al. Metformin and cancer risk and mortality: a systematic review and meta-analysis taking into account biases and confounders. Cancer Prev Res 2014;7(9):867-85.

44. Kowall B, Stang A, Rathmann W, Kostev K. No reduced risk of overall, colorectal, lung, breast, and prostate cancer with metformin therapy in diabetic patients: database analyses from Germany and the UK. Pharmacoepidemiol Drug Saf 2015;24(8):865-74 
45. Knapen LM, Dittrich ST, de Vries F, Starup-Linde J, Vestergaard P, Henry RM, et al. Use of biguanides and the risk of colorectal cancer: a register-based cohort study. Curr Drug Saf 2013;8(5):349-56.

46. Pollak MN. Investigating metformin for cancer prevention and treatment: the end of the beginning. Cancer Discov 2012;2(9):778-90.

47. Golozar A, Liu S, Lin JA, Peairs K, Yeh HC. Does Metformin Reduce Cancer Risks? Methodologic Considerations. Current Diab Rep 2016;16(1):4.

48. Smiechowski B, Azoulay L, Yin H, Pollak MN, Suissa S. The use of metformin and colorectal cancer incidence in patients with type II diabetes mellitus. Cancer Epidemiol Biomark Prev 2013;22(10): 1877 83.

49. Tsilidis KK, Capothanassi D, Allen NE, Rizos EC, Lopez DS, van Veldhoven K, et al. Metformin does not affect cancer risk: a cohort study in the U.K. Clinical Practice Research Datalink analyzed like an intention-to-treat trial. Diab Care 2014;37(9):2522-32.

50. Higurashi T, Hosono K, Takahashi H, Komiya Y, Umezawa S, Sakai E, et al. Metformin for chemoprevention of metachronous colorectal adenoma or polyps in post-polypectomy patients without diabetes: a multicentre double-blind, placebo-controlled, randomised phase 3 trial. Lancet Oncol 2016;17(4):475-83.

51. de Jong R, Burden AM, de Kort S, van Herk-Sukel MPP, Vissers PAJ, Janssen PKC, et al. Impact of detection bias on the risk of gastrointestinal cancer and its subsites in type 2 diabetes mellitus. Eur J Cancer 2017;79:61-71.

52. Patorno E, Garry EM, Patrick AR, Schneeweiss S, Gillet VG, Zorina O, et al. Addressing limitations in observational studies of the association between glucose-lowering medications and all-cause mortality: a review. Drug Saf 2015;38(3):295-310.

53. Kirkegard J, Mortensen FV, Cronin-Fenton D. Chronic Pancreatitis and Pancreatic Cancer Risk: A Systematic Review and Meta-analysis. Am J Gastroenterol 2017;112(9):1366-72.

54. Kirkegard J, Cronin-Fenton D, Heide-Jorgensen U, Mortensen FV. Acute pancreatitis and pancreatic cancer risk: A nationwide matched-cohort study in Denmark. Gastroenterology 2018;154(6): 1729-36.

55. Elashoff M, Matveyenko AV, Gier B, Elashoff R, Butler PC. Pancreatitis, pancreatic, and thyroid cancer with glucagon-like peptide-1-based therapies. Gastroenterology 2011;141(1):150-6. P

56. Raschi E, Piccinni C, Poluzzi E, Marchesini G, De Ponti F. The association of pancreatitis with antidiabetic drug use: gaining insight through the FDA pharmacovigilance database. Acta Diabetol 2013;50(4):56977.

57. Tseng $\mathrm{CH}$. Sitagliptin and pancreatic cancer risk in patients with type 2 diabetes. Eur J Clin Invest 2016;46(1):70-9.

58. Tseng CM, Liao WC, Chang CY, Lee CT, Tseng CH, Hsu YC, et al. Incretin-based pharmacotherapy and risk of adverse pancreatic events in the ethnic Chinese with diabetes mellitus: A population-based study in Taiwan. Pancreatology 2017;17(1):76-82.

59. Gokhale M, Buse JB, Gray CL, Pate V, Marquis MA, Sturmer T. Dipeptidyl-peptidase-4 inhibitors and pancreatic cancer: a cohort study. Diabetes Obes Metab 2014;16(12):1247-56.

60. Azoulay L, Filion KB, Platt RW, Dahl M, Dormuth CR, Clemens KK, et al. Incretin based drugs and the risk of pancreatic cancer: international multicentre cohort study. BMJ 2016;352:i581.

61. Azoulay L. Incretin-based drugs and adverse pancreatic events: almost a decade later and uncertainty remains. Diab Care 2015;38(6):951-3.

62. Knapen LM, van Dalem J, Keulemans YC, van Erp NP, Bazelier MT, De Bruin ML, et al. Use of incretin agents and risk of pancreatic cancer: a population-based cohort study. Diabetes Obes Metab 2016; 18(3):258-65.

63. Sturkenboom MCJM. Summary report: Safety Evaluation of Adverse Reactions in Diabetes (SAFEGUARD). European Commission, Community Research and Development Information Service (CORDIS), 2015.

64. Li L, Shen J, Bala MM, Busse JW, Ebrahim S, Vandvik PO, et al. Incretin treatment and risk of pancreatitis in patients with type 2 diabetes mellitus: systematic review and meta-analysis of randomised and nonrandomised studies. BMJ 2014;348:g2366.

65. Azoulay L, Filion KB, Platt RW, Dahl M, Dormuth CR, Clemens KK, et al. Association Between IncretinBased Drugs and the Risk of Acute Pancreatitis. JAMA Intern Med 2016;176(10):1464-73. 
66. Green JB, Bethel MA, Armstrong PW, Buse JB, Engel SS, Garg J, et al. Effect of Sitagliptin on Cardiovascular Outcomes in Type 2 Diabetes. N Engl J Med 2015;373(3):232-42.

67. Ray WA. Evaluating medication effects outside of clinical trials: new-user designs. Am J Epidemiol 2003;158(9):915-20.

68. Stratton IM, Adler Al, Neil HA, Matthews DR, Manley SE, Cull CA, et al. Association of glycaemia with macrovascular and microvascular complications of type 2 diabetes (UKPDS 35): prospective observational study. BMJ 2000;321(7258):405-12.

69. Nathan DM, Buse JB, Davidson MB, Ferrannini E, Holman RR, Sherwin R, et al. Medical management of hyperglycemia in type 2 diabetes: a consensus algorithm for the initiation and adjustment of therapy: a consensus statement of the American Diabetes Association and the European Association for the Study of Diabetes. Diab Care 2009;32(1):193-203.

70. de Beer JC, Liebenberg L. Does cancer risk increase with HbA1C, independent of diabetes? Br J Cancer 2014;110(9):2361-8.

71. Travier N, Jeffreys M, Brewer N, Wright CS, Cunningham CW, Hornell J, et al. Association between glycosylated hemoglobin and cancer risk: a New Zealand linkage study. Ann Oncol 2007;18(8): 1414-9.

72. Grote VA, Rohrmann S, Nieters A, Dossus L, Tjonneland A, Halkjaer J, et al. Diabetes mellitus, glycated haemoglobin and $\mathrm{C}$-peptide levels in relation to pancreatic cancer risk: a study within the European Prospective Investigation into Cancer and Nutrition (EPIC) cohort. Diabetologia 2011;54(12):3037-46.

73. Rinaldi S, Rohrmann S, Jenab M, Biessy C, Sieri S, Palli D, et al. Glycosylated hemoglobin and risk of colorectal cancer in men and women, the European prospective investigation into cancer and nutrition. Cancer Epidemiol Biomark Prev 2008;17(11):3108-15.

74. Vander Heiden MG, Cantley LC, Thompson CB. Understanding the Warburg effect: the metabolic requirements of cell proliferation. Science 2009;324(5930):1029-33.

75. Dregan A, Moller H, Murray-Thomas T, Gulliford MC. Validity of cancer diagnosis in a primary care database compared with linked cancer registrations in England. Population-based cohort study. Cancer Epidemiol 2012;36(5):425-9. 

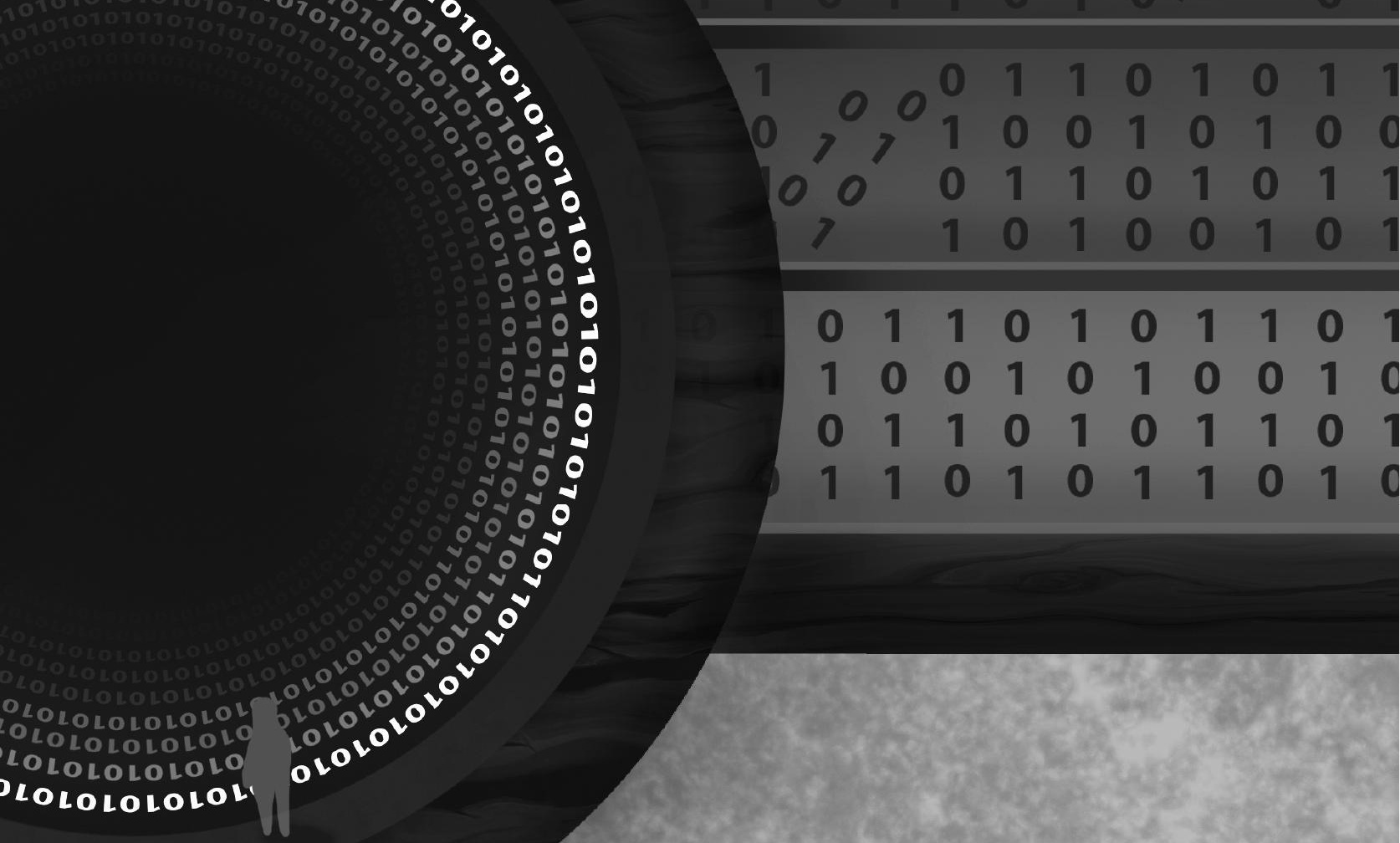

$\begin{array}{llllllllll}0 & 1 & 1 & 0 & 1 & 0 & 1 & 1 & 0 & 1\end{array}$

$\begin{array}{lllllllll}1 & 0 & 0 & 1 & 0 & 1 & 0 & 0 & 1\end{array}$

$\begin{array}{llllllllll}0 & 1 & 1 & 0 & 1 & 0 & 1 & 1 & 0 & 1\end{array}$

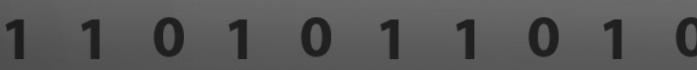

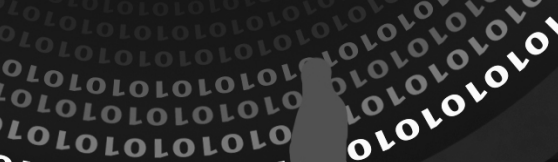
$010^{2}$ 
Summary 



\section{Summary}

Type 2 diabetes mellitus (T2DM) and gastrointestinal (GI) cancer both are increasing global health problems of which the incidence and prevalence are still rising. Over the past decades a growing body of evidence has been collected to support an association between T2DM and GI cancer risk. However, the association between these two entities is complex and is influenced by a wide range of factors. These include pathophysiological mechanisms (e.g. hyperglycaemia and hyperinsulinaemia), confounding due to common, shared risk factors (e.g. obesity, physical inactivity), drug use (e.g. the use of various antidiabetic drugs; ADDs), and different study methodologies which may introduce bias. In this thesis, multiple aspects of the complex association between T2DM and GI cancer were investigated. First, we focussed on the impact of detection bias on the incidence and risk of all types of GI cancer (Chapter 2 and Chapter 3). In this part the thesis, we also paid attention to the comparability of the population in the UK Clinical Practice Research Datalink (CPRD) database for the Dutch population as supportive evidence for the generalizability of study results using the CPRD database (Chapter 4). Second, the risk of GI cancer with use of metformin (Chapter 5) and the risk of (acute and chronic) pancreatitis with use of incretins (Chapter 6) were analysed. Furthermore, the possibility of selection bias in a pharmaco-epidemiological study was highlighted (Chapter 7). Third, we evaluated the association between GI cancer risk and glycaemic control by evaluating the degree of hyperglycaemia over time expressed as glycaemic burden (Chapter 8).

The general introduction of this thesis gives background information on T2DM and $\mathrm{Gl}$ cancer (Chapter 1). Evidence from previous research on the association between both entities is presented and we explain the motivation for our work. Based on existing data and literature, the association between T2DM and GI cancer is complex, not consistently reported, and subject to various methodological issues and unmeasured distortions, such as confounding and detection bias. Studies on the association between T2DM and cancer often focus on cancer in general, or on highly prevalent cancers, such as colorectal cancer, or cancers for which strong associations have previously been described in the literature, such as liver and pancreatic cancer. Evidence for an association between other types of GI cancer (oesophageal cancer, gastric cancer) is less pronounced.

In Chapter 2, incidence rates (IRs; per 100,000 person-years of follow-up) of GI cancers were determined in a British cohort of 333,438 anti-diabetic drug users and 333,438 matched non-diabetic individuals obtained from the CPRD database between 1988 and 2012. This study showed that T2DM patients had higher crude IRs of liver (IR 26, 95\% confidence interval [CI] 24-28 vs. 8.9, 95\% Cl 7.7-10), pancreatic (IR 65, 95\% Cl 62-69 vs. $31,95 \% \mathrm{Cl} 28-34$ ), and colon cancer (IR 119, 95\% Cl 114-124 vs. 109, 95\% Cl 104-114) 
compared to the non-diabetic cohort, whereas the IR of oesophageal cancer was lower (IR 41, 95\% Cl 39-44 vs. 47, 95\% Cl 44-51). Similar results were found in a sensitivity analysis that minimized detection bias by excluding 1 year of follow-up after the index date. A possible sign of detection bias was observed for pancreatic cancer, for which the IR declined from 65 to 48 in the diabetic cohort. However, the difference in IRs for pancreatic cancer between the T2DM and non-diabetic cohort remained statistically significantly elevated.

In Chapter 3, the risks of GI cancer and its subsites were analysed in new users of ADDs compared to matched non-diabetic controls. Data were obtained from the linked database of the Eindhoven region of the Netherlands Cancer Registry and PHARMO institute (E-NCR-PHARMO database) from 1998 through 2011. In order to explore the effects of detection bias on the association between T2DM and GI cancer, Cox regression analyses were performed with and without a 1-year lag-period to estimate hazard ratios (HRs) for GI cancer. In the overall analysis, a $50 \%$ increased risk of GI cancer was found in T2DM patients compared with controls (HR 1.5, 95\% Cl 1.3-1.7), which was attenuated to a $40 \%$ increased risk following adjustment for potential detection bias in the 1-year lagged analysis (HR 1.4, 95\% Cl 1.2-1.7). Stratified by cancer subsite, statistically significant increased risks of pancreatic (HR 4.7, 95\% Cl 3.1-7.2), extrahepatic bile duct (HR 4.2, 95\% Cl 1.5-11.8) and distal colon cancer (HR 1.5, 95\% Cl 1.1-2.1) were found, but not for other GI cancer subsites. The results show that T2DM is mainly associated with hepato-pancreatico-biliary (HPB) type cancers and suggest that detection bias may play in important role in the strength of the association. Moreover, future observational studies should include sensitivity analyses in which detection bias is kept to a minimum by including one or more years of lag-time.

In Chapter 4 we compared the age and sex distribution of the UK CPRD with that of the total Dutch population, in order to judge database representativeness. For this study the age and sex distribution of the UK CPRD were visually and numerically compared with Dutch census data from the StatLine database of the Dutch National Bureau of Statistics in 2011. The age distribution of men and women in CPRD was comparable to the Dutch male and female population. Differences of more than $10 \%$ only occurred in older age categories (75+ in men and $80+$ in women). This unique study was a first step in showing that results from observational studies using CPRD data are applicable to the Dutch population, and thus provide us with a useful resource for decision making in the Netherlands. Nevertheless, in pharmaco-epidemiological studies the generalizability may still be decreased because of differences in drug exposure likelihood between countries, as these differences could cause variations in the actual population studied when selecting individuals based on medication use. We hope that the results of this study 
may encourage scientists from other countries with similar healthcare systems to perform studies of CPRD representativeness.

In Chapter 5 a cohort study was presented evaluating the risk of GI cancer in users of metformin by employing the E-NCR-PHARMO database. Previous studies have shown large protective effects of metformin use on Gl cancer risk. However, time-related biases and other methodological shortcomings have limited the validity of reported risk reductions by metformin thus far. Moreover, recent studies that have used a timevarying approach of metformin exposure could not confirm lower risks of several types of cancer with use of metformin. In our study, patients who had used $\geq 1$ non-insulin antidiabetic drug (NIAD) from 1998 through 2011 were included ( $N=57,621)$. Drug exposure was modelled time-varyingly using 90-day time intervals, with exposure to metformin or other NIADs classified as 'current use' or 'past use' based on the drug prescriptions prior to the start of each 90-day time interval. Time-dependent Cox regression analyses were used to estimate HRs of Gl cancers in current metformin users versus current users of other NIADs, adjusted for various confounding variables. Furthermore, sensitivity analyses were performed using a new-user cohort of incident NIAD users only. We showed that current use of metformin was not associated with a decreased risk of $\mathrm{Gl}$ cancer [HR, 0.97; 95\% Cl 0.82-1.15] or specific $\mathrm{Gl}$ cancer sites. The sensitivity analyses yielded comparable results. Also, no dose-response trends were observed with increasing cumulative dose of metformin. In line with the recent evidence, we concluded that no decreased risk of Gl cancer was present with current use of metformin compared with current use of other NIADs.

In Chapter 6 we determined the risk of any, acute, and chronic pancreatitis with the use of incretin agents (dipeptidyl peptidase-4 [DPP-4] inhibitors and glucagon-like peptide-1 receptor agonists [GLP-1RA]). A population-based cohort study was conducted using data from the UK CPRD during 2007 to 2012. A total of 182,428 patients with $\geq 1$ NIAD prescription were included and matched to non-diabetic control subjects. Using Cox regression analysis, adjusted HRs of pancreatitis were estimated in incretin-users $(\mathrm{N}=28,370)$ compared with non-diabetic controls and with other NIAD users. Focusing on the comparison between incretin-users and users of other NIADs, we found that current incretin users had a 1.5-fold increased risk of any pancreatitis compared with other NIAD users (adjusted HR 1.47, 95\% Cl 1.06-2.04), but not of acute or chronic pancreatitis (adjusted HR 1.42, 95\% Cl 0.98-2.06 and adjusted HR 0.87, 95\% Cl 0.45-1.69 respectively). In incident current incretin users the risk of any and acute pancreatitis was doubled as compared with other NIAD users (adjusted HR 2.12, 95\% Cl 1.31-3.43 and adjusted $\mathrm{HR}$ 1.96, 95\% $\mathrm{Cl} 1.13-3.41$ ), whereas there was no increased risk found for chronic pancreatitis (adjusted HR 1.24, 95\% Cl 0.44-3.50). Interestingly, there was an increased risk of acute pancreatitis in current users of DDP-4 inhibitors only (adjusted HR 
1.59, 95\% Cl 1.05-2.40), suggesting that differences in the pharmacodynamics properties of different types of incretins may be important for the incretin-pancreatitis link. We showed in this study that the use of incretins was associated with an increased risk of pancreatitis. An association with chronic pancreatitis was not observed, possibly due to a low number of events. However, the evidence regarding the association between incretins and pancreatitis remains conflicting in the literature. Therefore, we believe that consequent monitoring of potential side effects by means of periodic safety update reports remains warranted.

In Chapter 7, by means of a letter to the editor, we commented on a pharmacoepidemiological study by Chin-Hsiao Tseng published in the European Journal of Cancer in 2016. ${ }^{1}$ The author investigated the risk of kidney cancer with use of metformin using a Taiwanese National Health Insurance reimbursement database. We noted that a significant selection bias may have occurred during the allocation process of individuals to the treatment group of never users of metformin. Patients using other antidiabetic drugs before they start with metformin were excluded from the study population $(\mathrm{N}=200,785)$. Therefore, possible follow-up time designated for the group of never users of metformin was wrongfully excluded from the analysis. We suggested Dr. C.-H. Tseng to reanalyse the risk of kidney cancer in users of metformin compared to non-users of metformin without the potential selection bias. Furthermore, in this comment it is also underlined that costly drug trials should be discouraged based on methodologically inaccurate studies.

In Chapter 8, we explored whether multiple high levels of glycosylated haemoglobin (HbA1c) over time impacts Gl cancer risk in T2DM patients using a novel measure of hyperglycaemia called glycaemic burden (GB). In previous studies it has been shown that high levels of $\mathrm{HbA} 1 \mathrm{c}$ are associated with an increased Gl cancer risk in T2DM patients. However, these studies mainly use single, time-fixed measures of $\mathrm{HbA} 1 \mathrm{c}$ as determinant in regression models, and therefore do not account for fluctuations in the level of hyperglycaemia over time. A cohort study was performed using the E-NCR-PHARMO database. All incident patients aged $\geq 30$ years using $\geq 1$ NIAD were included. All HbA1C measurements recorded between the first NIAD prescription and the end of follow-up were used to calculate GB. GB was based on the extent and duration that $\mathrm{HbA} 1 \mathrm{c}$ values exceeded a threshold of $7 \%(53 \mathrm{mmol} / \mathrm{mol})$ and was expressed as glycaemic burden years (GBY). The association between GBY and GI cancer was analysed using Cox regression analysis, with GBY entered in the regression model as a time-dependent categorical variable (no burden [0 GBY], >0-1.0 GBY, and >1.0 GBY). During >60,000 person-years of follow-up, $285 \mathrm{Gl}$ cancers were observed. Compared to patients with $>0-1.0 \mathrm{GBY}$, patients in the 0 GBY category (no burden) had a decreased risk of GI cancer (HR 0.71, 95\% Cl 0.53-0.96), but patients with >1.0 GBY did not have a further increased 
risk of $\mathrm{Gl}$ cancer (HR 1.15, 95\% Cl 0.84-1.57). For hepato-pancreatico-biliary tract (HPB) cancer, however, increased levels of GBY were associated with an increased risk of cancer. This was the first study investigating the association between GB and GI cancer risk. Therefore, future studies are warranted to further investigate the clinical value of $\mathrm{GB}$ as determinant of cancer risk. Of note, residual confounding and selection bias may have influenced the results.

In Chapter 9 the general discussion of this thesis is presented. Here the results of our studies are reflected upon in light of the currently available evidence. First, the general association between T2DM and GI cancer and its subsites is discussed in detail, while also looking at pathophysiological mechanisms and important confounders. We concluded that a diagnosis of T2DM is associated with a higher risk of GI cancer, mainly driven by an increased risk of HPB type cancers, but not by other GI cancer sites. However, residual confounding due to unmeasured or unaccounted risk factors may have influenced the results of our studies and those in the literature. Furthermore, detection bias is an important type of bias that may have inflated previously reported risk estimates of $\mathrm{Gl}$ cancer risk in patients with T2DM, especially for pancreatic cancer. Also, it is still unclear how the latency time of cancer affects the association between T2DM and Gl cancer. Second, focussing on the association between the use of antidiabetic drugs and GI cancer, we discussed that the use of metformin was not associated with a decreased risk of $\mathrm{Gl}$ cancer or its subsites. Therefore, clinical trials investigating the use of metformin as chemopreventive agent are not recommended. In contrast to more recent evidence, we found an increased risk of acute pancreatitis, but not of chronic pancreatitis, in users of incretins. In light of the mixed results and the fact that stratified results for acute and chronic pancreatitis have been reported for the first time in this thesis, additional studies on this association are warranted. Third, after examining the evidence on the association between hyperglycaemia and Gl cancer risk, we concluded that glycaemic burden (the degree of hyperglycaemia over time) may be associated with a higher GI cancer risk. However, future studies are needed to replicate and build upon our initial findings. Overall, Dutch clinicians should be aware of the association between T2DM and GI cancer, especially liver, biliary tract, and pancreatic cancer, in particular in patients newly diagnosed with T2DM or who are inadequately controlled. 


\section{References}

1. Tseng $\mathrm{CH}$. Use of metformin and risk of kidney cancer in patients with type 2 diabetes. Eur J Cancer 2016;52:19-25. 


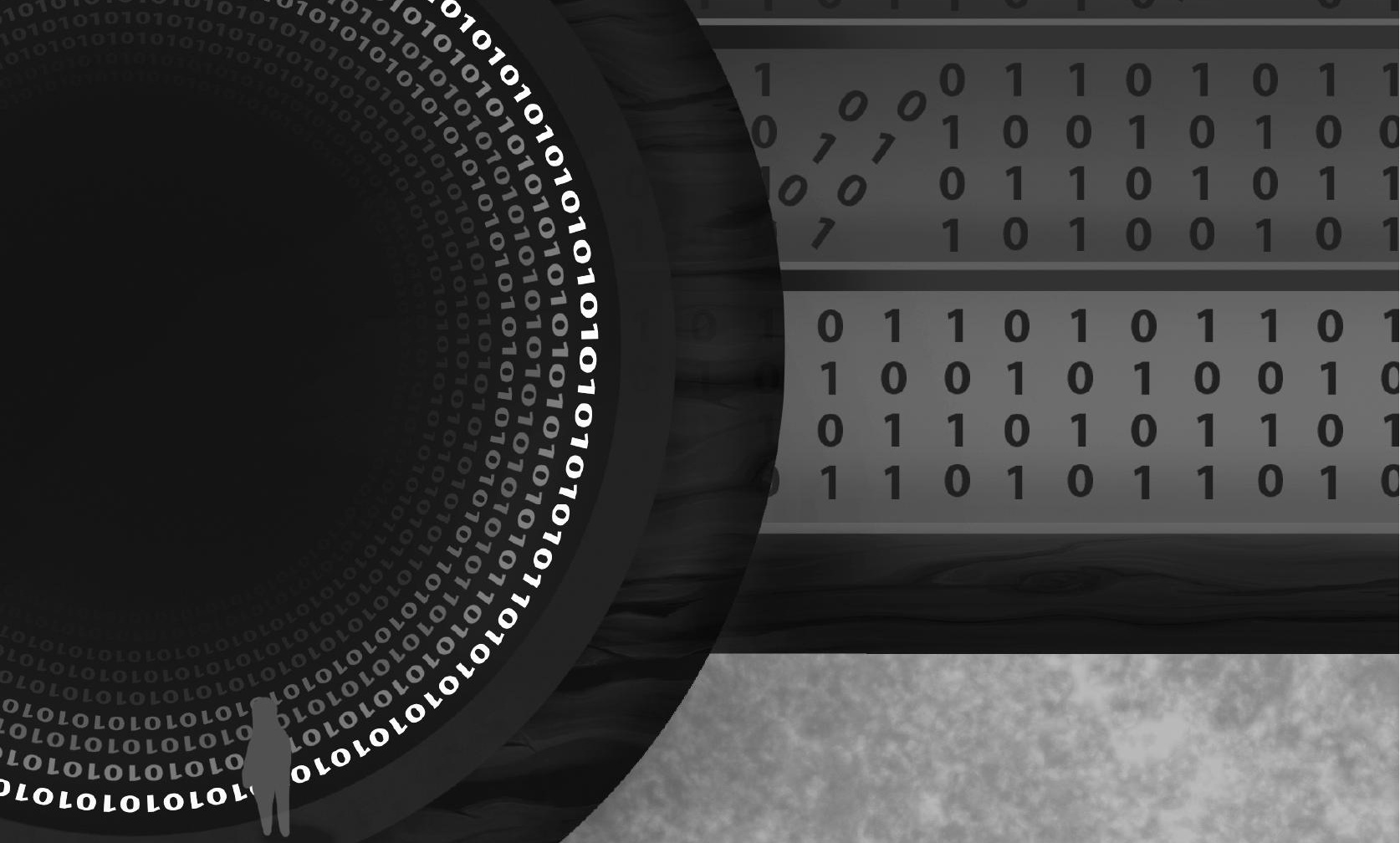

$\begin{array}{llllllllll}0 & 1 & 1 & 0 & 1 & 0 & 1 & 1 & 0 & 1\end{array}$

$\begin{array}{lllllllll}1 & 0 & 0 & 1 & 0 & 1 & 0 & 0 & 1\end{array}$

$\begin{array}{llllllllll}0 & 1 & 1 & 0 & 1 & 0 & 1 & 1 & 0 & 1\end{array}$

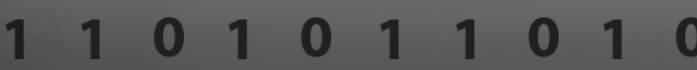

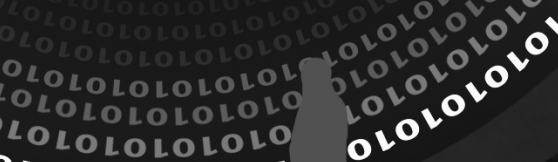
$010^{2}$ 
Nederlandse samenvatting 



\section{Nederlandse samenvatting}

Diabetes mellitus type 2 (DM2) en gastrointestinale (GI) tumoren vormen wereldwijd een steeds groter probleem. Zowel de incidentie als prevalentie van beide ziekten lopen op. In de afgelopen decennia is meer bewijs ontstaan voor een associatie tussen DM2 en het risico op de ontwikkeling van GI tumoren. Ook is gebleken dat het een zeer complexe associatie is, die wordt beïnvloed door diverse factoren. Deze factoren betreffen: pathofysiologische mechanismen (bijv. hyperglycaemie en hyperinsulinemie), vertekening van studieresultaten door de aanwezigheid van gezamenlijke risicofactoren (bijv. obesitas, onvoldoende lichaamsbeweging), medicatiegebruik (bijv. het gebruik van verschillende anti-diabetica) en variaties in onderzoeksmethodes, waardoor vertekening van resultaten kan optreden.

In dit proefschrift zijn meerdere aspecten van de complexe associatie tussen DM2 en GI tumoren onderzocht. Allereerst hebben we ons gericht op de invloed van detectiebias op de incidentie van, en het risico op Gl tumoren (Hoofdstuk 2 en Hoofdstuk 3). Ook schonken we in dit deel van het proefschrift aandacht aan de vergelijkbaarheid van de populatie in de Clinical Practice Research Datalink (CPRD) uit het Verenigd Koninkrijk (VK) met de algehele Nederlandse bevolking (Hoofdstuk 4). Daarmee hebben we bewijs willen vinden voor de generaliseerbaarheid van resultaten uit CPRD-studies voor de Nederlandse bevolking. Ten tweede zijn de effecten van het gebruik van twee antidiabetica onderzocht, respectievelijk in een studie naar het risico op Gl tumoren bij gebruikers van metformine (Hoofdstuk 5) en in een onderzoek naar het risico op (acute en chronische) pancreatitis bij gebruik van incretines (Hoofdstuk 6). Daarnaast wierpen we een kritische blik op het optreden van selectiebias in farmaco-epidemiologisch onderzoek (Hoofdstuk 7). Ten derde is de associatie bekeken tussen het risico op GI tumoren en de mate van hyperglycaemie in de tijd. Hierbij hebben we gebruik gemaakt van een nieuwe variabele genaamd 'glycaemische last' (Glycaemic burden; Hoofdstuk 8).

Hoofdstuk 1 bevat de algemene introductie. Hierin staat de achtergrondinformatie over DM2 en Gl tumoren beschreven, evenals de bewijslast uit voorgaand onderzoek betreffende hun onderlinge associatie, en de onderbouwing voor de studies in dit proefschrift. Tot op heden is gebleken dat de associatie tussen DM2 en GI tumoren complex is. Studieresultaten zijn inconsistent en worden beïnvloed door verschillende methodologische problemen en vertekening, waaronder confounding en detectiebias. In het verleden richtten observationele studies zich vooral op kanker in het algemeen, frequent voorkomende tumoren, of tumoren waarvan een sterke relatie al was beschreven in de literatuur. Voor meer zeldzame typen GI tumoren, zoals slokdarm- en maagkanker, is minder bewijslast te vinden in de literatuur. Derhalve zijn in dit proefschrift meerdere aspecten van de complexe associatie tussen DM2 en GI tumoren 
onder de loep genomen, met speciale aandacht voor de rol van anti-diabetica, glucoseregulatie, en methodologische aspecten.

In Hoofdstuk 2 werd de incidentie (incidence rate per 100.000 persoonsjaren; IR) van GI tumoren berekend in een Brits cohort dat bestond uit 333.438 gebruikers van antidiabetica (DM2 populatie) en eenzelfde aantal personen zonder DM2. De data werden verkregen van de CPRD database tussen 1988 en 2012. Patiënten met DM2 bleken hogere IR's te hebben voor leverkanker (IR 26, 95\% betrouwbaarheidsinterval [BI] 24-28 vs. $8,9,95 \% \mathrm{BI} 7,7-10$ ), alvleesklierkanker (IR 65, 95\% BI 62-69 vs. 31, 95\% BI 28-34) en dikkedarmkanker (IR 119, 95\% BI 114-124 vs. 109, 95\% BI 104-114) vergeleken met individuen zonder DM2. Daarentegen zagen we een lagere IR voor slokdarmkanker in de diabetespopulatie (IR 41, 95\% BI 39-44 vs. 47, 95\% BI 44-51). Vergelijkbare resultaten werden gezien in de sensitiviteitsanalyse waarbij het eerste jaar na start van follow-up werd geëxcludeerd uit de analyse. Door exclusie van het eerste follow-upjaar in deze sensitiviteitsanalyse werd de invloed van detectiebias op de IR verminderd. In geval van alvleesklierkanker leek detectiebias een rol te spelen. Bij exclusie van het eerste followupjaar verminderde de IR voor alvleesklierkanker in de diabetespopulatie namelijk van 65 naar 48. Echter, de IRs voor alvleesklierkanker bij patiënten met DM2 bleef statistisch significant hoger dan bij mensen zonder DM2.

In Hoofdstuk 3 werd het risico op de ontwikkeling van de verschillende GI tumoren geanalyseerd in nieuwe gebruikers van anti-diabetica (patiënten met DM2) ten opzichte van gematchte controlepatiënten zonder anti-diabetica (mensen zonder DM2). Hierbij werd gebruik gemaakt van de koppeling van de kankerregistratie van het IKNL Regio Zuid (voorheen bekend als Integraal Kankercentrum Zuid [IKZ]) aan het datanetwerk van het PHARMO Instituut, oftewel het IKZ-PHARMO cohort, tussen 1998 en 2011. Om de effecten van detectiebias op de associatie tussen DM2 en Gl tumoren te analyseren werden Cox regressie analyses verricht met en zonder latente periode van 1 jaar (bijv. tumoren die gediagnosticeerd werden $<1$ jaar na de start van follow-up werden geëxcludeerd voor de berekening van het kankerrisico). In de analyse zonder latente periode hadden patiënten met DM2 een 50\% verhoogd risico op de ontwikkeling van GI tumoren (hazard ratio [HR] 1,5, 95\% BI 1,3-1,7) vergeleken met individuen zonder DM2. Dit risico verminderde naar $40 \%$ na toevoeging van een latente periode van 1 jaar in de analyse, waardoor mogelijke detectiebias afnam ( $\mathrm{HR}$ 1,4, 95\% BI 1,2-1,7). In de subanalyse gestratificeerd naar tumorlocatie vonden we statistisch significant verhoogde risico's voor alvleesklierkanker (HR 4,7, 95\% BI 3,1-7,2), extrahepatische galwegkanker (HR 4,2, 95\% BI 1,5-11,8) en distale dikkedarmkanker (HR 1,5, 95\% BI 1,1-2,1) bij patiënten met DM2 vergeleken met mensen zonder DM2. Voor andere $\mathrm{Gl}$ tumorsubtypen werden geen verhoogde risico's gevonden. Uit deze resultaten blijkt dat DM2 voornamelijk geassocieerd is met tumoren van alvleesklier- en galwegstelsel. 
Bovendien konden we concluderen dat detectiebias een rol speelt bij de sterkte van de associatie ofwel de hoogte van het berekende risico of Gl tumoren. Voor toekomstig onderzoek is het daarom van belang om altijd sensitiviteitsanalyses te verrichten waarin detectiebias zoveel mogelijk wordt beperkt.

In Hoofdstuk 4 werden de leeftijds- en geslachtsverdeling van de CPRD database vergeleken met die van de Nederlandse bevolking. Het doel van deze studie was om een eerste stap te zetten om de toepasbaarheid van de CPRD database te beoordelen voor de Nederlandse populatie. Hiervoor werden voor het jaar 2011 de leeftijds- en geslachtsverdeling van de CPRD vergeleken met Nederlandse censusdata van de Statline database van het Centraal Bureau voor de Statistiek (CBS) en verschillen visueel en numeriek weergegeven. Voor zowel mannen als vrouwen bleek de leeftijdsverdeling tussen de twee databases vergelijkbaar. Verschillen in aantallen personen per leeftijdscategorie van $10 \%$ of meer kwamen enkel voor in hogere leeftijdsgroepen (75+ bij mannen en $80+$ bij vrouwen). Met deze studie is een eerste stap gezet om te beoordelen of resultaten uit observationeel onderzoek met de CPRD database toepasbaar zijn op de Nederlandse bevolking. Hiermee zou CPRD een zeer behulpzame bron kunnen zijn voor het maken van beleidsplannen in Nederland. Echter, in geval van farmaco-epidemiologisch onderzoek blijft het van belang om verschillen in blootstelling aan medicijnen of voorschrijfgedrag van artsen mee te nemen. Dit kan namelijk een belangrijk effect hebben op de generaliseerbaarheid van studieresultaten. Desalniettemin hopen wij dat deze eerste studie onderzoekers uit andere landen met vergelijkbare zorgsystemen inspireert om dergelijke studies naar toepasbaarheid van databases te verrichten.

In Hoofdstuk 5 werd een cohortstudie gepresenteerd, waarin het risico op GI tumoren bij gebruikers van metformine werd geëvalueerd. Voor deze studie werd opnieuw gebruik gemaakt van het IKZ-PHARMO cohort. Voorgaande onderzoeken hebben grote beschermende effecten van metformine laten zien op het Gl tumorrisico. Echter, het is gebleken dat meerdere van deze studies te maken hadden met methodologische problemen zoals tijd-gerelateerde bias, waarbij blootstelling aan metformine inadequaat werd geclassificeerd. Deze vorm van bias beperkt de validiteit van de gevonden lagere tumorrisico's bij gebruikers van metformine. Recentere studies, waarin blootstelling aan metformine adequaat was geclassificeerd, hebben geen verlaagd tumorrisico kunnen vaststellen bij gebruikers van metformine. Voor onze studie hebben we patiënten geïncludeerd die $\geq 1$ anti-diabeticum hadden gebruikt (exclusief insuline; non-insulin antidiabetic drug [NIAD]) tussen 1998 en 2011 ( $N=57.621$ ). Blootstelling aan medicatie werd tijdsafhankelijk gemodelleerd door gebruik te maken van tijdsintervallen van 90 dagen. Blootstelling aan metformine of andere NIAD's werd geclassificeerd als 'huidig' of 'voorheen' door te kijken naar medicatierecepten voorafgaand aan elk 90-dagen 
tijdsinterval. Tijd-afhankelijke Cox regressieanalyses werden toegepast om het risico op GI tumoren te berekenen bij huidige gebruikers van metformine vergeleken met huidige gebruikers van andere NIAD's, gecorrigeerd voor confounders. Daarnaast werden sensitiviteitsanalyses verricht waarbij gebruik werd gemaakt van een cohort van incidente (nieuwe) gebruikers van NIAD's (new-user cohort). Via deze aanpak konden we laten zien dat huidige gebruik van metformine niet geassocieerd was met een verlaagd risico op GI tumoren [HR 0,97; 95\% BI 0,82-1,15]. De sensitiviteitsanalyses met het incidente NIAD cohort toonden vergelijkbare resultaten. Ook werd er geen relatie gevonden tussen het Gl tumorrisico en de cumulatieve dosering van metformine. Met deze resultaten konden we concluderen dat gebruik van metformine niet geassocieerd was met een verlaagd GI tumorrisico, zoals ook andere recente studies lieten zien.

In Hoofdstuk 6 werd het risico bepaald op het optreden van pancreatitis (alvleesklierontsteking) bij gebruik van incretines (dipeptidylpeptidase-4 [DPP-4] inhibitoren en glucagon-like peptide-1 receptor agonisten [GLP-1RAn]). Als uitkomstmaat werd zowel gekeken naar pancreatitis in het algemeen als acute en chronische pancreatitis. Er werd een cohortstudie uitgevoerd met data van de CPRD database van 2007 tot 2012. Alle patiënten met $\geq 1$ voorschrift voor een NIAD werden geïncludeerd ( $N=182.428)$ en gematcht aan controlepatiënten zonder DM2. Via Cox regressieanalyse werden gecorrigeerde HR's berekend voor pancreatitis bij gebruikers van incretines $(\mathrm{N}=28.370)$ vergeleken met gebruikers van andere NIAD's. Huidige gebruikers van incretines hadden een verhoogd risico op pancreatitis in het algemeen ( HR 1,47, 95\% Bl 1,06-2,04), maar geen verhoogd risico op acute of chronische pancreatitis (HR 1,42,95\% BI 0,98-2,06 en HR 0,87, 95\% BI 0,45-1,69). Bij incidente, huidige gebruikers van incretines was het risico op pancreatitis in het algemeen en op acute pancreatitis tweemaal zo hoog in vergelijking met gebruikers van andere NIAD's ( $H R$ 2,12, 95\% BI 1,31-3,43 en HR 1,96, 95\% BI 1,13-3,41). Overigens was er een verhoogd risico op acute pancreatitis bij huidige gebruikers van enkel DPP-4 inhibitoren ( $H R$ 1,59, 95\% BI 1,05-2,40) en niet bij GLP-1RAn, wat suggereert dat verschillen in farmacologische eigenschappen mogelijk een rol spelen bij de relatie tussen incretines en pancreatitis. Concluderend hebben we in deze studie laten zien dat gebruik van incretines geassocieerd is met het risico op pancreatitis. Een associatie met chronische pancreatitis werd niet gezien, mogelijk door een zeer laag aantal gevallen van chronische pancreatitis in de populatie. Echter, de literatuur over de associatie tussen incretines en pancreatitis is vooralsnog zeer verdeeld. Hierdoor adviseren wij dat het monitoren van mogelijke bijwerkingen van incretines via periodieke veiligheidsrapporten van belang blijft.

In Hoofdstuk 7 gaven we via een ingezonden brief kritiek op een farmacoepidemiologische studie van Chin-Hsiao Tseng die in 2016 werd gepubliceerd in het 
European Journal of Cancer. Deze onderzoeker analyseerde het risico op nierkanker bij gebruikers van metformine met behulp van een Taiwanese nationale zorgverzekeringsdatabase. In het artikel viel ons op dat er mogelijk selectiebias was opgetreden tijdens het toewijzen van individuen aan specifieke behandelgroepen, namelijk de groep van personen die nooit metformine hebben gebruikt (never users). Personen met DM2 die andere anti-diabetica gebruikten vóórdat zij startten met het middel metformine werden geëxcludeerd van de studiepopulatie ( $N=200.785)$. Derhalve ging er mogelijk follow-up tijd verloren die was bestemd voor de groep never users van metformine. We hebben Dr. C.-H. Tseng daarom de suggestie gedaan om het risico op nierkanker bij gebruikers van metformine opnieuw te analyseren zonder deze bron van selectiebias. Verder sluit deze reactie op de studie van Dr. C.-H. Tseng aan op het debat over het feit dat dure medicijnproeven moeten worden afgeraden als het onderliggende bewijs methodologisch inaccuraat is.

In Hoofdstuk 8 werd onderzocht of de mate van hyperglycaemie over de tijd geassocieerd was met een verhoogd risico op GI tumoren. Hoewel een hoog HbA1cgehalte als maat voor langdurige hyperglycaemie in het verleden geassocieerd is met een verhoogd risico op GI tumoren bij DM2 patiënten, betrof dit meestal studies waarin enkelvoudige of statische variabelen met $\mathrm{HbA} 1 \mathrm{c}$ werden gebruikt in de regressiemodellen. Daardoor hielden deze studies geen rekening met fluctuaties van het $\mathrm{HbA1c}$-gehalte in de tijd. Om dit te kunnen analyseren werd een cohortstudie verricht met behulp van het IKZ-PHARMO cohort. Alle incidente gebruikers van NIAD's van 30 jaar of ouder werden geïncludeerd. De mate van hyperglycaemie in de tijd werd berekend tussen de start van de eerste NIAD en het einde van follow-up. Hiervoor werd een nieuwe variabele gebruikt, genaamd 'glycaemische last' (glycaemic burden; GB). De GB was gedefinieerd als de mate en de duur dat de HbAlc-waarde van een patiënt boven een drempelwaarde van $7 \%(53 \mathrm{mmol} / \mathrm{mol})$ uitkwam. Om rekening te houden met verschillen in follow-upduur werd de GB gedeeld door het aantal jaren follow-up, resulterende in de variabele glycaemic burden years (GBY) die werd gebruikt in de regressiemodellen. De associatie tussen GBY en Gl tumoren werd vervolgens geanalyseerd door middel van Cox regressieanalyse, met GBY als tijd-afhankelijke categorische variabele (geen glycaemische last [0 GBY], >0-1,0 GBY en >1,0 GBY). Tijdens meer dan 60.000 persoonsjaren aan follow-up werden $285 \mathrm{Gl}$ tumoren vastgesteld. Vergeleken met patiënten met >0-1,0 GBY hadden patiënten in de categorie 0 GBY (geen glycaemische last) een verlaagd risico op $\mathrm{Gl}$ tumoren (HR 0,71,95\% BI 0,53-0,96). Daarentegen hadden patiënten in de categorie $>1,0$ GBY geen verhoogd risico op $\mathrm{Gl}$ tumoren (HR 1,15, 95\% BI 0,84-1,57). Voor HPB-type tumoren vonden we echter wel dat een hogere GBY categorie geassocieerd was met een hoger risico. Met deze studie waren wij de eersten die de associatie tussen GB en de ontwikkeling van GI tumoren 
onderzochten. Wel konden onze resultaten onderhevig zijn aan selectiebias en confounding. Toekomstig onderzoek zal daarom verder moeten uitwijzen of GB een waardevolle toevoegde waarde heeft voor de klinische praktijk als maat voor GI tumorrisico.

In Hoofdstuk 9 werden de resultaten van onze studies geïnterpreteerd en gereflecteerd aan de hand van de huidige beschikbare literatuur. Allereerst werd de algemene associatie tussen T2DM en Gl tumoren in detail besproken. Hierbij werd ook gekeken naar mogelijke pathofysiologische mechanismen en belangrijke confounders. We concludeerden dat een diagnose van DM2 geassocieerd is met een hoger risico op G1 tumoren en dat dit verhoogde risico voornamelijk lijkt te worden gegenereerd door een hoger risico op HPB-type tumoren. Echter, studieresultaten kunnen onderhevig zijn aan enige vertekening indien voor belangrijke confounding factoren niet wordt gecorrigeerd in de analyses. Daarnaast is detectiebias een belangrijke vorm van bias die de hoogte van de gevonden risico's in voorgaande gepubliceerde studies mogelijk heeft verhoogd; dit geldt met name voor alvleesklierkanker. Verder is het op dit moment niet duidelijk welke invloed de latente periode van kanker precies heeft op de associatie tussen DM2 en GI tumoren. Ten tweede werd de associatie tussen anti-diabetica en het risico op GI tumoren besproken. We concludeerden dat metformine niet geassocieerd is met een lager Gl tumorrisico, zoals in eerder onderzoek werd gesuggereerd. Om deze reden raden wij het opzetten van medicijnproeven met metformine als anti-tumormedicijn af. In tegenstelling tot recente literatuur, vonden wij bij gebruik van incretines een verhoogd risico op acute pancreatitis, maar niet op chronische pancreatitis. Gezien de tegenstrijdige resultaten in de literatuur, en het feit dat in onze studie voor het eerst gerapporteerd werd over chronische pancreatitis als uitkomstmaat, is verder onderzoek naar de associatie tussen pancreatitis en incretines van belang. Ten derde werd het bewijs voor een associatie tussen hyperglycaemie en GI tumorrisico opgesomd. Uit onze studie bleek dat de mate van hyperglycaemie in de tijd, uitgedrukt in GBY, mogelijk geassocieerd is met een hoger risico op GI tumoren. Echter, verder onderzoek is nodig om onze resultaten te repliceren en om voort te bouwen op onze eerste bevindingen. In het algemeen kunnen we vaststellen dat Nederlandse artsen zich bewust moeten zijn van de associatie tussen DM2 en GI tumoren. Opvallend zijn vooral de associaties tussen DM2 en HPB-type tumoren, met nieuw gediagnosticeerde DM2 en met inadequate glucoseregulatie. 


\section{Referenties}

1. Tseng $\mathrm{CH}$. Use of metformin and risk of kidney cancer in patients with type 2 diabetes. Eur J Cancer 2016;52:19-25. 

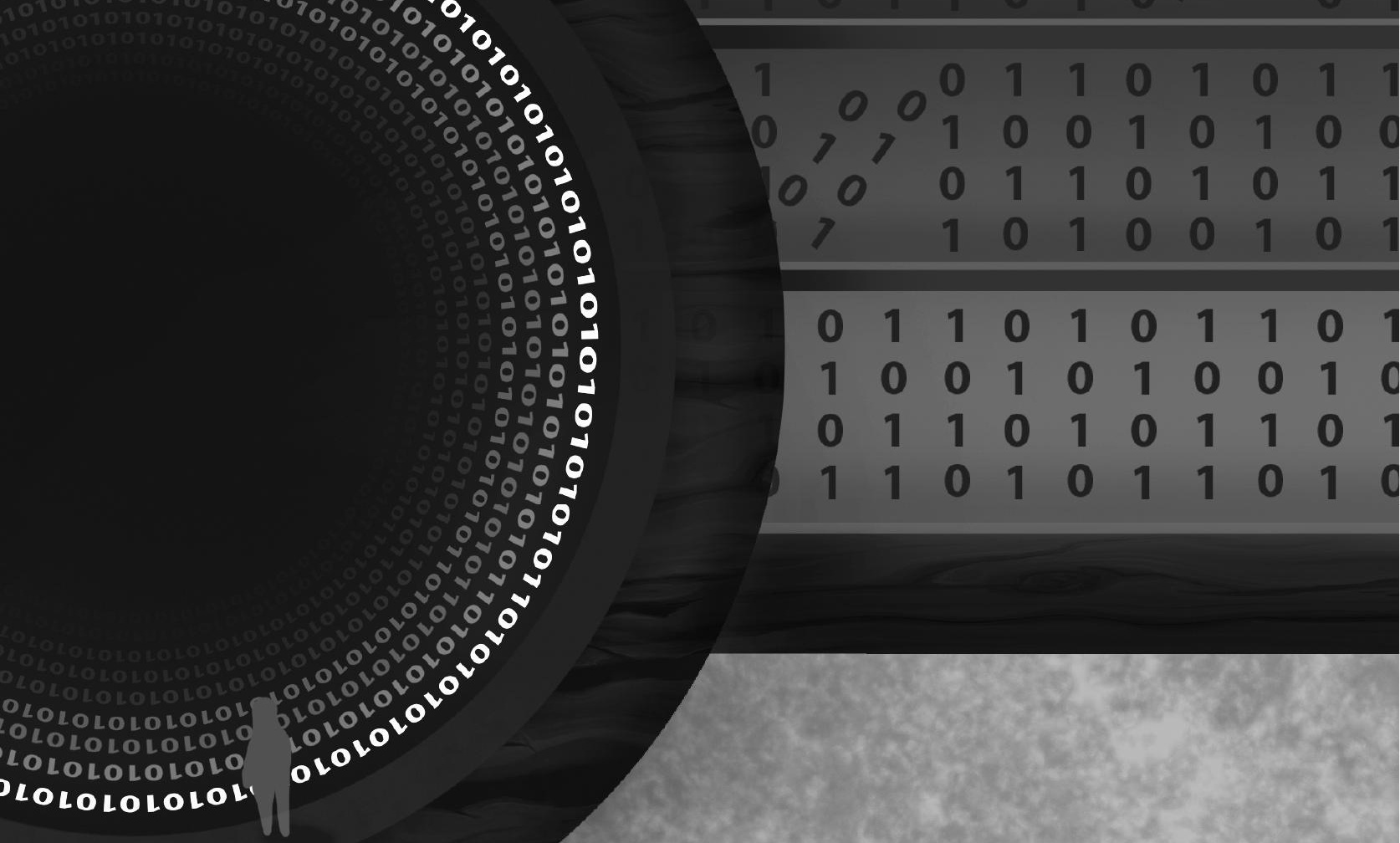

$\begin{array}{llllllllll}0 & 1 & 1 & 0 & 1 & 0 & 1 & 1 & 0 & 1\end{array}$

$\begin{array}{lllllllll}1 & 0 & 0 & 1 & 0 & 1 & 0 & 0 & 1\end{array}$

$\begin{array}{llllllllll}0 & 1 & 1 & 0 & 1 & 0 & 1 & 1 & 0 & 1\end{array}$

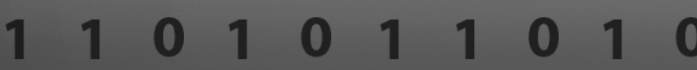

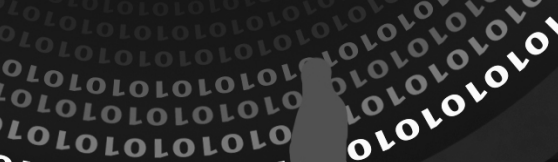
$010^{2}$ 
Valorisation 



\section{Valorisation}

\section{Value for society}

Over the past decades a rise in the incidence and prevalence of both type 2 diabetes mellitus (T2DM) and gastrointestinal (GI) cancer has been observed. Determining whether T2DM is an important risk factor for the development of GI cancer - and to what degree - helps governmental and medical institutions decide if T2DM is a possible target for cancer prevention or if patients with T2DM form a population that needs targeted (GI) cancer screening. In this thesis, we investigated the complex association between T2DM and GI cancer, focussing on the influence of a variety of factors on the association. In Chapter 2 we found higher incidence rates of liver, pancreatic and colon cancer in patients with T2DM compared with individuals without T2DM. In Chapter 3, a $40 \%$ increased risk of Gl cancer was found, which seemed mainly driven by increased risks of hepato-pancreatico-biliary type cancers. In both chapters, evidence of detection bias influencing the strength of the association was seen. The results of these studies help to determine the strength of the association between T2DM and Gl cancer, which can be used for future scientists and policymakers to decide whether targeted cancer screening of individuals with T2DM is needed.

In the past, multiple studies have pointed to lower risks of (GI) cancers in users of metformin compared to users of other anti-diabetic drugs. The results of these studies formed the basis for the launch of numerous drug trials to investigate the possibility of repurposing metformin as globally used first-line anti-diabetic drug to a more chemotherapeutic agent. There are currently over 100 clinical drug trials being conducted investigating the effect of metformin as therapeutic agent in the treatment of various cancers (www.clinicaltrials.gov; accessed on April 11, 2019). However, evidence has come to light that many previous studies on the risk of cancer with use of metformin have been afflicted by time-related biases, thereby inflating the protective effects of metformin on cancer development. More recent studies and our study presented in Chapter 5, using a time-dependent definition of drug exposure in order to minimize time-related bias, showed no differences in risk of Gl cancers in users of metformin compared to users of other non-insulin anti-diabetic drugs. Therefore, our results add to the debate whether performing costly drug trials is justified when purely based on (biased) information from observational studies. We recommend to replicate welldesigned pharmaco-epidemiological studies with minimal time-related bias to gain more robust evidence that indeed no association is present between the use of metformin and (GI) cancer risk. 


\section{Value for professionals}

Investigating complications of type 2 diabetes mellitus, including the risk for cancer development, is important for clinical practice. Generally, clinicians managing patients with T2DM are aware of the development of diabetic retinopathy, nephropathy, and neuropathy. If future research shows more concrete evidence of a causal biological link between T2DM and development of cancer, then clinicians can be more aware of this additional serious complication. Based on the evidence presented in this thesis, an association between T2DM and GI cancer is present, with a $40 \%$ increased risk of GI cancer in the T2DM population versus the non-diabetic population (Chapter 2). However, a causal link could not be proven with the studies in this thesis, and detection bias (Chapters 2 and 3 ) and residual confounding due to unmeasured confounding variables may be present. Furthermore, in Chapter 8 , a lower risk of $\mathrm{Gl}$ cancer was found in patients with T2DM without glycaemic burden compared to patients with up to one year of glycaemic burden. Although future studies are needed to confirm these findings, our results indicate that more stringent glycaemic control in patients with T2DM may be beneficial by reducing the risk of $\mathrm{Gl}$ cancer.

\section{Value for future research}

Most of the research in this thesis is part of an endeavour to learn more about the complex association between T2DM and GI cancer. First, the evidence presented in Chapters 2 through 9 will help to develop future research on the link between T2DM and GI cancer. For example, it is important to perform sensitivity analyses that include one or more years of lag period between the (assumed) onset of T2DM and the diagnosis of a (GI) cancer in order to minimize detection bias (Chapter 2). Furthermore, when investigating the association between (anti-diabetic) drugs and (GI) cancer, it is important to use a time-dependent covariate of drug exposure in order to capture variations in drug exposure over time (Chapters 3 and 6 ).

Second, in Chapter 4 we showed that the age- and sex distribution of the Clinical Practice Research Datalink (CPRD) is comparable to that of the total Dutch population. Investigating the generalizability of populations contained in large population-based databases will help translating study results to other populations. The results of our study can encourage scientists from other countries with similar healthcare systems to perform studies of CPRD representativeness.

Third, we were the first to investigate the association between a novel marker of hyperglycaemia of time, called 'glycaemic burden', and the risk of GI cancer (Chapter 8). As this is the first study more research is needed to confirm our findings and build on evidence that is currently presented. 
Finally, based on our data no causal link between T2DM and Gl cancer can be established. As the underlying pathophysiological mechanisms between T2DM and GI cancer remain to be elucidated, more basic research focusing on mechanistic aspects is needed.

In summary, while an association between T2DM and GI cancer has been clearly established, much is to be learned about their causal relationship and biological mechanisms that lead up to it. The results of the studies in this thesis will help develop future (observational) research on the link between T2DM and GI cancer and encourage other scientist to study the complex association. 

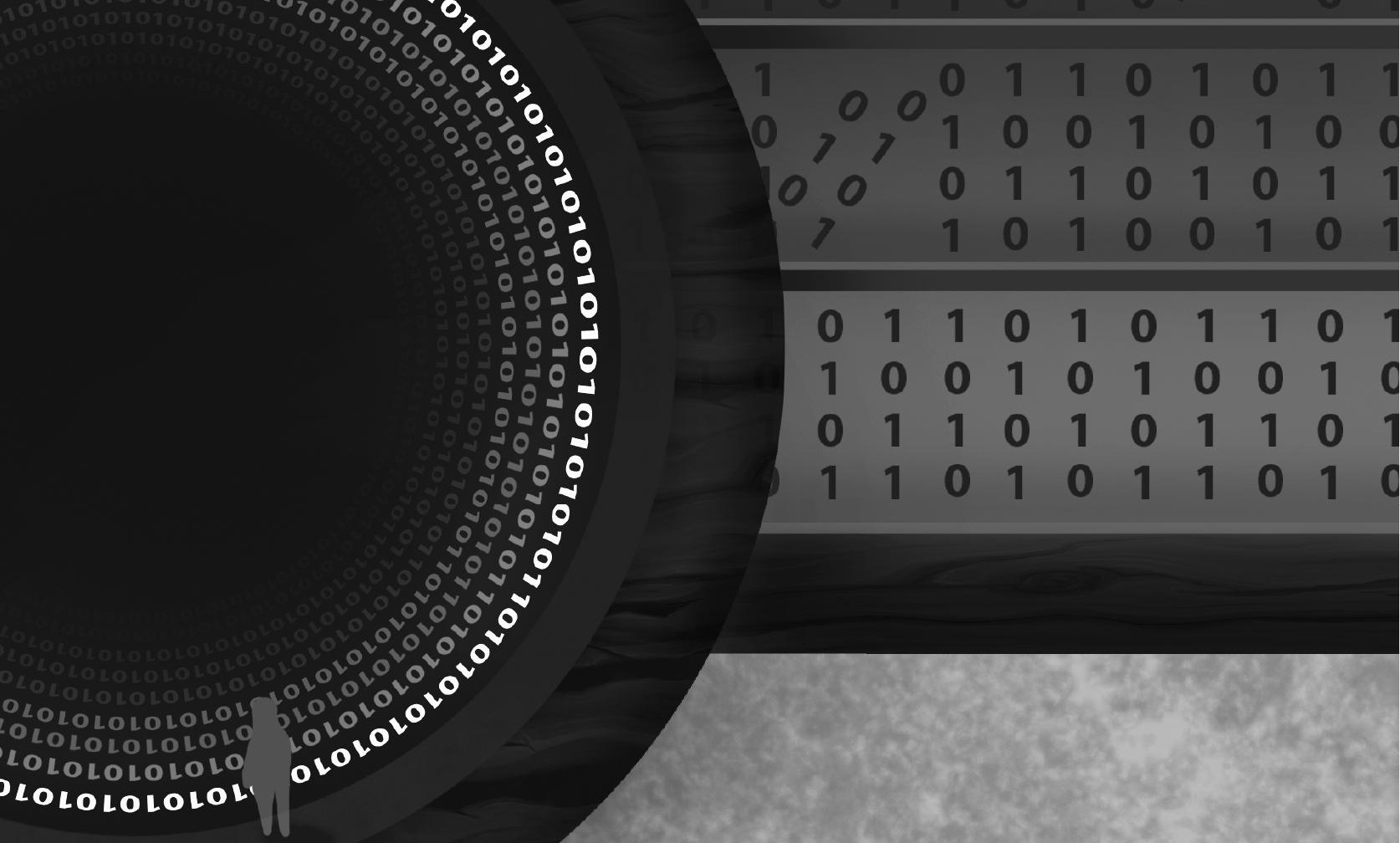

$\begin{array}{llllllllll}0 & 1 & 1 & 0 & 1 & 0 & 1 & 1 & 0 & 1\end{array}$

$\begin{array}{lllllllll}1 & 0 & 0 & 1 & 0 & 1 & 0 & 0 & 1\end{array}$

$\begin{array}{llllllllll}0 & 1 & 1 & 0 & 1 & 0 & 1 & 1 & 0 & 1\end{array}$

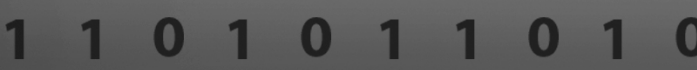

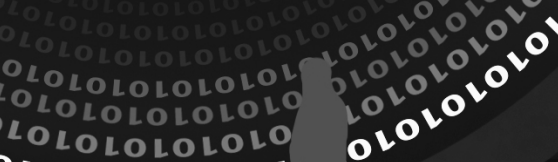
$010^{2}$ 
List of publications 



\section{List of publications}

Roy G.P.J. de Jong, Johannes T.H. Nielen, Ad A.M. Masclee, Maryska L.G. JanssenHeijnen, Frank de Vries. Comments on "Use of metformin and risk of kidney cancer in patients with type 2 diabetes", Chin-Hsiao Tseng, Eur J Cancer 2016;52:19-25. European Journal of Cancer 2016;61:157-8

Roy G.P.J. de Jong, Arlene M. Gallagher, Emily Herrett, Ad A.M. Masclee, Maryska L.G. Janssen-Heijnen, and Frank de Vries. Brief report: Comparability of the age and sex distribution of the UK Clinical Practice Research Datalink and the total Dutch population. Pharmacoepidemiology and drug safety 2016

Lotte M. Knapen, Roy G.P.J. de Jong, Johanna H.M. Driessen, Yolande C. Keulemans, Nielka P. van Erp, Marie L. De Bruin, Hubert G.M. Leufkens, Sander Croes, Frank de Vries. Use of incretin agents and risk of acute and chronic pancreatitis: A population-based cohort study. Diabetes Obesity and Metabolism 2017;19:401-411

Roy G.P.J. de Jong, Andrea M. Burden, Sander de Kort, Myrthe P.P. van Herk-Sukel, Pauline A.J. Vissers, Paddy K.C. Janssen, Harm R. Haak, Ad A. Masclee, Frank de Vries, Maryska L.G. Janssen-Heijnen. No decreased risk of gastrointestinal cancers in users of Metformin in the Netherlands; a time-varying analysis of metformin exposure. Cancer Prevention Research 2017;10:290-297

Roy G.P.J. de Jong, Andrea M. Burden, Sander de Kort, Myrthe P.P. van Herk-Sukel, Pauline A.J. Vissers, Paddy K.C. Janssen, Harm R. Haak Ad A.M. Masclee, Frank de Vries, Maryska L.G. Janssen-Heijnen. Impact of detection bias on the risk of gastrointestinal cancer and its subsites in type 2 diabetes mellitus. European Journal of Cancer 2017;79:61-71

Roy G.P.J. de Jong, Paul J.H.L. Peeters, Andrea M. Burden, Marie L. de Bruin, Harm R. Haak, Ad A.M. Masclee, Frank de Vries, Maryska L.G. Janssen-Heijnen. Gastrointestinal cancer incidence in type 2 diabetes mellitus; results from a large population-based cohort study in the UK. Cancer Epidemiology 2018;54:104-111

\section{Book chapters}

R.G.P.J. de Jong en Y.C.A. Keulemans. Buikpijn. In A.J.R. Balthasar, J. Bergsma, M.A. Siemonsma, red. Probleemgeöriënteerd denken in de pijngeneeskunde. Utrecht: De Tijdstroom, 2017. p 33-41 

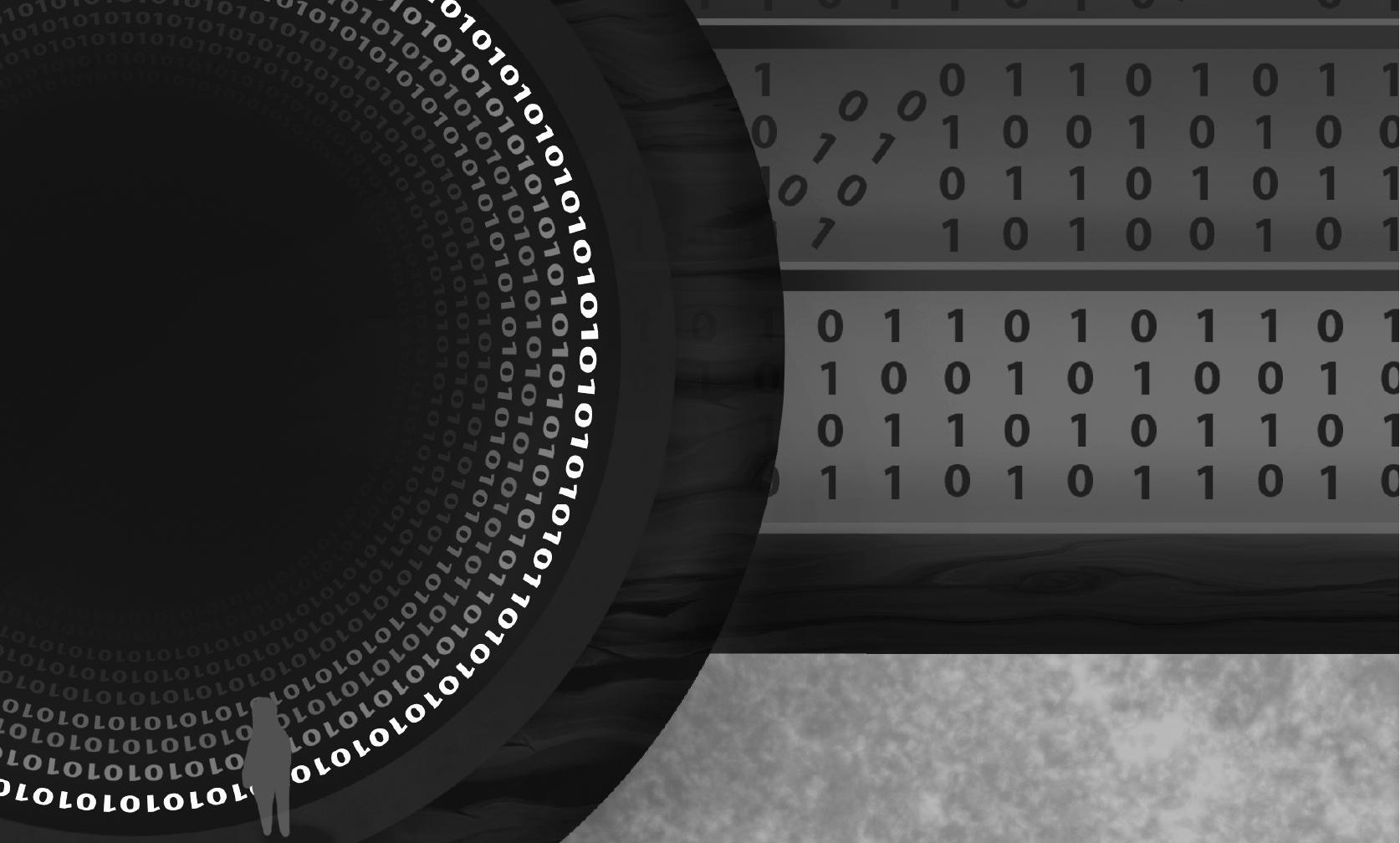

$\begin{array}{llllllllll}0 & 1 & 1 & 0 & 1 & 0 & 1 & 1 & 0 & 1\end{array}$

$\begin{array}{lllllllll}1 & 0 & 0 & 1 & 0 & 1 & 0 & 0 & 1\end{array}$

$\begin{array}{llllllllll}0 & 1 & 1 & 0 & 1 & 0 & 1 & 1 & 0 & 1\end{array}$

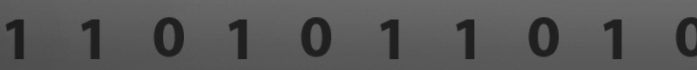

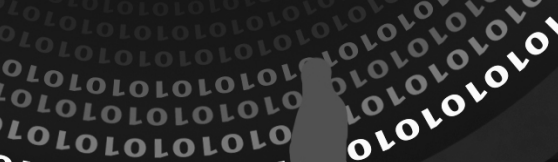
$010^{2}$ 
Dankwoord 



\section{Dankwoord}

$\mathrm{Na}$ een ontzettend leerzame periode is het dan zover, het proefschrift is klaar! Veel mensen hebben op hun eigen wijze bijgedragen aan de totstandkoming van dit proefschrift. Hiervoor ben ik hen enorm dankbaar.

Prof. dr. Janssen-Heijnen, beste Maryska, jouw sturende feedback heeft me altijd gemotiveerd om het beste in mezelf naar boven te halen. Hoewel jouw kennis in de epidemiologie ver rijkt, gaf je weleens toe dat de farmaco-epidemiologie ook niet geheel jouw expertise is. Je gaf mij de kans en het vertrouwen om me de theorie en praktische aspecten hiervan eigen te maken, wat heeft geresulteerd in dit proefschrift. Hopelijk kunnen we onze samenwerking in de toekomst blijven voortzetten.

Prof. dr. Masclee, beste Ad, tijdens ons eerste oriëntatiegesprek gedurende mijn stage als semi-arts bij de MDL inspireerde je mij om na te denken over het doen van wetenschappelijk onderzoek. Na enkele gesprekken met promovendi resulteerde die inspiratie tot mijn keuze om me te storten op het lopende project 'diabetes en darmkanker'. Jouw klinische blik hielp me om de resultaten voortdurend in klinisch perspectief te plaatsen. Na deze periode van onderzoek kijk ik uit naar onze samenwerking in de kliniek gedurende mijn opleiding tot MDL-arts.

Dr. de Vries, beste Frank, zonder jouw hulp was dit project nooit in zo'n vogelvlucht verlopen. Jouw ervaring in het doen van farmaco-epidemiologisch onderzoek en kennis van zaken hielp me enorm op weg. In korte tijd konden we daarom ook meerdere studies uitvoeren. Bedankt voor alle tijd en steun. Ik hoop dan ook dat we in de toekomst kunnen blijven samenwerken op het gebied van farmaco-epidemiologie!

Prof. dr. Weijenberg, beste Matty, bedankt dat je mijn proefschrift wilde beoordelen, maar ook voor de huisvesting die jullie me hebben geboden bij de vakgroep epidemiologie in Maastricht tijdens de eerste maanden van mijn onderzoek. Dat warme plekje naast de printer in het 'WESPenhok' zal ik nooit vergeten. Hoewel het uiteindelijk niet tot een samenwerking heeft geleid, vond ik de eerste besprekingen die wij hadden erg leerzaam.

Beste Prof. dr. de Bruïne, Prof. dr. van den Bergh, Prof. dr. Hardwick en Prof. dr. Sturkenboom. Hartelijk dank voor jullie bereidheid om deel uit te maken van de leescommissie. 
Van de vakgroep farmacologie \& toxicologie van het MUMC+ wil ik enkelen in het bijzonder bedanken:

Dear Andrea, thank you (dankjewel!) for all your support during the entire project. The endless meetings you invested in this project really helped to boost my independence as a programmer - and sometimes your assistance as a native English speaker was quite welcome.

Annemariek, in dit kader kan ik jou natuurlijk niet overslaan. Ook jouw hulp tijdens het programmeren en analyseren van de data heb ik erg op prijs gesteld. Je maakte altijd wel even tijd vrij als ik ergens niet uit kwam. Enorm bedankt!

Lotte, bedankt voor de samenwerking aan de studie over pancreatitis. Veel succes bij je toekomstige projecten in Maastricht en natuurlijk je eigen promotie!

Beste co-auteurs: Marieke de Bruin, Sander Croes, Nielka van Erp, Paddy Janssen, Yolande Keulemans, Sander de Kort, Hubert Leufkens, Yannick Nielen, Paul Peeters en Pauline Vissers, bedankt voor jullie kritische blik en waardevolle bijdrages aan de manuscripten en het onderzoeksproject. Prof. dr. Haak, heel erg bedankt voor uw klinische inzichten op het gebied van diabeteszorg.

Dear Arlene Gallagher and Emily Herrett. Thank you for the cooperation on the short report with the CPRD-data.

Beste Jos Slangen, een speciaal bedankje gaat uit naar jou. Zonder technische ondersteuning en de mogelijkheid om gebruik te mogen maken van de server was mijn onderzoek niet mogelijk geweest.

Dank aan alle (oud) collega's van het Leerhuis in VieCuri voor de ondersteuning - Jolanda, Quinten, Shan-Lan, Ineke, Dorine, Loes, Lizzy en alle anderen van wie ik de naam hier misschien vergeten ben.

Aan de (oud) medewerkers van IKNL en PHARMO database network: Jetty Overbeek, Josine Kuipers, Marjolein Zanders, Mieke Aarts, Myrthe van Herk-Sukel, en Rients van Wijngaarden, bedankt voor jullie tijd en hulp bij de totstandkoming van dit proefschrift. Ik kon vaak terecht, zowel in Eindhoven/Utrecht, als per telefoon, met vragen over de database.

Waarde collega's en (oud) onderzoekers van de afdeling Maag-darm-leverziekten in het MUMC+. Beste Anke, Ankie, Annyck, Bouke, Chantal, Corinne, Daisy, Ellen (Wilma), Elly, Eveline, Fabienne, Fedde, Freddy, Hao Ran, Kirsten, Lisa, Marin, Mark, Mietsie, Nienke, Pauline, Roel, Tim K, Wiesje, Yala, Zlatan en Zsa Zsa, bedankt voor de gezellige tijd op de 
universiteit tijdens alle lunches op de trappen of in het restaurant, de borrels, etentjes, uitjes, of gewoon tussendoor. Het congres in San Diego tijdens de DDW was fantastisch, van dagenlange sessies over MDL-ziekten tot dansen op de bar na het duurste rondje IPA's en tequila ooit! Ik verheug me er al op om jullie weer terug te zien in de kliniek.

Nu hebben jullie bijna het hele dankwoord gelezen en dan vragen jullie je misschien af of ik jullie ben vergeten? Nee hoor... Beste Tim, Bas en Steven, als doorgewinterde promovendi was jullie hulp en inspiratie voor mij enorm waardevol! Tim en Steven, bij jullie zat ik in het hart van het epidemiologisch onderzoek van de vakgroep MDL. De tijd bij jullie op de kamer was fantastisch. Beste Bas, als mede-Phd'er in de farmacoepidemiologie was jij (en ben je nog altijd) vaak genoeg mijn vraagbaak. Daarnaast zijn aan deze tijd, en later in de kliniek, mooie vriendschappen overgebleven. Allen bedankt!

Lieve familie en vrienden. Hier is 'ie dan. Lang verwacht en veel naar gevraagd. Bedankt voor al jullie steunbetuigingen tijdens de fase waarin ik dit onderzoek deed. Hopelijk vinden jullie het interessant om mijn werk te lezen. Beste Paul, dankjewel dat je paranimf wil zijn bij mijn verdediging! We zullen er een lekker (speciaal) biertje op drinken.

Lieve Anne. Als laatste wil ik jou bedanken voor de mogelijkheden die je me hebt gegeven om dit proefschrift thuis af te kunnen ronden in de late uurtjes of op vrije (zon)dagen. We hebben de afgelopen jaren veel mijlpalen bereikt; ons eerste echte huis, een onvergetelijke bruiloft en natuurlijk de geboorte van ons wondertje Sophie. Ik kijk uit naar alle mooie dingen die we nog zullen beleven. 

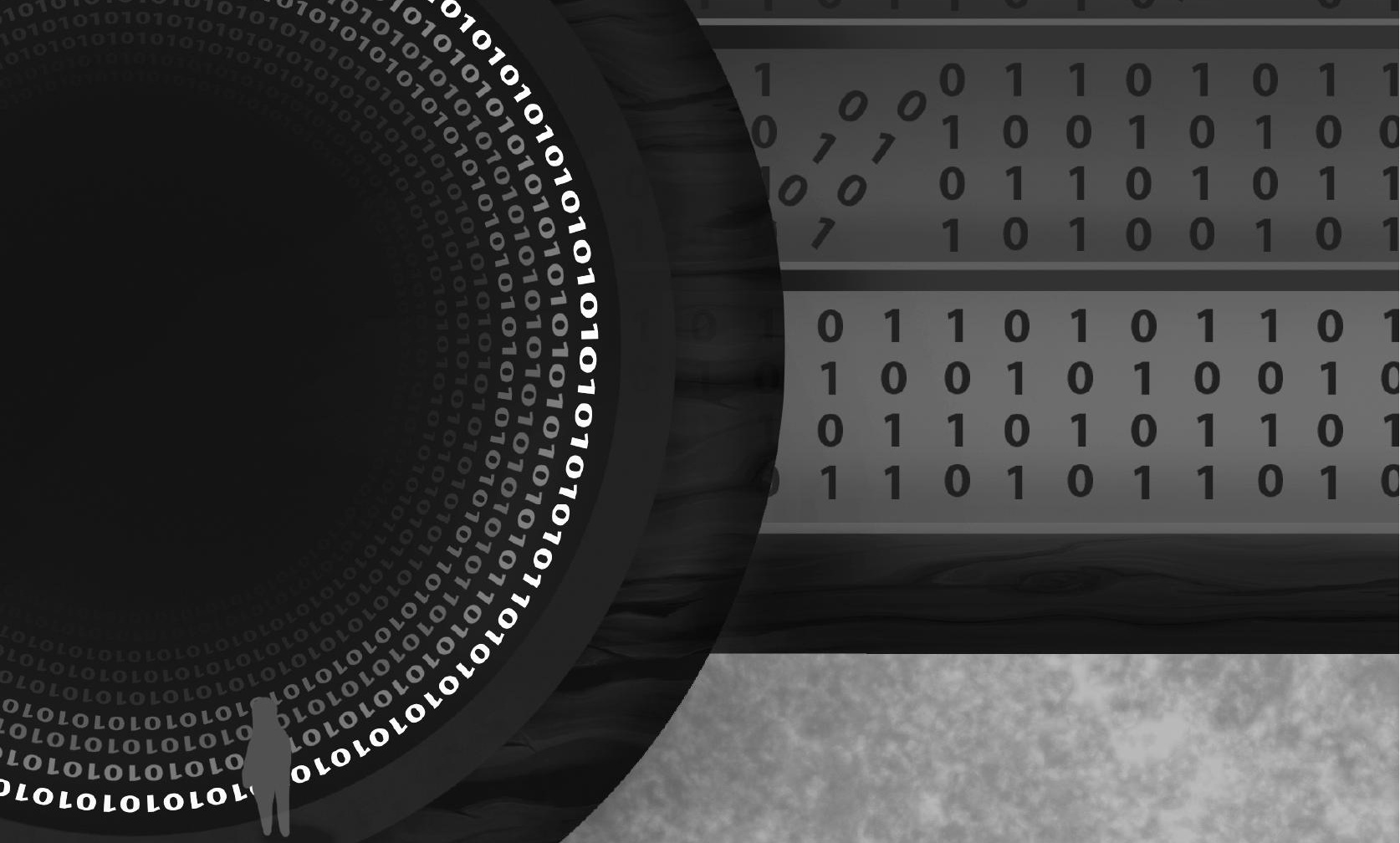

$\begin{array}{llllllllll}0 & 1 & 1 & 0 & 1 & 0 & 1 & 1 & 0 & 1\end{array}$

$\begin{array}{lllllllll}1 & 0 & 0 & 1 & 0 & 1 & 0 & 0 & 1\end{array}$

$\begin{array}{llllllllll}0 & 1 & 1 & 0 & 1 & 0 & 1 & 1 & 0 & 1\end{array}$

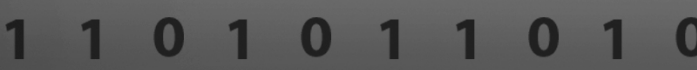

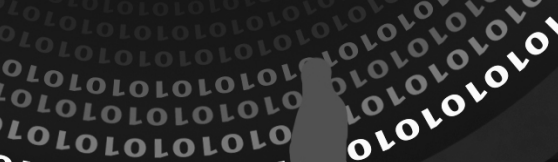
$010^{2}$ 
Curriculum vitae 



\section{Curriculum vitae}

Ronaldus Gerardus Petrus Jacobus (Roy) de Jong was born on the 11th of January 1990 in Roosendaal, The Netherlands. He grew up in the village of Kruisland, where he finished primary school. After graduation from the Jan Tinbergen College in Roosendaal in 2008, he started medical school at the Maastricht University, Faculty of Health, Medicine, and Life Sciences. During medical school he attended clinical and scientific traineeships at the division of Gastroenterology and Hepatology, department of Internal Medicine, Maastricht University Medical Centre+ (MUMC+). For his

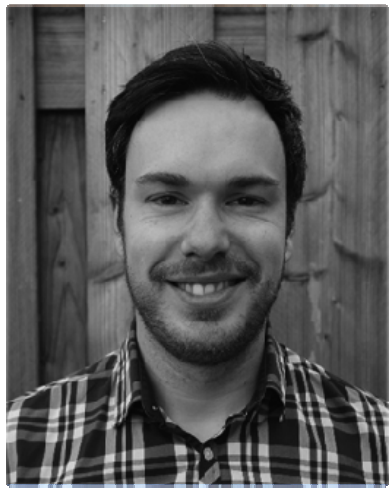
scientific traineeship, Roy studied aspects of pain in patients with chronic pancreatitis, and contributed a chapter on pain in chronic pancreatitis to the Dutch textbook 'Problem-based thinking in the specialty of pain medicine' (Probleemgeöriënteerd denken in de pijngeneeskunde), under supervision of Dr. Y.C.A. Keulemans. After obtaining his medical degree in 2014, he started his PhD affiliated to the department of Internal Medicine, VieCuri Medical Centre, to the division of Gastroenterology and Hepatology, MUMC+, and to GROW, School for Oncology and Developmental Biology, Maastricht University, under the supervision of Prof. dr. A.A.M. Masclee, Prof. dr. M.L.G. Janssen-Heijnen, and Dr. F. de Vries. In October 2016, Roy started his residency in gastroenterology and hepatology at the department of Internal Medicine of VieCuri Medical Centre. He is currently working as a resident in gastroenterology in Zuyderland Medical Centre under supervision of Dr. Y.C.A. Keulemans. Roy is married to Anne and they live together in Roermond with their daughter Sophie. 



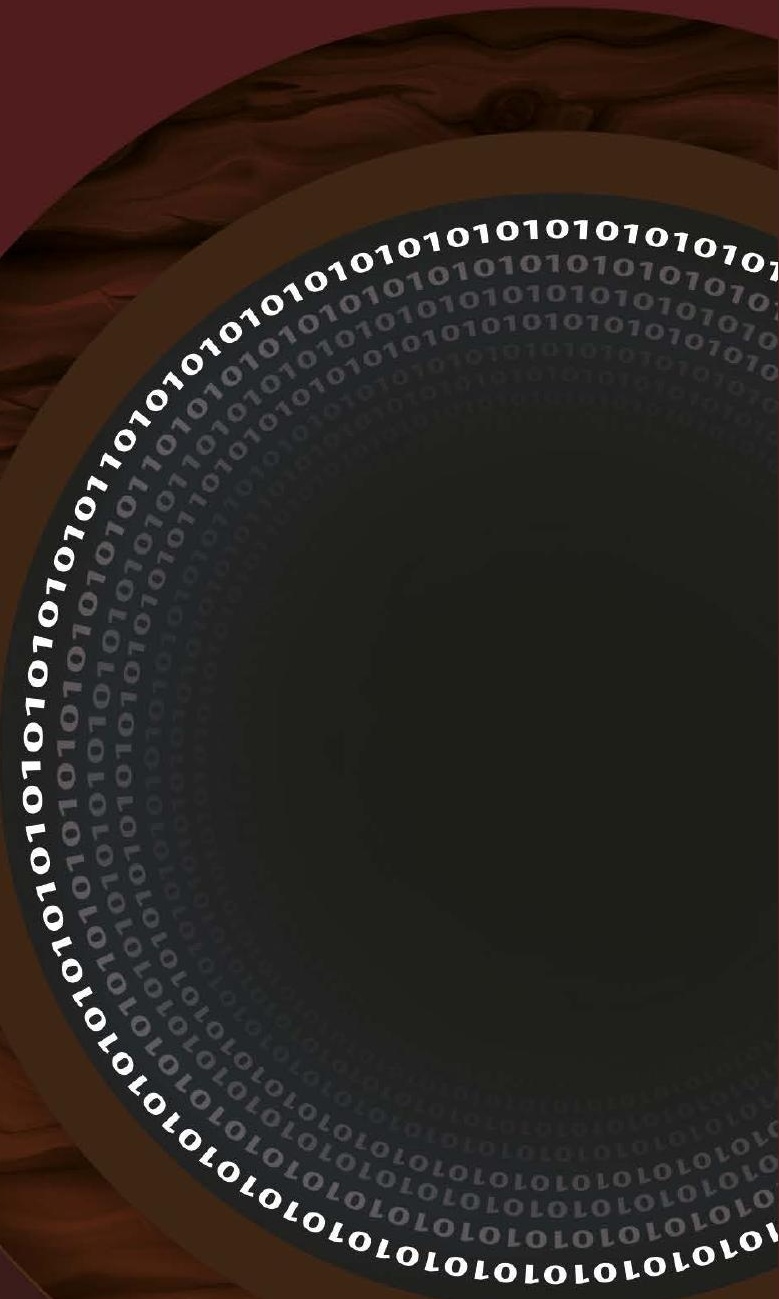

